\title{
Sociological aspects of drinking behavior, alcohol related problems and help-seeking : a longitudinal study
}

Citation for published version (APA):

Hajema, K. J. (1998). Sociological aspects of drinking behavior, alcohol related problems and helpseeking : a longitudinal study. [Doctoral Thesis, Maastricht University]. Universiteit Maastricht. https://doi.org/10.26481/dis.19980619kh

Document status and date:

Published: 01/01/1998

DOI:

10.26481/dis.19980619kh

Document Version:

Publisher's PDF, also known as Version of record

Please check the document version of this publication:

- A submitted manuscript is the version of the article upon submission and before peer-review. There can be important differences between the submitted version and the official published version of record. People interested in the research are advised to contact the author for the final version of the publication, or visit the DOI to the publisher's website.

- The final author version and the galley proof are versions of the publication after peer review.

- The final published version features the final layout of the paper including the volume, issue and page numbers.

Link to publication

\footnotetext{
General rights rights.

- You may freely distribute the URL identifying the publication in the public portal. please follow below link for the End User Agreement:

www.umlib.nl/taverne-license

Take down policy

If you believe that this document breaches copyright please contact us at:

repository@maastrichtuniversity.nl

providing details and we will investigate your claim.
}

Copyright and moral rights for the publications made accessible in the public portal are retained by the authors and/or other copyright owners and it is a condition of accessing publications that users recognise and abide by the legal requirements associated with these

- Users may download and print one copy of any publication from the public portal for the purpose of private study or research.

- You may not further distribute the material or use it for any profit-making activity or commercial gain

If the publication is distributed under the terms of Article $25 \mathrm{fa}$ of the Dutch Copyright Act, indicated by the "Taverne" license above, 
Sociological Aspects of Drinking Behavior, Alcohol-related Problems and Help-seeking

A Longitudinal Study

Klaas Jan Hajema 
Hajema, Klaas Jan

Sociological Aspects of Drinking Behavior, Alcohol-related Problems and Help-seeking. A Longitudinal Study /

Klaas Jan Hajema. Maastricht: Datawyse - Thesis,

Maastricht University - With ref. - Met samenvatting in het Nederlands.

ISBN 90-9011566-8

Trefw, alcohol, alcohol-related problems, help-seeking, longitudinal

Lay-out and cover design Klaas Jan Hajema

(O) Klaas Jan Hajema 1998

This studly was supported by a grant from NWO/Medigon and Ministry of Welfare, Health and Cultural Affairs .

Omslag: met dank aan Vereniging voor Alcohol- en andere Drugproblemen (V.A.D.), Laken, Belgie:: '2 minuten hierop staren is zo goed als heel de avond alcohol drinken". 


\title{
Sociological Aspects of Drinking Behavior, Alcohol-related Problems and Help-seeking
}

\author{
A Longitudinal Study
}

\section{PROEFSCHRIFT}

ter verkrijging van de graad van doctor aan de Universiteit Maastricht, op gezag van de Rector Magnificus

Prof. dr. A.C. Nieuwenhuijzen Kruseman, volgens het besluit van het College van Decanen, in het openbaar te verdedigen op vrijdag 19 juni 1998 om 14.00 uur

door

Klaas Jan Hajema 
Promotor:

Prof. dr. M.J. Drop

Co-promotor:

Dr. R.A. Knibbe

Beoordelingscommissie:

Prof. dr.ir W.H.M. Saris (voorzitter)

Prof. dr. H.F.L. Garretsen (Erasmus Universiteit Rotterdam)

Prof. dr. J.A. Knottnerus

Prof. dr. G.J. Kok

Prof. dr. F. Sturmans 
Chapter 1 Introduction

Chapter 2 Changes in alcohol consumption in a general population in the Netherlands: a 9-year follow-up study

Chapter 3 Changes in social roles as predictors of developments in drinking behavior: testing a theory

Chapter 4 Effects of drinking patterns and social conditions on incidence and chronicity of alcohol-related problems

Chapter 5 Social resources and alcohol-related losses as predictors of help-seeking among male problem drinkers

Chapter 6 Conclusions and general discussion

Samenvatting

References

Dankwoord

Curriculum Vitae 


\section{Chapter 1}

\section{Introduction}

\subsection{The goal and scope of this study}

The central focus in this thesis is on three issues with regard to alcohol consumption. The first issue in this study is the examination of the development of drinking behavior over time. "The consumption of alcohol is widespread and characterized by large differences between societies, across individuals and over the years. In the Netherlands per capita consumption increased rapidly in the 60 s and 70 s from 2.81 . of pure alcohol in 1961 to 9.41 . in 1979 . In the late 80 s and early 90 s per capita consumption gradually decreased to reach 8.01 . in 1995 (PGD, 1996).

The second issue in this thesis concerns the persistence and emergence of alcohol-related problems. The importance of alcohol research stems mainly from the large variety of problems caused by the use of alcohol in our society. An example of such a problem is the involvement of alcohol use in traffic accidents. Alcohol use was involved in $14.8 \%$ of the fatal incidents in 1979. This proportion started to declined in the middle of the 80 s to reach $7.9 \%$ in 1994 (CBS, 1982; CBS, 1996). Another example is the association between alcohol consumption and health problems. The mortality from liver cirrhosis as primary cause of death increased slowly from 5.0 (per 100,000 inhabitants) in 1960 to 6.9 in 1982 and decreased to 5.8 in 1994.

The third issue in this thesis considers help-seeking for alcohol-related problems. In the Netherlands there is one central organization with facilities for outpatient treatment. The number of alcohol clients in treatment at the Consultation Bureaus for Alcohol and Drug Problems (CAD) grew from about $\Perp 1,000$ in 1968 to more than 16,000 in 1979 and declined to less than 12,000 in 1994 (De Zwart \& Mensink, 1996).

The national data on per capita consumption suggest a small but steady decrease in total consumption during the 1980 s and early 1990 s. Whether this reflects an ageing process - with a growing proportion of older, moderate, drinkers- or a real decline in consumption among the total population, will have to become clear in the future. Registered data on alcohol-related accidents and alcohol-related hospital admissions (De Zwart \& Mensink, 1996) suggest a decline in such alcohol-related problems. Recently, the number of problem drinkers in treatment started to decrease. However, this downward trend of help-seeking for alcoholrelated problems in the Netherlands might reflect the policy of respectively local and national government and treatment organizations, to focus more strongly on drug-related problems (Spruit, Kok \& Knibbe, 1996).

This research project is a follow-up of a study that started in 1980 as a survey among the general population in the province of Limburg, The Netherlands (Knibbe, 1984). It was the 
first alcohol research project at the Department of Medical Sociology at the University of Linburg (Maastricht University, since 1996). In the 1980s several other alcohol projects were conducted, for instance, on situational aspects of adolescent drinking behavior (Van de Goor, 1990) and on the use of alcohol in daily life (Van Gelooven, 1990), on the measurement and distribution of alcohol consumption (Lemmens, 1991) and recently, on alcohol use across the life span (Neve, 1998). This study is the first Dutch longitudinal study on drinking behavior and alcohol-related problems of men and women in a general population.

The scope of this thesis is on drinking behavior, drinking problems and help-seeking for drinking problems as sociall phenomena. Social structure is considered to be important because it is expected to influence drinking behavior, as well as the emergence and persistence of alcohol related problems and seeking help for these alcohol-related problems. Consequently, it will be examined whether differences in drinking behavior, alcohol-related problems and helpseeking can be attributed to specific social categories. Therefore, in this longitudinal study social theories will be used to explain the development of drinking behavior, alcohol-related problems and seeking help. In other words, one of the tasks in this study is to investigate the extent of the social determination of these three topics. The central focus in this study is on changes and stability in drinking behavior, and alcohol-related problems and on help-seeking behavior. The aim is to explain social phenomena. In this study this means, firstly, the explanation of differences in the develojment of drinking behavior between categories of individuals. How can these differences in the development of drinking behavior be explained? Why do drinkers increase or decrease their alcohol consumption? In this thesis it will be investigated whether the embeddedness of individual drinkers in the social structure of a society can explain the development of drinking behavior. In section 1.2 the major theoretica] approach on drinking behavior in this thesis and the two research questions will be expounded.

The second issue to be explained is why some drinkers experience alcohol-related problems whereas others do not. In a longitudinal perspective this implies the explanation of the persistence of problems among those who had drinking problems at first measurement and the incidence of alcohol-related problems among those without drinking problems at first measurement. In section 1.3 alcohol-related problems will be detined and explanations for the occurrence of these problems will be presented together with the main research question about this topic.

The third explanatory problem concerns the explanation of help-seeking for alcoholrelated problems: why do some drinkers with alcohol-related problems seek help whereas most drinkers with drinking problems do not? Common theories to explain help-seeking and an additional theory to improve this explanation will be introduced in section 1.4. At the end of this section the main research question will be described.

The use of theoretical notions in this study differs from what can be considered as usual. or desirable in science. Although this thesis contains the first analyses of this longitudinal. research project it is a secondary analysis. Other researchers at the department of Medical Sociology were tesponsible for the data collection. In particular role theory and the social interaction theory were used as a starting point to develop the questionnaire. More importantly, however, the questionnaire at second measurement in 1989 had to match the questionnaire at 
first measurement in 1980. However, besides role theory and social interaction theory, other theories have been sought and used to explain and interpret the research fundings. It is needless to say that, at least to some extent, other questions will be asked and other thypotheses will be formulated if one uses one theory instead of another.

\subsection{Theories on drinking behavior}

Several theoretical notions in the alcohol research literature are in particular considered as important for the explanation of drinking behavior. These theories are: role theory as suggested by Knibbe, Drop \& Muytjens, 1987), the social interaction theory (Skog, 1980, 1985, 1986) and the theory of rational addiction (Becker \& Murphy, 1988; Becker, Grossman \& Murphy, 1991 ; but see also Skog. 1997).

\subsubsection{Role theory}

From the perspective of role theory differences in drinking behavior are explained by differences in social roles. In brief, individualls are considered as role-carriers or role-players and drinking behavior is determined by the characteristics accompanying those roles. In other words, the link between the individual and social structure is accomplished by the concept 'role', With regard to drinking behavior probably the most developed theory on the effects of social roles, was put forward by Knibbe et al (1987). Following Gerhardt (1971) and Philipsen (1976) they differentiated roles into status roles, position roles and situation roles. According to Knibbe and colleagues roles differ in the extent that they refer to the macro-level (status roles), meso-level (position roles) and micro-levell (situation roles). The three roles differ in scope: the order of different levels is expected to represent a decreasing importance for the determination of behavior from macro to micro. Status roles are expected to structure individual behavior stronger than position roles and position roles structure behavior more strongly than situation roles.

Status roles are specified by social expectations towands characteristics of persons that can hardly be influenced by themselves (such as gender, age, ethnicity, but also religion and social class). These status roles are important, firstly, because they facilitate the entry into position and situation roles, secondly, because they influence the norms that make up these position and situation roles. The status role "assists the individual in his choice of appropriate behavior" (Knibbe et al, 1987: 464) and accomplishes more or less uniform lifestyles. Individuals with the same status role are called "status groups".

Position roles are specified by social expectations towards characteristics of persons that are acquired (for instance, being a spouse, employee or parent). The position roles are assumed to form a system of mutual obligations and presume to a certain extent the performance of regular activities. Position roles are expected to structure the behavior of individuals in everyday life.

Situation roles are specified by sociall expectations that facilitate social behavior in shortterm situations in which specific goals are achieved (cating, going out for a drink, attending 
football matches). These situation roles do not structure behavior over a long period of time but facilitate choosing between altematives in specific social situations.

In general, for most people alcohol consumption is thought to be limited to situation roles. The extent to which drinking in situation roles is considered as appropriate is determined by status roles. Position roles influence drinking behavior because drinking is likely to interfere with the fulfiment of the role of employee, spouse or parent. Those who have such position roles will be more likely to drink less. Those without these roles have a less structured. everyday life, and may use situation roles, including those in which alcohol consumption takes place, to create a structure or as a means to neutralize the tensions caused by the lack of roles (Knibbe at a 1987 )

This distinction between different types of roles differs from other theories about social roles. Tumer (1990), for instance, distinguished between four types of roles of which 'basic roles" (like gender roles and age roles) and "structural status roles" (like occupational and family roles attached to a position) are the most important. In terms of Turner, "a social role is a comprehensive pattern of behavior and attitudes, constituting a strategy of coping with a recurrent set of situations,..." In other words, in terms of Turner and also according Biddle (1979) roles are by definition behaviors that are characteristic within a certain context. Close to Knibbe's situation roles are Biddle's contextual roles. Contextual roles are roles that are periodic (such as washing after awakening and eating at noon) or associated with the physical context or setting in which the behavior takes place or an activity (e.g. a soccer match or a church mass). Knibbe's status roles are in fact based on 'ascribed positions' and position roles are based on "achieved positions" according to Linton (1936) in Biddle (1979). Besides these differences in terminology between Knibbe and other role theorists, it can be concluded that in these theories roles are linked to behavior by means of role expectations and socialization.

\subsubsection{Social interaction theory}

The social interaction theory emphasizes the influence on individual drinking behavior by the drinking practices in the social network of the drinker. While the influence comes from both sides - from the individual to the network members and from the network members to the individuat a population or sociely can be considered as one large network. The ultimate consequence is that every individual in a society is under influence of all other individuals. Dependent on certain conditions (specified later on in this section) one can designate drinking behavior in a society as collective drinking behavior. The development of drinking practices in a society will be a collective development in the same direction. Therefore, a strong association might exist between (changes in) the general level of consumption and (changes in) the prevalence of excessive drinking. The influence of the members of a society on each other is called the principle of long-range indirect ties. Although each individual is influenced directly by only a small number of relevant others, indirectly one is tied to a very large number of persons. This can be considered as a system of actors connected by various social relations that has the feature to coordinate behavior (Skog, 1986).

According to Skog (1980) the factors that influence drinking behavior can be distinguished into three categories: (a) drinking behavior of relevant others, (b) endogenous factors such as biological constitution, and psychological characteristics like personality, 
previous experiences, motives and preferences, (c) exogenous factors, such as prices. availability and other economic aspects, the mass media such as advertising, and norms and traditions. The dispersion of consumption or, in other words, the extent of differences in drinking behavior, are determined by at least three factors: the degree in which subcategories differ in drinking behavior; the degree in which network members are influencing one's drinking behavior; and the connectedness between the members of a society.

The tendency of an individual to change drinking behavior is assumed to depend on, firstly, the difference between his drinking behavior and the drinking behavior as determined by exogenous factors such as traditions and norms but also prices and availability. Secondly, it, depends on the difference between his level of consumption and those of his relevant others, such as friends. "Thirdly, it depends on endogenous factors as the tenelency to change drinking behavior at all or to resist pressume. Individuals are assumed to influence each others drinking behavior directly, in face-to-face situations, such as in groups. In addition, Skog also states that more indirect forms of social control exist. Three sorts of informal social control that are distinguished by Skog are social disapproval (e.g. an angry spouse), the adoption of the new drinking habits of relevant others and communication about drinking. Changes in drinking practices are likely to spread through the social network. A development that started in $a$ specific subpopulation might lead to an array of modifications among subpopulations that were not directly influenced by the exogenous cause of this development. Whether a change in drinking behavior of a subpopulation will spread is dependent on the interconnectedness of various subpopulations.

\subsubsection{Rational addiction theory}

The theory of rational addiction uses an economic approach to explain human behavior. Individuals are considered as consumers, and with consumption -in our study alcohol- they produce utility. The theory assumes that people are "making the best of it" and try to maximize their utility. The starting point in the rational addiction theory is the rational consumer with stable preferences. For the explanation of behavior it is assumed that individuals are rational consumers who anticipate on possible future consequences while they try to maximize their utility.

Central concept in the rational addiction theory is 'consumption capital' (Becker \& Murphy, 1988; Becker, Grossman \& Murphy, 1991). Every individual has a certain amount of consumption capital that is determined by the experiences (utility) of consumption in the past. The amount or stock of consumption capital is determined by past consumption and events of the life course. The experiences with consumption in the past - accumulated in an amount of consumption capital - determines the utility of consumption by a process of learning. In fact, the concept "consumption capital' resembles the concepts "Human capital' and "social capital'. Each individual has a certain amount of these sorts of capital. In brief, human capital consists of skills and knowledge that facilitates the individual to act or to reach certain goals, social capital consists of the relations between individuals (Coleman, 1990). According to Becker \& Murphy alcohol consumption is considered to be a function of the stock of consumption capital. The theory assumes that events can have a direct influence on the stock of consumption capital. If events lower the total utility (i.e. overall well-being) of a person then 
the marginal utility of the addictive and harmful good increases. They suggested that consumption of harmful goods might be stimulated by stressfull events, such as divorce, unemployment and the loss of beloved ones. In fact this suggests that alcohol (or other drugs) can be considered as a coping device to compensate for the loss of well-being.

One of the most important aspects of this theory is the explanation of the continuation of addictive behaviors by the effects of short-term positive consequences and long-term negative consequences of drinking on the decision making of individuals. Most positive consequences are immediately experienced while most negative consequences are delayed. The more distant in time these negative consequences are, the more likely the negative consequences will be discounted. Moreover, some of the problem drinkers can be considered to be myopic with regard to future consequences of drinking. Therefore, it seems that positive consequences will often exceed the discounted negative consequences and this implies further consumption and risk taking. In this way, Becker \& Murphy explain addictive behaviors by persons maximizing their utility according to their preferences. Their theory suggests that behavior related to the consumption of alcoholic beverages can be explained as rational behavior. This approach might be useful because it helps to explain collective behavion as the outcome of purposive individual action and choice behavior.

\subsubsection{Incompleteness of role theory}

In this paragraph several strong and weak points of role theory will be specified. Firstly, in contrast to social interaction theory and the rational addiction theory, role theory suggests explicitly the deduction of hypotheses between drinking behavior and social characteristics. Social characteristics or social conditions of individuals are defined into social roles. If drinking interferes with the fulfilling of one's social roles than those who have such roles will be more likely to drink less. A second advantage is that the concept 'role' is commonly used in daily language which makes it a concrete and understandable theory for outsiders. Nevertheless, a disadvantage of the use of terms of daily language might be that the technical term as used in science could have a different connotation than the common connotation (Wippler, 1983). Furthermore, it was shown that between role theorists some terminological confusion exists about the differentiation of roles.

There are several problems in the use of role theory as an explanatory framework that one could consider as weak points. The critics on role theory can be divided into two categories: firstly, how role theory explains (at the collective level or individual llevel); secondly, the contents of the explanation. Although this is not the place to repeat two decades of discussion about this issue, some important comments can be made. Often debated in sociology is whether one obtains a sufficient explanation by explaining collective behavior as such, or whether one needs to explain collective behavior by a general explanation at the individual level (Coleman, 1990; Boudon, 1981). Role theory aims to explain behavior only at the collective level. Generally, role theorists assume that collective phenomena can be explained without an explanation of the behavior of those who act, namely, the individuals playing their roles. However, with role theory one can formulate hypotheses for categories characterized by the same roles. Roles are expected to influence individual drinkers, but generally it is not questioned how, for instance, role expectations, influence behavior at the 
individual level. One is focused on systematic differences in behavior that are explained as the result of systematic or structural differences in expectutions with regard to appropriate behavior (Gelooven, 1990:134).

Boudon (1981) formulated four general problems about explanations for social phenomena in role theory: (1) roles are not described so explicitly that there is no margin for interpretation. This means that there is variance in roles; (2) the norms related to roles are often contradictory. In other words, these norms are characterized by ambiguity; (3) a role is often constructed out of elementary subroles that might form a complex combination; (4) each person possesses more than one role and role conflicts might exist between those multiple roles. Role players have to decide which role expectations will be applied. Hence, mixed role expectations are not straightforward but are still expected to deternine behavior. According to Boudon these four problematic characteristics of roles illustrate that the role-player always has some autonomy in his behavior. If one neglects the fact that roles are heterogeneous, ambiguous, contradictory and have variance and if one conceives all actions as interpretations of roles one introduces a form of hyper functionalism (Boudon, 1981).

\subsubsection{Incompleteness of the sociall interaction theory}

The social interaction theory is concentrated on the relation between average consumption, the spreading of consumption over different individual levels of consumption and the prevalence of excessive drinking. Although this theory was not meant to explain differences in drinking behavior between social categories, the basic ideas of this theory are considered as important: due to interaction people influence each other's drinking behavior. This produces a synchronization of drinking habits and, consequently, the drinking habits in one's social network will have a predictive value for the individual drinker. However, one of the weaknesses of this theory is that it remains unclear how network members influence each other. The main concept is contagion but how this mechanism of contagion works has to be made more explicitly. In the social interaction theory a quite deterministic view of drinking behavior is presented. Therefore, it seems not redundant to emphasize that in most societies individuals have the possibility to choose their drinking behavion by themselves within certain structural restraints.

\subsubsection{Incompleteness of the rational addiction theory}

A weak point of the rational addiction theory is that it remains undeveloped how and to what extent social structure influences drinking behavior. The theory is Locused primarily on the effects of prices and income. Events are thought to be important for the stock of consumption capital and, in this way, may influence consumption. The strong point of the theory, however, is that it suggests that heavy drinking or excessive drinking, can be explained as rational behavior. In other words, behavior that is known to lead to all sort of negative consequences can still be explained from the point of view of rational choice and as the most rewarding alternative.

One of the first important questions with regard to the theory of rational addiction is the nature of the stable preferences. What is the goal of persons who are maximizing their utility? Stigler \& Becker (1977) put forward the proposition that individuals have stable universal 
preferences that can be considered the same for everyone. The means to reach these universal preferencess are instrumental preferences. However, without specifying these preferences unexpected and unexplained preferences can always be interpreted as universal preferences. It was Lindenberg (e.g. Linderberg. 1990) who fomulated these universal preferences explicitly. He assumed that the general and universal goals are social approval and physical well-being. All ather preferences are instrumental preferences that are considered as means to reach the ultimate goals. The possession of these means is limited and, therefore, can be considered as constraints for reaching the general goals.

The term 'rational choice' is often misinterpreted as synonymous with a logical, reasonable or wise choice. However, what is meant is that a cholice is made while anticipating on the expected consequences and the expected likelihood of these consequences. Furthermore, with drinking behavior as the result of rational choice is not meant that all consumptions of alcoholic beverages are preceded by a process of decision making. Individuals may develop habitual ways of drinking in certain situations so the consumption of another drink does not necessarily require a consideration of pros and cons. According to Becker (1992) habitual behavior presumes a positive relation between past and current consumption and addiction is to be defined as a strong habit. It can be expected that drinking often occurs in repetitive choice situations that are characterized by a stable reward structure (see also Lindenberg, 1983). The results of Van Gelooven (1990) suggested that a large proportion of the total consumption of alcohol is consumed in a limited number of situations. The most important situations of alcohol consumption at home were found to be during watching TV, visits of friends or family, and at meals. Outdoors, the most important drinking situtation is in bars. Therefore, the assumption seems tenable that alcohol consumption occurs mainly in repetitive choice situations that do not need an explicit or new consideration each time.

\subsubsection{Assumptions and the explanation of drinking behavior in this thesis}

Starting-point is that the analytic primacy in this thesis belongs to collective phenomena. In other words, the analyses tries to explain a phenomenon at the level of a system. Furthemore, these collective phenomena are considered to be the result of the behavior of the individual actors within the system. The major reason to explain collective phenomena at the level of human action is that there are no general laws on the system level. For instance, role expectations about drinking behavior are not stabla, they might change over time. During a certain era the role expectations about drinking for individuals who accuired the spouse role may be more strict than for individuals who lost their spouse role or who never had the spouse role. In another period this link between marital roles and drinking might be different. One needs a theory to explain the link between the macro-level of collective phenomena and the micromevell of human action.

It can be considered a basic assumption that a theory for the explanation of drinking behavion should indicate how social conditions influence drinking behavior of individuals and how these individual drinking practices together with social conditions are producing a collective outcome. Such a theoretical model has the feature that in the analyses of the aggregate level a step is made to the individual level. In addition, social characteristics are 
assumed to create differences in the utility of alcohol consumption, and, conseguently, these differences lead to variations in drinking behavior between social categories. As a result, the consequences of an increase (decrease) in consumption for the individual drinker can be interpreted in terms of marginal utility. Following this line of reasoning, differences in drinking behavior by employment status, for instance, can be explained as the result of differences in marginal utility of consumption between employed and unemployed drinkers. With an explanation of the component parts (individuals) explanations at the aggregate or collective level are more stable and gain in depth (e.g. Coleman, 1990; Esser, 1994). These theories allow to bring in social conditions at the individual level. In other words, such a theory creates an explanatory structure to integrate the individual and the social. However, it should be noted that the distinction of individual action at micro level and collective phenomena at macro level is theoretical. Neither level is conceivable without the other. Social circumstances and structural conditions as such, are not active, only individual human actors drink. This theoretical point of view in sociology is often called the structural-individualistic approach or methodological individualism.

It was described above that role theory, social interaction theory and the rational addiction theory are incomplete theories for the explanation of drinking behavior but valuable. A theory that incorporates the strong points of these theories could be promising as a theoretical framework to explain drinking behavior. In alcohol research, among others, Knibbe emphasized the importance of social roles, Skog emphasized the influence of network members and the importance of social interaction, Becker and colleagues, from a microeconomic view, emphasized the possibility to explain addiction as rational, purposive behavior. Social roles can possibly partially explain drinking behavior because they structure the situations in which drinking is accomplished. On the one hand, these roles might constrain drinking behavior or, on the other hand, they might facilitate drinking behavior. Several characteristics are often used as indicators of social roles: sex, age, social class, employment staius, marital status, parental status, ethnicity and religion. However, the data of this research project were collected in the province of Limburg in the Netheriands with only little differentiation by ethnicity and religion. Therefore, these characteristics were not included as indicators of differences in drinking behavior. Social interaction between an individual and his or her network members is considered to be important because it structures the situations in which one can drink and how much one can drink. In contrast to role theory and social imteraction theory, the theory of rational addiction concentrates explicitly on drinking behavior as the outcome of choices and purposive action of individuals. These three theoretical perspectives are used in chapter two and three for the selection of relevant variables and interpretation of the results.

\subsubsection{Research questions on drinking behavior}

In general, the alcohol consumption patterns within most societies can be characterized as a continuing process of change. The drinking patterns of a society refer to a wide variety of drinking practices. These drinking patterns concern, for instance, typical drinking situations, types of beverages that are being consumed and volume of consumption. The term 'usual 
drinking patterns' might suggest a large similarity in drinking patterns across society. In that sense, this concept must be considered as misguiding. Drinking patterns can be defined by means of some generalizations such as average weekly consumption or per capita consumption, however, such descriptions have limited informative quality. It is more informative to use more specific indicators of drinking behavior. One might want to indicate who continue to drink a certain wolume of consumption or a certain frequency of heavy drinking. On the other hand, it might be informative to indicate who changes his/her drinking behavior and starts to drink above a certain level of consumption or above a certain frequency of heavy drinking. In chapter two a description of the developments of drinking behavior will. be presented together with an analyses of gender and age-associated patterming of these developments.

\section{Gender and age-associated patterming of drinking behavior}

In chapter two the main findings on changes and stability in drinking behavior ate presented. The aspects of drinking patterns that are being examined are abstinence, level of consumption and heavy drinking. As mentioned above, one can define a general trend in drinking behavior but by indicating a general trend one joins all individual changes into one measure. Therefore, estimates of prevalences and of incidence and chronicity of drinking patterns are used to indicate the developments of drinking behavior. In other words, in the analysis of drinking: patterns the focus will be on both aggregate and individual level. From a public health and policy perspective, the analyses at the individual level facilitates the detection of specific categories at risk for drinking problems due to high levels of consumption or high frequencies of heavy drinking. The main research question can be formulated as:

\section{Do changes in drinking partems differ according ro age and gender?}

In general, both gender and age are considered as important determinants of drinking behavior. It should of course be noted that part of these gender and age differences in consumption can probably be explained by physical differences. For instance, the capacity to metabolize alcohol is in general lower for women and older persons. Physical differences, however, can explain only a small part of the variance between men and women and age categories and within men and women and age categories. Recently, Wilsnack et al. (1997) found no positive association between body water and alcohol consumption among women. It may be concluded that the considerable differences in drinking practices between men and women and between age categories are to a large degree culturally defined.

\section{Drinking behawior and social rolles}

For both theoretical and empirical reasons characteristics such as gender, age, and other social characteristics are expected to play an important factor in the determination of drinking behavior. In many empirical studies social chancteristics are being been used to describe differences in drinking behavior. As mentioned above, the fact that these characteristics indicate social roles has often been used to explain diflerences in drinking behavior. In many alcohol studies social roles are, both explicitly and implicitly, thought to be determinants of 
consumption. Hence, for theoretical and ampirical reasons social roles are expected to be associated with drinking behavior. In chapter three this line of reasoning has been pursued on the development of changes in alcohol consumption and heavy drinking. This study offers the opportunity to examine the effects of social roles in a longitudinal design. If roles are indeed influencing drinking behavior than it can be expected that a change in roles implies a change in drinking behavior. The research question is formulated as:

2. Are changes in social characteristics predictors of changes in comsumprion and heavy drinking?

In contrast to most other alcohol studies this study starts explicitly with a theoretioal perspective. Shortly, the loss of marital, employment and parental roles is expected to lacilitate an increase in consumption and heavy drinking while the acquirement of these roles is expected to facilitate a decrease in consumption and heavy drinking (see Neve et al, 1997, for a. comparable approach).

\subsection{Alcohol-related problems: definition and occurrence}

\subsubsection{Defining and measuring alcohol-related problems}

The consumption of alcoholic beverages might have negative consequences that can be considered as indicators of alcohol-related problems. However, what is defined as an alcoholrelated problem differs according to time and place. In other words, what is considered an an alcohol-related problem, is defined culturally (e.g. Roon, 1985, 1996).

In psychiatric epidemiology alcohol-related problems are often indicated by DSM-III-R, DSM IV, ICD-10, the ADS (Alcohol Dependence Scale), or the SADQ (Severity of Alcolol Dependence Questionnaire), and labeled as alcohol dependence, alcohol abuse or harmful drinking. In fields such as social epidemiology, social psychology and sociology warious other instruments are used to indicate alcohol-related probloms. Examples of these measures are the CAGE (Cut down, Annoyed, Guilty, Eye-opener; Mayfield, MoLeod \& Halt, 1974), whe MAST (Michigan Alcohol Screening Test, Selzer, 1971), and the Problem Drinking Index of Cahalan (1970). Recently, Finney, Moos \& Brennan (1991) developed a Problem Drinking Index specificaly for older drinkers and Comel et al (1994) constructed an intervall scale to measure the severity of drinking problems among patients of general practitioners

The measures of alcohol-related problems in psychiaric epidemiology and in clinical settings indicate a pathology of the individual and bave a limited value for social research. As Cahalan (1987) stated, alcohol-related problems thave a range that includes many conditions and behaviors with no necessary connection to physical or mental conditions. Several studies suggested that, as a measure of severity, alcohol dependence and alcohol-related problems are different concepts. In a clinical population measures of alcohol dependence were weakly associated with measures of alcohol-related problems (Corman et al. 1989; Cooney et al., 1986). On the other hand, Vaillant, Gale \& Milofky (1982) showed that about 75\% of those 
defined as problem drinker by Cahalan's scale are defined as alcohol dependent by DSM III, and vice versa. Vaillant and colleagues concluded that the overlap was only about $75 \%$. However, when not considered as an either-or feature but as a continuum the correlation between the scales was high.

The measure of alcohol-related problems in this thesis contains 18 items that are divided into four subcategories of problems: social consequences, health consequences, symptoms of problem drinking and frequency of intoxication. The scores on the four subcategories are added into an index to indicate the severity of alcohol-related problems. The 18 items stem from the, approximately, 60 items of Cahalan's problem drinking index. Therefore, the problem drinking index of this research project can be considered as a short version of Cahalan"s index. More details will be presented in chapter four and five. Although the index includes only a small part of these 60 items, the index still covers a wide area of indicators of potentiall drinking problems, including job problems, problems with relatives or friends and problems with the law.

\subsubsection{Consumption and drinking contexts}

By definition ${ }_{*}$ alcohol-related problems are caused by the consumption of alcoholic beverages. In general, a higher level of consumption implies a greater probability to experience alcoholrelated problems. This suggests, also by definition, that even at a low level of consumption there is a small risk of having an alcohol-related problem (for a discussion see Lemmens, 1996). Alcohol research showed that no cut-of-points exisis under which alcohol consumption can be considered as totally save with zero risk (Room, Bondy \& Ferris, 1995).

Although indicators of total consumption, such as a weekly recall of consumption or average daily 'typical' consumption, are major determinants of negative consequences of drinking, drinking patterns other than crude volume of alcohol consumption are causing differences in the occurrence of alcohol-related problems (Bondy, 1996). While keeping volume of consumption constant drinking patterns may vary in the extent of causing drinking problems (Knibbe, 1984; Relum et al, 1996). It is likely, for instance, that heavy drinking once in a while might produce more alcohol-related problems than regular moderate consumption (e.g. Walsh \& Rehm, 1996). Similarly, drinking contexts are likely to differ in the extent of generating problems.

Drinking patterns can be distinguished according to several characteristics such as volume and frequency of drinking, heavy drinking, drinking situations and the types of beverages that are consumed. Recently, Stockwell et al (1996) differentiated between total consumption and 'hazardous' consumption. In their study hazardous consumption was defined as the number of glasses following prior consumption of six glasses. Hazardous consumption was considered as a better indicator of various physical or social problems than volume of consumption. Rehm (1996) defined drinking patterns as all other aspects of alcohol use than volume of drinking. This term includes aspects such as settings, heavy drinking, temporal variations, frequency of drinking and variances in quantity consumed. Fitzgerald \& Mulford (1993) divided drinking contexts into drinking places (such as bar, club, own home, other's home, outdoor recreation), drinking companions (e.g., alone, with spouse, relatives, colleagues) and drinking situation (at a meal, at celebrations, when thirsty, etc.). 
One can think of several reasons why drinking contexts are determinants of drinking problems. Drinking contexts differ in the extent of meeting social approval or disapproval. For instance, drinking mostly occurs in leisure time when there are no obligations, stemming from employment or other social roles. Such situations are visiting family or friends, eating, being in bars or restaurants and watching TV (for a description of drinking situations in the Netherlands see Van Gelooven, 1990). Therefore, it can be assumed that the possibility of experiencing negative drinking consequences differs according to the specific context. In the same study, Van Gelooven showed that heavy drinkers differed fron light or modernte drinkers by drinking in situations in which light or moderate drinkers did not drink. Contexts, particularly in terms of drinking settings or locations, might difer in the probability of experiencing drinking problems or for being at risk for instance, Gruenewald, Mitchell \& Treno, 1996; Stockwell, Lang \& Rydon, 1993; Casswell, Zhang \& Wyllie, 1993). For example, it is not surprising that drinking in bars or restanrants is associated with drunken driving (Gruenewald et al, 1996; Casswell et al, 1993). Another type of context that was found to be associated with drinking problems were temporal aspects of drinking. Dawson (1996) showed that early and late-night drinking increased the odds of experiencing a wide variety of social consequences.

\subsubsection{Roles, social control and social learning}

As indicated in section 1.2, social characteristics are assumed to be determinants of drinking behavior. Social characteristics are determinants of volume of intake, heavy drinking and other drinking patterns. In this way social characteristics are - indirectly - influencing the occurrence of drinking problems. Moreover, individuals who differ in social characteristics might also differ in their vulnerability for alcohol-related problems. In a similar way as for drinking behavior, social roles may also be indicators of differences in alcohol-related problems.

Several important notions about the effects of social characteristics on drinking problems stem from the perspective of role theory. To a large extent the effects of social roles on alcohol-related problems is caused indirectly by drinking behavior. Role deprivation (defined as the lack of roles) might lead to a decrease of social control and therefore to less restrictions on alcohol consumption and higher risks for drinking problems (Wilsnack \& Cheloha, 1987). Because of the lack of roles the remaining role-relationships are less constraining with regard. to drinking. Consequenty, drinkers are probably more likely to engage in hazurdous behavior and have a higher probability to experience alcohol-related problems. On the other hand, those drinkers characterized by the possession of roles will be more likely to avoid risky siluations and potential drinking problems.

In addition to the role perspective of Wilsnack \& Cheloha it is argued by Knibbe ot al (1987) that "status' roles defined by characteristics such as gender, age, religion and social class specify drinking styles that are considered as appropriate. Sociall categories delined by such roles differ in the vulnerability to drinking problems because, for instance, they differ in the dispersal of total consumption over drinking occasions. However, in this line of reasoning the effects of status roles are explained by the effects on drinking patterns and therefore can be considered as an indirect effects of these roles on alcohol-related problems. Knibbe at al argued that, besides negative consequences caused by drinking style, the exteni in which 
drinking has negative consequences is influenced by the structure of everyday life. In particular employment roles, spouse roles and child-rearing roles specify this structuration of the day. Knibbe et al. state that social roles that make the structure of everyday life influence the degree in which alcohol-related problems occur. People with a less structured everyday life will experience more alcohol-related problems because, firstly, they will be more likely to combine the use of alcohol with the use of sedatives, secondly, because they in general score lower on indicators of health and well-being.

In more or less similar ways other researchers emphasized the effects of norms and social control that may produce differences in problem drinking between social categories. For instance, Fillmore \& Midanik (1984) who investigated the chronicity of drinking problems hypothesized that older men are more likely to have chronic alcohol-related problems. They assumed that problematic drinking of young men is normative for their subculture. Drinking problems among older men may be more deviant, but if they occur they are of a more chronic nature. Therefore, drinking problems are more likely to be temporary among young men, which was confirmed by the results. In addition, Knupfer (1984) discussed several hypotheses in which differences in drinking problems are explained by differences in drinking norms towards different social categories.

Mäkelä \& Simpura (1985) stressed the importance of social control, in addition to volume of consumption, on drinking problems. Categories of drinkers defined by, for instance sex or age, differ in the way their drinking behavior is controlled and sanctioned. If level of consumption and other aspects of drinking behavior are about the same, the individuals in drinking categories that are more controlled and sanctioned will experience more alcoholrelated problems. The social learning theory of Akers et al. $(1979,1991)$ is also connected with notions of sociall control. This theory explains deviant behavior as the effect of a process of social learning. Specifically peers and parents are thought to be important in the imitation of deviant behavior. Two aspects of their theory are important. Firstly, behavior is established by behavioral conditioning and through imutation or modeling of others" behavior. Secondly, behavior is determined by the balance of past, present, and anticipated consequences ("rewards or punishments' $\mathrm{s}^{3}$ ) of behavior.

Makeld \& Mustonen (1996) used the concept 'reward structure' to investigate diffrences in consequences of drinking between age categories and at different levels of intake. The reward structure includes both positive and negative consequences of drinking. It can be assumed that the reward structure of drunking not only differs by age as found by Makela \& Mustonen, but also for other social characteristics. In fact, the concepi reward structure resembles the basic principles of microeconomic theories on drinking behavior (e.g. Becker \& Murphy, 1988), Akers' theory on deviant behavior (1979) and rational choice theory in general. When compared to each other, these theories can be classified as non-exclusive theories. The concept reward structure might be important because it helps to explain (1) why some social groups have a higher probability of experiencing social consequences of drinking behavior, and moreover (2) why some social groups differ in the extent they take risks through hazardous behavior. The first type of problem derives from the interaction of the drinker with the social environment (e.g.. one's spouse or family, one's work or the law). The origin of the second type of problem is the drinker himself/herself (e.g., health problems, symptomatic 
behavior, intoxication, psychological dependence).

\subsubsection{Research questions on drinking problems}

Drinking alcoholic beverages is by definition the major determinant of alcohol-related problems. Thus, if over a period of time the norms about appropriate drinking behavior and what constitutes a drinking problem remain the same, in particular changes in drinking behavior will be the major cause for changes in drinking problems. However, not only volume of consumption but also other aspects of drinking behavior, such as contexts of drinking, are determinants of alcohol-related problems. Furthermore, it can be expected that factors other than drinking behavior are likely to be predictors of alcohol-related problems. In chapter four the effects on the emergence and persistence of alcohol-related problems are examined of, respectively, drinking behavior, drinking contexts and social characteristics. In this study the main research question is formulated as:

3 Do, besides consumption and heavy drinking, drinking contexts and spectic social conditions explain the chronicity and incidence of alcoholmelated problems.

Alcohol-related problems are caused by alcohol consumption and as a result it is likely that also moderate and light drinkers have a (small) probability to experience alcohol-related problems. Generally, a higher level of consumption will imply a higher probability of alcoholrelated problems. To determine the effect of drinking contexts it is examined whether drinking situations, like drinking locations and time of drinking, influence the emergence and persistence of alcohol-related problems. Regardless of drinking behavior, drinkers that differ in social position differ in the positive and negative consequences of hazardous behavior. Social conditions such as gender, age, employment status, marital status, socioeconomic status, child rearing roles and the drinking patterns of parents during childhood are expected to differ in the degree they yield positive and negative consequences for drinking behavior. Therefore, these variables are included in the analyses as possible determinants of chronicity and incidence of alcohol-related problems.

\subsection{Theories on help-seeking behavior}

In general, the severity of alcohol-related problems is considered to be the main determinant for seeking help to overcome these problems. In addition, however, several studies have suggested that factors other than severity are also influencing help-seeking for drinking problems (for an overview see Jordan \& Oei, 1989). 


\subsubsection{The Socio-Hehavioral Model \& the Health Belief Model}

In research on help-seeking behawior for alcohol-related problems two models are often applied to explain help-seeking and to select relevant characteristics. The first model is the Socio-Behavional Model of societal and individual deteminants of the utilization of care (e.g. Andersen \& Newman, 1973; Andersen, 1995). Societal determinants are defined as, firstly, the availability of medical technology to provide proper help and, secondly, as norms including formal legislation and beliefis and values that form the health service system and utilization patterns. Individual determinants refer to demographic characteristics, social structure and beliefs that affect the predisposition to use services. The second model is the Health Belief Model, it emphasizes health beliefs as the determinants of use of medical care facilities (e.g. Rosenstock, 1966, Becker et al, 1977). In general, persons are only expected to seek help if they have at least a minimum level of health motivation and expect the intervention to be effective. Finally, a cue to action is assumed to trigger help-seeking. In the literature about help-seeking for alcohol-related problems various versions of these models have been applied in search for the major determinants of seeking help (Weisner, 1993; Brennan \& Moos, 1991; Bardsley \& Beckman, 1988).

Beckman \& Kocel (1982) developed a comprehensive model in which both models were combined to describe which characteristics of women with alcohol-related problems and which characteristics of the treatment delivery system operate as barriers to treatment. In their model the propensity and ability to seek help is thought to be determined by individual beliefis, characteristics of the service delivery system and social enabling factors. Individual predisposing factors, personal enabling factors, social norms and policies, and cues to treatment seeking are influencing helpmseeking indirectly by their effect on individual beliefs, social enabling factors or the characteristics of the treatment delivery system (see fing. 1.1).

In terms of Beckman \& Kocel characteristics such as age, socioeconomic status, gender, ethnicity and religion are individual predisposing factors. Predisposing factors are expected to be characteristics that imply differences in treatment options. "Individual beliefs's consists of perceptions and beliefs about alcohol, treatment and health. Personal enabing factors include personality characteristics such as alienation and efficacy and experiences with drinking or treatment. Geographic proximity, insurance coverage, child-care responsibilities and social support are defined as social enabling factors. In particular 'cues to action' are thought to be important for the decision of the drinker to seek help for his or her alcohol-related problems. According to Beckman \& Kocel, cues - such as inter-personal or intra-personal crises or an increase in severity - may alter the motivation, individual perceptions and beliefs and induce thelp-seeking.

By means of empirical generalizations from the alcohol research literature, Weisner (1993) unfolded a simplified version of the Beckman Kocel model to investigate differences between problem drinkers in the general population and in treatment. Four factors were distinguished as influencing help-seeking behavior: individual predisposing, social predisposing, need and enabling factors. Individual predisposing factors that were included into her analyses were age, gender, education, ethnicity and treatment history. Marital status, social network density and pressure of relevant others to cut down drinking were included as social predisposing factors. Heavy drinking, social consequences and dependence symptoms 


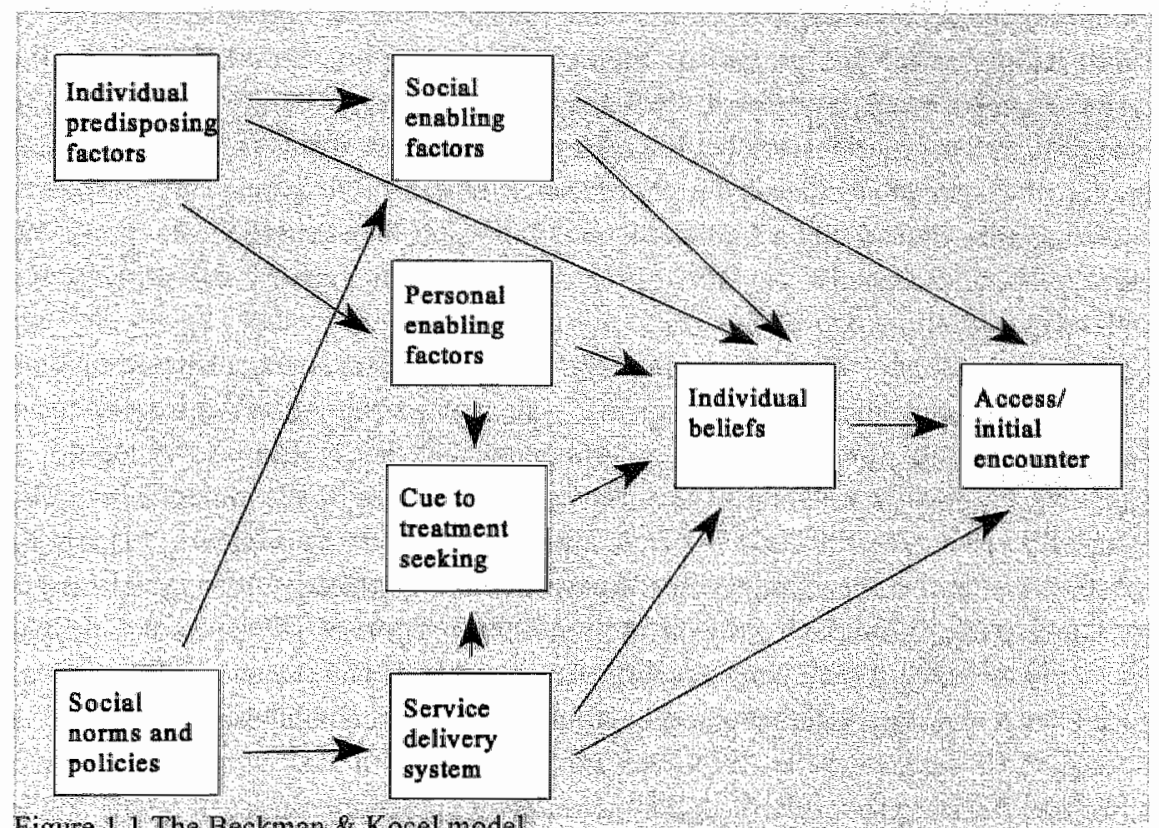

Figure 1 I The Beckman \& Kocel noodel

were used as indicators of need and income and employment were used as indicators of enabling factors.

The results of several empirical studies suggested effects of characteristics as age, gender, marital status and employment status on help-seeking behavior. For instance, Andersen \& Newman (1973) stated that age is a predisposing condition because age groups differ in severity and, therefore, have different patterns of medical care utilization. Education and occupation, on the other hand, were considered as indicators of life style and as influencing halp-seeking behavior. Although these factors may not be unimportant as determinants of need, our research question does not focus on predisposing factors of drinking behavior and alcohol-related problems but on factors associated directly with seeking help.

One of the weak aspects in the models is that it remains unclear which mechanisms can explain the effects of social structure on help-seeking. Except for need, all kind of possible determinants of help-seeking seem to be ordered rather arbitrarily into categories of variables. Therefore, it seems as if the model is being applied as a specific heuristics without a theoretical explanation or deductive argument. The limited empirical support has not elicited a discussion about the usefulness of the model (e.g. Bardsley \& Beckman, 1988; Weisner, 1993).

\subsubsection{Help-seeking behavior as choice behavior}

The critical review of the Beckman \& Kocel model indicates that a better theoretical explanation is needed. A more general model that might be useful to explain help-seeking behavior has been proposed by Pescosolido (1992). In what she has named the social 
organization of help-seeking" she stresses the importance of social networks and events. "Events set into motion a specific process of coping with uncertainty, initiated either by the focal individuals facing a problem or by network members who perceive a shift in the ongoing rhythm of social life* (Pescosolido, 1992: 1105). This model differs in two important aspects from the model of Beckman \& Kocel. Firstly, decision making is explained by purposive action and cost-benefit calculation. Secondly, the model includes help-seeking from among all possible help providers instead of only from among professionals or professional organizations.

In contrast to the Socio-behavioral model and the Health Belief model it is assumed explicitly that the behavior that causes problems - alcohol consumption - also produces rewards. Help-seeking will inply a change of drinking habits and cutting down drinking. Consequently, one will lose at least part of the utility that is produced by drinking. The social organization strategy framework of Pescosolido is interesting because also in help-seeking for alcohol-related problems social networks and social interaction are likely to be crucial factors (George \& 'Tucker, 1996; Room, Bondy \& Ferris, 1996; Tucker, 1995; Room, 1989). Moreover, it should be realized that many alcohol-related problems and the awareness of these problems are the outcome of the interaction of the drinker with his social enviromment.

In addition to the perspective of Pescosolido two theoretical notions are thought to be important for the explanation of the decision to seek help. The first perspective refers to the question of what can be considered as a good indicator of severity and of the need to change the behavior which causes all kind of problems. Lindenberg (1988) emphasized the importance of losses in decision making. It is hypothesized that the prevention of imminent loss and the reduction of recent loss frame certain decision situations and the likelihood that this frame dominates other possible frames grows disproportionally with the size of the loss. Therefore, it can be assumed that the extent to which cues to action are important for individual behavior is determined by the actual and potential losses due to drinking. This is what Lindenberg calls "the motivating power of loss". A change in behavior, such as a decrease of alcohol consumption, can be a means to prevent these losses or to regain a lost position (for instance, employment, a spouse or friend, health, social approval of social nework members). Consequently, help-seeking can be a way to prevent or regain such losses, particularly for those having difficulties with culting down their drinking by themselves. If the alcohol-related losses are high the benefits ol help-seeking can also be expected to be higher. Now, alcoholrelated problems differ in the extent to which they can be considered as losses. In general, it is expected that problems with the social environment (such as problems with a spouse or employment) and health problems, constitute greater losses than symptoms of problem drinking or heavy drinking (for instance, skipping meals, sneaking drinks and intoxication).

Secondly, in the process of decision making certain characteristics of drinkers can be considered as resources that influence the costs and benefits of help-seeking. It is assumed that the possession of these resounces facilitates the avoidance of help-seeking and the continuation of drinking thabits. In other words, these resources can be considered as "social capital' that ease the continuation of drinking behavior. Social capital is made up of social relationships that are embedded in social structure and can be used to achieve certain goals (Coleman, 
1990). Social capital is not just a feature of an indiwidual actor but a product of the structure of the relation of the actor with other actors. According to Furstenberg \& Hughes (1995) the notion of social capital is attractive because it links the characteristics of individuals with their social context. With more resources for a person it is easier to maintain the idea, in the minds of relevant others, that he (or she) is functioning well and is fulfulling his (role) obligations, that others should trust him to control his drinking and that there are no alcohol-related problems. Social capital in this form is not based on concrete help for drinking problems but can be seen as a credit slip with which one can continue one's drinking behavior. One can imagine that one gets credit, as an employee, a spouse, as belonging to the middle or high social class or even as an youngster.

It can be expected that drinking problems might generate a stimulus to change one"s drinking behavior and lead to a decrease in alcohol consumption to avoid these negative consequences. Although this assumption may seem plausible, alcohol-related problems are often continued for a longer period of time and this phenomenon keeps on puzzling alcohol researchers (Moos, 1994). An explanation for this continuation of drinking, notwithstanding its negative consequences, is addiction. It is debated, however, whether being addicted serves just as an excuse to continue one's drinking habits or whether it has to be considered as a disease or a biological process (e.g. Peele, 1985; Davies, 1992). It seems, on the one hand, that many drinkers can overcome their alcohol-telated problems by themselves. On the other hand, many severe problem drinkers cannot control their drinking and continue to drink and to have alcohol-related problems. Only a relative small proportion of problem drinkers apply for treatment and try to decrease their drinking with the help of others (Brennan \& Moos, 1991). Many researchers have found that besides severity or need, other characteristics influence help-seeking behavior in general and help-seeking for allohol-related problems in particular. In chapter five the effects of social resources on help-seeking are investigated.

\section{Social resources and seeking help for alcohol-related problems}

The severity of alcohol-related problems is the main determinant of help-seeking for drinking problems. However, in the fourth and last study of this thesis other factors besides severity are sought to explain seeking help for drinking problems. The research question is formulated as:

What differences, besides severity of alcohol-related problems, can explain help-seeking for alcohol-related problems

It is hypothesized that both social resources and in particular alcohol-related losses determine whether people seek help. The possessions of paid work, a spouse, high socioeconomic status but also being at a younger age and heavy and frequently drinking network members are considered as resources that facilitate the continuation of drinking and the avoidance of helpseeking. Alcohol-related problems that imply losses are expected to be more likely to provoke seeking help than symptoms of problem drinking, indicators of alcohol dependence or frequency of intoxication. 


\subsection{Outline of this dissertation}

In this longitudinal study the aim was to explain part of the changes in drinking behavior, changes in alcohol-related problems and seeking help for alcohol-related problems. From the point of view of sociology this implied the examination of the embeddedness of drinking, drinking problems and help-seeking in social structure. In 1980 and 1989 data were acquired with questionnaires among the general population in the province of Limburg, The Netherlands. This panel study was extended by a study among problem drinkers who applied for treatment at an outpatient treatment center in the province of Limburg.

The first two studies in this thesis focus on gender- and age-associated patterning of drinking behavior (Chp.2) and on social roles as a possible explanation for the development of drinking behavior ( $\mathrm{Chp}$.3). The third study in this thesis concentrates on the effects of drinking behavior, drinking contexts and social characteristics on the occurrence and persistence of alcohol-related problems (Chp.4) To explain help-seeking behavior the last study examines differences between male chronic problem drinkers in the general population and males who applied for treatment (Chp.5). In the final chapter of this thesis the main results of the study will be summarized and discussed.

\section{References}

Akers, R.L. (1991) Addiction, the troublesome concept. The Jownal of Drug Isues, 21, pp. $777-791$.

Akers, R.L., Krohn, M.D., Lanza-Kaduce, L. \& Radosevich, M. (1979) Social learning and deviant behawior: a specific test of a general theory. American Soctological lewew, 44, pp. 636-655.

Andersen, R.M. (1995) Revisiting the behavioral model and access to medical care: does ut matter? Joumd of Healh and Sochal Behowior", 36, pp. 1-10.

Andersen, R.M. \& Newman, J.F. (1973) Societal and indjwidual determinants of medical care utilization in the United States, The Mibank Mernarial Qwarterly, 51, pp. 95-124.

Biadsley, P.E. Beckman, L.J. (1988) The Health belief model and entry into alcoholism treatment, The Interpaiomal Jounal of the Addictions, $23, \mathrm{pp} .19-28$.

Becker, G.S. (1992) Habits, addilictions and traditions, Kyklos, 45, pp. $327-346$

Bccker, G.S. and Murphy, K.M. (1988) A theory of rational addiction. Wownd of Polfical Economy, 96, pp. $675-700$.

Becker, G.S., Grossunan, M. And Murphy, K.M. (1991) Rational atdiction and the effect of price on consumption. Awerican Ronomic Revitu Paperis and Procedings, 81 , pp. $237-241$.

Becker, M.H., Hather, D.P., Kasl, D.P." Kirscht, J.P., Mainan, L.A., \& Rosenstock, I. (1977) Selected psychosocial models and correllates of individual health-related behaviors, Medical $\mathrm{Car}$, $15, \mathrm{pp} .27-46$.

Beckman, L.J. \& Kocel, K.M. (1982) The treatment-delivery system and alcohol abuse in women: social policy implications, Joumal of Social /s:mes, 38, pp. 139-15n.

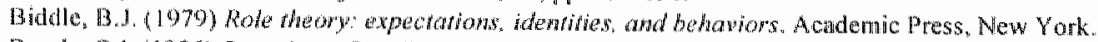

Bondy. S.J. 1996) Overview of stadies on drinking pattertis and consequences, Addiction, 91, pp. 1663-1674

Boudon. R. (1981) Thas logic of social action. An introdwction to sociologicat analyses. Routledge \& Kegan Paul, London, Great Britain.

Brennan, P.L. de Mos, R.H. (1991) Functioning, life context, and help-seeking among late-onset problem drinkers: comparisons with: noruproblem and earlymonset problem drinkers, British Journat of Addiction, 86, pp. 1139 . 1150 .

Cahalan, D. (1970 Problem drinkers; a mational survey. Jossey-Bass Publishers, San Francisco.

Cahalan, D. (1986) Studying drinking problems rather than alcoholism. In: Galantar et al. (Eds.) Recent developntents iw alcoholism. Wol 5 , chapter 15, pp. 363-372, Plenum press, New York, US.

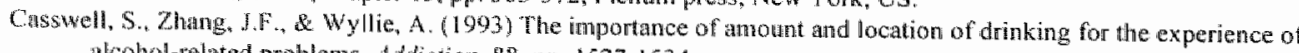
alcohol-related problems, Addiction, 88, pp. 1527-1534. 


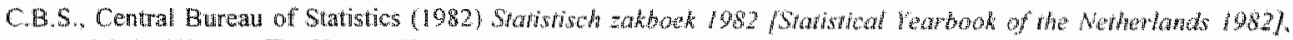
Sdu/publishers, The Higur, The Netherlands.

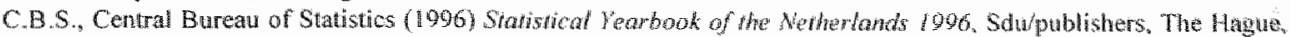
The Netherlandis.

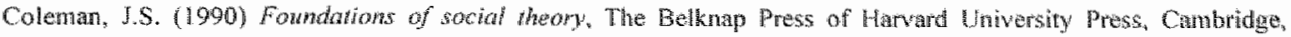
Massachusetis, and Londors, England.

Cooney, N.L.. Meyer, R.E., Kaplan, R.F. \& Baker, L.H. (1986) A validation stady of four seaties ancasumg sevenity of alcoho depentence. British Yournal of Addiction, 81, pp. 22, 229.

Comel, M. Knibbe, R.A.Zutphen, M.M. val, \& Drop. M.I. (1994) Problem drinking in a general practice population: the construction of an unterval scale for the severity of problem drinking, fonma of shudtes on Afohol, s5, pr. 466-470.

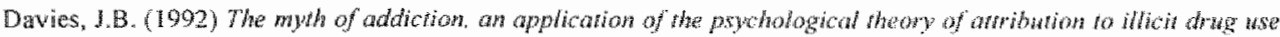
Harwood Academic Pubilishers, Chur, Switzeriand.

Datwson, D.A. (1996) remporal drinking patterns and variation in social conseguences. Addicron, 91, pp. $1623-1635$

Esser, H. (1994) Explanatory sociology. Soziologie, nr 3, pp. 177-190.

Filmore, K.M. \& Midanik, L. (1984), Chronicity of drinking probtems anong meat a longitudinal study, fownd of Srudies on Alcohol, 45 , pp. $228-236$

Fintey, J,W., Moos, R.H. \& Brennan, P.L. (1991) The drinking problems index: a measure to assess aloohol-related problems among older adults. Journal or Substance Aburse, 3, pp. 395-40ht.

Fustenberg. F.F. \& Hughes, M.E. (1995) Social capital and atucessful development among at-risk youth. Joumal of Marriage and the Family. 57 , pp. $580-592$

Gelooven. R.M.W. van (1990) Drinksimaties en drinkgedrag, akoholgebraik in her dogelijks feven, proefsehrit [Drinkswations and drinking behavior, alcohol we weveryday life. thesis], University of Limbirg, Datawyse, Maastricht.

Gerhard, U. (1971) Rollenanalyse als Krinische Soziologic. Luchterhand, Neuwied, Berlin.

Goor L.A.M. wan de (1990) Simational aspects of adolescent drimking belmator. Thesis "University of Limburg. Datawyse, Manstricht.

Gorman, D.M., Duffy, S.W., Rairu, S. \& Taylor, C.L. (1989) Lewel of agreennent between gunestionmaire measures of alcohol dependence, alcoholism and problen drinkung in a sample presenting at a specialist alcohol treatment service. Dur and Alcohol Dependence, 24, pp. $227-232$.

Gruenewald, P.J., Mitchell, P.R. \& Theno, A.J. (1996) Drinking and drïving: drinking patterns and drimking problems. Addichion, $91, \mathrm{pp}, 1637-1649$

Jordan, C.M. \& Qei, T.P.S. (1989) Help-seeking behaviou in problem drinkers a review. British Jonnal of Addiction, $84, \mathrm{pp} .979-988$.

Knibbe, R.A. (1984) Van gangbaar tot problewaries drankgebwik, proefschrift fFrom social drinking io problematic arinking, thesis], RU-Limburg, Matastrictht.

Knibbe, R.A., Drop, M.J. \& Minytjens, A. (1987) Correlates of stages in the progression from everyday drinking 10 problem drinking. Sacial Sicrence and Medicine, 24, pp. 463-473.

Knupler, $G$. (1984) The risks of drunkerness (or, Ebrietas Resurrecto) a comparison of frequent intoxication andices of population sub-groups as to problen risks. British Jomyd of iddiction, 79, $185-196$.

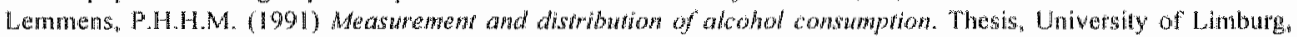
Datawyse, Matastricht.

Lemanens, P.H.H.M. (1996), When is a social problem alcohol-related? Aldiction, 91. pp. 1445.1447.

Lindenberg. S.M. (1983) Rational, repititive choice: the discrimination model wersus the Camille-Borger model. Soctal Psychology Quaterly, 44, pp. 312-330.

Lindenberg, S.M. (1988) Contractual Relations and weak solidarity: the behavioral busis of restraninis on gatin maximization. Journal of Institudional and Theorefical Economics. 144, pp. $39-58$.

Lindenberg. S.M. (1990) Hono sociomoconomicus; the emergence of a general model of than in the sociai sciences. Journat of Institutionat and Thearetical Economics, 146, pp. 727-748.

Linton, R. (1936) The shady of man. Appleton-Century-Crofts, New York.

Makela, K., \& Mustonen, H. (1996) The reward structure of drinking anong younger and older mala drinkers. Contemporary Drug problems, 23, pp. 479-492.

Moos, R.H. (1994), Why do some people recover from alcohol dependence, wherens athers continue to drink and become worse aver time? Addichon, 89 , pp. $31-34$

Makela, K., \& Simpura, J. (1985) Experiences related to drinking as a function of annual intake and by sex and age. Drug and Alcohol Dependence. 15 , pp. 389.404.

Mayfield, D., MaLeod, G., and I-Hall, P. (1974) The CAGE questionnaire: Validation of a new alcoholism screening instrument. American foums of Pychiatry, 131, pp. \$121-1123.

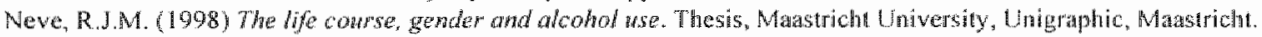




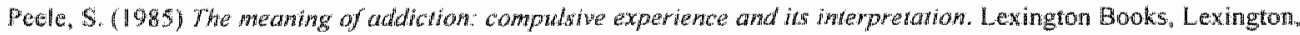
Mass.

Pescosonto, D.A. (1992) Beyond Rational Choice: The Social Dymamics of How People Seek Help. American Journat of Solology, 97, pp, $1096-1138$

POD. Productschap woor Gedestileerde Dranken (1996) Wortd Drinking Trends. Henley-on-Thames, NTC Publications Lid.

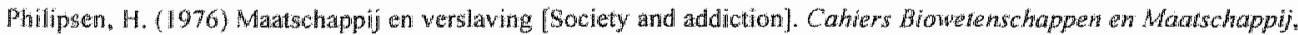
3, $\mathrm{pp}, 25-31$.

Rehm, J., Ashley, M.J., Room, R., Singte, E., Bondy, S. Ferrence, R, a Ciesbrecht, N. (1996) On the emerging paradigm of drinking patterns and their social and health consequences. Addicriox, 91, pp. 1615-1621.

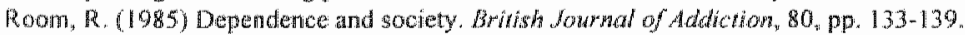

Room, R. (1989) The U.S. general population's experiences of responding to alcohol problems. Brinsh Jow wat af Addiction, 84, pp. 1291-1304.

Room. R. (1996) A Joohol consumption and social ham - comceptual issues and historical perspectives. Contemporary Drugratskm, 23, pp. $373-388$.

Room, R., Bondy, S.J. \& Ferris, J. (1995), The risk of harm to oneself from drinking, Canada 1989. Addichon 90, pp. 499-513.

Room, R., Bondy, S.J. \&e ferris, J. (1996), Determinants of stggestions for alcohol treatment. Addiction, 91, pp. 643$65 \%$

Rosenstock, M. (1966) Why people use health services, Milbank Mamoral Fund Quarterly, 44, pp. 94-124.

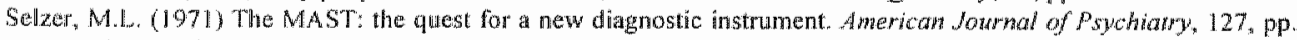
$1653-1658$.

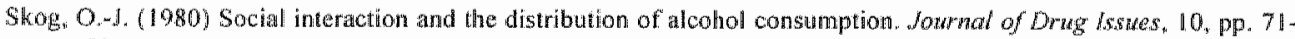
92.

Skogg, $0 .-1 .(1985)$ The collectivity of drinking cultures: A theory of the distribution of alcohol consumption. Brivish

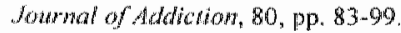

Skog, O.-J. (1986) The long waves of alcohol consumption. sactal network perspective on cultural change. Sociol Nemorks, 8, pp. 1-32.

Skog, O.-1. (1997) Rationality, ijrationality, and addiction: Notes on Becker and Murphys theory of addiction. In: Elster, I. \& Skog, O.J. (Eds). Geiting hooked: Rationaliy and addiction. Cambridge: Cambridge Uniwersify Press.

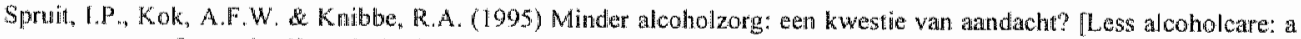
matier of attention? Tjaschriff voor Alcohol, Drugs ew andere Psychorrope shoffen, 21, pp. 148-156.

Stigler, $G$.J. \& Becker, O.S. (1977) 'De Gustibus Non est Disputandum', American Economic Review, 67, pp. 76-90.

Stockwell, T., Daly, A. Phillips, M.., Master, L., Midford, R., Gahegan, M. \& Philip, A. (1996) Total versus hazardous per capita alcohol consumption as predictors of acute and chronic alcohol-related harm. Contemporany Drang Problems, 23, pp. 441-464.

Stockwell, T., Lang, E., \& Rydon, R. (1993) High risk drinking settings: the association of serving and promotional practices with harmful drinking. Addictionn 88 , pp. $1519-1526$.

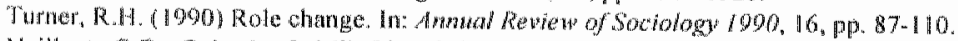

Vailant O.E. Gate, L. \& Milofsky, E.S. (1982) Natural hustory of male alcoholism. If. The relationship between diflerent diagnostic dimensions. Jourmal of Srudies on Alwohol, 43, pp. 216-232.

Wabh, G. \& Rehm, 1. (1996) Daily atrinking and harm. Confewporary Drug Problems, 27 , pp. 465-478.

Woisner, $C$. (1993) Toward an alcohol treatment entry modet: a comparison of problem drinkers in the general population and in treatment, Alcoholism. Chinical amol Experiwemal Researh 17, pp. 746-752.

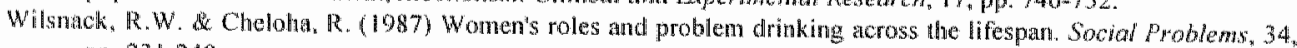
Pp. $21-248$.

Wilsmak, R.W., Kristianson, A.F, Vogeltanz, N.D. \& Wilsnack, S.C. (1997) Body water and women"s drinking

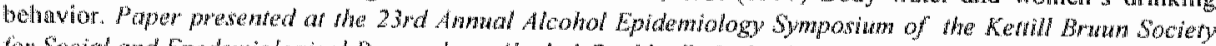
for Social awd Epedermologicat Research on Alcohol, Reykjavik, Iceland. June 2-6, 1997

Whppler, R. (1996/1983) De plats war roltheoretische ideez in de sociologie [Role theory and sociologyt. In:

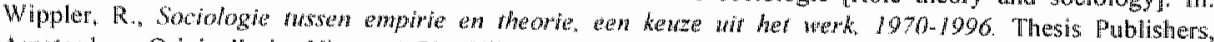
Ansterctan. Originally in: Visser, A.Ph., Viert. E. Van de, Heine, E.J.H. res, Winnubst J.A.M. (Eds) Rohen. Persontijhe en saciale invloc der op gedrag. Boony, Meppel.

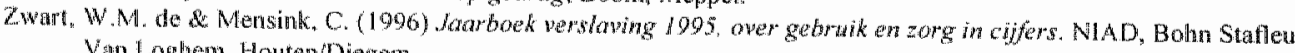
Van Loghem, Houten/Dikgen. 


\title{
Chapter 2
}

\section{Changes in alcohol consumption in a general population in the Netherlands: a 9-year follow-up study}

Published in Addiction, 1997, Vol. 92, pp. 49-60.

\author{
Klaas Jan Hajema, Ronald A. Knibbe and Maria J. Drop
}

\begin{abstract}
Changes in drinking patterns are described for men and women and per age group using data from a 9-year follow-up study in the Netherlands $(n=1327)$. Aspects of drinking patrerns in our study are drinking status, level of consumption and frequency of heavy drinking. The awerage consumption and average fiequency of heavy drinking are used to examine changes at aggregate level. Changes at individual level are examined in terms of adopting certain drinking patrerns (incidence) and continuing certain drinking patterns (chronicity). A swall decrease is found in the proportion of drinkers for both sexes. Only women show a decrease in mean consumprion. Average frequency of heavy drinking is stable for borh seres. Ar individwal level, proportions of chronicity and incidence of drinking paterns are higher among men. Swall aggregate changes in arinking patterns are accompanied by rather large shifs in individuals upardidown level of consumprion and frequency of howy drinking. No or only very small period effects are observed and linle evidence is found for a cohorl effect among men. A negative association beween incidence and age is found for drinking status anong women, for low moderate and high level of consumplion and for heavy drinking for both sexes. In terms of chronicity, negative associations with age are found for arinking status of both sexes, and for high level of consumprion and heavy drinking anong men.
\end{abstract}




\subsection{Introduction}

Consumption patterns of individuals and total consumption of populations are not constant but change over time (e.g. Neve er al., 1993; Fillmore et al., 1991). In the Netherlands from 1961 to 1980, per capita consumption of alcohol more than tripled, from 2.8 to 8.9 liters of pure alcohol (PGD, 1993). In the 1980's, per capita consumption slowly decreased to 8.2 liters in 1989. In this paper changes and stability of drinking patterns are investigated with data of a representative sample in a 9-year follow-up study in the Netherlands (measurements in 1980 and 1989). Aspects of drinking patterns in our study are drinking status (abstainer or drinker), level of consumption and frequency of heavy drinking. The longitudinal data form a unique resource for describing changes in patterns of alcohol use in a general population in the Netherlands.

Gender is probably the most important factor related to alcohol consumption. Generally, findings of alcohol research show that a larger proportion of men are drinkers, and men have a higher level of consumption and a higher frequency of heavy drinking. Therefore, in this article drinking patierns are analyzed separately for men and women. Besides gender, it is assumed in the alcohol research literature that age is associated with drinking, particularly with respect to changes in drinking patterns (e.g. Fillmore ef al., 1991). Accordingly, this study investigates gender and age-associated patterning of change and stability of alcohol consumption. Hence, the goal of this paper can be formulated as the examination of changes and stability of drinking patterns and of whether change in drinking patterns differ by age and gender.

In the analysis of drinking patterns we will focus on both aggregate and individual level. Aggregate-level changes indicate trends and social processes. These changes in means of consumption or heavy drinking may neutralize changes in groups or individuals which taken together produce a general trend. In this way we will be able to indicate, for instance, whether stability of average consumption also means stability of level of consumption for most individuals. From a public health perspective, individual-level changes are more informative than aggregate-level changes. Individual-level changes can indicate, for example, which particular groups become heavy drinkers (incidence) and which groups are chronic heavy drinkers or show remission. Analyses at the individual level therefore, allow one to specify social categories with high proportions of chronicity or incidence of high level of consumption, which deserve special attention in, for instance, prevention projects.

When studying changes in drinking patterns over time, possible explanations of the results are period effects, cohort effects or age effects. Changes in drinking patterns which are the result of influences that change over time are called period eflects. Period effects in the Netherlands in the 1980's appear to be small, per capita consumption decreased by approximately $8 \%$ (source: PGD, 1993). Hence, as period effects can be ignored, changes in drinking patterns over time can be interpreted as age effects or cohort effects.

While in this article we are mainly interested in gender and age specific drinking patterns, cohort effects will be analyzed to prevent us from drawing wrong conclusions. Glenn (1981) recommends performing a cohort analysis only if one can think of a reason or 
hypothesis why birth cohort could be related to drinking. Cohort analysis is often approached with the hypothesis that socialization in the formative years innuences drinking behavion and these effects of learning can determine characteristics and development of drinking behavior at an older age. In other words, socialization during an historic period might create stable learning effects and differences in the beginning of drinking careers. These differences in career beginnings probably have an impact on the entire drinking career. Research in the US often mentions the period of Prohibition as such a historic drinking period (e.g. Meyers $e$ al. 1981; Glynn et al, 1985; Fillmore, 1987a).

Although there has not been such a period of prohibition in the Netherlands, cohort effects might possibly proceed from the rapid and large increase in per capita consumption during the 1960's and the early 1970's. It could be hypothesized that birth cohorts who reached drinking age in a period of low per capita consumption would keep a relatively low proportion of drinkers, a low average level of consumption and a low frequency of heavy drinking. Following this line of reasoning, cohort effects in the Netherlands could be expected for cohorts born before 1950 because they reached drinking age during a period of relatively low per capita consumption.

Age effects can be described as 'effects of biological, psychological, and social change which tend to accompany chronological aging' (Glenn, 1981:362). Age effects are often explained by pointing out that age categories, due to different stages of the life course (e.g. Fillmore et al., 1991), or social roles (Knibbe, Drop \& Muytjens, 1987), differ with regard to drinking. An interpretation might be that different stages of the life course and different roles produce differences in constraints with respect to alcohol consumption. These differences in constraints lead to differences in opportunities and preferences and, as a result, to differences in drinking patterns at the aggregate level.

Alcohol research in the Netherlands finds only weak support for cohort effects but stronger support for age effects on drinking patterns. Neve et al. (1993) combined several Dutch surweys (measurements in 1958, 1970, 1981 and 1989) into a cohort analysis of abstinence, weekly consumption and heavy drinking. Period and cohort effects were not found for abstinence. At every measurement abstinence increased with age, but for women the increase was more pronounced and regular than for men. It is concluded that age, rather than birth cohort, can explain higher proportions of abstinence anoug older age categories. Data on average consumption for men and women showed a strong increase untill 1981 and stability afterwards. Only in 1970 was a significant negative association found for mean consumption and age, a relatively high average consumption being found for the youngest age group. Neverthelless, at all measurements average consumption for men and women in their 60 's was lower than for men and women in their 50's. A similar patern was found at most measumements of men and women in their 50 's with regard to men and women in their 40 's. Probably an age effect on consumption is only apparent at older age and not among age groups younger than 50. Patterns of heawy drinking (defined as the prevalence of men and women drinking respectively 21 and 14 glasses per week) resembled paiterns of mean consumption and no systematic cohort effects were found. For both sexes, the proportion of heavy drinkers declined after 50. Other studies, with cross-sectional Dutch data, found that after 50 proportions of abstainers increase, though for women more strongly than for men (CBS, 1994; 
Knibbe, 1984: Garretsen, 1983). Mean consumption was lower for men after 40, for women after 50 (Knibbe. 1984). A similar negative association with age was found for heavy drinking (CBS, 1994; Knibbe, 1984), however, Knibbe found this association to be valid only for men.

To sum up, in the Netherlands in the 1960's and the early 1970 's, large period effects on consumption and heavy drinking were observed, in the late 1970's and 1980's only small period effects were found; little or no vidence was found for cohor effects; moderate to large age effects were found on abstinence, small to moderate age effects were found on consumption and heavy drinking , particularly after 50 and among women.

\subsection{Method}

\subsection{The study samplle}

Data for this study come from a panel of the general population in the province of Limburg, the Netherlands. Limburg is one of the twelve provinces of the Netherlands and has about one million inhabitants. The first measurement in 1980 (T1) consisted of 1980 respondents, a response tate of $76 \%$. The data were collected using a face-10-face interview. The second measurement in $1989(\mathrm{~T} 2)$ consisted of 1,327 respondents, a response rate of $67 \%$. Data were collected in the second measurement by means of a maled questionnaire (76\%) or the same questionaire in a face to face interview (24\%). Interviews were held face to face mainly to enhance response among respondents classified as problem drinkers at T'1 ${ }^{1}$. In 1980, the age of respondents anged from 16-69. Age groups were defined by their age at first measurement.

The non-response rates for 1980 and 1989 were 24 and $33 \%$. In 1980 , differences between population and sample in several demographic characteristic were small, and not significant (Knibbe, 1984). The non-response in 1989 was analyzed with the 1980 data and with an interview by telephone among $30 \%$ of the drop outs $(n=168)$. Mortality $(n=85,4.3 \%)$ was not related to drinking patterns or alcohol-related problems. No significant differences in response were found for age and sex. For all 1980 drinking variables (such as weekly consumption, heavy drinking and drinking status), no differences in response were found. The drop outs that were reached by telephone were on the average four years older than those that could not be reached. A comparison of the dropmout sample and the panel showed that in the drop-out sample a higher percentage stopped drinking (16\% vs $7 \%$ ) and decreased their frequency of heavy arinking (e.g. for chronicity of monthy heavy drinking $60 \%$ vs $33 \%$ ). "This selective drop out can only be partly explained by age. No selective drop out was found for changes in typical consumption among men and for drinking status, ypical consumption and heavy drinking among women. In conclusion, the panel represents the general population with regard to age and sex. There are no indications for selective drop out according to drinking

1 In a logistic regression analysis both abstinence, consumption and heavy drinking at $T 2$ did rot differentiate respondents whose data were collected by a malled questionnaire from those who were interviewed facewto-face. Moreover, between both categories no difference was found in the response at $T 2$. 
patterns at first measurement. However, men who stopped drinking and who decreased their frequency of heavy drinking are under-represented in the panel.

\subsubsection{Alcohol consumption measures}

Respondents were asked whether they had consumed any alcohol in the past six months. If they had not drunk in the past six months they were defined as abstainers. The level of consumption of each respondent who reported to have drunk in the past six months was assessed with a 4-day weekly recall. Consumption was measured by the number of standard glasses on Saturday and Sunday and of the two most recent weekdays. The mean of these two days was used as an estimate of the average consumption of all weekdays.

The frequency of heavy drinking was determined with a question about the frequency of drinking six glasses or more. This frequency was measured on an eight-point scale from 'never' to "every day" and recoded into a weekly frequency. Hence, a score on heavy drinking of 1 means drinking six or more glasses per occasion once a week, a score of 0.25 means drinking six or more glasses once every four weeks. Prevalence, chronicity and incidence of drinking at least 7,14 or 21 glasses per week were estimated to indicate the quantity of and change in alcohol consunption at individual level.

Note that by definition the prevalence of drinking 7 glasses per week, is included in the prevalence of drinking 14 glasses per week. Monthly and weekly frequency of drinking six glasses or more were used to indicate prevalence, chronicity and incidence of heavy drinking. Incidence is defined as those respondents reporting behavior at T2 as a percentage of those who did not report it at T1. Chronicity is defined as those respondents reporting behavior at T2 as a percentage of those who reported it at T1. Note that by definition the percentage of remission is the converse of chronicity.

\subsubsection{Anallysis}

Results will be presented for drinking status, consumption and heavy drinking respectively. For each drinking characteristic, changes are presented at aggregate level and individual level. Chronicity and incidence of the three drinking aspects are presented with regard to age. Finally, period and cohort effects are examined and outcomes are presented if they are likely to interfere with age effects.

The means for weekly consumption and weekly frequency of heavy drinking in 1980 and 1989, and the change in average consumption and heavy drinking were determined for men and women. To assess means of level of consumption and heavy drinking and to assess change from 1980 to 1989 only cases were used who participated in both measurements. To determine the statistical significance of change of consumption and heavy drinking, Iwotailed t-tests were performed in SPSS 5.0. Changes of drinking patterns at individual level were determined by estimating the prevalence, incidence and chronicity of drinking in the past six months, of drinking 7, 14 and 21 glasses per week and of monthly and weekly frequency of heavy drinking. In men, drinking 7, 14, or 21 glasses per week can be considered as low, moderate and high level of consumption. In women, if mean consumption is taken into account, drinking 7 glasses or more can be considered as a moderate level of consumption and drinking 14 or 21 glasses or more can be considered as a high level of consumption. 
Age-related drinking patterns are presented in figures 2.1-2.4. Age is divided into four categories: 16-19,20-29, 30-49 and 50-69. Differences between the four age groups were tested with a Chi ${ }^{2}$-test. More specific results of age will only be indicated if results differ notably within the four age categories. As an alternative classification for which drinking patterns were tested age was divided into the teens (16-19), the early 20 's (20-24), the late 20 's $(25-29)$, and the $30^{\prime} \mathrm{s}, 40^{\prime} \mathrm{s}, 50^{\prime} \mathrm{s}$ and $60^{\circ} \mathrm{s}$. Iricidence and chronicity of several drinking patterns cannot be differentiated across age due to small cell sizes caused by respectively high and low prevalences at TI.

The analysis of change in drinking patterns concentrates on gender and age-related patteming of drinking at aggregate and individual level. As mentioned above, period effects can be indicated with per capita consumption. Another indication of period effects are the changes in drinking patterns of the panel while controlling for age (at both measurements only age categories 25-69 were included). A cohort analysis was performed by constructing a "standard" collort table (Glenn, 1981) and searching for regular cohort effects for all. three drinking aspects. By defining birth cohorts of nine years, the youngest cohort at $T 1$ has the same age range at T2 as the second cohort at T1 (i.e. aged 16-24 and 25-33, etc.). Results with regard to period and cohort effects are presented successively for drinking status, consumption and heavy drinking.

\subsection{Results}

\subsubsection{Drinking Status}

Table 2.1 shows the percentage of drinkers in 1980 and 1989 and the change in percentage between the first and second measurement for men and women. A large majority of both sexes were consumers of alcoholic beverages. However, abstinence was much more common among women. The proportion of femalle abstainers at both measurements was about three times the proportion of male abstainers, respectively 23.9 and $7.5 \%$ at $\mathrm{T} 1$ and 31.0 and $10.6 \%$ at $\mathrm{T} 2$. At the second measurement the proportion of drinkers decreased slightly for both sexes.

Table 2.2 displays prevalence, chronicity and incidence of alcohol consumption. The chronicity of drinking alcohol was high, almost all men kept on drinking. Although women's chronicity of drinking was lower, still a latge majority of women were long-term alcohol consumers. Thus from the perspective of abstinence, remission of drinking alcohol occurred amost three times as often among women than among men. Incidence of drinking alcohol was found among half of the male and a third of female T1-abstainers. For example, $50 \%$ of the males who were abstainers at $\mathrm{T} 1$ were drinkers at $\mathrm{T} 2$. Specifically, the incidence anong men can be considered as high. As a result, men who never drunk were exceptional $(3.8 \%)$. 
Table 2.1 Changes in drinking status, level of consumption and frequency of weekly heavy drinking $(1980-1989)$ by gender.

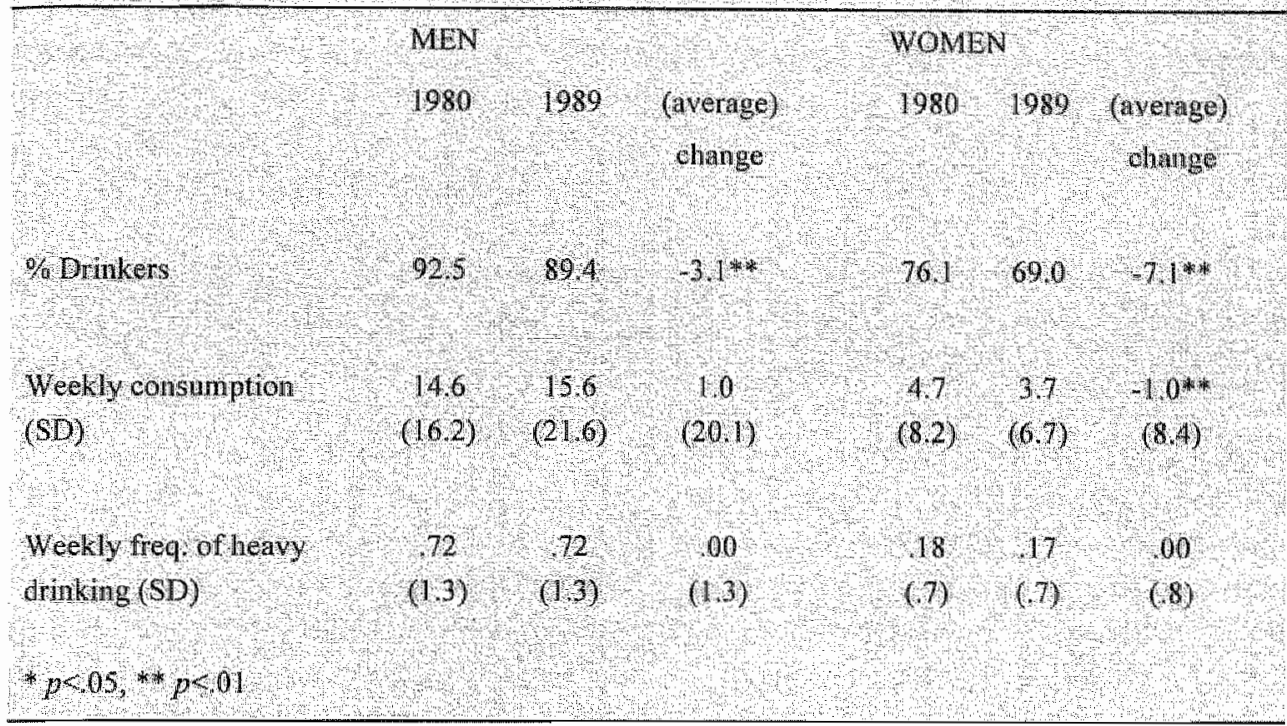

The association between drinking status and age is shown respectively for men and women in figures 2.1-2.3. Drinking status seemed to be more associated with age among women than among men. Prevalence (not presented), chronicity, and incidence declined at older age. In men, chronicity had a weak negative association with age (figure $2.3, p<.01$ ). The prevalence at $\mathrm{T} 1$ was too high to have significant incidence proportions for different age categories. The data suggest however, that incidence is lower after 50 , less than $40 \%(\mathrm{n}=18)$ while higher than $50 \%(\mathrm{n}=32)$ at younger age. In women, chronicity was highest in the youngest age group and lowest in the oldest age group (figure $2.1, p<.001$ ), incidence was highest in the late teens $(67 \%)$, decreased after 20 and was lowest in the oldest age yroup $(19 \%, p<001)$.

\subsubsection{Level of consumption}

As shown in table 2.1, the average consumption for women decreased from about 5 to 4 glasses per week, men increased average consumption from about 15 to 16 glasses per week, but not significantly. As a result, there was no change in average consumption of the total population (not presented)

In men, the prevalences at $\mathrm{T} 1$ and $\mathrm{T} 2$ of drinking at least 7, 14 or 21 glasses per week were almost the same (table 2.2). Chronicity of consumption was high, about $75 \%$ of the men who drank 7 or more glasses at first measurement also drank 7 or more glasses at second measurement. Chronicity of higher levels of consumption was lower, but chronicity of drinking at least 21 glasses was still more than $50 \%$. Incidence of drinking at least 7 glasses per week was $33 \%$. Thus, of those men drinking less than 7 glasses at first measurement, 33\% drank at 


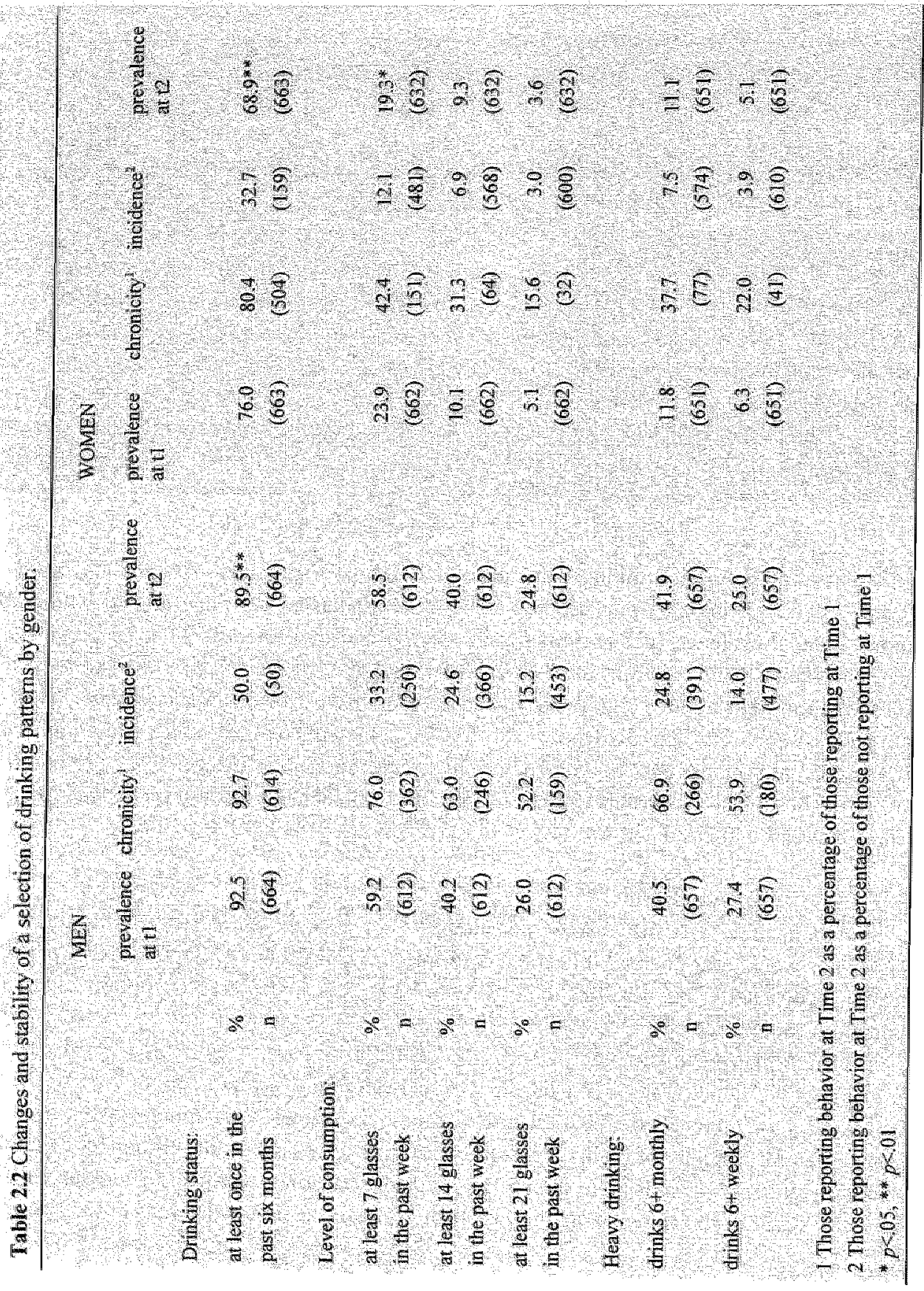


least 7 glasses at second measurement. Similar to chronicity, proportions of incidence were lower at higher levels of consumption, the incidence of drinking at least 21 glasses was only half the proportion of the incidence of drinking at least 7 glasses (15\%). Prevalences of consumption of men at $\mathrm{Tl}$ and $\mathrm{T} 2$ were about the same, hence, incidence of levels of consumption fully counterbalanced remission.

In women, prevalences at $\mathrm{T} 2$ were lower than at $\mathrm{T} 1$. However, onlly the decrease at $\mathrm{T} 2$ of drinking at least 7 per week glasses was significant $(p<05)$. Less than half of the women $(42 \%)$ who consumed at least 7 glasses per week at T"I also drank 7 glasses at T2. Chronicity of drinking 14 or 21 glasses per week was considerably lower. The incidence of levels of consumption was rather low, a moderate level of consumption of 7 glasses per week had an incidence of only $12 \%$. Hence, incidence was too low to compensate remission of consumption.

Figures $2.1 \& 2.3$ suggest only weak or even no association between chronicity of consumption and age. The prevalence at T1 of women drinking 14 and 21 glasses weekly was too low to determine chronicity of these consumption levels. Chronicity of drinking at least 7 glasses was not associated with age for either men or women. Figure 2.3 suggests that among

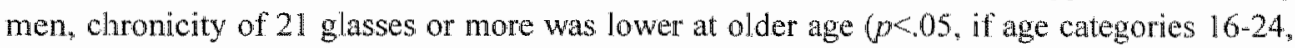
25-39, and 40-69 are used). More precisely, chronicity was highest in the late 20 's and decreased monotonously with age.

A strong association was found between the incidence of low, moderate and high level of consumption and age. For men, figure 2.4 shows a considerable decline after 50 in incidence of drinking 7,14 and 21 glasses weekly $(p<05, p<, 001, p<01)$. For women, the incidence of drinking 7 and 14 glasses weekly was highest in the late teens and declined gradually to very low proportions at older age (figure $2.2, p<.001, p<.05$ ).

\subsubsection{Heavy drinking}

Similar to level of consumption, results are presented for both sexes at aggregate level (means and average change of frequency of heavy drinking), and at individual level (prevalence at $\mathrm{T} 1$ and $\mathrm{T} 2$, chronicity and incidence of weekly and monthly fiequency of heavy drinking). As mentioned above, heavy drinking was defined as drinking six or more glasses per occasion. On average, men consumed six or more glasses per occasion three times eyery four weeks, women only once every five weeks. Table 2.1 shows that there was no change in average frequency of heavy drinking at $\mathrm{T} 2$ for either sex.

Although the mean frequency of heavy drinking did not change, table 2.2 depicts that among men the chronicity of drinking six or more glasses per occasion every week was $54 \%$. Hence, during the 9-year follow-up period remission occurred among almost half of the drinkers who drank weekly six glasses or more per occasion at $[1$. Incidence of weekly heavy drinking was $14 \%$ and counterbalanced remission at $\mathrm{T} 2$. Changes in prevalence of monthy and weekly heavy drinking of men were not significant. In women, both chronicity and incidence of heavy drinking of women were low compared to men. Chronicity of heavy drinking among women was $22 \%$. In other words, nearly $80 \%$ of those at TI who drank heavily once a week, showed remission at T2. Incidence of weekly heavy drinking was $4 \%$. 


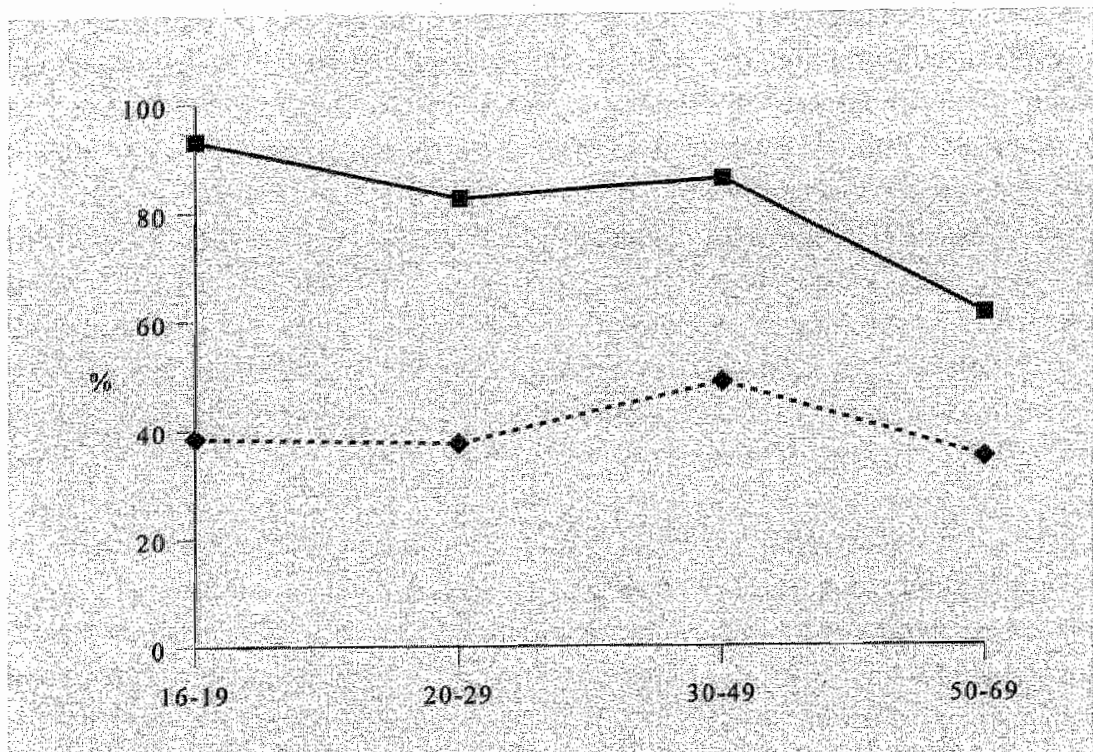

Digure 2 . Chronicity of dinking patterns for women

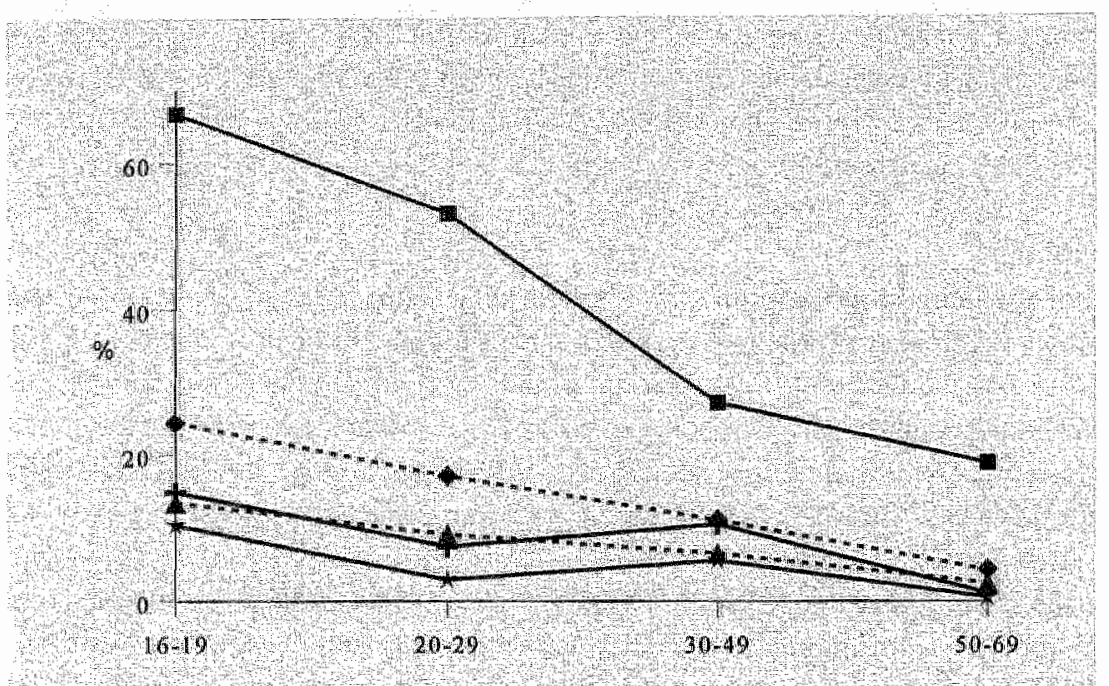

Tigure 2.2 lnoidence of drinking patteras for women

- dinkkers $(-),+7$ per week $(-), 414+$ per week $(-), 021+$ per week $(-\rightarrow)$ + monthy $6+$ per occasion $(-$ ), t week 1 y $6+$ per oceasion $(-)$ 
The decrease in the prevalence of monthly and weekly heavy drinking was not significant.

In figures 2.2-2.4 an obvious association is visible between chronicity and incidence of heavy drinking and age. In women, prevalence at first measurement of heavy drinking was too low to determine chronicity. For men, figure 2.3 depicts that chronicity of monthly heavy drinking was about $67 \%$ between 16 and 50 , after 50 chronicity decreased to $33 \%(p<01)$. More specifically however, chronicity of monthly heavy drinking was highest in the late 20 's and 30 's $(75 \%)$ and decreased in the 40 's $(60 \%)$, and after 50 (33\%). The pattern of chronicity of weekly heavy drinking with age was somewhat different. Chronicity at both younger and older age was lower than at middle age. If the age-pattern is looked at in more detail chronicity was highest in the late 20 's $(73 \%)$ and decreased substantially only after 50 . While chronicity in the early 20 's was rather low (44\%), chronicity of the four age groups was highest between 30 and $49(p<05)$. Patterns of incidence of monthly and weekly heavy drinking with age differed from chronicity. Incidence of monthly heavy drinking was highest in the late teens $(48 \%)$ and decreased monotonously to $3 \%$ after 60 . Incidence of weekly heavy drinking fluctuated between $17 \%$ and $22 \%$ in the late teens, 20 's and 30 s, and decreased to about $10 \%$ in the 40 's and 50 's and to $2 \%$ after 60 .

In women, due to the low prevalence of heavy drinking at $\mathrm{T} 1$, data on chronicity with regard to age are not informative and not presented. A clear pattern however, is found for incidence. Incidence of monthly heavy drinking was highest in the late teens (15\%), decreased in the $20^{\circ} \mathrm{s}$, increased in the 30's and decreased again after 40 to $1 \%$ in the 50 's and $60^{\prime} \mathrm{s}$. Patterns of incidence of weekly heavy drinking were only slightly different. Incidence was highest in the late teens (10\%), decreased sharply in the early $20 \%$ s (3\%) and increased monotonously to $7 \%$ in the 40 's, to decrease again to $1 \%$ after 50 .

\subsubsection{Period or cohort effects on change of drinking patterns?}

To determine period effects on level of consumption of alcohol between 1980 and 1989, data on per capita consumption were used as an indication of change. As mentioned earlier, per capita consumption in the Netherlands decreased by about $8 \%$ from 8.9 to 8.2 litres of pure alcohol. Period effects with regard to abstinence and heavy drinking are indicated with change at $\mathrm{T} 2$ while controlling for age.

The percentage of drinkers among men and women aged 25-69 decreased, but not significantly for either sex. Hence, period effects can be considered to be very small. A cohort effect was found in men for birth cohort 1929-1937. This cohort (together with the youngest cohort) showed an increase in the percentage of drinkers while all other cohorts showed a decrease in proportion of drinkers. It is likely that age effects on chronicity of drinking alcohol would have been a little stronger without this cohort effect.

The decrease in per capita consumption suggested a small period effect with regard to consumption. The observed minor decline of mean consumption of women in our study confirmed this period effect. However, the opposite was found for men, mean consumption for age group 25-69 increased from 14 to more than 16 glasses per week $(p=.05)$. Similar to abstinence, the same cohort of men displayed an increase in prevalences of drinking 7,14 and 21 glasses per week. As a result, the prevalence of low, moderate and high levels of consumption increases for drinkers in their 50 's. The incidence and chronicity of consumption. 
of cohort 1929-1937 resembled the incidence and chronicity of younger cohorts. Age effects on chronicity were only found at the high level of consumption. Without this cohort effect the age effect at the high level of consumption would perhaps have been stronger. However, it is likely that even without this cobort effect there would have been no age effects at lower levels of consumption.

There were no period effects found on mean frequency of heavy drinking for both sexes. Nevertheless, the change in the prevalence of monthly and weekly heavy drinking in men suggested a small period effect. Prevalence of monthly and weekly heavy drinking for age group $25-69$ increased from respectively $35 \%$ to $44 \%$ and $21 \%$ to $26 \%(p<.01, p=.06)$. Again, a cohort effect appeared with regard to frequency of heavy drinking and probably reduced the age effect at middle age. Incidence and chronicity of birth cohort 1929-1937 were high in comparison to younger and older birth cohorts. Chronicity of monthly and weekly heavy drinking was highest for cohort 1947-1955 (aged 25-33 at T1, respectively 76\% and 70\%) and decreased monotonously with age. Incidence of monthly heavy drinking was highest for the youngest birth cohort (1956-1964,46\%). Incidence of cohort 1938-1946 was lower than incidence of cohort 1929-1937, and decreased strongly for cohorts born before 1929. Incidence of weekly heavy drinking was highest for cohort 1947-1955 and decreased gradually among older cohorts. While age effects were found on both incidence and chronicity of heavy drinking, the observed cohort effect weakened the effect of age.

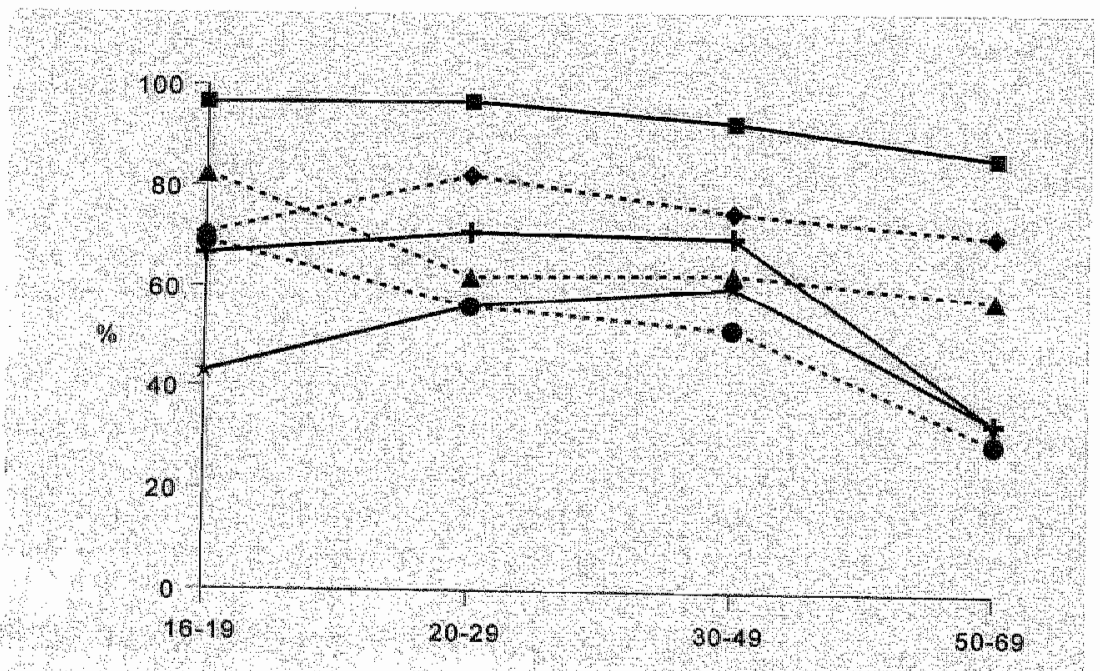

Pigure 23 Chronicity of drinking patterns for men 


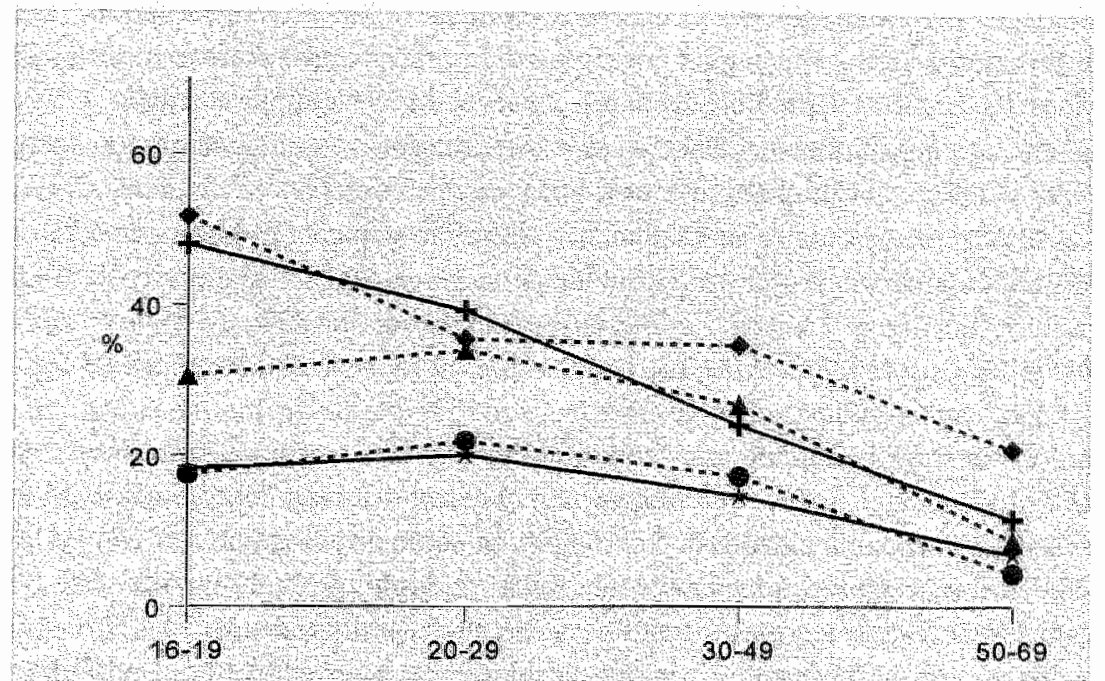

Figure 24 Ineidence of drinking patterns for men

- drinkers $(-), 7+$ per week $(-), 414+$ per week $(-), 021+$ per week $(-)$

+ montlily $6+$ per occasion $(-),+$ weekly $6+$ per occasion $(-)$

\subsection{Conclusions and discussion}

The purpose of this longitudinal study was to examine gender and age-associated patterning of changes and stability of alcohol consumption. Change in proportion of drinkers, average consumption and frequency of heavy drinking were used to indicate aggregate-llevel changes. Results on prevalence, incidence and chronicity were used as an indicator of individual-level changes and age effects.

Main findings at aggregate level can be formulated as follows: a large majority of men and women were consumers of alcoholic beverages, but at second neasurement a small decrease was apparent in the proportion of male and female drinkers. Average consumption for men exceeded consumption for women by about three to four times. At second measurement women showed a significant decrease in average consumption, an increase in average consumption was suggested for men (not significant). The mean frequency of heavy drinking was stable for both sexes.

Most prevalences of drinking patterns were stable. The stability of most prevalences means that at individual level there were about as many new cases (incidence) as cases who no longer reported these drinking patterns (remission). Incidence counterbalanced remission of prevalences with three exceptions: the prevalence of drinkers for both sexes and the prevalence of women drinking 7 glasses or more weekly decreased. The decrease of drinking 7 glasses or more weekly could be expected given the observed decrease of mean consumption. The 
more weekly could be expected given the observed decrease of mean consumption. The chronicity of all drinking patterns was higher among men. In other words, women more often showed remission in drinking alcoholic beverages, in level of consumption and in heavy drinking. Similar to chronicity, the incidence of drinking patterns was higher among men, which is probably related to their higher prevalences of these drinking patterns in general. For both sexes, proportions of chronicity and incidence were lower among higher levels of consumption and higher frequency of heavy drinking. The percentage of chronicity of high level of consumption for men and women, drinking respectively at least 21 or 14 glasses per week, was $52 \%$ and $16 \%$. Chromicity of weekly heavy drinking for men and women was $54 \%$ and $22 \%$.

The extent to which drinking patterns are modified by age was examined with incidence and chronicity of drinking status, level of consumption and heavy drinking. Unfortumately, due to small cell sizes, differences in incidence and chronicity of some drinking patterns cannot be interpreted for the four age groups. Incidence for men of drinking alcohol could not be determined for different age categories because of the high prevalence at $\mathrm{T} 1$. The low proportion of incidence among women af drinking 21 glasses or more weekly did not allow differentiation by age. Furthermore, in women chronicity of drinking 14 and 21 glasses per week and heavy drinking could not be determined due to the low prevalence at T1.

With regard to the conclusions several limitations have to be kept in mind. Firstly, it would probably be more informative to use drinking four glasses or more on an occasion as an indicator of heawy drinking among women. With the question about six glasses or more the chronicity of heavy drinking by age could not be assessed. Secondly, the results of a nonresponse analyses suggested that among men the response was lower among those who stopped drinking and who decreased heavy drinking. However, while the selective drop out clid not differ by age the influence on the results is likely to be limited.

In general, the results suggest that the drinking patterns of women are more often and more strongly related to age than in men. Results on drinking status have shown that for men chronicity and for women both chronicity and incidence of drinking alcoholic beverages, are related to age. Yet, the decline of incidence with age is much stronger than the decline of chronicity with age. While a majority of both men and women keep on drinking alcohol even at an older age, incidence decreases strongly after 30 . Furthermore, with older age the decrease of chronicity among women is stronger and starts at a younger age. These results are to a lange extent in accordance with the findings of Fitzgerald \& Mulford (1983) and Fillmore (1987a, b). As in our study, in Fillmore"s studies chronicity of drinking seems to be weakly related to age for men and somewhat more strongly related to age for women. But in contrast to our study, incidence in women (and men) is found not to be related to age.

Only little evidence is found for an association between chronicity of level of consumption and age. Chronicity among men of drinking at least 21 glasses weekly was lower at an older age, however, lower levels of consumption of both men and women are likely to be not related to age. Incidence of consumption was rather strongly related to age, the association was stronger for women and at higher levels of consumption. Our results resemble results on frequency of drinking of Fillmore $(1987 \mathrm{a}, \mathrm{b})$, who found some evidence of a negative association of age and incidence in women and both incidence and chronicity in men. Other 
studies (Glynn et al., 1985; Temple \& Leino, 1989) did not find an age-related decrease in level of consumption.

The results have shown a clear pattern of chronicity and incidence of heawy drinking with age. Chronicity of weekly heavy drinking in men was highest in the late 20 's, the 30 's and $40^{\prime} s$ and decreases after 50 . Once again, the association of age with incidence was stronger. Incidence decreased sharply after 40 . In women a pattern appeared where incidence was lowest after 50 and where incidence in the $30^{\circ}$ s and $40^{\prime}$ s was higher than in the 20 's. Both Fizgerald \& Mulford (1983) and Fillmore (1987a, b) found a negative association of heavy drinking with age. Our patterns of chronicity and incidence differ from results of Fillmore (1987), who found an erratic pattern of chronicity with age in men and a stable pattern of incidence with age, except for a high proportion of incidence among men in their $20^{\circ} \mathrm{s}$. Similar age-related patterns with highest proportions for middle-aged women were found by fillmore (1987b). In her study however, incidence decreased only after 60. Our results differ from Glynn et al. (1985) and Temple \& Leino (1989), whose studies did not find an association between heavy drinking and age either. From a public health perspective it can be concluded from this study that both chronicity and incidence of levels of consumption and heavy drinking occur more often among men. More importantly however, middle-aged men have a greater risk of chronic heavy drinking and therefore might deserve special attention with regard to the prevention of developing alcohol-related problems.

As mentioned earlier, in our study period effects were found to be very modest and an indication of cohort effects was only found for men born in the 1930's. While younger cohorts showed a clecrease in prevalences, this cohort showed a remarkable increase in prevalence of consumption and heavy drinking. However, it is not clear how an increase in the prevalence of several drinking patterns can be explained by low per capita consumption at the moment of reaching drinking age, as hypothesized in the introduction. Therefore, the interpretation of the observed cohort effect is difficult. Without a multivariate analysis that takes into account changes associated with chronological aging, this finding remains difficult to interpret. The increase in proportion of drinkers, level of consumption and frequency of heavy drinking of this cohort was probably a combination of age and cohort effects. As a result, the cohort effect among older birth cohorts might not have occurred because of age effects. In the context of social interaction theory (Skog, 1980, 1985) the increase in prevalences of men at middle age could be explained as social influence from younger birth cohorts. Although they reached drinking age during a period of low per capita consumption, they caught up with younger birth cohorts after some time. The difference in age between the younger and older birth cohorts is probably too large, and therefore social influence too little for the older birth cohort, to approach the younger birth cohorts in drinking patterns. However, if drinking is to a certain extent determined by drinking patterns in the social network, then why does the colort effect appear in the 1980"s and not earlier? Since per capita consumption in the Netherlands in the 1970 's could already be considered as high, it would be more likely that a cohort effect had occurred (if it occurred at all) in those years, and not in the 1980's.

Although several longitudinal studies find support for an association of aging with drinking patterns, on the other hand there are studies which stress the importance of cohort effects (e.g. Temple \& Leino, 1989; Glynn ef al., 1985; Fitzgerald \& Mulford, 1983 ). People 
al an older age have a lower tolerance of alcohol and a greater chance of having health problems and being advised not to drink. However, to our knowledge there is not a general lawi in the social sciences that produces lower prevalences of drinking patterns at older age. Lower tolerance and health can possibly only partly explain the negative association of drinking patterns with age. Probably age-related drinking patterns can be explained by life-style, since at older age there are more constraints on drinking and the elderly are more likely to abstain or to have more moderate drinking patterns. In this study it is concluded that a negative association of incidence and chronicity with age exists. However, if hifestyles change, drinking patterns at older age could approach or might ewen exceed drinking patterns at younger age.

\section{References}

CBS (1994) Trend figures netherlands health interview surwey; aspects of unhealthy behaviour 1989-1993. In:

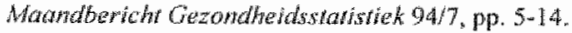

Filmore, K.M. (1987a) Prevalence, incidence and chronicity of drinking patterns and problems among men as a furction of age: a longitudinal and cohort analysis, British Joumal of Addiction, 82, pp. $77-83$.

Fillmore, K.M. (1987b) Women's drinking across the adult life course as compared to men's, British a/owrmal of Addiction, 82, pp, $801+811$.

Fillmore, K.M., Harka, E. Johmstone, B.M., Leino, E.V., Motoyoshi, M. \& Temple, M.T. (199\#) A meta-analysis of life course variation in drinking. The colloborative alcohol-related longitudinal project. Brinish Jourmol of Addiction, $86, \mathrm{pp}, 1221-1268$.

Fitzgerald, J.L. \& Mulord, H.A. (1983) Maturational and generational changes in drinking behavior and attitudes in Jowa, 196-1979. Jownall of Studies on Alcohol, 44, pp. 476-484.

Garretsen, HFL. (1983) Probleendrinken,proefschrift, (Problemdrinking thesis] Katholieke Universiteit te Nijnegen, Swets \& Zeillinger, Lisse.

Glenn, N.D. (1981) Age, birth cohorts, and drinking: an illustration of the hazards of inferring effects from cohort data, Jonmal of Cerowology, 36, pp, 362-369.

Glymn, R.J., Bouchard, G.R., LoCastro, J.S. \& Laird, N.M. (1985) Aging and generational effects on drinking

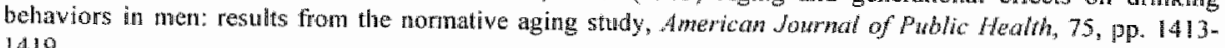
1419

Knibbe, R.A. (1984) Van gangbraar tor prablematies drankgebrwik, proefschrift, from social drinking to problematio drinking. thesis/. RU-Limburg, Mastricht.

Knibbe, R.A., Drop, M.I., Muytjens, A. (1987) Correlates of stages in the progression from everyday drinking to problem drinking Sochal Science awal Medicitie, 24, pp. 463-473.

Knibbe, R.A. Swinkels, H. (1992) Aleoholgebralk Hr Nederland; een analyse wan gegevens uit de CBSgezondheidsenquete 1989 . Alcohol consuniption in the Nethertands; an analyses of data from the CBS Health

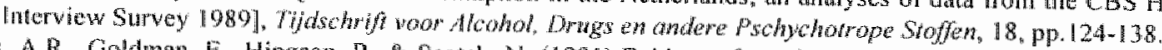

Meyers, A.R., Goldman, E. Hingson, R. Scotch, N. (1981) Evidence for cohort or generational differences in the drink ing behawior of older adults. Jwernowomat Jownal of Aging and Homan Development, 14, pp. 31-44.

Neve, R.M. Diederiks, J.M.M. Knibbe, R.A. \& Drop, M.J. (1993) Developments in drinking behavior in the Netherlands from 1958 to 1989 , a cohort amalysis. Addichon, 88, pp. 611-621

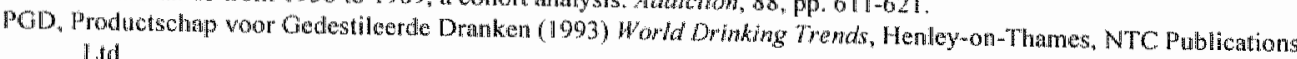
Ltol.

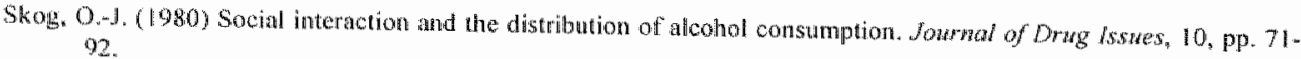

Skog, O, - (1985) The collectivity of drinking cultures: A theory of the distribution of alcolrol consumption. Brish Jownat of Addichion, 80, pp. $83-99$.

remple. M.T. \& Laino, E.V. (1989) Long-term outcomes of drinking: a 20 -year longitudinal study of men. British

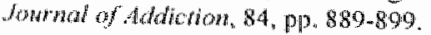




\title{
Chapter 3
}

\section{Changes in social roles as predictors of developments in drinking behavior: testing a theory}

Submitted for publication

Klaas Jan Hajema \& Ronald A. Knibbe

\begin{abstract}
Aim- To assess the effects of changes and stability of marital status, employment status, and having children at home on the level of consumption and the frequency of heavy drinking. With role theory as a starting point it was expected that the shift into social roles would decrease consumption and heavy drinking while the shift out of social roles would lead to an increase in consumption and heavy drinking.

Design-Prospective cohort study.

Setting- The general population in the Province of Limburg, The Netherlands (1980-1989).

Participants-1327 men and women aged 16-69 at first measurement.

Measurements the weekly consumption of standard glasses $(10 \mathrm{~g}$ ethanol) of alcoholic beverages, the frequency of drinking six glasses or more.

Findings-In particular the acquirement of a spouse role and the parenial role often led to a decrease in consumption or heavy drinking. No effect was found for the acquirement of the employment role. With regard to losing roles only the loss of the spouse role among women generated an increase in heavy drinking.

Conchsions - In general, it can be concluded that limited support was found for the effects of changes in roles on drinking behavior. Our study suggests that probably other theories must be sought to explain social differences in drinking behavior.
\end{abstract}




\subsection{Introduction}

One of the main issues of alcohol research in the social sciences concerns the relationship between social characteristics and drinking behavior. Can differences in drinking behavior be explained by differences in social conditions? A large body of research findings exists that suggests associations of social characteristics of drinkers with drinking behavior. Numerous studies have investigated the associations of drinking behavior with characteristics such as age, gender, religion, marital status, employment status and socioeconomic status. In this longitudinal study we focus primarily on the effects of marital status, employment status and the presence of children in the household on drinking behavior. Two essential aspects of drinking behavior that will be examined in this article are the level of consumption and the frequency of heavy drinking. The main research question can be formulated as: are changes in social characteristics determinants of changes in consumption and heavy drinking? Data over a period of time are required to investigate the development of drinking behavior. In this study a longitudinal design was used to assess both changes in drinking behavior and changes with regard to marital status, employment status and parental status. Hence, it can be examined prospectively whether transitions in maritall status, employment status and parental status can explain developments in drinking behavior.

In the alcohol research literature the theoretical concept "role" is often used to explain associations of drinking behavior with social characteristics (e.g. Temple et al., 1991; Wilsnack \& Cheloha, 1987; Knibbe, Drop \& Muytjens, 1987; Johnson, 1982). Many researchers, however, use 'roles" only as a concept to indicate variables that should be included in the analyses without a deductive argument with regard to drinking behavior. With role theory the differences in drinking behavior, for instance between those employed and unemployed, or married and unmarried, are explained by differences in roles. Temple et al. (1991) used role theory in its most elementary form and suggested that shifts in roles leading to more stable relations in an individuals life cause a decrease in consumption. Shifts in roles leading to less stable relations were expected to cause an increase in consumption.

More specifically, Wilsnack \& Cheloha (1987) explained the effects of social roles on drinking behavior by the effects of multiple roles and by role deprivation. Firstly, multiple roles are accompanied by a reduction of the psychological need to use alcohol and by an increase in social monitoring and social control of drinking. Moreover, due to an increase in performance demands multiple roles leave less opportunity for behavior impairment caused by drinking (See also Wilsnack \& Wilsnack, 1991). Secondly, several effects of role deprivation on drinking behavior have been suggested. The loss of roles means more drinking opportunities, less restrictions on drinking behavior, more importance of role-relationships that require drinking, and drinking as coping behavior for the stress of role deprivation.

Probably the most elaborated role theory to explain drinking behavior and drinking problems has been developed by Knibbe et al. (1987). According to Knibbe et al. roles differ in the extent that they refer to the macro-level (status roles), meso-level (position roles) and micro-levell (situation roles) of action. Status roles are defined by social expectations with regard to characteristics that can hardly be influenced by individuals (such as gender, age, 
ethnicity but also social class and religion). Position roles are defined by social expectations of characteristics that are acquired (for instance, being a spouse; employee or parent). Situation roles are defined by social expectations that facilitate social behwwior in short-term situations in which specific goals are achieved (eating, going out for a drink, attending football matches, watching TV). In general, for most people alcohol consumption is thought to be limited to situation roles. The extent to which drinking in situation roles is considered as appropriate is determined by status roles. Position roles infuence drinking bethavior because drinking is likely to interfere with the fulfilment of employment roles, sponse roles or parental roles. Those who have such position roles will be more likely to drink less. Those without these roles have a less structured everyday life, and will probably use alcohol consumption to create a structure or as a means to neutralize the tensions caused by the lack of roles (Kuibbe et al, 1987).

\subsubsection{Results of longitudinall studies}

Most studies found only limited support for the effects of marital status, employment status and the presence of children in the household on drinking behavior. An important study is the meta-analysis of the effects of change in marital status and employment status on alcohol consumption of twelve longitudinal studies by Temple et al. (1991). Their results showed that marital status and employment status were associated with quantity at follow-up and that the effects differed according to gender and age. If one compares role transition with role stability only the effects for marital status were as hypothesized. An increase in consumption was found for younger women who became unmarried and men who became employed. Significant decreases in consumption were suggested for getting married among both younger and older men and among younger women.

Besides this meta-analysis there are several longitudinal studies which have examined the effects of social roles more precisely and have findings that are more specific or even different from the study of Temple and colleagues. For instance, Wilsnack et al. (1991) found a negative association between being divorced and heavy drinking among women. Furthermore, they found that women who started cohabiting increased their level of consumption compared to other unmarried women and married women. Harford, Hanna \& Faden (1994) stressed the importance of distinguishing between being divoreed and separated. In contrast to divorced women, separated women resembled married women with a relatively low level of consumption. They also found length of marriage to be negatively associated with consumption. The same authors (Hanna, Faden \& Harford, 1993) concluded that transitions in marital status, and not marital status or marriage as such, explained changes in drinking behavior. In another study, however, Miller-Tutzaner, Leonard, and Windle (1991) found that persons being single over three measurements showed a higher level of consumption and a higher frequency of heavy drinking than those stably married. Other results of this study suggested that consumption and heavy drinking decreased before getting married. It was assumed that the change in drinking behavior reflected 'a role transition phase' before marriage, instead of the constraints of marriage itself (Miller-Tutzauer et all. 1991:439).

With regard to employment status, the results of Wilsnack at al. (1991) showed that for women, being employed part time was negatively associated with heavy drinking. Janlert $\&$ 
Hammerstrom (1992), in a 5-year follow-up study among teenagers, found the duration of unemployment to be positively associated with alcohol consumption for both men and women. Power \& Estaugh (1990) in a study of young adults found effects of unemployment on heavy drinking among men but not among women. Recently, a Finnish study (Lahelma, Kangas \& Manderbacka, 1995) found employment status to be not related to frequency of drinking or intoxication.

A few studies have examined the effects of parental roles on drinking behavior. The results of Power \& Estaugh (1990) suggested a decrease in consumption for both young women and young men who became parents. In a survey among African-American and white women Darrow et al. (1992) found a positive association of parental roles with heavy drinking among. African-American women. The authors suggested that the multiple roles of being employed and becoming a parent produced stress that furthered heavy drinking.

\subsubsection{Social roles and drinking behavior in this study}

The empirical results suggested that social roles are associated with drinking behavior. However, these associations are often not as hypothesized by Temple et al (1991) or Knibbe et al. (1987). In particular, most associations regarding employment were not as expected. The results of Temple et al. and Darrow et al. suggest that roles such as marital status, employment or having children at home cannot just be added together in order to define the stability of relationships or the structure of daily life.

As a possible solution for the small explanatory power of employment Wilsnack \& Wilsnack (1992) argued in favor of more complex theories. They made the plausible suggestion that the effects of employment will be different according to age and other roles (like having a spouse or having children). The same hypothesis is likely to be valid for the effects of marital status. More generally, Knibbe et al. (1987) argued that the norms for positions such as employment and marital status might differ according to characteristics such as gender and age (which they described as status roles). Consequently, this implies that the analyses should not only include the main effects but also the effects of the combinations of these characteristics.

Our study follows Temple et al. (1991) and Kribbe et al. (1987) in the definition of the roles of employment status, marital status and parental status. In brief, one has or plays an employment role, spotuse role or parental role or one does not. In this study the similarities between these three social rolles are emphasized. More stable relations are expected to reduce the opportunity to drink, both the entrance of typical drinking situations as well as the quantity of drinking in such situations. Generally, drinking is assumed to be incompatible with the rulfiment of these roles. Hence, a decrease in consumption and frequency of heavy drinking is expected from acquiring roles. Those who become employed, become a spouse or become a parent are expected to decrease consumption and heavy drinking. An increase in consumption. or frequency of heavy drinking is supposed for those who lose roles. If one loses paid cmployment. if one becomes ummarried or if all one's children have left the parental home, an increase in consumption or frequency of heavy drinking is expected.

In addition, in our study several specifications will be made both in addition to and following other studies. As suggested by several studies we will examine whether the effects 
af acquirement of a spouse role differ for becoming marnied and cohabiting, and whether the effects of loss of employment differ for becoming retired and memployment. A further refinement of our study concems the effects of multiple roles and the combination of the effects of changes in social roles with age. Moreover, changes in social roles are to a large extent concentrated within certain age categories. Outside these age categories these changes are less likely to occur. Therefore, it might in particular be useful to investigate the effects of changes in social roles within these age categones. In the conclusion and discussion we will elaborate on the implications of the results and discuss sone general problems of role theory.

\subsection{Method}

\subsubsection{Data collection}

The data presented in this article come from a panel of the general population in the province of Limburg, the Netherlands. Limburg is the most southern province of the Netherlands and has about one million inhabitants. Measurements were conducted is $1980(0=1,980)$ and 1989 $(n=1,327)$. In 1980, the sample was stratified by sex, age, urbanization and region. Response rates at first and second measurement were $76 \%$ and $67 \%$, respectively. At Tl the data were collected using a face-to-face interview, and at $\mathrm{T} 2$ partially by a mailed questionnaire (76\%) and with the same questionnaire in a face-to-face interview $(24 \%)$. Interviews were held face to-face at $T 2$ to enhance response among respondents classified as having drinking problems at: T1. At first measurement the age in the sample ranged from 16-69.

In 1980, differences between population and sample for several demographic characteristic were small, and not significant (Knibbe, 1984). Persons classified as nonresponse were approached by telephone. The non-response analyses showed that no differences were observed between the sample and those classified as non-response. For the follow-up in 1989, the non-response was analyzed with the 1980 data and with a telephone interview among $30 \%(\mathrm{n}=168)$ of the non-response cases (mortality excluded). Mortality $(\mathrm{n}=85,4.3 \%)$ was not related to drinking behavior or alcohol-related problems. No significant differences in response were found for sex, age, and employment status, but small differences in response were observed for marital status, social class and level of education. The response was somewhat lower among those men and women with primary education only (54\%). among unskilled manual workers $(60 \%)$ and small proprictors $(61 \%)$ and anong those who were widowed $(50 \%)$, cohabiting $(56 \%)$, or diworced $(57 \%)$ at T1. For all 1980 drinking variables (such as weekly consumption, heavy drinking and drinking status), no differences in response were found. However, with regard to changes in drinking behavior the results of the interviews by telephone suggested that the drop out was higher among mren who stopped drinking and among men who decreased their frequency of havy drinking. It must be noted that those who could be reached by telephone were on the average four years older.

In conclusion, there are no indications for selective drop-out according to drinking patterns at TI, nevertheless, men who stopped drinking and men who decreased theil frequency of heavy drinking were probably underrepresented. The effects of bias due to non- 
itesponse are likely to be limited (see also Lemmens, Tan \& Knibbe, 1988).

\subsubsection{Alcohol Consumption Measures}

If respondents had not drunk any alcohol in the past six months they were defined as abstainers. The level of consumption of drinkers was assessed with a 4-day weekly recall. Consumption was measured by the number of standard glasses (10 g of ethanol) on Saturday and Sunday and of the two most recent weekdays. The mean of these two days was used as an estimate of the average consumption on weekdays. The frequency of heavy drinking was determined with a question about the frequency of drinking six glasses or more on one occasion. This frequency was measured on an eight-point scale from 'never' to 'every day' and transformed into a weekly frequency. Hence, a score on heavy drinking of 1 means drinking six or more glasses per occasion once a week, a score of 0.25 means drinking six or more glasses once every four weeks.

\subsubsection{Measures of socinl characteristics}

The social characteristics used in this study were marital status, employment status, parental status (with or without children at T1 and/or T2), gender, age and socioeconomic status. The measures of all variables were determined at both $T 1$ and $T 2$. The stability or changes of employment status, marital status and parental status were related to the development of the level of consumption and the frequency of heavy drinking. For each variable four categories were created to indicate shifts in marital roles, enployment roles and parental roles: without the role at both measurements, with the role at both measurements, those who gained the role at second measurement or lost the role at second measurement. Changes and stability of social roles are presented in table 3.1 .

Gender and age are both important predictors of drinking behavior (e.g. Fillmore et al, 1991). As described in a previous article, gender and age were also associated with changes in drinking pattems in our study (Hajema, Knibbe \& Drop, 1997). Consequently, analyses were performed separately for men and women and age was included as a control wariable. The results of sevaral studies suggest that socioeconomic status influences changes in drinking behavior (Temple al, 1991; Hupkens, Knibbe \& Drop, 1993). Therefore, sociocconomic status was included as a control variable in our study. The level of education was used to indicate socioeconomic status and was measured on an eight-point scale. Measures at 12 ware used in the analyses because they were considered to be a better indicaton for the youngest age calcgories who would not have reached their highest level of education at TI.

\subsubsection{Duta analyses}

Results are presented for the dependent variables consumption and heavy drinking respectively. Bivariate and multivariate analyses were performed on the level of consumption and the frequency of heavy drinking with SPSS 6.1.2 for Windows. Data were examined separately for men and women and abstainers on both measurements were excluded from the analyses. 
Table 3.1. Stability, loss and gain of sponse roles, enployment toles and parental roles among men $(n-639)$ and women $(n-556)$ excluding abstainers at bod measmenents.

\begin{tabular}{|c|c|c|c|c|}
\hline & \multicolumn{2}{|l|}{ MEN } & \multicolumn{2}{|c|}{ MOMEN } \\
\hline & in & $\%$ & n: & 6 \\
\hline spouse role at $\mathrm{C} \& \mathrm{~L}$ & 418 & 65.7 & 38 & 608 \\
\hline spouse role at 1 only & 32 & 30 & 39 & 210 \\
\hline no sponse tole at 1 \& 12 & 84 & 132 & 51 & 92 \\
\hline spouse role at 2 only & 102 & 160 & 83 & 150 \\
\hline employment role at 11 \& 12 & 392 & 629 & 104 & 19 \\
\hline employment role at 11 only: & 77 & 124 & 62 & 11. \\
\hline no employment role at $1<<0$ & 93 & 14.9 & 281 & 528 \\
\hline enployment role at 2 only & 61 & 9.8 & 8,3 & 15 \\
\hline paremital role at 11 \& 12 & 240 & 393 & 229 & 430 \\
\hline parental role at 11 only & 71 & 11,6 & 77 & 14. \\
\hline no prarental role at $1 / \& 12$ & 207 & 399 & 146 & 274 \\
\hline parental role at 12 only. & 93 & 152 & 81 & 152 \\
\hline
\end{tabular}

As mentioned above, if social roles are causes of drinking behavior than it can be expected that changes in these roles generate changes in drinking behavior. To test this hypothesis several analyses were performed: (1) in order to provide background information data on level of consumption and frequency of heavy drinking at second measurement were presented; (2) differences in the development of consumption and heavy drinking were compared between those who gained the role and who remained without the role and between those who a lost role and those who kept a role. One-tailed t-tests were used to indicate the significance of the expected effects of shifts in roles; (3) the effects of changes in roles were examined within the age categories in which these shifts in roles were concentrated. Changes in social roles are often concentrated in specific age categories, as shown in table 3.2. In this panel, the gain of marital roles, employment roles and parental roles was mainly concentrated in age categories 16-29. Among women, however, the gain of employment roles was spread over age category 16-39. The loss of parental roles, the loss of employment roles among men and the loss of spouse roles anong women was highly concentrated in the age category 40-69. Among men, the loss of spouse roles was more spread over younger age categories. The loss of employment roles among women was in particular concentrated in the age categories 20-39. The effects of the changes in social roles were analyzed within the specific age categories in which these changes were to a large extent established; (4) the elfects of losing (acquiring) roles were differentiated by the loss (acquirement) of the other roles; (5) with regard to acquiring spouse roles we examined whether cohabiting and getting married differed in their effects on drinking behavior. Similarly, with regard to losing the employment role differences between retirement 
and becoming unemployed were analyzed; (6) multiple tegression analyses were performed for the level of consumption and the frequency of heavy drinking. The dependent variables in the regression analyses were the differences between the measurements at T1 and T2. The independent variables in the analyses were the alterations in the spouse role, the employment role and the parental role. Drinking measures at $\mathrm{Tl}$, age and level of education were included as covariates.

\begin{tabular}{|c|c|c|c|c|}
\hline & MEN & & wom & \\
\hline & $\mathrm{age}$ & $\%$ & age & $0 \%$ \\
\hline gain of spouse role & 1629 & 892 & 16,20 & 85,5 \\
\hline 10ss of spouse role & $40-69$ & 46,9 & 40.69 & 749 \\
\hline gain of employment role & 1624 & 869 & $16 \cdot 39$ & 882 \\
\hline los of employment role & 40.69 & 793 & $20-39$ & 62,9 \\
\hline gain of parental role & 1629 & 88,1 & $16-29$ & 92,5 \\
\hline loss of parental role & $40-69$ & 859 & $40-69$ & 84,5 \\
\hline
\end{tabular}

In the regression analyses a natural logarithmic function $L N(x+1)$ was used to transform weekly consumption and the frequency of heavy drinking. Frequencies of heavy drinking were adjusted into a six months-frequency (for instance, dally=182). Dummy variables were created to indicate the shifts in marital status and employment status and whether children were living in the household ( 1 =presence of role change; $0=i$ ts absence). Having the spouse role, the employment role and the parental role at both measurements were used as reference categories and, therefore, excluded from the regression analyses. To estimate the significance of diflerences between those who remained without a certain role and those who acquired that role the regression analyses were also perfomed witl, as reference categories, being without the spouse role, employment role and parental role at both measurements.

Several interaction effects were analyzed: marital roles with employment roles and parental roles. employment roles with parental roles and the interactions of these three roles with age. In the regression analyses the method of forced entry was used for the main effects of all independent variables. Interactions between the roles and of the roles with age were included in the final model if they added significantly to the explained variance. In other words, only the sparsest models will be presented. Reference groups for the interaction effects were the interactions that included the possession of a role at both measurements. Interaction effects of the dummy rariables were estimated by taking, for instance, the interaction of having the employed role and marital role at both measurements as a reference category. 


\subsection{Results}

The data on consumption and heavy drinking at second measurement provided background information for the association of changes in social roles with drinking belavior (table 3.3 ). The findings suggested associations of drinking behavior with employment roles, marital roles and parental roles. However, for both sexes only some of the associations of employment roles and parental roles with drinking behavior were significant. Marital roles were not associated with drinking behawior. Note that only the association of heavy drinking and acquiring parental roles was as expected.

Table 3.3 Consumption and heavy drinking at follow-up by stojal moles (abstainers tat both measurements exeluded)

\begin{tabular}{|c|c|c|c|c|c|c|c|}
\hline \multirow[b]{2}{*}{ Total } & \multicolumn{2}{|c|}{$\begin{array}{l}\mathrm{MEN} \\
(\mathrm{n}=587)\end{array}$} & \multicolumn{2}{|c|}{$\begin{array}{l}\text { WOMEN } \\
(1-525)\end{array}$} & \multicolumn{2}{|c|}{$\begin{array}{l}\mathrm{MEN} \\
(\mathrm{n}=632)\end{array}$} & $\begin{array}{l}\text { wOMNN } \\
(\mathrm{n}=544)\end{array}$ \\
\hline & 162 & $(21.8)$ & 45 & $(7.2)$ & 75 & $(132)$ & $211(72)$ \\
\hline Married or colhabiting & & & & & & & \\
\hline spouse tole at 1 \& 12 & 144 & $(177)$ & 44 & $(6.5)$ & .62 & $(1,23)$ & $18(0.62)$ \\
\hline lost spouse role at te & 241 & $(37,4)$ & 36 & $(9.8)$ & 103 & $(992)$ & $52 \quad(1.64)$ \\
\hline no spouse roles nt $11 \& \& 2$ & 8.6 & $(24,3)$ & 47 & $(7.4)$ & 1,07 & $(1,49)$ & $17(0.42)$ \\
\hline gained spouse role at 2 & 20.0 & $(251)$ & 57 & $(8.9)$ & 90 & $(129)$ & $23(0.52)$ \\
\hline Paid employ ment & & & & & & & \\
\hline employment role at $11 \&$ \& & 199 & $(243)$ & 70 & $(9.7)$ & 91 & $(1,42)$ & $25(0.65)$ \\
\hline lost employment role at 12 & $10.9 \%$ & $\times(13.6)$ & $32 * *$ & $(52)$ & $39 *$ & $(111)$ & $18,(0.74)$ \\
\hline no empl, role at 11 \& 2 & 87 & $(12.0)$ & 39 & $(6,4)$ & 52 & $(1.34)$ & $21 \div(0.76)$ \\
\hline gained employment role at ? & $14,4 *$ & $(175)$ & 46 & 17.6 & 61 & $(0,75)$ & $240(074)$ \\
\hline Children at liome: & & & & & & & \\
\hline parental role at $11 \& \mathrm{l}$ & 157 & $(20,2)$ & 42 & (6.6) & $\pi 1$ & $(1,2)$ & $21 \div \quad(0,70)$ \\
\hline lost parental role at 12 & 127 & $(243)$ & 33 & $(57)$ & $31 \%$ & $(07)$ & $02 * *(0,07)$ \\
\hline no parental role at il \& 12 & 17.7 & $(227)$ & 61 & $(93)$ & 87 & $(1,53)$ & $37 \quad(1,01)$ \\
\hline gained parental role at 2 & 171 & $(20,0)$ & $4.0^{*}$ & (6) & 82 & $(1.21)$ & $11 \cdot(0.4)$ \\
\hline 1 weekdy consumption of $\mathrm{s}$ & blast & an 2 & & & & & \\
\hline frequency of thea & ing & & & & & & \\
\hline Two-tailed t-test $<05, *$ p & $* * \mathrm{p}$ & & & & & & \\
\hline
\end{tabular}

In table 3.4, results are presented of the changes in the level of consumption and frequency of heavy drinking at second measurement by the loss or gain of social roles. For the total sample of men and women the level of consumption was stable (not presented). However, the changes 
in the level of consumption differed by sex $(p<0.05)$. Consumption decreased by about one standard glass per week for women, the increase in consumption for men was not significant (see also Hajema, Knibbe \& Drop, 1997)

With regard to gaining and losing marital roles most effects were in the expected direction. However, only the effects of acquiring the spouse role for both consumption and heavy drinking among women were significant.

For employment status, for both sexes the effects of both losing and acquiring the employment roles on consumption were not in the expected direction (ns). The effects of employment roles on heavy drinking were very small and not significant.

A decrease in consumption among men and women and a decrease in frequency of heavy drinking among women was observed for those who gained the parental role (ns). The results of losing the parental role were contrary to the expected effects.

Thble 3,4 Changes in consumption and heavy drilking by changes in social roles for men and women (abstamers at both measurements excluded)

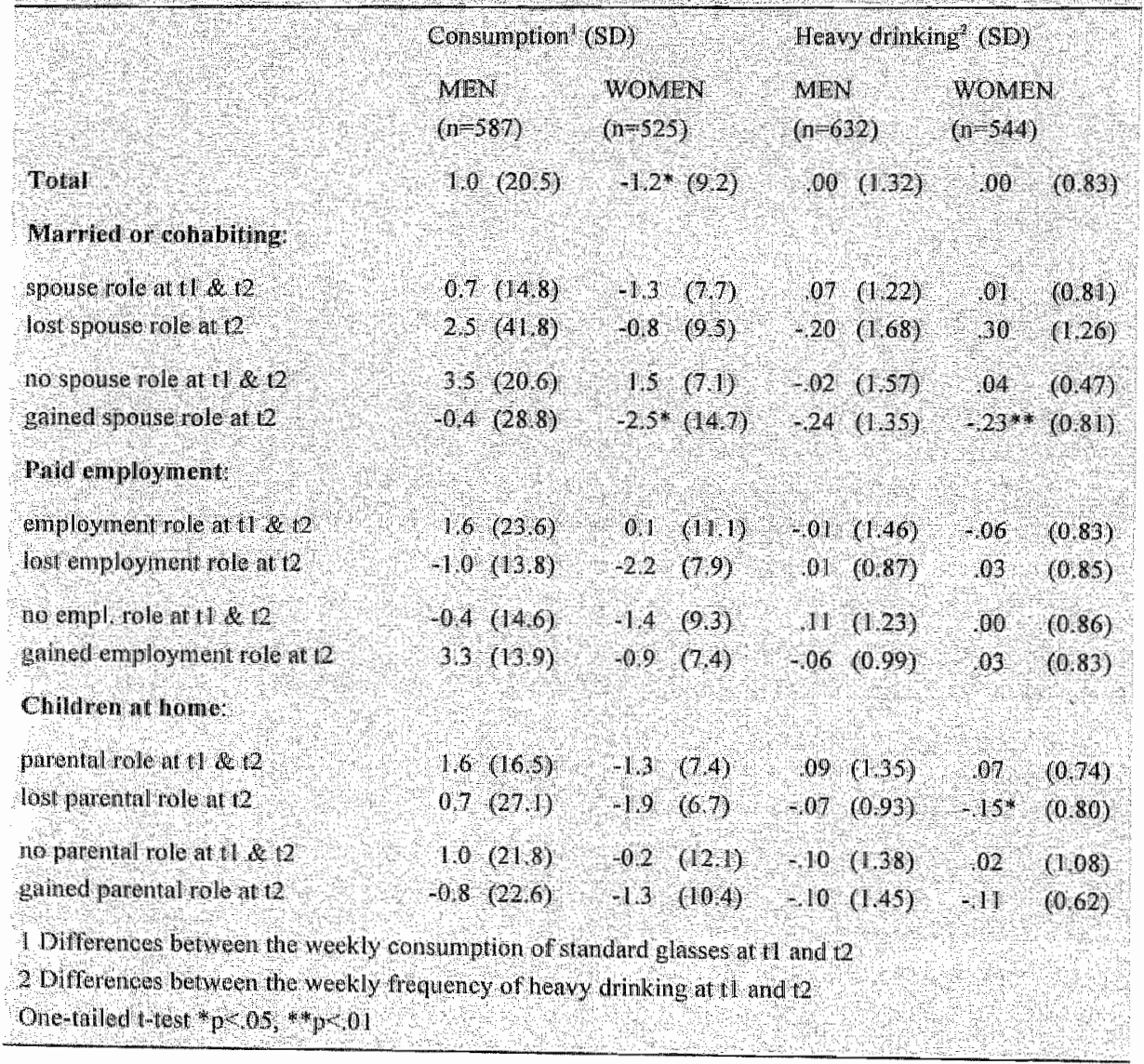


In general, most results of the analyses for specinc age categories were the same as for the total population (except for gaining the spouse role, no significant associations in the expected direction). For women, the effect of gaining the spouse role appeared to be stronger, mainly because in the specific age category the increase for those who remained without the spouse role was higher. Similarly, the effect of gaining the parental role seemed stronger, but still not reaching statistical significance. In contrast to what was hypothesized, women who lost employment decreased consumption $(p<0.05)$ and men who lost their parental role decreased consumption compared to men who maintained their parental role $(p=0.09)$.

In table 3.5 the results of the differentiation of acquiring the spouse role and losing the employment role are presented. Notice that in table 3.4 remaining unmarried includes, besides remaining single, also remaining divorced or widowed at both measurements. For men, differences were suggested between remaining single and getting married or cohabiting for both consumption and heavy drinking, however, the differences were not statistically significant. Among women, those who got married decreased consumption compared to those remaining single. Corresponding with getting married, women who started cohabiting decreased consumption (ns) but not as strongly as those who got married. Among men, the results for the losing employment indicated that losing employment by becoming unemployed led to an increase in consumption while losing employment by retirement led to a decrease in. consumption. Nevertheless, both differences were not significant. No differences were suggested between unemployment and retirement with regard to heavy drinking. Among women, no differences with regard to employment roles were suggested for consumption. Finally, for heavy drinking small differences were obserwed between remaining employed and becoming unemployed or retired (ns).

Table 35 changes in consumption and heavy drinking by the specific changes in social roles among men and women

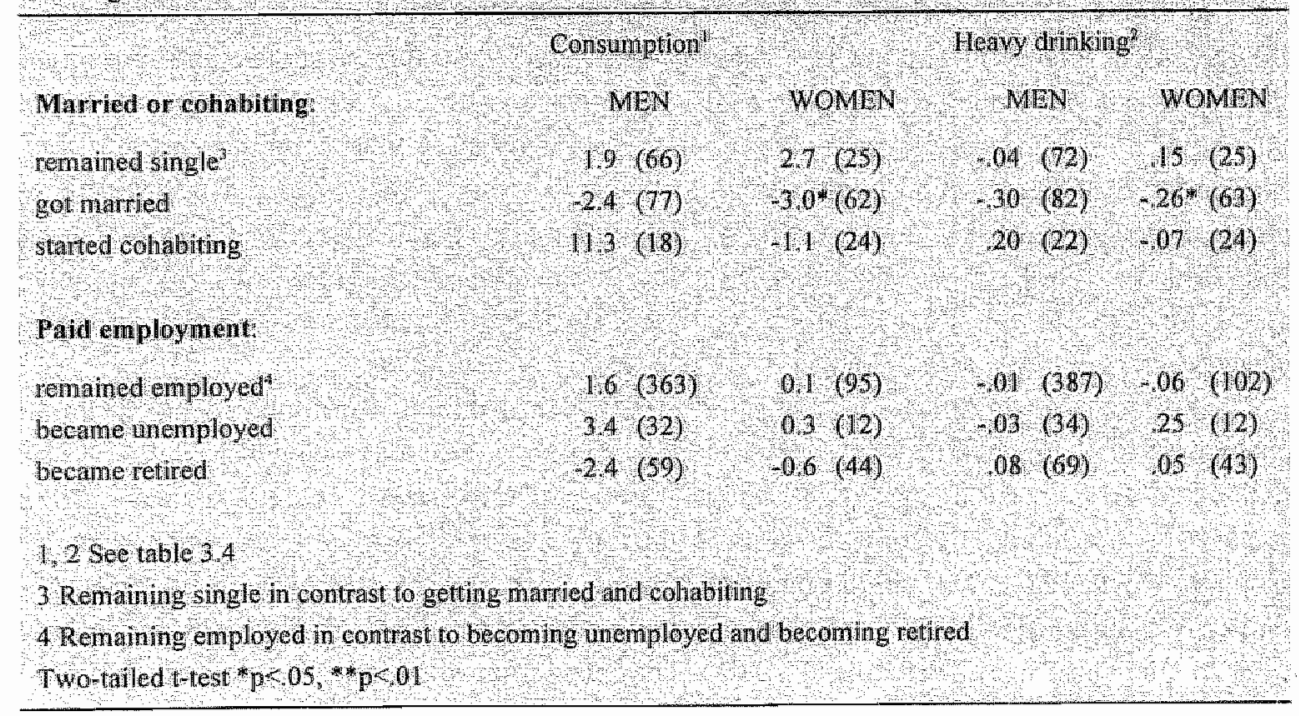


An additional refinement of the effects of social roles was made by analyzing the effect of gaining or losing a certain role while controlling for the gain or loss of the other two roles. The effects of role transitions while differentiating for other role transitions were observed to be not significant or opposite to expected. However, anong men weak effects were suggested $(p<10)$ for several combinations of shifts in social roles. Men who acquired employment and who became a parent decreased consumption compared to men who acquired employment and remained without the parental role. Similar results for heavy drinking were observed for acquiring employment and whether or not one acquired the spouse role. A decrease in consumption was also suggested for becoming a parent and gaining employment compared to remaining without employment. With regard to losing roles, men who lost both spouse and parental roles increased consumption compared to those who lost their spouse role but kept their parental role. For women, no effects were observed for combinations of gaining roles and combinations of losing roles.

In the nultiple regression analyses, besides the main affects of the roles, the effects of the combinations of the roles with each other and with age were examined. In the analyses the measures at $T I$, age and the level of education were included as covariates. For men, the partial correlation of regression analysis showed that consumption at $\mathrm{T} 1$ was the main determinant of the changes in the level of consumption at $T 2$. The adjusted $R^{2}$ with only the level of consumption included in the regression equation was. 19. As mentioned above, being married, being employed, and having children at home at both measurements were used as reference categories in the regression analyses. The effects of gaining roles on drinking behavior can be assessed by using those without the roles at both measurements as reference categories. This additional analyses gives the same results but facilitates the presentation of the $p$-value of the effect of gaining social roles compared to being without social roles at both measurements.

No significant effects on the level of consumption were observed for losing the spouse role, the employment role and the parental role. However, acquiring the spouse role was found to be associated with changes in the level of consumption $(p<0.05$ ). The main effect suggested that men who acquired the spouse role increased consumption. The combination with age, sustained by a breakdown for age categories (not presented), suggested a strong increase among men aged $16-19$ at TH $(p<0.01)$, while men in their 20 s and older decreased consumption. No effect was found for acquiring the employment role. $A$ weak negative association was observed for gaining the parental role and consumption $(p=16)$. The effect of age showed that older men were more likely to decrease consumption.

Similar to consumption, the initial level of heavy drinking was found to be the main determinant of changes in the frequency of heavy drinking. With only heavy drinking at $T l$ as predictor in the regression equation the adjusted $\mathrm{R}^{2}$ was 27 . No effects on theavy drinking were found for losing the spouse role or the parental role. The results suggested a weak negative ussociation between losing employment and heavy drinking. No effects were observed for gaining the marital role or the employment role. Acquiring the parental role led to a decrease in the frecuency of heavy drinking $(p<0.01)$. The interaction of gaining the parental role with age difered from the interaction of remaining without the parental role and age $(p<0.01)$. The 
regression analyses, supported by a breakdown for age categories at TI (not presented), suggested that in particular men who became a parent at age categories 16-24 decreased the frequency of heavy drinking. Like consumption, a negative association was observed of changes in frequency of heavy drinking and age

For women, the regression analyses showed that consumption at Tl was the main determinant of changes in the level of consumption at follow-tup. The adjusted $R^{2}$ of the model with only consumption at T1 as independent variable was 32. The effect of consumption at T1

Table 3.6 Regression analyses on changes in weekly consumption and freguency of heavy drinking among ment.

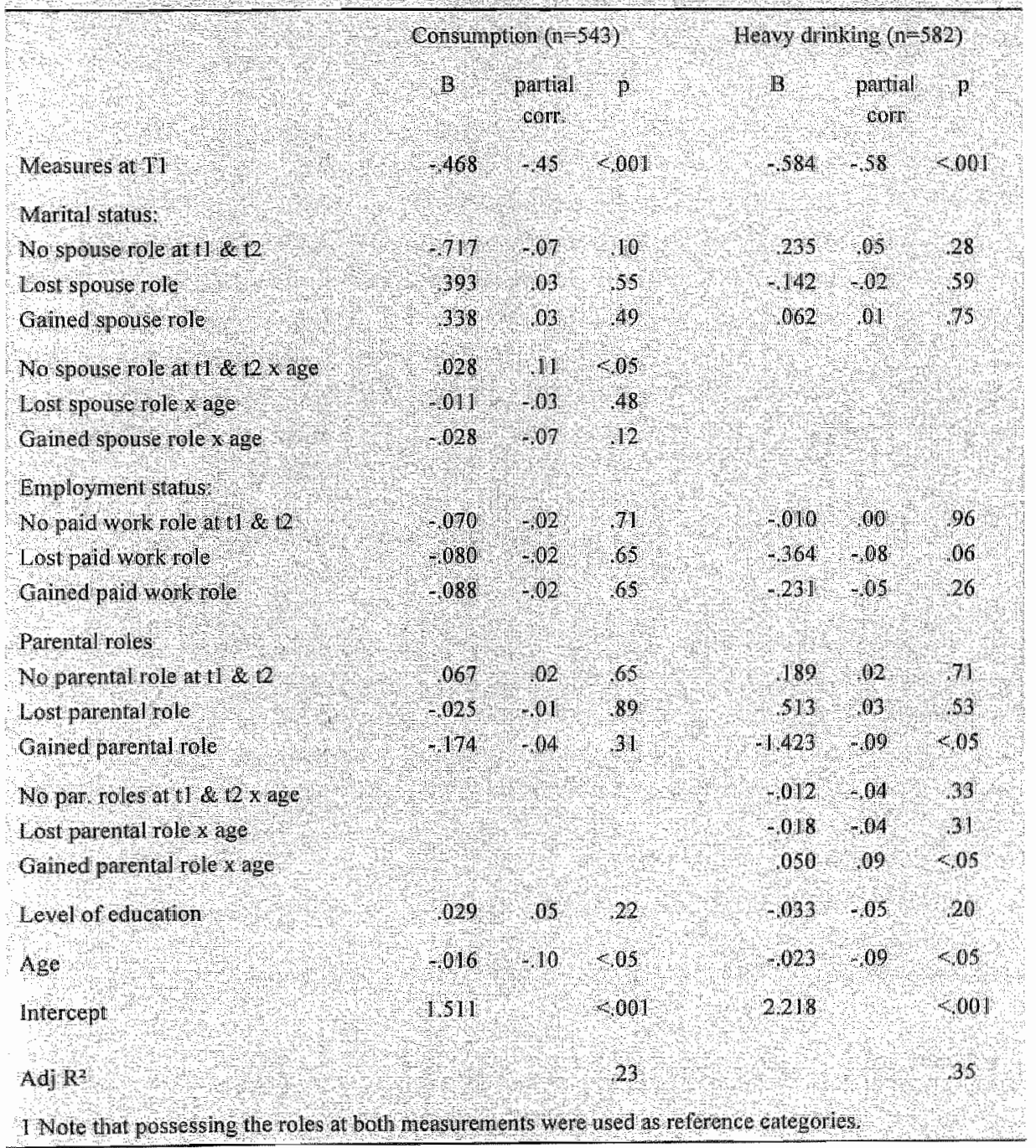


differed by age. Young women (16-19) increased consumption and the decrease in consumption became stronger among women at an older age.

Ony weak associations and opposite to expected were observed for losing the spouse role, employment role or parental role. Women who gained the spouse role decreased consumption $(p<0.05)$. Weak negative associations with consumption were found for gaining the employment role $(p=0.17)$ or the parental role $(p=0.08)$. Finally, a negative association with changes in consumption was found for age and a positive association was found for level of education.

Table 3.7 Regression analyses on changes in weekly consumption and frequency of lieav drinking ariong wonenl:

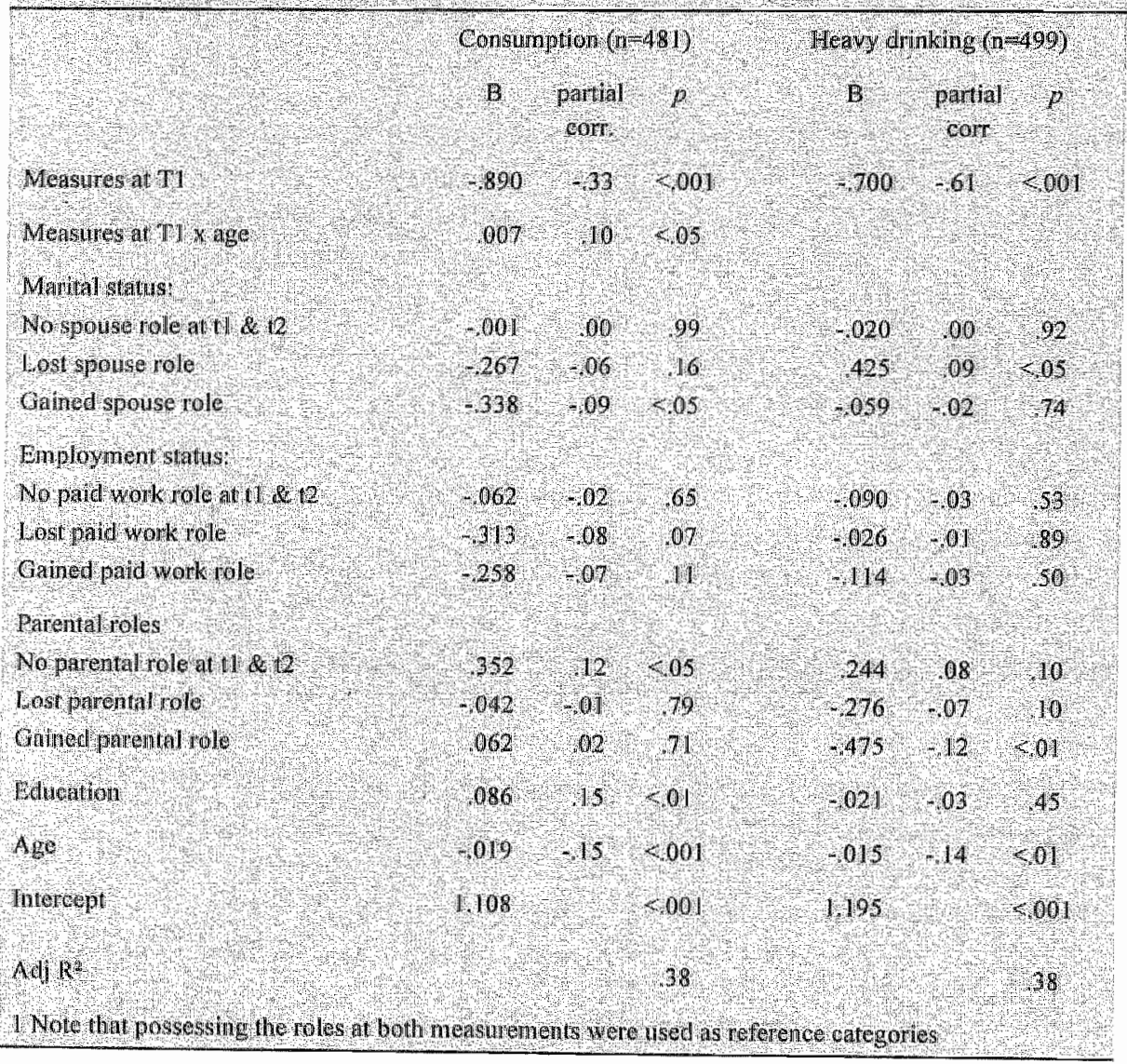

The strongest predictor of changes in heavy drinking was heavy drinking at $\mathrm{T} 1$ (adj $\mathrm{R}^{2}=35$ ). Women who lost their spouse role increased the frequency of heavy drinking. No effect was found for the loss of the employment role. A weak negative association was found for losing 
the parental role. No effects were found for gaining the spouse role or employment role. Women who acquired the parental role decreased their frequency of heavy drinking $(p<0.000)$. Similar to consumption and heavy drinking among men and to consumption among women, changes in heavy drinking were negatively associated with age. In contrast to the other regression analyses, the regression model for changes in heavy drinking was not good at predicting large increases in heavy drinking among women.

\subsection{Conclusions}

In a longitudinal study among men and women in a general population both bivariate and multivariate analyses were applied to investigate the effects of changes and stability of marital status, employment status, and having children at home on drinking behavior. In this article, we were primarily interested in the longitudinal effects of acquiring or losing a spouse role, employment role, or parental role on consumption and heavy drinking. With role theory as at starting point it was expected that the shift towards certain roles would decrease consunption and heavy drinking while the shift away from certain roles would lead to an increase in consumption and heavy drinking. Other alcohol studies that investigated the effects of role transitions concluded that this infuence is likely to be dependent on other roles or more specific features of the roles. Therefore, several additionel analyses were perfomed that could be considered as refinements of the investigation of only the main effects of gaining and losing roles. We examined whether the effects of shifts in roles differed according to shifts in the other roles and by gender or age. Moreover, we examined whether the effect of loss of employment differed for retirement and unemployment and whether the effect of acquiring the spouse role differed for getting married and cohabiting. Finally, since most role changes are concentrated in specific age categories the effects of shifts in roles were investigated within these specific age categories.

Table 3,8 Summary for the hypotheses that more socinl roles lead to a deerease and less secial roles lead to an increase in consumption or heavy diunking

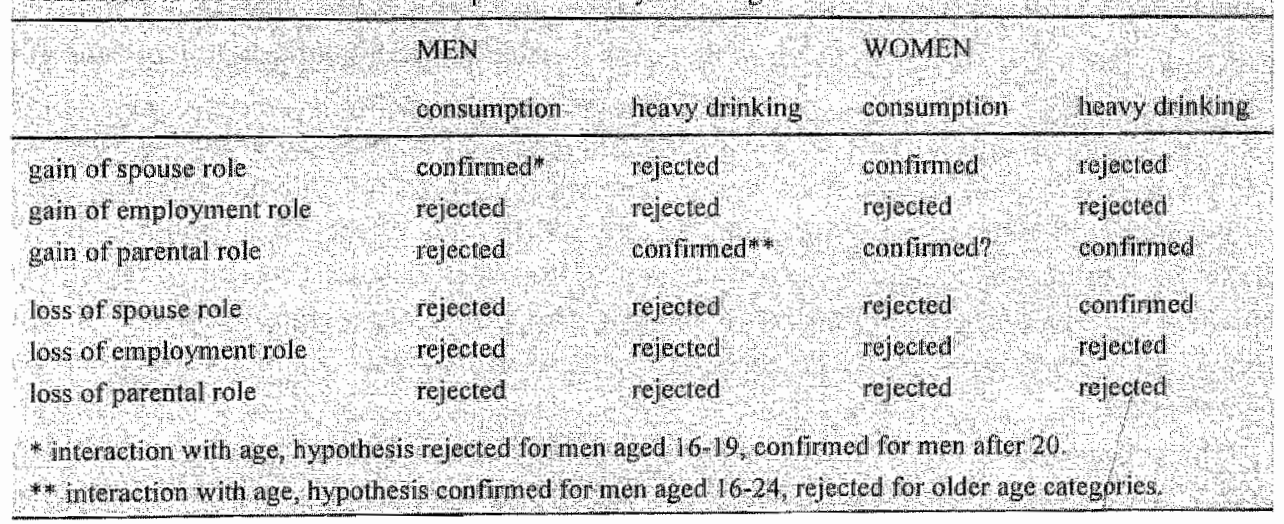


Table 3.8 summarizes the main findings of the multiple regression analyses. Among men, the effects of acquiring a spouse role differed by age. Except for the youngest age categories aged 16-19 at $T$, acquiring the spouse role predicted decrease in consumption. A small and weak effect was found for acquining the parental rolk. With regard to heavy drinking it can be concluded that the influence of acquiring the parental role differed with age. Among young

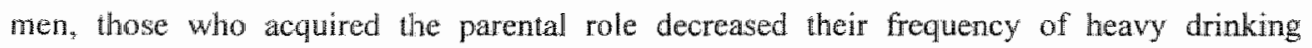
compared. For men in the late 20 s and older a reversion of this effect occurred.

Among women, weak negative associations were observed for losing the employment role and acquiring the parental role. For employment, this finding is opposite to expected. For women, interactions of shifts in social roles did not add to the explanation of changes in consumption or heavy drinking. On the whole, for both men and women the interactions between shifts in employment roles, spouse roles and parental roles were found not to be associated with changes in consumption or heavy drinking.

The results on changes in drinking behavior and role transitions are often not perceivable in the drinking patterns at follow-up and vice wersa. For instance, men and women who acquired the spouse role do not have a lower level of consumption at T2. On the other hand, women who acquired the parental role had a low levell of consumption at T2 but only weak effect on changes in consumption was observed. Employment was associated with consumption and heavy drinking at follow-up but not with changes between first and second measurement.

Most results of the multivariate analyses corresponded with findings of the bivariate analyses. Among women, the bivariate analyses suggested that women who acquired the spouse role decreased not only their level of consumption but also their frequency of heavy drinking. While controlling for other variables in the regression analyses these findings for heavy drinking could not be confirmed.

For men, the bivariate analyses for the total population and for specific age categories did not suggest the confirmation of any other expectations than in the regression analyses. In addition, the analyses on the combinations of gaining roles or losing roles did not add to the explanation of drinking behavior. Corresponding to the results for men, the analyses for women which focused on specific age categories added little to the analyses of the total population. Similarly, the combination of the shifts in social roles did not lead to more specific lindings.

The differentiation of gaining the spouse role into getting married and cohabiting and losing the employment role into becoming unemployed or retired did not produce any significant - different results. Although not significant, the effect of cohabiting and of becoming retired among merl deserve attention. However, these effects can probably be explained by age because an additional analysis (not presented) suggested that men who cohabit are younger and men who retire are older than men who marry or who become unemployed.

In conclusion, in this 9-year follow-up study shifts in social roles predicted a small part of the changes in the level of consumption and the frequency of heavy drinking. Most expectations about shifts in social roles have to be rejected. Therefore, it seems that role theory is not very satisfactory as a theory for explaining developments in drinking behavior. The most 
consistent results come from the shift to the spouse role, though only for the development of the level of consumption. For both spouse roles and employment roles our results matoh to a large extent the results of the meta-analysis of Temple and colleagues (1991) on the effects of changes in roles on consumption. In addition, acquining the parental role was found to be associated with heavy drinking for both sexes. As suggested by Wilsnack \& Wilsnack (1992), interaction effects between the social roles and with age were analyzed. Only differentations of social roles with age added to the explanation of changes in drinking behavior. Mainly weak, not statistically significant effects, were observed for the combinations of the different social roles.

\subsection{Discussion}

The results of our longitudinal study suggest that most shifts in social roles do not lead to particular developments with regard to consumption and heavy drinking. In other wonds, the effects of these shifts in roles are heterogeneous. This implies thit, in general, role transitions of marital status, parental status and employment status cannot be considered as social determinants of drinking behavior.

Our study can be characterized by two basic findings. Firstly, gaining roles causes a decrease in consumption or heavy drinking but losing roles does not lead to an increase. It can be concluded that one alters drinking after roles are acquired but not when roles are lost. On. the one hand, the effect of gaining roles can be explained by a decrease in coming into typica! drinking situations, such as in bars or other licensed premises. On the other hand, roles may restrict consumption in typical drinking situations. Social control or sanctions may influence the drinking behavior of those who gain roles. However, it seems that a reduction of social control or more leisure time is not necessarily a stimulus to increase drinking. It appears that the mechanism that can explain the effects of acquiring roles does not exist the other way around for the loss of roles.

Secondly, in particular effects were found for gaining the spouse role or parental role and not for the employment role. The spouse and parental role make it less likely to proceed in arinking venues such as bars or clubs. Employment possibly leaves enough opportunilies to drink or may even create drinking situations related to work. For instance, drinkers may only come into trouble when (excessive) alcohol consumption prevents a proper fulfilment of the employment role, such as the next morning.

The assumption that the effects of role transitions depend on other roles could not be confimed. Probably, several weak interaction effects suggest that with a larger sample size these hypotheses would have been confirmed. In this study the effects of gaining roles among men differed according to age. In other words, age mediates the effects of the acquirement of the spouse role. For men in the youngest age category a different pattern was observed than for older men. An explanation for this pattern might be that among young men age influences alcohol consumption more strongly than the spouse role. Apparently, at a younger age, men who acquire the spouse role have more opportunities to increase their drinking. Furthermore, 
among men an interaction between acquing the parental role and age was observed. Men in the older age categories who acquired the parental role had a relatively low frequency of heavy drinking at TI and did not decrease their heawy drinking to lower frequencies at follow-up. As suggested by Miller-Tutzauer et al. (1991), they might have entered the role-transition phase of future parenthood and already decreased heavy drinking at first measurement. Men who were younger probably acquired the parental role several years later and decreased heavy drinking betwen the two measurements. Unfortunately, there are no data available to test this hypothesis.

No interaction between roles and age were observed among women. Possibly, gaining the spouse role influences women's drinking behavior at all age categories. Other data of this study showed that a much stronger decrease in drinking on licensed premises was found among young women than among young men (Hajema at al., 1997). Moreover, women acquire both the spouse and parental role at a younger age. Therefore, the period between onset of drinking and gaining the spouse or parental role is shorter.

There are several limitations of role theory in general might be of importance for drawing conclusions about the effects of social roles on drinking behavior: the norms for drinking behavior for persons with different social roles are not defined precisely and leave the interpretation of role expectations open for the greater part, the norms of certain roles milght even be contradictory, and in the case of multiple roles it is not clear which norms attached to the different roles should be applied (Boudon, 1981). However, roles can be important, not in terms of role expectations and determinants of drinking behavior, but as constraints in choice situations that are related to drinking behavior. Several authors have stressed the importance of the connection between norms and drinking contexts (e.g. Simpura, 1991). Norms in particular define the appropriateness of drinking in certain situations. In our study, gaining the spouse role was found to decrease consumption. This effect can probably be explained, not by different norms of this category, but through a decrease in the frequency of being in situations where drinking is considered as appropriate. Hence, after one has gained the spouse role the desire to go to public drinking places decreases and this is only partly compensated by an increase in drinking at home (our data on these aspects suppont this proposition, not presented). Wheretore, the acquisition of the spouse role and probably the parental role can be seen as a constraint on drinking behavior.

There are a few changes in the 1980 s with regard to marriage, parenthood and employment that may have influenced the results. In the Netherlands this period can be characterized by a rapid increase in labor participation of women. Furthermore, the age of getling married and having a first child rose with about tree and two years respectively (CBS, 1993). Without doubt, paid employment has become a more important aspect in women"s lives. However, in both men and women employment was not a determinant of changes in drinking behavior. Therefore, it seems unlikely that this role change in women has influenced the results. The postponing of marriage and having children may indicate a delay in gaining the spouse role or parental role the delay in gaining the spouse role and parental role suggests that the role transition and the decrease in alcohol consumption will also be delayed. Accordingly, the period in which young adults have a high level of consumption is longer but it is not likely that this delay in acquing roles has influenced the effects of the role 


\section{transitions.}

In alcohol research one is often interested in differences in alcohol consumption between social categories. For the explanation of drinking behavior it is important to roalize that individuals are not just a social product. Moreover, the social circumstances and structural conditions that define these social categories are not active, only the individuals within these categories drink. In our opinion there is another theoretical point of wew that can be useful for future alcohol research in the social sciences. Theories that focus on drinking behavior as choice behavior and on cost-benefit analyses might indicate new directions in the explanation of drinking behavior. In addition to role theory, a promising theoretical concept is the "reward structure' of drinking behavior (Makela \& Mustonen, 1996). The concept 'reward structure' is closely related to the concept 'utility" in microeconomic theorizing (for an explanation see Skog, in press). Similarly, Gruenewald (1995) has focused on drinking choices and urility maximizing. In brief, the reward structure contains both positiwe and negative consequences of alcohol consumption and these consequences are supposed to vary for different social categories. If such a theory can indicate which social characteristics are important for the rewards and costs of drinking behavior than this theory can generate new hypotheses and give more insight into alcohol consumption as social behavior. In terms of reward structure, when roles are acquired there are more constraints on alcohol consumption. Consequently, it might be more rewarding to restrain drinking. However, in case of role loss if is not necessarily more rewarding to increase drinking, neither will it necessarily be more rewarding to enter typical drinking situations. Role loss does not induce more positive consequences of alcohol consumption, except for drinking as coping behavior. There may be less negative consequences if consumption is increased but, as such, that is not an incentive to raise consumption.

\section{References}

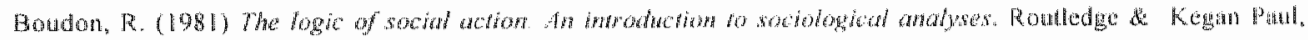
London. Great Britain.

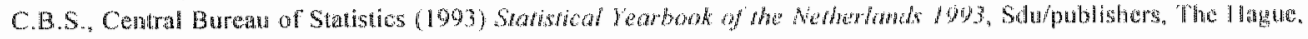
The Nertherlands.

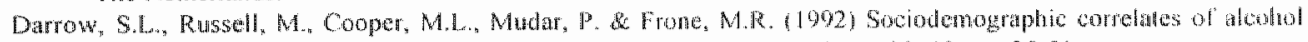

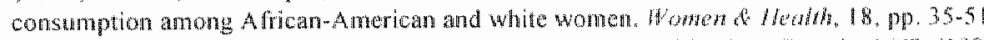

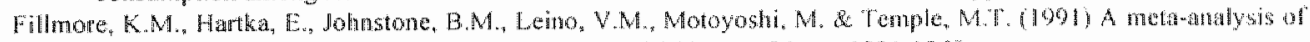

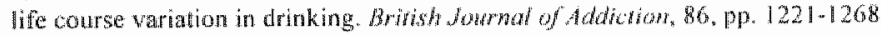

Gruenewatd, P.J., Treno, A.J., Nephew, T.M. \& Ponicki, W. R. (1995) Routhe ativities and alcohol use constraints on outlet utilization. Alcohotish: Chicat and Experimental hesearch. 19, $9 \mathrm{p}, 44-53$.

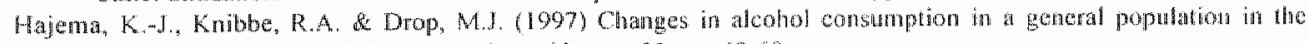
Netheriands: a 9-year follow-rp study. Addiction, $92,0 p, 49-60$

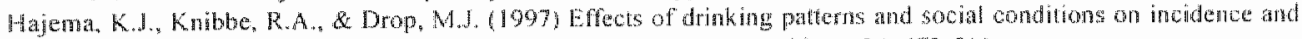

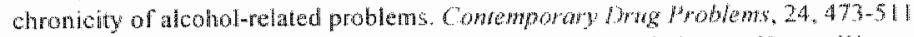

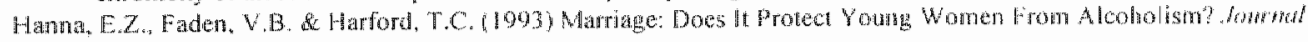
of Substance Aburse, 5 , pp. $1-14$.

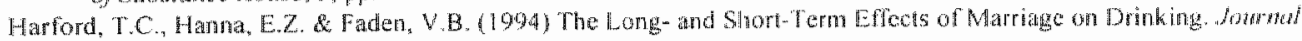

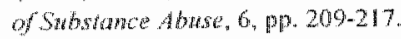

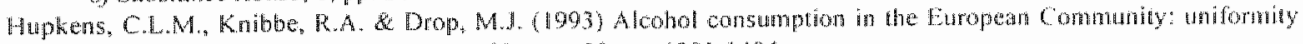
and diversity in drinking patterns. Addiction, $88 . \mathrm{pp}, 1391-1404$. 


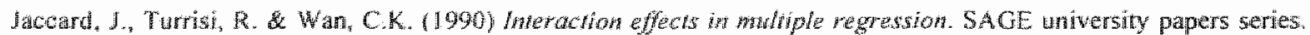
Quantitative applictions in the social seiences; no. 72. Londor, UK.

Janted, $U$, \& Hammerstron, $A$. (1992) Alcohol consumpinon among unemployed youths: results from a prospective study. Brifsh Jow rual of Addotion, 87 , pp. $703-714$

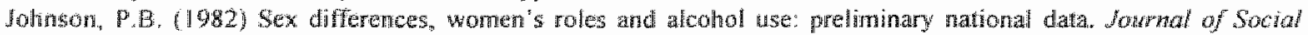
Issistesi, $38, \mathrm{pp} .93-116$.

Knibbe, R.A., Drop, M.l. M. Mutjens, A. (1987) Comelates of stages in the progression from everyday drinking to problem drinking. Socral Srience a Melicine, 24, pp. 463-473.

Luhemma, E。 Kanges, R. \& Manderbaka, K. (1995) Drinking and anemployment: contrasting patems among men and women. Dragrand Alcohst Dependence, $37, \mathrm{pp} .71 .82$.

Lemmens, F, Tan, E.S., \& Krbte R.A. (1988) Bas due to non-response in a Dutch survey on alcohol consumption.

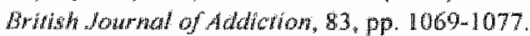

Lewisibeck, M.S. (1993) Regression andysis. International handbooks of quartiative applications in the social sciences: Vol,2, SACE Publicatione, Toppam Publighing, London, UK.

Makela, K... Mustonen, H. (1996) The reward structure of drinking among younger and older male drinkers

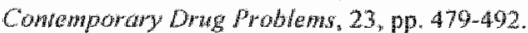

Miller Tutzatuer, C., Leonard. K.E., \& Windle, M. (1991) Marrage and alcohol use: a longitudinal study of "maturing

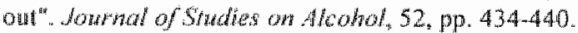

Power, C. E. Estagh. V. (1990) Employment and drinking in early adulthood: a longitudinal perspective. British Jowrial of Adatiction. 85, pp. 487-494.

Power, C. \& Estatuh. V. (1990), The role of fanily formation and dissolution in shaping drinking bethawior in early

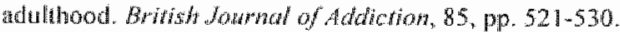

Simptra, 1. (1991) Studying norms and contexts of drinking. Confenposary Drug Problems, 18, pp, 477-498.

Skog O.-1. (1997) Rationality, irfationatity, and addiction - Notes on Becker and Murphy"s theory of addiction. In. Elster, J. \& Skog, O-J. (Eds), Getring howked-Rationality and Addiction.

Temple, M.T.,Filmore, K.M., Hatka, E, Johnstone, B, Leino, E.V. M Motoyoshi, M. (H99u) A meta-élalysis of change in natrital and employment status as predictors of alcohol consunption on a bypical occasion. British Hournat of Adriction, 86, pp $1269-1281$.

Wisnack, R.W. \& Cheloha, R. (1987) Women's roles and problem drinking across the lifespan. Socrat Problems, 34 , $\operatorname{pos} 231.248$.

Wilsnack, R. W. \& Wilsuck, S.C. (1992) Women work, and alcohol: failutes of simple theories, Ahoholism: Chical and Fxpermemal Resedehn 16. Pp. 172-179.

Wilsnack, S.C., Klassen, A.D., Sclur, B.E. \& Wilsnack, R.W. (1991) Predicting onset and chronicity of women's problem drinking: a five-year longitudinal analysis. Anerican Jound of Pablic Hearh, 81, pp. 305-317.

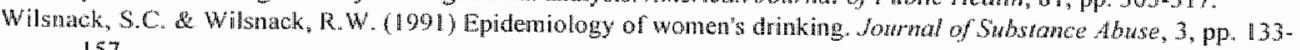
157. 
Chapter 4

\title{
Effects of drinking patterns and social conditions on incidence and chronicity of alcohol-related problems
}

Published in Contemporary Drug Problems, 1997, Vol. 24, pp. 473-512.

\author{
Klaas Jan Hajema, Ronald A. Kmibbe and Maria Il. Drop
}

\begin{abstract}
The central issue of this article is the extent to which, besides consimmption and heany drinking, drinking contexts and specific social conditions can explain the chronicity and incidence of alcohol-related problems. This study is the first longitudinat study of the Duth general population on drinking behavior and alcahol-reloted problems $(N=1327)$. The andysis of chronicity of drinking problems is concentrated on the selection of respondents with alcohol-related problems at first measument, the andysis of incidence is concentrated on those who did not report alcohol-related problems an first measuramew. In general, it can be conchaded that bexides level of conswmplion and heavy drinking anking tontexs and social conditions add to the explanation of incidence and chronicity of alcohol-related problems.
\end{abstract}




\subsection{Introduction}

The central issues of this anticle are the development and persistence of alcohol-related problems. In a 9 -year follow-up study data were analyzed on the association of chronicity and inciduce of alcohol-related problems with seweral aspects of drinking behavior and some social conditions. The main purpose of the study was to assess which aspects of drinking behavior, other than the level of consumption or heavy drinking, and which social factors contribute (1) to the chronicity and remission of alcohol-related problems and (2) to the incidence of alcohol-related problems. The development and persistence of alcohol-related problems refer wo processes that should be assessed by longitudinal data, as in fact do the concepts of incidence and chronicity. Therefore, measurements at T1 and changes at $\mathrm{T} 2$ of level of consumption, frequency of heavy drinking, drinking contexts and social conditions were analyzed to find indicators of chronicity and incidence of drinking problems. The longitudinal data of this study offer the opportunity to assess which aspects of drinking patterns, including contexts of drinking, and which social characteristics or changes in social conditions, are associated with:

- the chronicity of alcohol-related problems among drinkers who reported alcohol-related problems at first measurement;

- the incidence of alcohol-related problems among drinkers free of alcohol-related problems at first measurement.

\subsubsection{Drinking patterns and drinking problems}

By defintion, alcohol-related problems are likely to emerge, to persist, or to remit, in association with the consumption of alcohol. No general theory is required to understand that a higher level of consumption means a greater probability of experiencing alcohol-related problems. In alcohol research the two most important aspects of drinking behavior related to drinking problems are the level of consumption and heavy drinking (e.g. Makelä \& Simpura, 1985; Room, Bondy \& Ferris, 1995; Hiton, 1987). Recently, Room et al (1995) found that alcohol-related harm started at less than one drink per day and increased roughly linearly with higher levels of consumption. In the same study, however, heavy drinking was found to be a stronger predictor of alcohol-related ham than average daily consumption.

Only a rew studies have examined the influence of aspects of drinking behavior other than volume and heary drinking (e.g. Gruenewald, Mitchell \& Treno, 1996; Single \& Wortley, 1993; Casswell. Zhang \& Wylliw, 1993; Stockwell, Lang \& Rydon, 1993; Fitzgerald \& Mulford. 1984). These studies suggest that besides volume and frequency of heavy drinking also other aspects of drinking betwavior. such as contexis of drinking, might also play a sigmificant role in the development of alcoholrelated problems. For example, Fitzgerald \& Mulford (1983) found that the frequencies of drinking in bars, at others' homes, at own home, and at sports events contributed to the explanation of drinking problems, even when controlling for volune and heavy drinking. In addition, Hartord (1994) found an effect of the frequency of drinking in bars on drinking problems. As an explanation Harford suggested that drinking in bars might be related to lifestyles at a higher risk for alcohol-related problems. 
Gruenewald et al. (1996) investigated the infuence of quantivy and frequency of drinking and also of the variation in quantities consumed over time on alcohol-related ingurias. Among drinking pattern data the variance in drinking quantities consumed over time was found to be the strongest predictor of alcohol-related injuries.

\section{1.2 Social conditions and drinking problems}

There are at least two reasons why in research on alcohol-related problems the sudy of the effects of social conditions is important: firsily, social conditions are predictors of the level of consumption, heavy drinking and other aspects of drinking behavior. These variations in drinking behavior produce differences in the amount and development of alcohol-related problems; secondly, categories of drinkers who differ in social characteristics vary in their vulnerability to alcohol-related problems. In other words, even when controlling for drinking behavior, categonies of drinkers defined by social characteristics may differ in the development and persistence of alcohol-related problems. This article is rocused on the second aspect, the direct infuence of social conditions of drinkers on alcohol-related problems.

In the literature several studies have found gender (e.g. Schutte et al. 1994; Fillmore, 1987b; Knibbe, Drop \& Muytjens, 1987), age (c.g. Harford, 1994; Single \& Wortloy, 1993; Fillmore 1987a,b; Fillmore \& Midanik, 1984), employment status (e.g. Harford, 1994: Wilsnack et al., 1991; Knibbe et al., 1987), marital status (e.g. Miller-Tulzauer, Leonard \& Windle, 1991; Wilsnack et al., 1991) and socioeconomic status (e.g. Room. et al., 1995) "to modify the effects of alcohol consumption on drinking problems. However, explaining the mechanisms of the effects of social conditions on drinking problems is difficult.

Most explanations of the effects of social conditions focus on the differences in drinking problems being explained by the effects of social conditions on drinking behavior (social conditions - - drinking behavior - alcohol-related problems). Central concepts in these theories are drinking norms, restrictions, drinking opportunities, role deprivation and coping behavior (for an overview, see Wilsnack \& Cheloha, 1987). In our article, however, we wish to investigate the direct influence of the social conditions of drinkers on alcoholmelated problems.

A promising theoretical perspective for the explanation of drinking problems, in particular of the effects of social conditions, is possibly the concept 'reward structure' (Makela \& Mustonen, 1996). The reward structure is detemined by positive and negative consequences of alcohol consumption and these consequences are supposed to vary for different social groups. The concept 'reward strucure' is used to explain the drinking behavior and drinking consequences of age groups. In the study of Mäkelä \& Mustonen the overall reward stucture was found to be more favorable for younger than for older drinkers. The concept 'reward structure' is closely related to the concept 'utility' in microeconomic theory (see also Skog, 1996). In the analysis of. the aggregate level these models make a step to the individual level: the consequences of an increase in consumption for the individual drinker can now be interpreted as marginal utility. With an explanation of the component parts explanations at the aggregate or collective level are more stable and gain in depth (e.g. Coleman, 1990; Fsser, 1994). The concept reward structure allows the incorporation and combination of notions from. for instance, role theory 
and social learning theory. More specifically, noms, social control and leaming effects can be interpreted as determinants of the reward structure, for example, the extent in which conformation to norms produces positive or negative consequences is expected to differ by social position. The combination of the theoretical concepts of roles, social control and social learning with reward structure might be very useful in clarifying the mechanisms of the influence of social conditions on alcohol-related problems.

In our view, several theoretical notions are of importance in explaining the effects of social conditions on alcohol-related problems. Wilsnack \& Chelloha suggest that role depriwation leads to a decrease in social control and therefore to less restrictions on alcohol consumption and higher risks for drinking problems. In terms of reward structure, those who are unemployed, divorced, or who have lost their child-rearing role, will experience more positive consequences from drinking because their remaining role-relationships are less constraining with regard to drinking. As a result, they are more likely to engage in hazardous behavior and to have a higher probability of developing alcohol-related problems. If, however, a person already had drinking problems, role deprivation might imply that there are less constraints to hazardous behawior. Or, the other way around, we assume that in case of employment, marriage or child-rearing roles, it will be more rewarding to avoid drinking problems.

Knibbe et al. (1987) stresses the importance of different social roles. Roles defined by gender, age, religion and social class prescribe drinking styles which are considered as appropriate. Hence, social categories with their specific roles differ in the extent that they are vulnerable to drinking problems. Fillmore \& Midanik (1984), who try to explain age eflects, hypothesize that problematic drinking of young men is normative for their subculture. Therefore, drinking problems are more likely to be temporary among young men. Drinking problems among older men may be more deviant, but if they occur they are of a more chronic nature. In addition, Knupfer (1984) proposes a theory in which differences in drinking problems are explained by differences in drinking norms towards different social categories.

Mäkelä \& Simpura (1985) stress the importance of social control, in addition to volume of consumption, on drinking problems. Categories of drinkers defined by, for instance sex or age, difer in the way their drinking behavior is controlled and sanctioned. Thus, more controlled and sanctioned drinking categories will experience more alcohol-related problems. Conseguenty, social groups that are defined by social roles differ in the way their drinking behavior produces positive or negative social consequences. Similarly, the presence or absence of child rearing roles might not only be related to role deprivation but also to normative constraints. Constraints are likely to be stronger when children are present in the household.

The sociall leaming theory of Akers et al. (1979) is also connected with social control. This theory explains deviant behavior as the effect of a process of social learning. Specifically peers and parents are important in the imitation of deviant behavior. The drinking behavior of parents forms a resource which influences the reward structure of their children. The drinking behavior of the children which resembles the drinking behavior of their parents can be interpreted as the result of a social learning process. Therefore, it can be expected that the drinking behavior of parents (in particular the presence of problems) is positively associated with the drinking problems of their children. 
The concept reward structure might be important because it helps to explain (1) why some social groups have a higher probability of reporting social consequences of drinking behawior. and moreover (2) why some social groups differ in the extent they take risks through hazardous behavior. The first type of problem has its origin in the interaction of the drinker with the social environment (e.g., one's spouse or family, one's work or the law). The origin the second type of problem is the drinker himself/herself (e.g., health problems. symptomatic behavior, intoxication, psychological dependence). While controlling for drinking behawior, drinkers that differ in social position differ in the positive and negative consequences of hazardous behavior. Social conditions such as gender, age, employment status, marital status, socioeconomic status, child rearing roles and the drinking patterns of parents during childhood are expected to differ in the way they yield positive and negative consequences for drinking behavior. Therefore, these variables are included in the analyses as possible predictors of chronicity and incidence of alcohol-related problems.

\subsection{Methods}

\subsubsection{Data collection}

Data for this study came from a panel, that in 1980 started with a random sample of the gemeral population in the province of Limburg, the Netherlands. Limburg has about one million inhabitants and is one of the twelve provinces of the Netherlands. The first measurement in 1980 (T1) consisted of 1980 respondents, a response rate of $76 \%$. The data were collected using a face-to-face interview. The second measurement in 1989 ( $\mathrm{T} 2$ ) consisted of 1,327 respondents, a response rate of $67 \%$. Data in the second measurement were collected by means of a mailed questionnaire $(76 \%)$ or with the same questionnaire in face-to-face interview $(24 \%)$. Interviews were held face-to-face mainly to enluance response among respondents with alcohol-related problems at $\mathrm{Tl}$.

At first measurement differences in non-response between population and sample on several demographic characteristic were snall, and not significant (Knibbe, 1984). For the follow-up the non-response was analyzed with the 1980 data. Mortality $(n=85,4.3 \%)$ was not related to drinking behavior or alcohol-related problems. For all drinking variables of 1980 (such as weekly consumption, heavy drinking and drinking status), no diferences in response were found. No significant differences in response were found for age, sex urbanization and region. Small differences were found for marital status, social class and level of education. The response among those married and never married was higher than anong those divorced, cohabiting or widowed. Furthermore, the response was found to be lower among unskilled workers, and those with only primary school education. The main conchusion from this nonresponse analysis was that no differences in response were found with regard to all drinking variables and alcohol-related problems. It seems unlikely that the effects of small differences in response caused by marital status, level of education and social class will confound the results of the research. 


\subsubsection{Measures of drinking variables}

Respondents were defined as drinkers if they had drunk one or more glasses of alcoholic beverages the past six months. The level of consumption was assessed with a 4-day weekly recall. Consumption was measured with the number of standard glasses on Saturday and Sunday and on the two most recent weekdays. The mean of these two days was used as an estimate of the awerage consumption of all weekdays. This 4aday weekly recall is to a large extent similar to the "standard" weekly recall method. Therefore, it was expected that the proportion of consumption that was underreported would be the same for all consumption levels (Lemmens et al., 1992).

The frequency of heavy drinking was determined with a question about the frequency of drinking six glasses or more: How often did you drink six glasses or more on one drinking occasion in the past gix months?" This frequency was measured on an eight-point scale from 'never' to 'every day" and recoded into a weekly frequency. Hence, a score on heavy drinking of I meant drinking once a week six or more glasses per occasion, a score of 0.25 meant drinking once every four weeks six ol: more glasses.

Drinking contexts were divided into drinking locations and drinking situations. Both drinking locations and drinking situations were measured in the same way as heavy drinking and recoded into a weekly frequency. Six drinking locations were distinguished: at home, at others' homes (friends or family), in bars or restaurants, at social clubs and in bars of sports clubs, and at work. Drinking situations were measured using drinking at four different moments during the day, at lunch, in the afternoon, at dinner and in the evening. No questions were asked about the wolume of drinking in connection with drinking contexts. Changes in consumption, frequency of heavy drinking, frequency of drinking in different situations and at different location were determined by subtracting the score at $\mathrm{T} 1$ from the score at $\mathrm{T} 2$. Consumption variables and indicators of alcohol-related problems were asked at both $T 1$ and $\mathrm{T2}$, however, drinking situations at $\mathrm{T} 1$ were asked retrospectively at $\mathrm{T} 2$.

\subsubsection{Measures of drinking problems}

Negative consequences of alcohol consumption were assessed with a problem index that can be considered as a short version of Cahalan's problem index (Cahalan, 1970). The problem index consists of 19 items and four categories of (sub-)problems were distinguished: (1) symptomatic drinking, for example, when one started drinking, having difficulty stopping, or having blackouts or lapses of memory; (2) problents with the social environment caused by drinking, for example, problems with the family or partner, job problens or problems with the law: (3) problems with health, such as being advised by a physician to cut down on drinking; and (4) the trequency of drunkenness and hangovers. The maximum score on each category was 2 points, the maximum total score was 8 points. Two thresholds had to be passed before points on the problem index were scored. To obtain one point on the subproblem symptomatic drinking at least wo items had to be soored and a person had to be drunk at least once a month to obtain one point on the subproblem frequency of drunkenness (see also Hajema, Knibbe \& Drop. 1994).

Chronicity of alcohol-related problems was defined as a score of at least one point on the problem index at both $\mathrm{T} 1$ and T2, remission was defined as a score of at least one point on the 
problem index at $T 1$ but not at $T 2$, incidence was defined as a score of at least one point on the problem index at $\mathrm{T} 2$ but not at $\mathrm{T} 1$.

\subsubsection{Measures of social conditions}

The demographic characteristics and social conditions used in this sudy were sex, age, marital status, employment status, socioeconomic status, type of household (with or without children at $T 1$ and/or T2) and the drinking behavior of parents. All variables, except drinking of parents, were asked at $\mathrm{T} 1$ and $\mathrm{T} 2$. The type of household was determined to indicate the presence of child-rearing roles at both measurements. The stability or change of the type of household, employment status and marital status stability were related to the development and persistence or drinking problems. The level of education and occupational status were used to indicate socioeconomic status. The level of education was measured on an eight-point scale while accupational status was measured on a six-point scale. Only a very small change in socioeconomic status was observed between T1 and T2. Measures at T2 were used in the analyses because they were considered as a better indicator for the youngest age group who would not have reached their highest level of education or occupational level at $\mathrm{M}$.

\subsubsection{Amalyses}

In accordance with the two research issues the analysis of this study focused on chronicity and incidence of alcohol-related problems. The analysis of chronicity of drinking problems concentrated on the selection of drinkers with alcohol-related problems at first measurement. Those at $\mathrm{T} 2$ who persisted with drinking problems were compared to those at $\mathrm{T} 2$ who remitted drinking problems. The analysis of factors related to the incidence of alcohol-related problems concentrated on drinkers at first measurement who initially did not repont alcohol-related problems. Within this category, those who at second measurement reported alcohol-related problems were compared with drinkers who at both measurements reported not having experienced alcohol-related problems.

Firstly, level of consumption, frequency of heavy drinking and alcohol-related problems at $T 1$ and $T 2$ and chronicity and incidence of alcohol-related problems at $T 2$ were described by age and sex. The results of this description provided background information and might indicate trends between $\mathrm{T} 1$ and $\mathrm{T} 2$ related to the chromicity and incidence of alcohol-related problems.

Secondly, bivariate associations are presented of chronicity and incidence with independent variables at $T 1$ and change of the same variables at T2. A change in frequency of . 1.0 stands for a decrease in frequency of a drinking habit at T2 of one time per week. Chi²tests, Fisher's Exact-Test, analyses of variance and two-tailed t-tests in SPSS 5.0 were used to detemine the significance of the independent variables. The level of significance (p-value) of .10 is presented to indicate possible differences of the independent variables among women.

Thirdly, logistic regression analyses were used to investigate the effects of the independent variables simultaneously. A logistic regression analysis can indicalc whether the variables that were associated with drinking problems in the bivariate analyses also added to the explanation of chronicity and incidence in a multivariate design. To prevent exclusion of important variables by a too stringent p-value, the p-entry was set at 10 while the p-remowe 
was set at 15 (Hosmer \& Lemeshow, 1989:108). Thus, the probability of missing important variables was reduced, howewer, it must be realized that the probability to include variables of minor importance was increased. Variables were selected from the model with all independent variables by backward elimination of variables with the likelihood-ratio test. Three different models are presented, the model with only level of consumption and heavy drinking, the model with level of consumption, heavy drinking and drinking contexts, and the model with level of consumption, heavy drinking, drinking contexts and social conditions. To facilitate a clear comparison of the three models analyses were performed on the cases with no missing values on all drinking variables and social conditions. The logistic regression models were evaluated with the log likelihood, also expressed as $R_{4}{ }^{2}$, the $R^{2}$ and the classification results. The $R_{1}^{2}$ measures the proportional reduction in the absolute value of the log-likelihood measure. The $\mathrm{R}^{2}$ "permits direct comparison of logistic regression models with linear probability, analysis of wariance, and discriminant analysis models when predicting the observed value' (Menard, 1995:23). Due to collinearity problems the change in frequency of drinking at lunch at $T 2$ had to be excluded from the logistic regression andysis. Similarly, the frequency of drinking at work was excluded because of a large number of missing values.

In this study the independent variables could be distinguished as (1) level of alcohol consumption and requency of heavy drinking (a matural logartithmic function $L N(x+1)$ was used to transform weekly consumption); (2) contexts of drinking divided into frequency of drinking at different drinking locations and at different situations and (3) social conditions. The frequencies of drinking in bars, at social clubs and at sports clubs were taken together to indicate frequency of drinking on licensed premises. The independent variables used in the analyses were characteristics at $T 1$ and change or stability of the characteristics at $T 2$ with regard to $T \rrbracket$.

Interactions of change in weekly consumption and weekly frequency of heavy drinking with both intial Jevel of consumption and heavy drinking were included in the logistic regression analysis. Interactions of drinking contexts with consumption, and of consumption, heavy drinking, and drinking contexts with age caused problems of collinearity and were not included in the logistic regression analysis. The results are presented separately for men and women. Unfortunately, the logistic regression analysis could only be performed for men. Among women. the prewalence of drinking problems at $\mathrm{Tl}$ and $\mathrm{T} 2$ was too low and the number of cases too small, to perform a logistic regression analysis.

\subsection{Results}

Rekvant for the interpretation of the results on changes in consumption and alcohol related problems between 1980 and 1989 might be two trends: (1) per capita consumption of alcohol in the Netherlands decreased slightly from 8.9 liters of pure alcohol in 1980 to 8.2 in 1989 (PGD, 1993): (2) the development of prices of alcoholic beverages resembled the general changes in consumer prices (CBS, 1991). In table 4.1, findings are presented by gender and age for level of consumption, heavy drinking, alcohol-related problems at $\mathrm{T} 1$ and $\mathrm{T} 2$, and 
chronicity and incidence of alcohol-ralated problems al T2. Among men, level of consumption, frequency of heavy drinking and the proportion of those with alcohol-related problems were found to be higher than among women.

Level of consumption differed by age for men at $\mathrm{T} 1$ and $\mathrm{T} 2$, and for women only at $\mathrm{T} 2$. When the same age categories at T1 and T2 were compared the results showed a higher level of consumption of men at 22 , particularly anong men in the 40 s. For women, a small decrease in consumption was observed for all age categories, except those in the late 20 's. However, these results were not significant. A negative association was found between the frequency of heavy drinking and age among men. Among women, no clear age pattern was found. At T1 only a weak association was observed while no association was observed at $\mathrm{T} 2$. For both men and women a negative association was found of alcoholmelated problems with age. For women, however, at $\mathrm{T} 2$ a weak nonlinear association was found of alcohol-related problems with age. Except for men in their 40 's, no significant differences were found for the proportion of men and women with alcohol-related problems for age categories at T1 and T2. Men in their $40^{\prime}$ s at $T 2$ showed a substantially higher proportion of alcohol-related problems than the same age category at T1.

Both chronicity and incidence of alcohol-related problems were higher among men. The chronicity of alcohol-related problems at $\mathbb{T} 2$ was $52.0 \%$ for men and $31.8 \%$ for women $(p<.01)$. Hence, women were more likely to show remission from drinking problems than men. The incidence of alcohol-related problems was respectively $20.5 \%$ for men and $5.6 \%$ for women $(p<001)$. No association was found for chronicity of alcohol-related problems with age for either sex. Incidence, on the other hand, was found to differ with age. In men, a high incidence was found among the youngest age categories and a low incidence among the older age categories. In women, a high incidence was found at middle age, in particular in the $40^{\prime \prime}$, while incidence was lowest in the late 20 's and 30 's.

Drinking contexts by age and gender are presented in table 4.2. In general, men drank more often in all contexts than women. For both men and women several age-related drinking patterns were observed. In men, age differences were observed at $\mathrm{T} I$ and $\mathrm{T} 2$ for drinking at home, at others' homes and on licensed premises. Age differences in drinking at noon, at dinner and in the evening were only significant at T2. No, or only weak age partems were observed for drinking at work and in the aftemoon. In women, differences in drinking on licensed premises and in the afternoon were found for age at boln $T \|$ and $T 2$, differences of drinking at home and drinking at dinner were only significant at respectively $T$ and $T 2$. No age-related differences were found for drinking at others' homes, at work, at noon, and in the ewening.

Both men and women drank relatively less often at home at a younger age, specifically in their teens and 20 's. The reverse was found for drinking on licensed premises for men and women and for crinking at others homes for men, the frequency of drinking on licensed premises and others homes was found to be higher at a younger age. Among men, and 10 a lesser extent also among women, a drinking pattern appeared in which the frequency of drinking at dinner was lower at older age while the frequency of drinking in the evening was somewhat lower at younger age. Finally, table 4.2 shows that for several age calegories significant changes were observed between TI and T2. Probably the most notable were the 
decreases in frequency of drinking in the evening among men in the late 20 's and 50 's.

Bivariate analyses of chronicity and incidence with volume, heavy drinking and drinking contexts are presented in table 4.3 . The results indicate that men who have chronic alcoholrelated problems initially had a higher level of consumption and a thigher frequency of heavy drinking than men who remitted from alcohol-related problems. The difference in change ( 2 11) of consumption and heavy drinking at T2 between those with chronic drinking problems

Table 41 Consumplion, heavy drivking and alcohol-related problems by gender and age

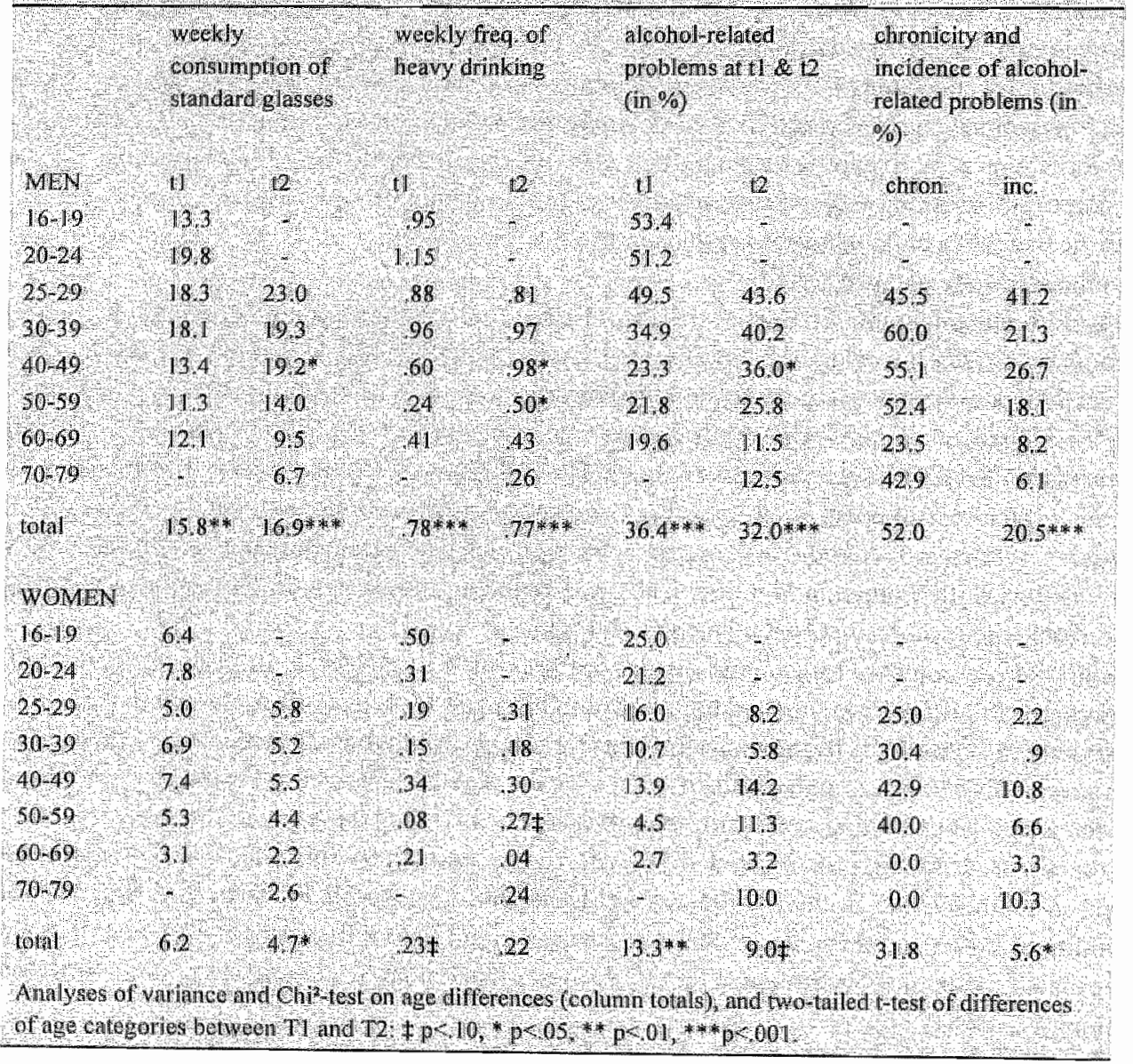

and those who remitted was not significant. Differences in drinking contexts were found for drinking at lunch, in the aftemoon and in the evening. Men with chronic drinking problems drank more often in the aftemoon and in the evening. Those with chronicity of drinking problems showed a stronger decrease in drinking at lunch and in the evening compared to those who remitted their drinking problems. No differences were found for drinking at home, 
at others ${ }^{7}$ homes, on licensed premises, at work and at dinner. These results indicate that besides consumption and heavy drinking also drinking in different situations (at lunch, in the afternoon and in the evening) were positively associated with chronicity of drinking problems.

The incidence of men with drinking problems was associated with level of consumption, heavy drinking, drinking at home, and drinking on licensed premises. Note that the level of consumption of those who developed alcohol problems at 12 had almost doubled. Men who developed drinking problems drank more often on licensed premises and increased their frequency of drinking at home. No differences were found for drinking at others' homes, at work or at any of the drinking moments (table 4.3). The results suggest that, besides affects of consumption and heavy drinking, higher frequencies of drinking on licensed premises and at home were positively associated with the incidence of drinking problens.

Bivariate analyses on chronicity of drinking of women showed significant differences in lewel of consumption and heavy drinking, of drinking in the afternoon and anking in the evening. No differences were found for the frequency of drinking at home, at others homes, on licensed premises, at work, at lunch and at dinner. All the differences were in the expected direction and suggest that the level of consumption, the frequency of heavy drinking, and the frequency of drinking in the afternoon and in the evening were positively related to having chronic drinking problens. The incidence of alcohol-related problems in women was associated with the level of consumption, heavy drinking. drinking at home, on licensed premises, and with drinking in the afternoon, at dinner and in the evening. No differences were found for heavy drinking, drinking at others' homes, at work and at lunch. Again, all the differences were in the expected direction and suggest that the level of consumption, the frequency of heavy drinking, and the frequency of drinking at home, on licensed prenises, in the afternoon, at dinner and in the evening were positively associated with the incidence of alcohol-related problems.

Table 4.4 and 4.5 depict the associations of chronicity and incidence with demographic characteristics and social conditions. Significant associations of social conditions with chronicity were found for marital status, employment status and drinking behavior of the parents. Being divorced at T2, change of employment status and the frequency of drumkenness of the parents were associated with chronicity of alcohol-related problems of men. The results show that men who got divored between $\mathrm{T} /$ and $\mathrm{T} 2$ were more likely to thave chronic drinking problents compared to men who did not get divonced; men who became unemployed or who had lost their paid job by disability were more likely to have chronic drinking problens than men who had not lost their job; and men with parents with a relatively high frequency of drunkenness were more likely to have chronic drinking problems as adults. On the other hand, men who became employed or retired at $T 2$ were more likely to have remitted from alcohol. related problems and, in other words, were less likely to have chronic drinking problems.

Incidence among men was found to be related to marital status, employment status, and drinking behavior of the parents. Men who started cohabiting between T1 and $\mathrm{T} 2$ were more likely to develop drinking problems; men who became unemployed or disabled were more likely than others to develop drinking problems; and men whose mother drank frequently had a greater chance of developing drinking problems; finally, men with parents with a relatively high frequency of drunkenness were more likely to develop drinking problems. 


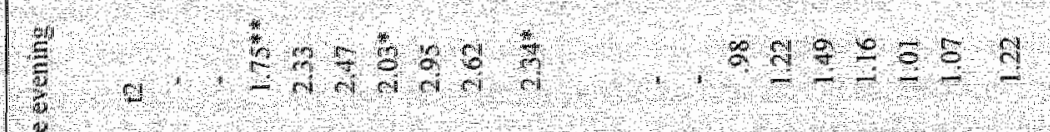

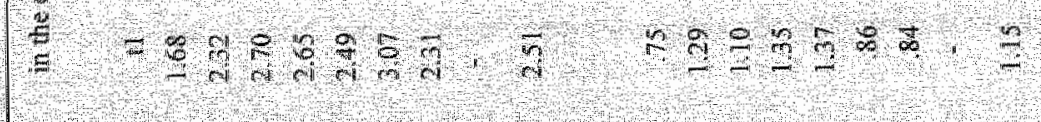

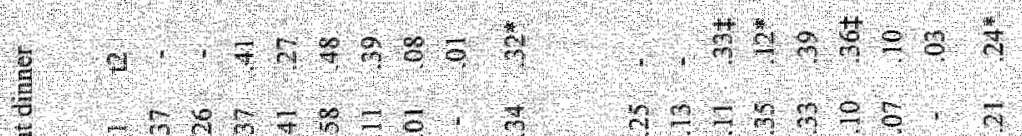

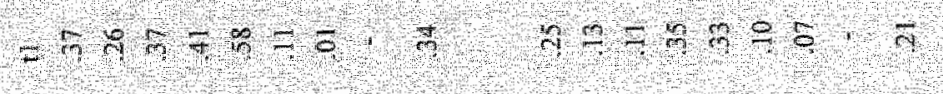

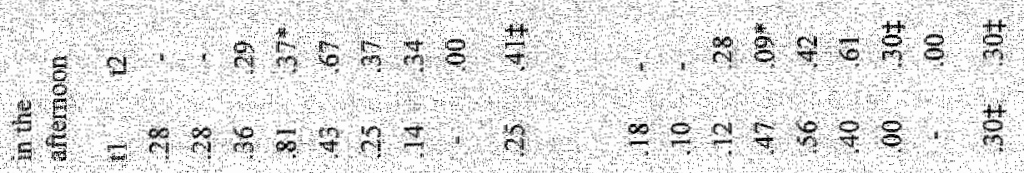

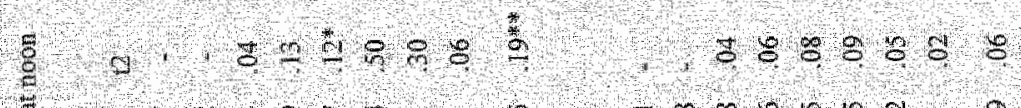
$=\neg$ ป $9 F=$,

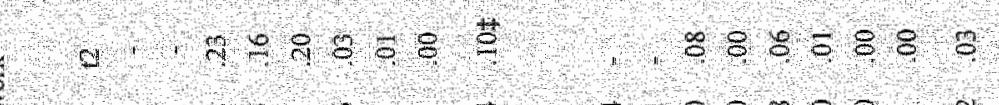

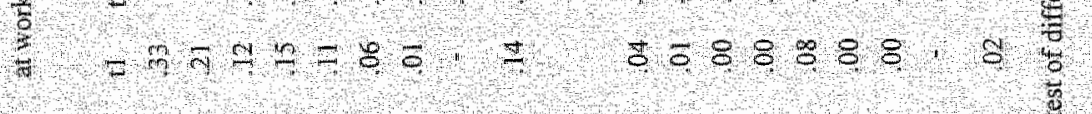

क ल

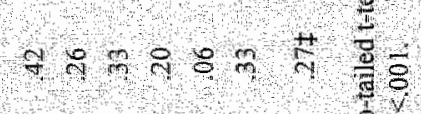

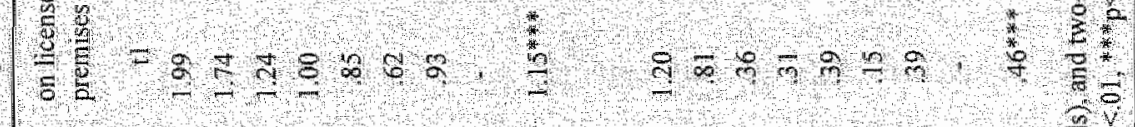

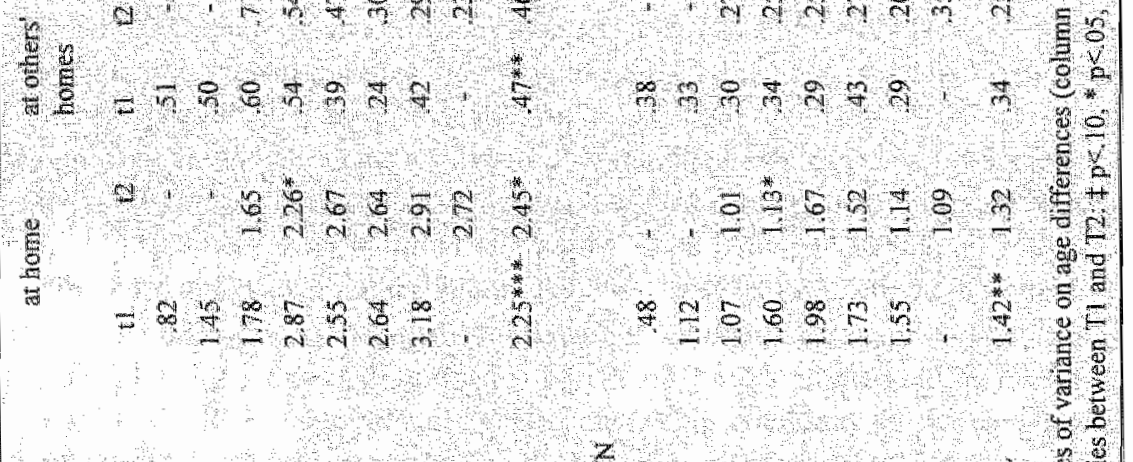




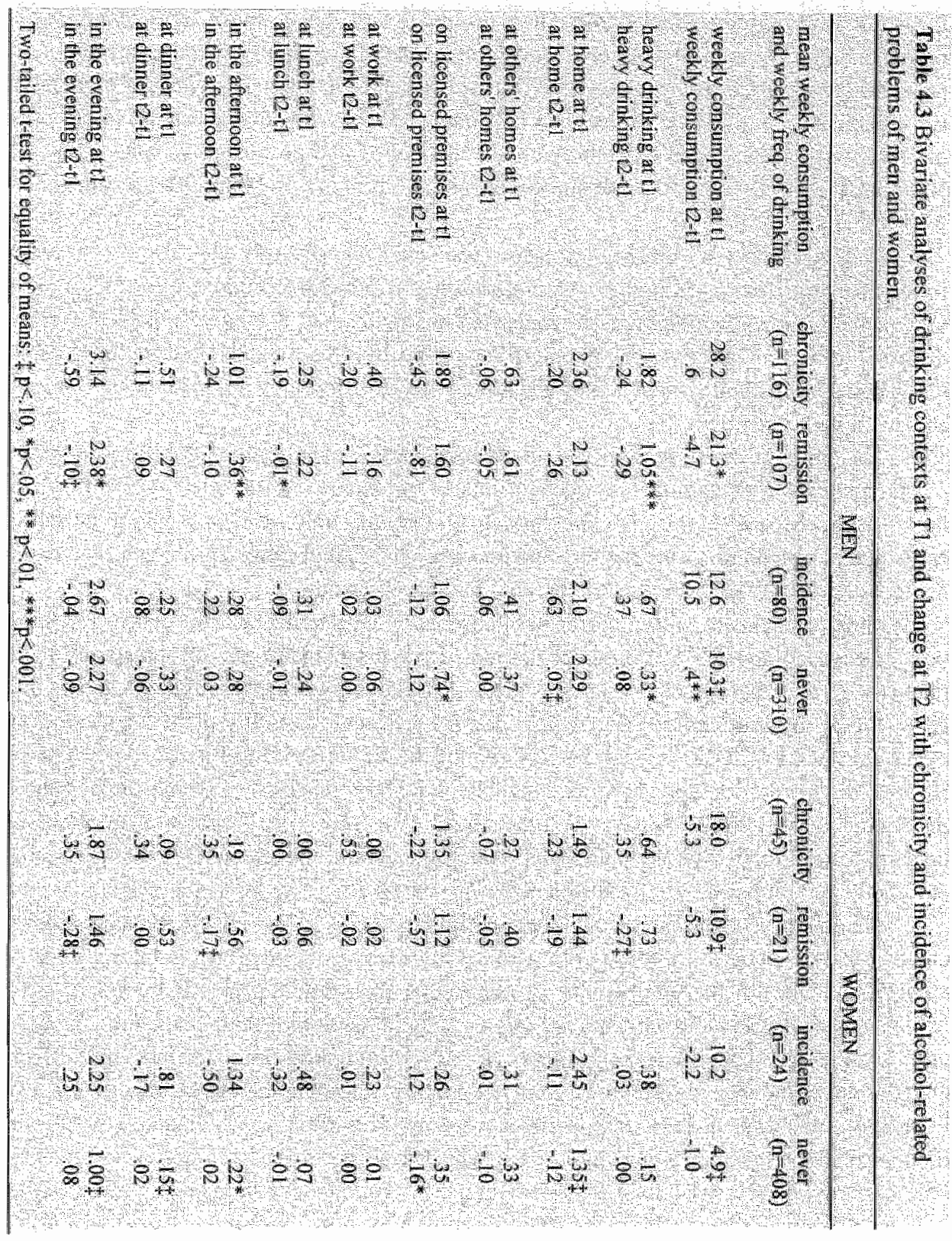


In women, chronicity of alcohol-related problems was only significantly associated with mantal status. Women who started cohabiting were more likely to have chronic drinking problems than other women. Women who married between $\mathrm{TI}$ and $\mathrm{T} 2$ were more likely 10 show remission of drinking problems. The findings for household suggested that the presence of children was associated with chronicity of alcohol-related problems. Women with children at home at $T 2$ were more likely to show remission of drinking problems. The results, however, were not signi hicant.

The incidene of drinking problems was only significantly associated with age and frequency of drinking of the father during childhood. Women at middle age were more likely to develop drinking problems and women whose father had a relatively high frequency of drinking were nore likely to develop drinking problems. Other results on drinking behavior of the parents and employment status suggested an association with incidence, but without statistical significance.

The bivariate analyses did not allow conclusions to be drawn about predictors of the persistence and developmeni of alcohol-related problems. Multivariate analyses, such as logistic regression, might give an answer to the question of which variables could be considered as predictors of chronicity and incidence of alcohol-related problens. The resulis of the logistic regression analysis are presented in tables 4.6 and 4.7 .

Three models are presented for both chronicity and incidence. The first model includes only the vartables level of consumption and heavy drinking, in the second model drinking patterns are added and social conditions are added in the third model. Table 4.6 shows that the fit of the third model exceeded the fit of the second model and the fit of the second model exceeded the fit of the first model. Indicators of the fit are the Log Likelihood, expressed as $\mathrm{R}^{2}$, and $\mathrm{R}^{2}$. In addition, the classification table could be considered as an indicator of the fit of the model (see method section). Although the $\mathrm{R}^{2}$ was not very large, consumption, heavy drinking, drinking patterns and social conditions could be considered as predictor's of chronicity and remission of alcohol-related problems.

Change in consumption and heavy drinking at $\mathrm{T} 1$ were posilively associated with chronicity. An increase in consumption and a high frequency of heavy drinking at $T 1$ were associated with a higher probability of chronicity. Consumption at T1 did not add to the explanation and was removed from the model. The interaction of both change in consumption and change in heawy drinking with level of consumption implied that the effects of consumption and heawy drinking were not simply limear. The interaction effects can be interpreted as follows: the likelihood of continuing with drinking problems is ligher among men who increased their consumption but who had a low level of consumption at T, and among men who increased their freguency of heavy drinking and who already had a high level of consumption at $\mathrm{T} 1$

In the second model a relatively high frequency of drinking at others" homes was associated with a higher probability of remission. A high frequency of drinking on licensed premises at $T$ and an increase in frequency of drinking on licensed premises and a high frequency of drinking in the aftemoon led to a higher probability of chronicity.

The third logistic regression model for chronicity included the frequency of heavy drinking. and the interactions of change in consumption with both initial level of consumption 


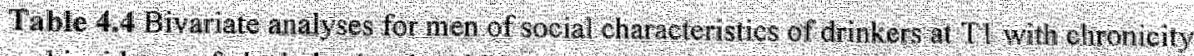
and incidence of alcoliot related problenis

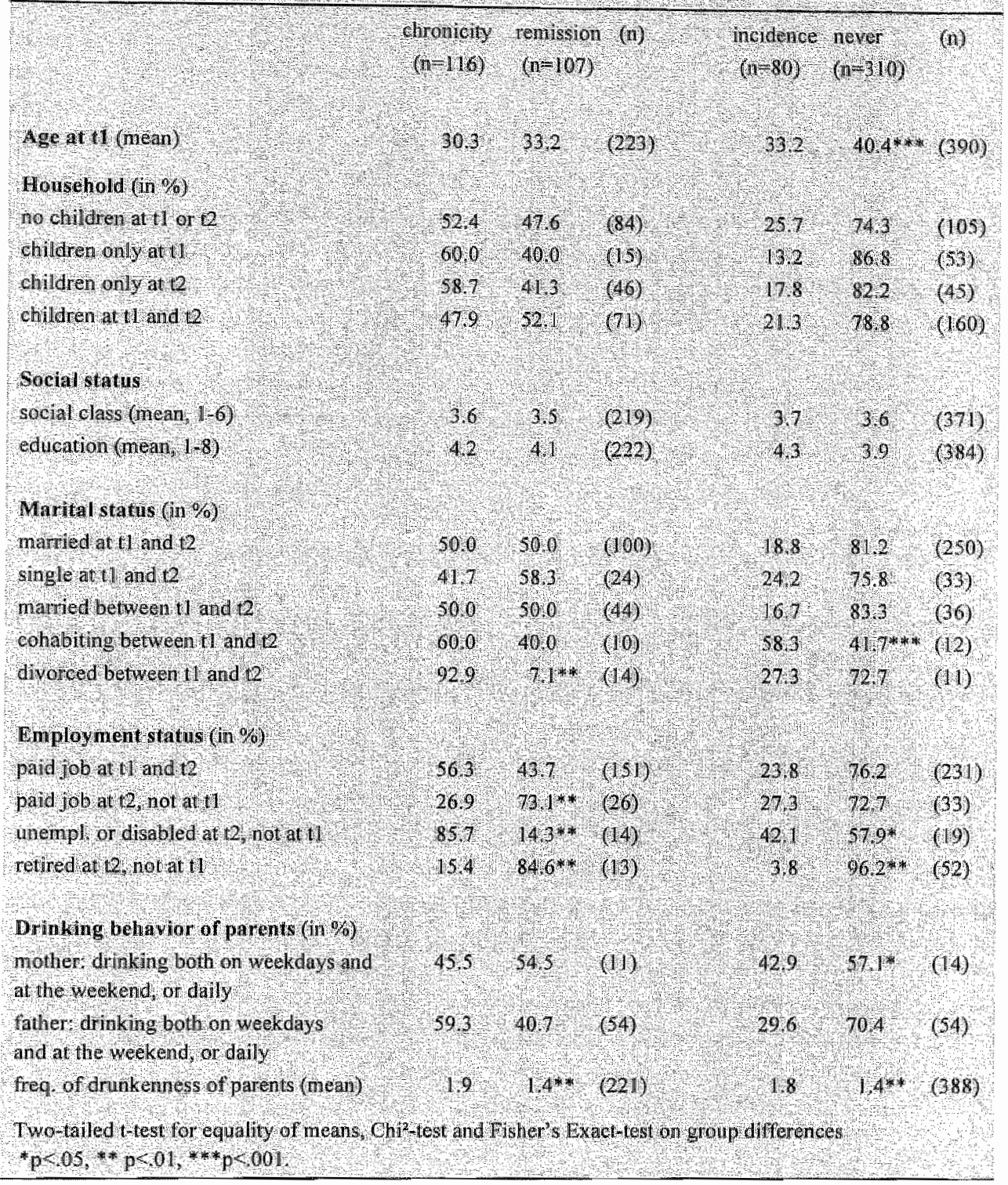

and heavy drinking. Hence, the average effect of change in consumption was zero, but the interaction effects implied that the probability of continuing with drinking problems was higher among those with a relatively high frequency of heavy drinking at $T 1$ and also among men with a low initial level of consumption. Two aspects of drinking contexts were remowed from the final model (drinking on licensed premises at TI and change in drinking on licensed 


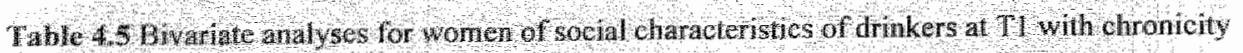
and neidence of ucohol-reated problems

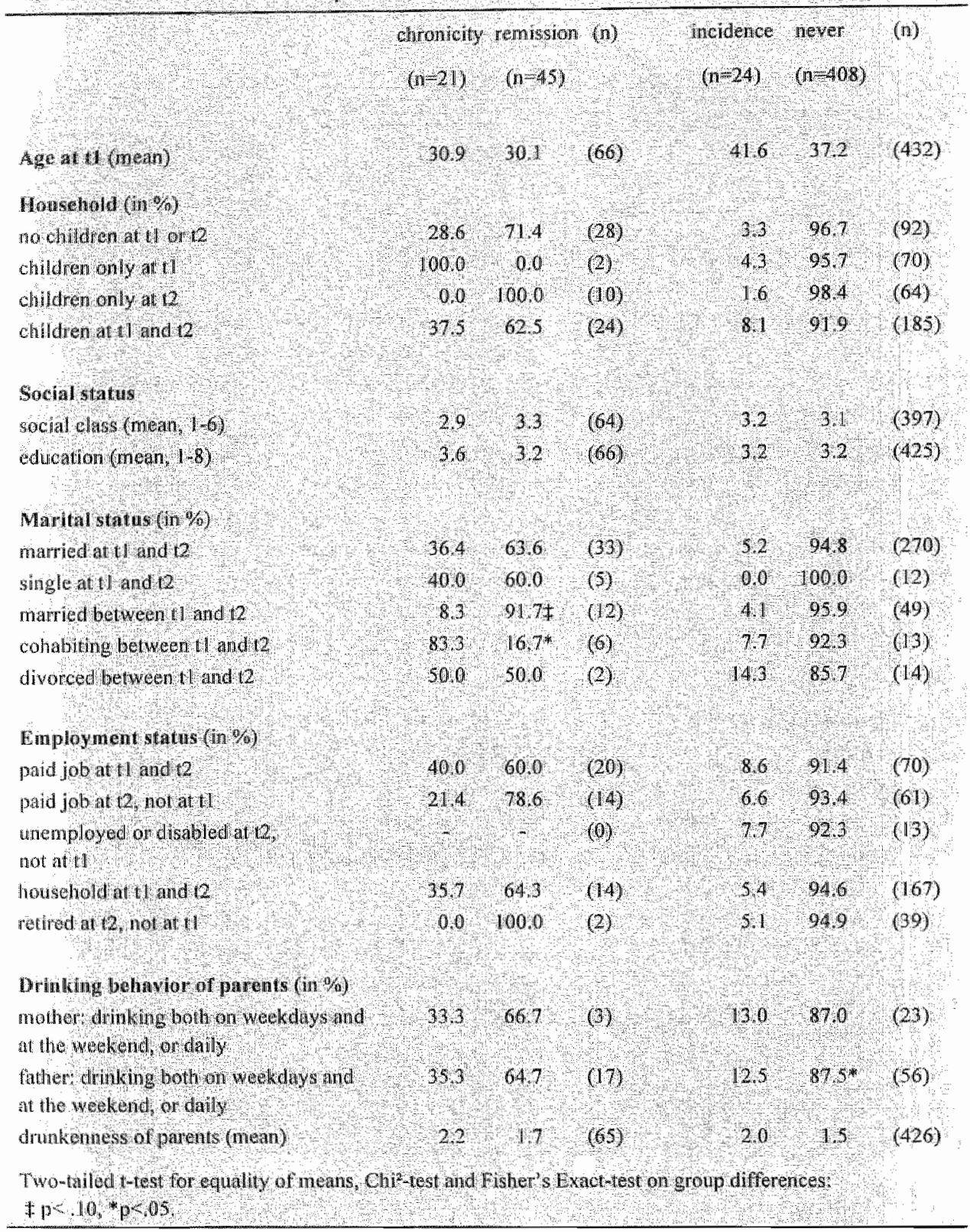

premises at T2). Four social factors that were included in the model were employment status, marital status, age and drinking behavior of the parents. Being employed at both $\mathbb{T} 1$ and $T 2$ was used as a reference category tor employment status, being married at $\mathrm{T} 1$ and $\mathrm{T} 2$ was used 
as a reference category for marital status.

The results showed that men who became wnemployed had a higher probability of chronicity, men who became employed had a higher probability of remission, belonging to the 'other' category also implies a higher probability of chronicity of alcohol-related problems. The category 'other' covered a variety or eight categories and could not be interpreted clearly. for example, those retired at $\mathrm{T} 2$ or at both $\mathrm{T} 1$ and $\mathrm{T} 2$, those unemployed or disabled at $\mathrm{T} 1$ and $\mathrm{T} 2$. The effect of marital status was caused by the positive association of the category "olher" with chronicity. The category 'other' covered patterns as, for example, those divorced at $\mathrm{T} 2$ or at both $T 1$ and $T 2$, and those cohabiting at $\mathrm{T} 1$ or at both TI and T2. Compared to men married at both measurements, men with such a pattern of marital status were more likely to have chronic drinking problems. Although social conditions added moderately to $\mathbb{R}^{2}$, the effects of employment status, marital status and age were rather weak.

Similar results were found with regard to the incidence of alcohol-related problems. Both drinking patterns and social conditions added considerably to the explanatory power compared to the model with only consumption and heavy drinking, as indicated by $R^{2}$ and $R_{1}^{2}$. Three interaction effects were included in the first model. The effects of a change in heavy drinking were found to differ acconding to heavy drinking at II as well as to the level of consumption at $T 1$. The results suggest that an increase in frequency of heavy drinking furthers the development of drinking problems, in particular among those with a low frequency of heavy drinking at T 1 and those with a high level of consumption at TI. Furthernore, it was found that the change in consumption was significant when the level of consumption at TI was taken into account.

Heavy drinking at "T"1 was included in the second model and those with a high frequency of heavy drinking at TI were more likely to develop drinking problems at T2. The effect of a change in heavy drinking differed by the level of consumption at T1. The odds ratio suggest that an increase in heavy drinking influences the development in case of a high level of consumption at T1. Additionally, the probability to develop drinking problems is higher if the level of consumption increases. A weak interaction effect is observed for the change in consumption and frequency of heavy drinking at TI, the cffect of an increase in consumption is stronger if the frequency of heavy drinking at TI was relatively low. Drinking contexts included in the second model were drinking in the aftemoon, drinking at dinner, the change in frequency of drinking on licensed premises, of drinking in the atternoon and in the evening. Drinking in the afternoon was positively associated with the incidence of alcohol-related problems, driaking at dirner was negatively associated with incidence, an increase in drinking in the eveming and on licensed premises decreased the probability of incidence. The effect of arinking on licensed premises, however, was weak.

In the third model the effect of a change in consumption differed according to consumption at 71 . The effect of an increase in consumption was stronger among inose with an already high level of consumption at T1. Weak effects were observed for the interaction effects of change in heavy drinking with level of consumption and frequency of heavy drinking at TI, as in the first model. Social conditions that were included in the model were age and 
Table 4,6 Logitic regression analyses on chroninity and remission $(1,0)$ or alcohol related probilens with consumption and heayy drinking drinking contexts and social conditions.

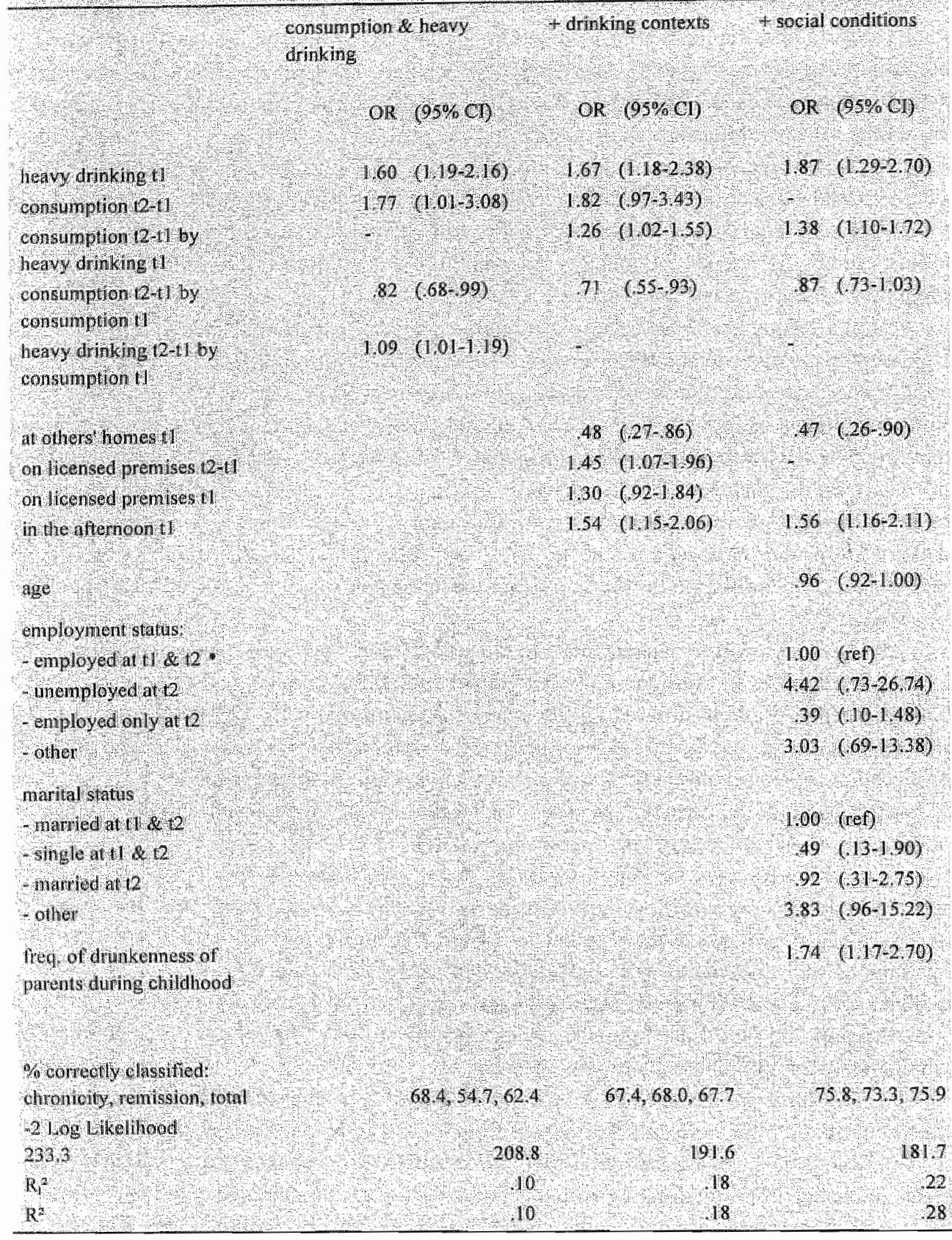


Table 47 Logistic regression analyses on medence $(1,0)$ of alcoliol related problems anth consumption and heavy drinking drinking pattens and soetal conditions.

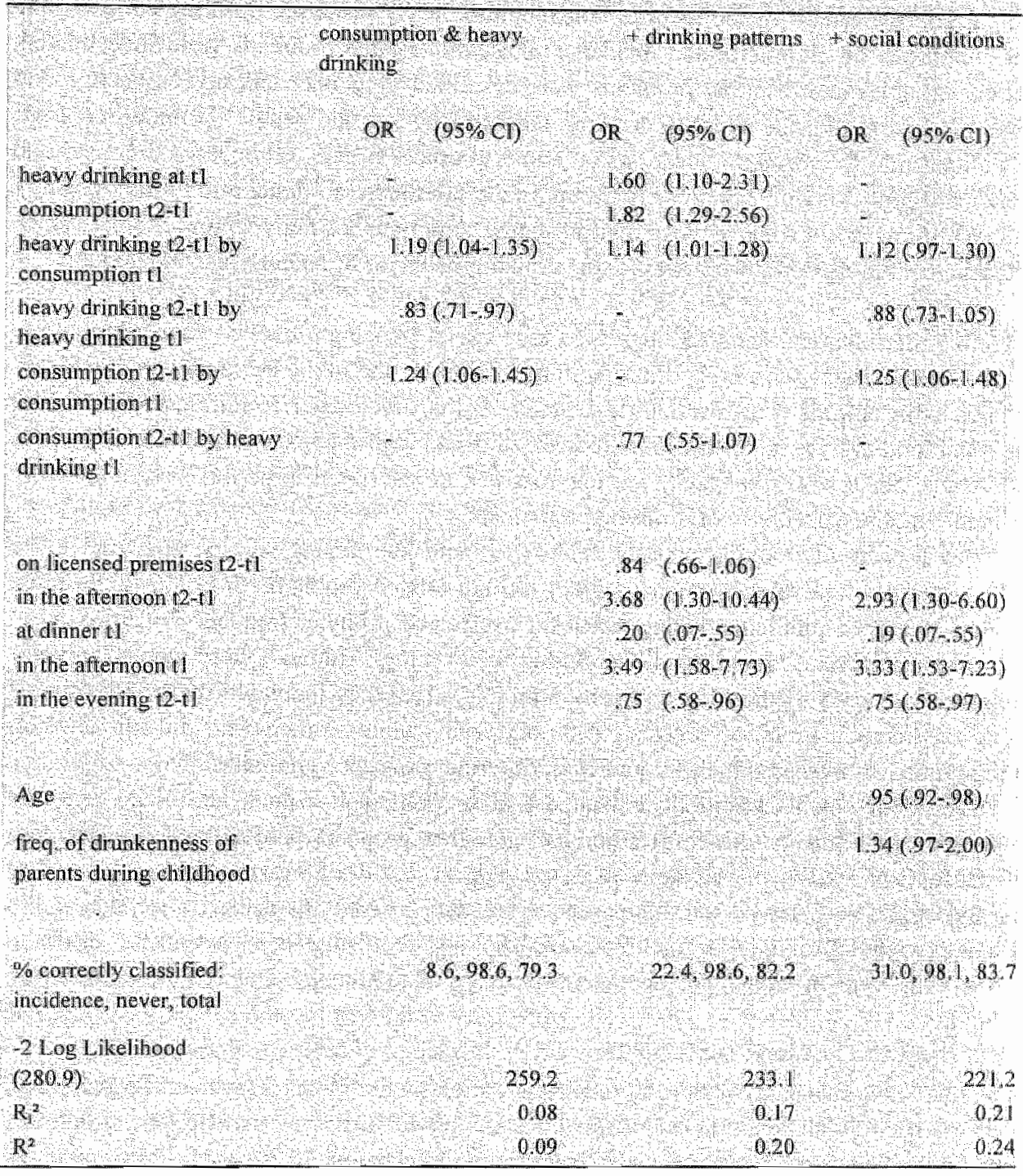

drunkenness of parents during childhood. Older men were less likely 10 get drinking problems. A. weak positwe effect was observed of the froquency of drunkenness of parents. Possibly, drunkenness of the parents is associated with drinking problems of their chidren later on. 


\subsection{Conclusions}

In this article the effects of the level of consumption, heavy drinking, drinking contexts and sacial conditions on chronicity and incidence of alcohol-related problems were investigated. Drinking variables and drinking problems were described by gender and age as background information and to indicate shifts in drinking problems by age and gender. Drinking contexts were divided into four drinking locations (at home, at others' homes, on licensed premises and at work) and four drinking situations (at noon, in the afternoon, at dinner and in the evening). Social conditions in our analysis were marital status, employment status, socioeconomic status, the presence of children in the household, the drinking behavior of parents, age and gender.

For women, the bivariate analyses suggested that a relatively high level of consumption and high frequency of heavy drinking, drinking in the afternoon and in the evening were positively associated with chronicity of drinking problems. Among the social conditions only marital status was found to be associated with chronicity of drinking problems. Cohabitation at T2 was found to be positively associated, getting married in the interim period was negatively associated with the persistence of drinking problerns.

Most aspects of drinking patterns related to incidence among women appeared to be already present before these women reported alcohol-related problems. In 1980 the women who later developed problems distinguished themselves by a higher frequency of drinking at home, drinking in the afternoon, at dinner and in the evening. Although these women initially had a lower frequency of drinking on licensed premises (ns) they increased their frequency of drinking on licensed premises between 1980 and 1989 while women who did not develop drinking problems decreased their frequency of drinking on licensed premises.

Results for social conditions indicated that in particular women at middle age and women with a frequently drinking father had a higher probability of developing drinking problems. On the whole, the bivariate analyses suggest that drinking situations, age, marital status and drinking behavior of the parents were associated with drinking problems. No associations with chronicity or incidence of drinking problems were found for drinking locations, employment staius, socioeconomic status and for the presence of children in the household.

In men, the bivariate analyses on chronicity of drinking problems suggested associations, besides effects of consumption and heavy drinking, with drinking in different situations, marital status, employment status and the drinking behavior of parents. For incidence, associations were found for drinking on licensed premises, age, marital status, employment status and drinking behavior of the parents. What is more, the multivariate logistic regression analyses showed that it is likely that not only consumption and heavy drinking but also drinking contexts and social conditions added to the explanation of chronicity and incidence of alcohol-related problems. The effects of some social conditions, however, were rather small.

For drinking contexts the final model showed that drinking in the afternoon was positively associated while drinking at others" homes was negatively associated with chronicity 
of alcohol-related problems. Several social conditions were found to be associated with chronicity: age, employment status, marital status and the frequency of drunkenness of parents. Aithough the fit of the model with social conditions is considerably better than the model with only consumption, heavy drinking and drinking pattems, the odds ratios indicated that most associations with chronicity were rather weak. Men at an older age were less likely to buve chronic drinking problems. Besides, the highy skewed confidenee intervals of the odds ratios suggest that becoming unemployed increases and finding employment decreased the probability on chronic problem drinking. Likewise, results of marital status suggest a positive association of divorce and cohabitation with chronicity of drinking problems. Moreover, men whose parents had a relatively high frequency of drunkenness had a higher probability of reporting drinking problems at both measurements.

Besides effects of consumption and heavy drinking on incidence, the final logistic regression model showed a positive association with drinking in the afternoon. Drinking at dinner and the change in frequency of drinking in the evening were negatively associated with incidence. Among the social conditions a negative effect was found for age, older men were less likely to develop drinking problems. Furthermore, a higher frequency of drunkenness of the parent was weakly associated with incidence. No effects on chronicity or incidence of drinking problems among men were found for socioeconomic status and for the presence of children in the household.

\subsection{Discussion}

The logistic regression analyses showed that effects of consumption and heavy drinking were not simply linear. It seems plausible that the effects of a change in consumption differ according to the initial level of consumption and heavy drinking. An increase had a stronger effect if consumption at $\mathrm{T} 1$ was low, in other words, in case of a relatively large increase in consumption. The interaction of change in consumption with heavy drinking, however, can probably be explained as a multiplicative effect of the combination of both drinking aspects: men with both a high frequency of heavy drinking and a high level of consumption are note likely to continue having alcohol-related problems.

Two factors can probably explain the effects of drinking contexts: Firstly, contexts as such, may differ in their probability of creating drinking problems (e.g. at home versus in bars, in the aftemoon versus at dinner). Drinking at others homes is an indicator of social drinking and social drinking is likely to cause less problems than for instance solitary drinking. Research has shown that, in particular, solitary heavy drinking is a risk factor for alcoholrelated problems (Bourgault \& Demers, 1995). Drinking on licensed premises compared to, for example, drinking at home, might provide more opportunities for problematic situations to arise, for example, drunken driving. It must be noted, however, that in our study drinking on licensed premises was excluded from the model after social conditions were included. These findings suggest that social conditions are predictors of the frequency of drinking on licensed premises and that drinking on licensed premises does not add independently to incidence or 
chronicity of alcohol-related problems. These results of the effect of drinking on licensed premises agree whth the modest findings of Fitzgerald \& Mulford (1984) but contrast findings of Harford (1994) Stockwell et al. (1993) and Casswell et al. (1993) who found effects of drinking on licensed premises together with socio-demographic characteristics.

Secondly, drinking contexts refer o different lifestyles and these lifestyles differ in the vulnerability for drinking problems. In fact this explanation matches Harford's ideas of lifestyles at higher risk for drinking problems. It was observed, for instance, that drinking in the afternoon was positively associated with chronicity and incidence of alcohol-related problems. Drinking in the afternoon, as such, might not cause drinking problems but it is part of the drinking style of those with drinking problems. Simpura (1991) emphasizes the importance of norms and the appropriateness of specific drinking patterns. The appropriateness of drinking patterns suggests that noms are probably important in producing negative consequences for drinkers in certain drinking contexts. In our view, drinkers are not just socialized, nom-oriented conformers but socialization and noms have their influence on drinking behavior through the influence on the reward structure.

Employment status, marital status, age and drunkenness of parents were found to be predictors of alcohol-related problems. In terms of reward structure, those who became unemployed lost some credibility compared to those who stayed employed. They were confronted with mone criticism than employed drinkers. Their unemployment, for example, might be atributed to their drinking behawior. Those who became employed fulfilled their 'social obligations' and were probably less criticized than before. A second explanation of the influence of social conditions might be that categories of drinkers differ in the degree to which they take risks. For instance, an explanation of the age effects could be that the benefits of drinking were higher among younger drinkers (see Mäkelä \& Mustonen, 1995). Therefore, younger drinkers would be more likely to participate in hazardous drinking behavior and to have a higher probability to obtain drinking problems. Probably the age effects were even weakened by the trend that at T2 for men in their $40^{n}$ s the proportion with drinking problems has increased. The finding of high chronicity in men at middle age by Fillmore (1987b), cannot be confirmed. In the multivariate analysis even a (weak) negative association of chronicity with age was observed. As mentioned in the introduction, the effects of frequency of drunkenness of the parents on chronicity and incidence of drinking problems can be explained as social letining. Although biological explanations are possible, among those with a family history of heavy drinking the consumption of alcohol has becone an habit in which future consequences are discounted more strongly. For most drinkers with a relatively high frequency of drunkenness of parents this would mean a stronger discount of negative consequences. As a result. such drinkers would engage in risky drinking situations and obtain (or keep) drinking

2. In this stidy problems with the law were considered to be an indicator of a possible alcoholrelated problem regadless of the period in which this potylen occured. However, if problems with the law are neasured with the same time frame as the other problems several men shifed from chronic drinking problams to remission $(n-9)$ to incidenes $(n=1)$ or never drinking problems (n=l), from incidence to newer (n-5) and from rempsion to mever (n- 1). The logistic regression analyses with the strict definition suggested that an increase in drinking on licensed premises implied a highter

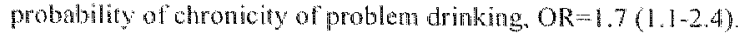


problems.

An alternative explanation of the effects of social conditions might be that social groups differ in the extent of underreporting drinking problems. Additionally, if the impact of drinking problems varies with social conditions, it cannot be excluded that social groups differ in the extent to which certain problems are remembered.

The results of this study on the effects of social conditions support other empirical findings: of incidence, chronicity and gender (Filmore, 1987b), of incidence and age among men (Fillmore, 1987b); of incidence and marital status among women (Wilsnack et al., 1991), of employment status and drinking problems (Knibbe et al., 1987). However, at least one study did not find any strong associations of social conditions with drinking problems (Hilton, 1987).

Several limitations of this study have to be noted. First, alcohol-related problems were defined as a dichotomous variable. Therefore, possible effects of the independent variables on the increase or decrease of severity could not be determined. It must also be noted, however, that most scales that measure severity of alcohol-related problems are not an interval or ratio scale. Hence, one has to be cautious when using such scales as dependent variables in a regression analysis. Second, the non-response at $\mathrm{T} 2$ of those cohabiting at $\mathrm{T} 1$ was somewhat higher. It could be that this non-response weakened the observed effects of marital status on incidence and chronicity of drinking problems. These two limitations indicate that probably the effects of social conditions on the development of alcohol-related problems are likely to be stronger than our results suggest. Third, the multivariate analysis was only performed on men. It is suspected that a multivariate analysis among women would produce different results than among men. Fourth, the results are likely to be culture specific. The effects of drinking contexts and social conditions on drinking problems may vary between different cultures. In this way, the effects of social conditions can be seen as a cultural phenomenon (White, 1982).

With regard to our theoretical perspective, the concept reward structure might be practical for interpretation of results and in the use of other theoretical notions for the explanation of drinking behavior and drinking problems. Further elaboration of such a model is needed. With respect to the empirical findings it seems that, to reproduce findings on possible effects of social conditions and drinking contexts on drinking problems for men and women, large samples should be used in a longitudinal design.

\section{References}

Akers, R.L, Krohn, M.D., Lanza-Kaduce, L. R Radosewich, M. (1979) Social fearning and dewant betavior: a specific test of a generall theory. American Sochological Pewew, 44, 636-655

Bourganl, C.\& Demers, A. (1995) Sulitary drinking: a risk factor for alcohol-related problens? 1 aper presented an

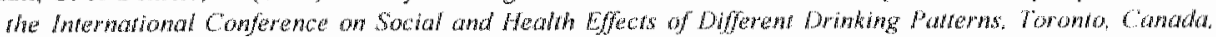
november $13-17,1905$

Cahalan, D. (1970) Problem drinkers, Jossey-Bass Publishers, San Francisch, USA.

Casswell, S., Zhang, J.F. W Wyllie, A. (1993) The importance of amount and location of drinking for the experience of alcohot-related problems. Addiction, 8g, pp. $527-1534$.

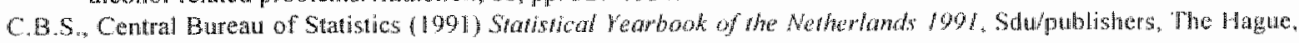
The Natherlands.

Coleman, J.S. (1990) Fomdarions of Sochat theory, The Belknap Press of Hanard Universty Press, Cambridge. 
Messachusertus and London, England.

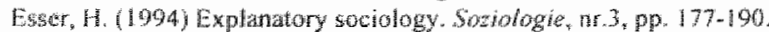

Fillmore, K.M. (1987a) Prevalence, incidence and choncity of drinking pattems and problems among men as a funethon of age: a longhtudinal and cohor amalysis. Brish Jownol of Addichon, 82, pp. 77-83.

Fillmore, K.M. (1987b). Women's driking across the adult life course as compared to men's. British Journal of

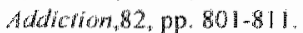

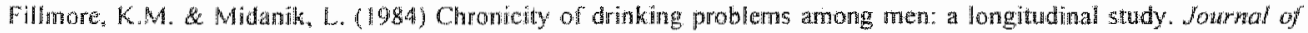
Sithises on Alowol, 45, pp, $228-236$.

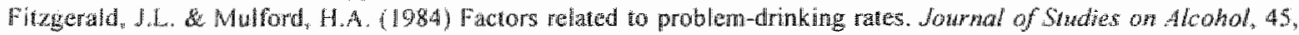
$9 \mathrm{p} .424 .432$

Gruenewald, P.J., Mitchell, P.R. Treno, A, J. (1996) Drinking and driving: drinking patterns and drinking problems. Addichon, $91, \mathrm{pp}, 1637-1649$.

Hacma, KJ, Knibbe, R.A., \& Drop. M.J. (1994) Other factors than sewerity retated to help-seking of problem

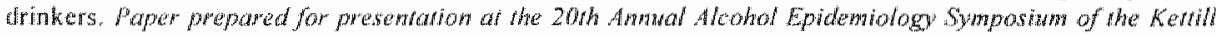

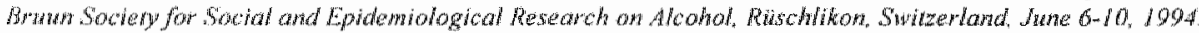

Haford, T.C. (1994) Public drinking contexts and alcohol dependence: is there a link? paper prepared for

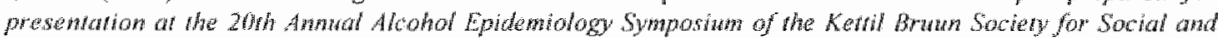

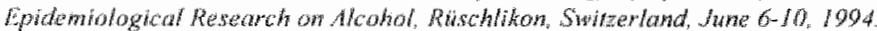

Hilton. M.E. (1987) Demogtaphic characteristics and the frequency of heavy drimking as predictors of self-reported

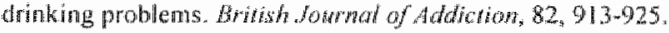

Hosmet, D. W. Lemeshow, S. (1989) Applied loging regression, John Wiley de Sons, Mew York, USA.

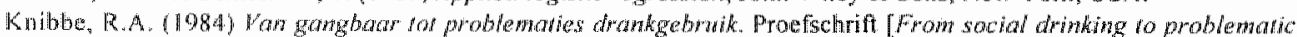
drithimg, thesis , RU-Limburg, Mastuticht.

Knibibe, R.A., Drop MJ, de Mutjens A (1987) Correlates of siages in the progression from everyday dninking to problem drinking. Sowal Science and Modkipe. $24,463-473$.

Knupfer, G. (1984) The Rjsks of Drunkemness (or, Ebrietas Resurecta). A comparison of frequent intoxication indices of population sub-groups as to problem rasks. British bounat of Addition, 79, $185-196$.

Lemmens, P.,Tan, E.S. \& Knibbe, R.A. (1092) Measuring quantity and frequency of drinking in a general population survey: a comparison of five indices. forwhat of Sindies on Alcohol $53,476-486$.

Makela, K., Simpura, J. (1985) Experiences related to drinking as a function of anmal intake and by sex and age Drre and Alcohol Dependence, $15,389-404$.

Makela, K... Me Mstonen H. (1996) The reward stheture of drinking among younger and older male drinkers. Confenporay Drug problems, 23, pp. 479.492.

Menard, S. W. (1095) Appled logistic neguession andysis. SA GE university papers series. Quantitative applications in the social sciences; $170,07-106$. London, UK.

Miller-Thtzatmer, C. Leonard, K.E., \& M. Windle (1991) Marriage and alcohol use: a longitudinal situdy of maturing ont ${ }^{\text {in }}$. Sind Alokhol $52: 434-440$.

P.G.D., Productschap voor Gedestileerde Dranken (1993) World drinking trends (Henley-on-Thames, NTC Publicar Rons L Ltd.

Room, R., Bondy, S.J. \& Fartis, J. (1995), The risk of thatm to oneself from drinking, Canada 1989. Addic/iom, 90, 490. $\$ 13$.

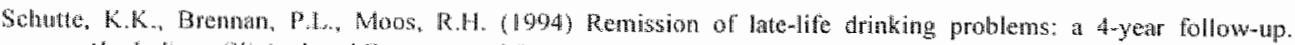

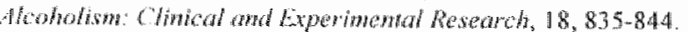

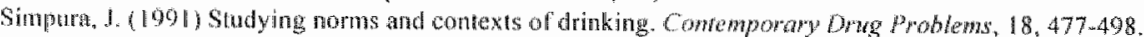

Single, E. \& Worthey, S. (1993) Drinking in various sethings as it relites to demographic watiables and gevel of

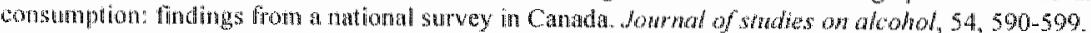

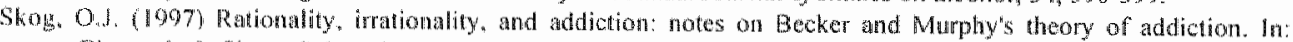
Elster, 1. Skog. O.l. (Eds). Geting hooked: Rationaity and addiction. Cambridge: Cambridge Uniwersity Press.

Stoetwell, T., Lang. E., 决 Rydon. R. 199\%) Hight tisk drinking settings: the association of serving and promotional practices with hatmfist drinking. Addiction, $88,1519-1526$.

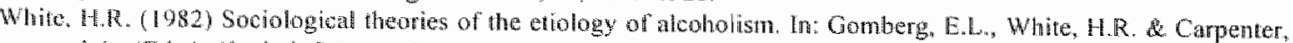

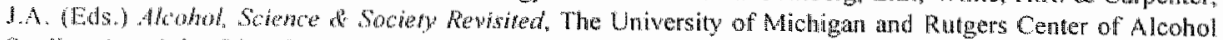
Suldies, Ant A bor New Brunswidk, 205-232

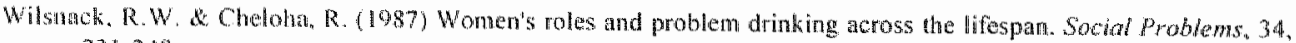
$23 \mid-248$

Wismenc. S.C. Klassen, A.D. Schtr, B.E. \& Wilsmack, R.W. (1991) Predieung onset and chroncity of women's problem drinking a five-year longitudinal analysis. American fow of of Public Heath, 81, 305-317. 
Chapter 5

\title{
Social resources and alcohol-related losses as predictors of help-seeking among male problem drinkers
}

In press, Journal of Studies on Alcohol

\author{
Klaas Jan Hajema, Ronald A. Knibbe \& Maria J. Drop.
}

\begin{abstract}
.
Objective: In this study it was examined whether factors other than severity of alcohol-rolated problems add to the explanation of seeking help for drinking problems. Method: Help-seeking was investigated by comparing male problem drinkers who applied for treatment with nale chronic problem drinkers in the general population. Subjects were selected from an outpatient treatment center $(n=129)$ and from a panel of the general population $(n=86)$ in the Netherlands. A shortened version of Cahalan's problem drinking index, including symptoms, social consequences, health problems and frequency of intoxication, was used to indicate the severity of problem drinking. It was hypothesized that particularly drinking problems that indicate losses (social consequences and heath problems) were associatied with help-seeking. Furthermore, resources such as paid work, a spouse, high socioeconomic status, younger age and a 'wet' social network were expected to facilitate the continuation of drinking behavion" and drinking problems and the avoidance of help-seeking. Resuls: Social and health consequences were associated more strongly with seeking help than symptoms of problem drinking and intoxication. The effects of type of alcohol related problem, employment and age were as hypothesized. However, the hypotheses about marital status, socioconomic status and social network characteristics could not be confirmed. Conchwions. The results suggest that in particular employed men and men of a younger age deserve attention with regards to detecting problem drinking and prevention.
\end{abstract}




\subsection{Introduction}

Most studies comparing problem drinkers who apply for treatment with problem drinkers in the general population observe a large difference in the severity of alcohol-related problems (c.g. Bannenberg, Raat, \& Plomp, 1992; Brennan \& Moos, 1991). Room (1977) calls this the two worlds of alcohol problems and concluded that there is a wide gulf between reality in the context of the general population and clinical reality. However, the width of this gulf is difficult to estimate because one of the most important aspects of problem drinking - the chronicity of alcohol-related problems - is not adequately measured in most studies.

Out: study differs in two ways from most other studies. Firstly, a 9-year follow-up study was used to identify male chronic problem drinkers in a general population. Secondly, factors other than severity were examined in a multiwariate design by controlling for alcohol-related problems. The comparison of treated and untreated problem drinkers may indicate which factors, besides severity, add to the explanation of help-seeking of problem drinkers. Nevertheless, in our study the matching of alcohol-related problems in the general population with those problems in the clinical population also remains questionable with regards to several aspectis.

The help-seeking behavior of problem drinkers is an inportant issue in -at least- two respects: the treatment perspective and the problem drinkers" perspective. The most important aspect is that only a small number of problem drinkers apply for treatment (e.g. Brennan \& Moos, 1991). For example, Raat (1987) concluded that about $5 \%$ of the problem drinkers in the Netherlands applied for treatment, and Cornel et al. (1994) found that general practitioners in the Netherlands identified only about $10 \%$ of the problem drinkers among their patients. These observations arouse several questions among which the detection of problem drinking by health professionals, the capacity and quality of treatment centers and the knowledge of problem drinkers about treatment facilities.

From the perspective of the problem drinker, demanding treatment means that he admits he has drinking problems and that these drinking problems interfere with, for instance, family responsibilities or other social roles. Moreower, he admits he is unable to solve these problems on his own. In the case of problem drinking choosing to get professional help and demanding treatment might lead to a stigma (c.g. Cunningham et al, 1993). But perhaps most compellingly, treatment implies that the drinker will have to give up his habit or addiction. In other words, entry to treatment for the help-seeker is also likely to generate several negative consequences that can be considered as 'personal and social costs' (Beckman \& Amaro, 1986). Another major point is that several studies have found that many problem drinkers can resolve their problems without treatment (e.g. Sobell, Cumningham \& Sobell, 1996; Fillnore et al, 1988; Hasin \& Grant, 1995). Therefore, the problem drinker might claim that he can manage his drinking problems and that others have to trust him to deall with his own problems.

We suppose that there is a transitional stage of problem drinking with approximately the same severity of alcohol related problems, but in which only some apply for treatment. Therefore, we examined to what extent the severity of alcohol-related problems in problem drinkers of the general population overlapped with the severity in problem drinkers who 
applied for treatment. The main research question was formulated as: what differences between problem drinkers, besides severity of alcohol related problems, can explain help-seeking for alcohol-related problems?

\subsubsection{Theoretical models for explaining help-seeking}

In the alcohol research literature two models dominate, which are used both separately and together, to explain help-seeking behavior. The first model emphasizes societal and individual determinants of use of medical care facillities (e.g. Aday \& Andersen, 1974). The second model (the health belief model) emphasizes health behefs as the determinants of use of medical care Lacilities (e.g. Rosenstock, 1966; Becker et al, 1977). An important theoretical contribution was made by Beckman \& Kocel (1982) who created a comprehensive model in which both models were combined to explain help-seeking for alcohol-telated problems. The propensity and the ability to seek help are thought to be affected by individual beliefs, individual predisposing factors, personal enabling factors, social enabling factors and characteristics of the 'serwice delivery system'. They suggested that in particular 'cues to action' are important for the drinker to seek help for his or her alcohol-related problems. Weisner (1993) used a modified version of the Beckman \& Kocel model to investigate differences beiween problem drinkers in the general population and in treatment. Four factors were distinguished as influencing help-seeking behavion: individual predisposing (such as age and education), social predisposing (such as marital status and social pressure), need (indicators of severity) and enabling factors (such as income and employment).

However, in these models it remains undear which mechanisms can explain the effects of social structure on help-seeking. It seems as if the model is being applied as a specific heuristics without a theoretical explanation. The limited empirical support found in the aforementioned studies has not elicited a discussion about the usefuness of the model (e.g. Bardsley \& Beckman, 1988; Weisner, 1993). Except for need, variables seem to be ordered rather arbitrarily into categories of wariables.

A more general model that might be useful to explain help-seeking has been developed by Pescosolido (1992). In what she has named 'the social organization of help-seeking' she stresses the importance of social networks and events. "Events set into motion a specific process of coping with uncertainty, initated either by the focal individuals hacing a problem or by network members who perceive a shift in the ongoing rhythm of social life' (Pescosolido, 1992. 1105). Thus model differs in two important aspects from the model of Beckman \& Kocel. Firsty, decision making is explained by purposive action and cost-benefit calculation. Secondly, the model includes help-seeking from among all possible help providers instead of only from among professionals or professional organizations. Accordingly, in this article helpseeking for alcohol-related problems is considered as a decision-making process determined by purposive action and by weighing up the pros and cons of the alternatives.

In the following we will propose how several notions of the Beckman \& Kocel model can be used in the explanation of help-seeking together with two additional theoretical notions. Firstly, how can the effects of "cues to action" be explained? Lindenberg (1988) hypothesized that the prevention of imminent loss and the reduction of recent loss frame certain decision situations and the likelihood that this frame dominates other possible frames grows 
disproportionally with the size of the loss. Therefore, we assume that the extent to which cues to action are important for an individual is detemined by the actual and potential losses due to drinking. For the individual drinker help-seeking can be a means to prevent these losses or to regain a lost position (for instance, employment, a spouse or friend, health, or social approval of social network members). We assume that alcohol-related problems differ in the extent to which they can be considered as losses. It is expected that social consequences (such as problems with a spouse or employment) and health consequences, constitute greater losses than symptoms of problem drinking or heavy drinking (e.g. skipping meals, sneaking drinks and intoxication).

Secondy, how can the effects on help-seeking of variables described as "predisposing factors" and 'enabling factors' be explained? Certain characteristics of drinkers can be considered as resources that influence the costs and benefits of help-seeking in the process of decision making. It is assumed that the possession of these resources facilitates the avoidance of help-seeking and the continuation of drinking habits. In other words, these resources can be considered as 'social capital' that ease the continuation of drinking behavior. Social capitall is made up of social relationships that are embedded in social structure and can be used to achieve certain goals (Coleman, 1990). As Furstenberg \& Hughes (1995) stated, the notion of social capital is attractive because it links the characteristics of individuals with their social context. With more resources a person may easier convince relevant others, that he (or she) is functioning well and is fulfilling his role obligations, that others should trust him to control his drinking and that there are no alcohol-related problems.

\subsubsection{Hypotheses}

In this study the effects on help-seeking of employment status, marital status, socioeconomic status, age, social network characteristics and type of alcohol-related problem were analyzed. Characteristics such as paid work, a spouse, and high socioeconomic status, are considered as resources that enable problem drinkers to avoid help-seeking. While controlling for the negative consequences of drinking, employed and unemployed problem drinkers may differ in the positive and negative consequences of help-seeking. It can be argued that the costs of helpsecking -such as stigma and social disapproval- are larger for employed persons. It might become difficult, for instance, to keep an employer unaware of his drinking problems. Moreover, unemployed men are relatively deprived compared to employed men. Hence, those unemployed might have more to gain from seeking help.

In general, excessive drinking is likely to be more tolerated among young adults. It is expected that heavy drinking among young people matures out and constitutes a transitional phase belore acquiring obligations with regard to employment, a spouse, children, and the social environment in general. Consequently, the costs of excessive drinking are higher for older men. In other words, heavy drinking is more rewarding for younger drinkers and suggests that being young can be considered as a form of social capital to continue one's drinking habits and to awoid help-seeking. An important study on age and drinking consequences (Mäkelä \& Mustonen, 1996) showed that at high levels of consumption younger drinkers experienced more positive consequences whereas older drinkers experienced more negative consequences. However, older age may not only indicate higher costs of heavy and problematic drinking, but 
also a longer duration of problem drinking (e.g. Mäkelä \& Mustonen, 1996; Room, 1980). Therefore we will not only analyze whether age contributes directly to the explanation of helpseeking, once alcohol related problems are controlled for. We will also analyze whether age moderates the effects of drinking consequences on help-seeking. Such a moderating effect would more explicitly support an interpretation of age in tems of social costs.

There are several reasons why the costs and benefits of help-seeking are likely to differ with the characteristics of the social network. Firstly, in a "wet' social network characterized by a high level of consumption, heavy drinking and a high frequency of drinking together with network members, heawy drinking and alcohol-related problems are more likely to be tolerated. Therefore, in such a 'wet' social network social pressure to cui down on drinking or to seek help for alcohol-related problems will be less likely to arise. Thus, while the costs of heavy drinking are lower, problen drinkers with a 'wet' social network will be less likely to seek help for alcohol-related problems. Secondly, in a large social network with a bigh frequency of interaction there are more potential critics of one"s drinking behavior. These critics could make it more rewarding for a problem drinker to seek help. On the other hand, however, it can be argued that such a network implies more informal help-providers and probably more alternatives to seeking help from a professional organization. Since these effects are opposite to each other, no hypotheses will be formulated for the effects of network size and frequency of contact. However, both characteristics are included in our study to gain insight in their effects on help-seeking.

From the above, the following hypotheses can be derived: alcohol-related problems that can be viewed as losses are more likely to lead to help-seeking. When controlling for the severity of alcohol-related problems, problem drinkers who are employed, married or in the higher social strata will be less likely to seek help. Similarly, since help-seeking is thought to be more rewarding for older problem drinkers, younger problem drinkers will be less likely to seek help. Finally, problem drinkers with a wet personal network will be less likely to seek help.

\subsection{Method}

\subsubsection{Data}

Male chronic problem drinkers in the general population were taken from a randomly selected panel of the population in the province of Limburg, the Netherlands. At first measurement was in 1980 the sample was between 16 and 70 years of age. The response rate was $76 \%(\mathrm{~N}=1980)$. The second measurement was in 1989 (age of the respondents $(25-29)$ and had a response rate of $67 \%(\mathbb{N}=1327)$ At second measurement the response rate was lower among those with only primary education $(54 \%)$, among those who were widowed $(50 \%)$, cohabiting $(56 \%)$ or divorced $(57 \%)$. However, the non-response was not related to allcohol-related problems, heavy drinking or level of consumption at first measurement. None of the chronic problem drinkers in the panel had sought help for their alcohol-related problems.

The problem drinkers applying for treatment were selected from an outpatient treatment 
center in the prowince of Limburg, the Netherlands. Interviews were held between June 1993 and January 1994. Because there were very few chronic female problem drinkers in the panel of the general population, only male problem drinkers at the treatment center were selected for comparison. Furthemore, to ensitue optimum comparability problem drinkers who were younger than 25 year, without the Dutch nationality or referred to treatment by the police or count were excluded. The outpatient clients consisted of men who had at least several consultations at the treatment center. Clients were asked to participate by their councillor. For some clients, the councillors thought that an interview was undesirable because of a critical situation. In seweral other cases, an interview was not possible because the clients were hospitalized, jailed, or had died recently. Hence, the non-response was probably somewhat higher among the most severe problem drinkers. There are no differences in the availability of uratment services between 1989 and 1994. Consequenily, it is not likely that the discrepancy in the dates of data collection will have influenced possible help-seeking patterns.

To obtain an indication of the chronicity of problem drinking of the outpatient clients it was asked when they first thought they were having a drinking problem. Although all applied for treatment four men reported they did not have a problem at all. On average, the other men reported they first experienced a dinking problem almost seven years ago (varying from just before they entered treatment to 30 years). No association was found between the chronicity of problem drinking and age.

\subsubsection{Treatment for alcohol-related problems in the Netherlands}

It is important to realize that differences in health care systems between countries might produce differences in characteristics that are suggested as determinants of help-seeking. In the Netherlands treatment for alcohol-related problems is offered by a national organization financed by the government and local authorities with facilities in the major cities and regions. As a consequence, problem drinkers do not have to pay for the services of the treatment centers and financial resources or insurance coverage do nof form barriers for entry to treatment (see Amaro, Beckman \& Mays, 1987).

A.though some private treatment centers exist, most health care professionals and social workers refer most, if not all problem drinkers (and other addicts) to outpatient treatment centers. If necessary. the outpatient treatment centra will refer to impatient treament centers. The relative number of AA groups in the Netherlands is several times smaller than in the neighboring countries of Germany and Belgitum, and about ten times smaller than in the US or Canada (Makelai, 1991).

To stmmarize, in this study outpatient clients were selected from an organization that serves all problem drinkers or alcoholics and the number of alternatives, in terms of other protessional or non-professional organizations, was limited.

\subsubsection{Measures of problem drinking}

Respondents in the general population were defined as chronic problem drinkers if they met two criteria: (1) in 1980 or 1989 they had a consumption level of at least three glasses per day or at least once per week, six or more glasses per occasion; (2) both in 1980 and 1989 they had a score of one or more points on a problem drinking index (PDI). The index is a short version 
of Cahalan's problem drinking index and contains its most relevant items (Cahalan, 1970). The outpatient clients were asked about their problems and their drinking behavior over the period before they entered treatment.

Chronic problem drinking was defined by both alcohol-related problems and consumption, to ensure that the alcohol-related problems were not just incidents but at consequence of drinking behavior and embedded in a way of life. Most items of the PDI measured the occurrence of a problem during the past year (yes/no). The items were distinguished into four types of problems: (1) symptoms of problem drinking, such as having difficulty in stopping drinking or sneaking drinks; (2) problems with the social environment, for example, problems with the spouse or family, employment, or the law; (3) problems with health and accidents, such as hospitalization for a disease caused by excessive alcohol consumption; (4) frequency of drunkenness and hangovers. Reliability analyses showed that the four types of problems formed a reliable scale (Cronbach's $=81$ ). The maximum score on each subcategory was 2 points and, consequently, the maximum total score was 8 points. As can be seen in Table 5.1 the index included two thresholds. Firstly, at least wo out of seven symptoms had to be reported to obtain one point on the subcategory symptoms of problem drinking. Secondly, a person had to report being drunker or intoxicated at least monthly to obtain one point on the subcategory frequency of drunkenness (see also Hajema et al., 1994). In particular problems with the social environment and health were seen as indicators of losses. Therefore, in the analyses these problems were included separately from symptoms of problem drinking and frequency of intoxication.

Table S.1 Construction of a problem drinking index out of alcohol-related problems.

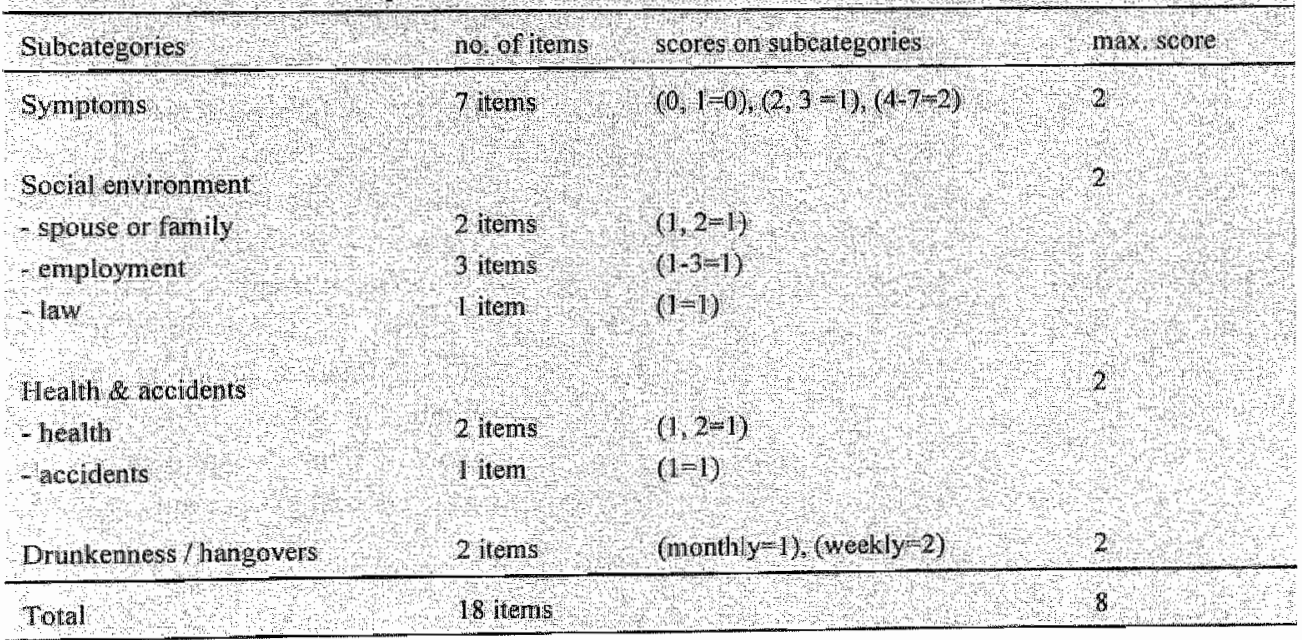

Concerning the crucial question whether the score on the PDI is a valid indicator of severity for both the general population sample of problem drinkers and the problem drinkers in treatment, two opposing arguments can be given. Firstly, because of an essential difference in the 
interview context, the differences in reported alcohol-related problems are probably smaller than observed (see also Room, 1977). The interview context of the panel study is more likely to result in underreporting of alcohol-related problems and alcohol consumption than the interview context of the treated problem drinkers. Both the respondent and the interviewer knew about the alcoholism of the respondent and perhaps even some overreporting of alcohol related problems might have occurred.

Secondly, the ranges of the original scales for symptoms, social and health consequences and intoxication were reduced to a 0-2 range when combined in the index (see table 5.1). The reason for using a similar range of variation for each type of alcohol related problems was to give each type of problems an equal weight when combining them into the index. However, it is clear that the range over which problem drinkers can differ is reduced. Moreover, it was asked whether the items of the PDI had occurred during the past year (yes/no), and not how often. Consequently, the differences in alcohol related problems are probably larger than indicated by figure 5.1. It is obvious that our study cannot provide a definitive answer to these opposing arguments. However, in the multivarjate analyses the total and untransformed scales were used to reduce this problem. The seven symptoms of problem drinking defined a reliable scale (Cronbach's $=82$ ). Because of the small number of health consequences they were taken together with social consequences to form a scale. One item (problems with spouse) with negative correlations with the other items was excluded from the scale (Cronbach's $=76$ ). To faciliate a comparison of the effects of the different scales a transformation to z-scores was applied.

Nevertheless, in our study we identified chronic problem drinkers in the general population. It seems valid to claim that, compared to most other studies, we will be able to control more fully for differences between treated and untreated problem drinkers in chronicity

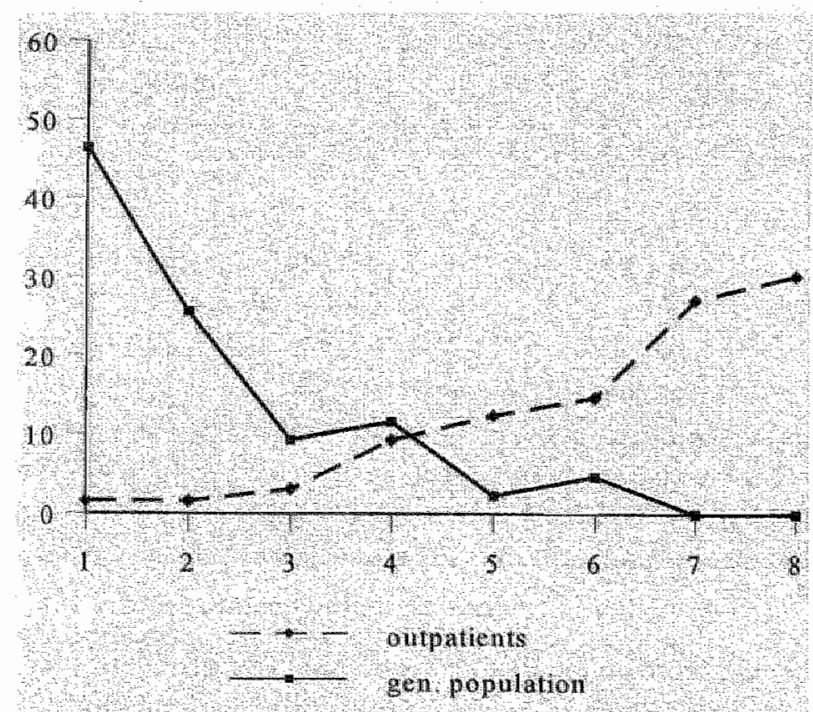

Figure 54 the score on lhe PDI of problem dritkers in the gencral population $(\mathrm{n}-86)$ and outpatientelients $(\mathrm{n}-129) \mathrm{n} \%$ 
and severity .

\subsubsection{Measures of social characteristics}

The social characteristics used in his study were marital status (married/ never married/ divorced, widower), employment status (paid employment/ unemployed, disability pension/ full time education, retired), age (year of birth) and socioeconomic status. Socioeconomic status was indicated by the level of education (eight-point scale) and occupational status (sixpoint scale). Occupational status was converted into a three-point scale to indicate low, middle and high occupational status.

All network variables in this study are based upon a series of questions in which at the first question the respondent was asked to list maximum 5 persons (not of the same household) with whom he most often had contact. The characteristics of the social network used in this study are size of the network (0-5), the frequency of interaction with network members (five categories ranging from daily to less than once a month), the frequency of drinking (five categories ranging from never to daily) of the network members and the number of network members drinking six or more glasses $(0-5)$. Drinking together with members of the social network was a variable constructed by (1) selecting only the persons with whom they always drank together when they met each other, (2) asking how frequenty they met and expressing it as a weekly frequency, (3) adding up the scores for all members of the network. The minimun score on this variable was 0 (no network menber with whom always alcohol is consumed), the maximum score was 35 (drinking together with all five network members every day).

\section{2 .5 Analyses}

The analysis of help-seeking in this article was twofold. Both bivariate and multivariate analyses were applied to distinguish help-seekers from those not applying for treatment. In the bivariate analyses, ${ }^{2}$-tests and one-tailed t-tests were used to investigate differences between both groups. As mentioned in the introduction, no hypotheses were formulated for network. size and frequency of contact with network members and, consequently, two-tailed t-tests were performed to indicate differences in means. Logistic regression analyses werc applied to discriminate problem drinkers who entered tratment from chronic problem drinkers in the general population. The results of the logistic regression model were indicated by the loglikellhood, the classitication results and the $\mathrm{R}^{2}$. In logistic regression analysis the $\mathrm{R}^{2}$ is similar to the $R^{2}$ in OLS regression analysis. It measures the association of the dependent variable with the independent variables (Menard, 1995). In the regression analyses a natural logarithmic function was used to transform the lrequency of intoxication.

\subsection{Results}

Figure 5.1 shows the scores on the PDI of the problem drinkers in the general population and of the outpatient clients. Some overlap was observed in the severity of alcohol-related problens between problem drinkers in the general population and in treatment. However, the 
results atso indicated that most problem drinkers in the general population had a lower score on the PDI compared to problem drinkers who applied for treatment. The average score (SD) on the PDI of problem drinkers in the general population and for the outpatients were respectively $6.3(1.7)$ and $2.1(1.4)$. p $<.001$.

Tables.2 Average score (SD) and average $t$-score (SD) on subscales of the PDI of problem drinkers in the general population $(n-86)$ and outpatient clients $(\mathrm{m}=129)$

\begin{tabular}{llll}
\hline & \\
\hline
\end{tabular}

Large differences were found in scores on the different types of problems. On average, problem drinkers in the general population reported less symptoms ( 1 vs. 5 ) a lower frequency of intoxication ( 1 vs. 4 times a week) and a lower score on social and health consequences $(0.5$ vs, 4). The results of the $z$-transformation suggested that the differences between both groups were larger for symptoms and social and health consequences compared to intoxication.

It was hypothesized that those of a younger age, with a higher level of education, in the middle or higher social classes, marnied, employed and with a "wet' social network would be less likely to seek help for drinking problems. Most biwariate results were in the expected direction. (table 5.3$)$.

On average, outpatient clients were four years older. Most chronic problem drinkers in the general population were in their 30 s while most outpatient clients were in their 40 s. With regard to the level of education and occupational status the results indicated that the outpatient clients were on average less educated and had a lower occupational status. Those men who not applied for treatment were mostly married whereas most outpatient clients were either never married, divorced or widower. With regard to employment status it was found that most problem drinkers in the general population were amployed compared to half the population of outpatient clients. Outpatient clients differed from those not applying for treatment with a higher proportion being unemployed or disabled. The results for the characteristics of the social network indicated that the network size among those who applied for treatment was somewhat smaller but the contact frequency was higher. However, those who applied for 
treatment reported more drinking partners than problem drinkers in the general population did. In other words, their frequency of drinking with members of the social network was higher. No differences were found in the drinking frequency and in the number of heavier drinkers among network members.

Table S, 3 Characteristics of treatuent status groups

\begin{tabular}{|c|c|c|c|}
\hline & $\begin{array}{l}\text { general } \\
\text { population }\end{array}$ & outp patienis & alue \\
\hline Mean age & $387=10.6$ & 431489 & 8001 \\
\hline Education $(1-8)$ & $40+20$ & $34+2,2$ & $80 s$ \\
\hline occupational status $(1-6)$ & $3.6+1.5$ & $27+13$ & Sogl \\
\hline Marital status ( $n$ \% $\%$ ) & & & 800 \\
\hline Gramred/oohabiting & 791 & 481 & \\
\hline - never naried & 151 & 256 & \\
\hline - droreedwidowed & 58 & 264 & \\
\hline Employment status (61, \% & & & $\circ 001$ \\
\hline employed & 812 & 492 & \\
\hline unemployedrisabled & 141 & 453 & \\
\hline - retired & 3.5 & 49 & \\
\hline - in training & 12 & 16 & \\
\hline Social network & & r, & \\
\hline size & $43+1,0$ & $388+14$ & 801 \\
\hline - contact fequency & $7,7+61$ & $101+90$ & 109 \\
\hline -dinking together & $21+40$ & 43468 & 801 \\
\hline -heau y drinkers' & $23+16$ & $20,1.5$ & 07 \\
\hline - freq of drinking & $39+32$ & $43+, 3$ & 2 \\
\hline * number of nerw & s drinking six & res or nowe (yes? & \\
\hline $\begin{array}{l}\text { proportion of netwo } \\
\text { wreekend or (alnost }\end{array}$ & bers drinking & in wreekdays an & \\
\hline
\end{tabular}

In the logistic regression analyses the effects of alcohol-related problems and social characteristics were examined in three steps. Firstly, symptoms of problem drinking, frequency of intoxication and social and health consequences were entered in the regression equation. The results suggested that the model with these problems fits quite good. The OR suggested that the effect of social and health consequences was stronger than the effect of symptoms, no significant effect was found for frequency of intoxication. In the second step age was entered into the model. The OR indicated that older age implied a higher probabillity of applying for treatment. The OR was round up to 1.1, one year older meant an increase in the odds to seek help of almost $10 \%$. 
Tabile S.4 Logistic regression analyses on helip-seeking among problem drinkers

\begin{tabular}{|c|c|c|c|c|}
\hline & $\mathrm{on}^{\prime} \quad 05 \% \mathrm{CD}$ & $(95 \% \mathrm{Cl})$ & $\mathrm{OR}$ & $(93 \%, 0)$ \\
\hline \multicolumn{5}{|l|}{ Subertegories of PDI } \\
\hline seymptoms of PD & $60(2,1 / 1)$ & $63(2019,6)$ & 71 & $(16312)$ \\
\hline $\begin{array}{l}\text { social be lieallh } \\
\text { colssequences }\end{array}$ & $18,6(5,-67.5)$ & $21.9(9,1,92.8)$ & 01 & $(0.1-45)$ \\
\hline freq, of inroxication & $1.4(0,727)$ & $17(0.89 .4)$ & 22 & $(0.859)$ \\
\hline gige & & $1,1,(1,1,2)$ & 1.2 & $(1,1,4)$ \\
\hline $\begin{array}{l}\text { age X social o thealtil } \\
\text { consequenees }\end{array}$ & & & 1.2 & $(1 / 1,5)$ \\
\hline eductibion & & & 14 & $(0.921)$ \\
\hline acoup 1 iondl starus & & & 0.4 & $(0.1-6)$ \\
\hline enplayments status & & & & \\
\hline employed & & & 10 & (refi) \\
\hline - unempl/disabled & & & 72 & $(1,480)$ \\
\hline - retined/in naining & & & 504 & $(0.8-3213,8)$ \\
\hline narital stailus & & & & 4 \\
\hline - martied & & & 10 & (ref) \\
\hline - never manried & & & 0.4 & $(0,1,8)$ \\
\hline divorced/widowed & & & 21 & $(0.227)$ \\
\hline \multicolumn{5}{|l|}{ social networle } \\
\hline$=\operatorname{size}$ & & & 09 & $(0,42,0)$ \\
\hline - coniach frequency & & & 10 & $(0,9)$ \\
\hline - drinking logether & & & 1.11: & $(0913)$ \\
\hline - Meavy drinkers & & & 14 & $(0,6-2,2)$ \\
\hline - freg of drinking & & & 0.8 & $(0,1,19,3)$ \\
\hline$d$ & 3 & 4 & & 16 \\
\hline \multicolumn{5}{|l|}{ to contedily clossified } \\
\hline $\begin{array}{l}\text { (no treatment, } \\
\text { outpatients lotal) }\end{array}$ & $90,5,918,9,3$ & $881,92,6,90: 8$ & 912 & 943,932 \\
\hline $2 \mathrm{log}$ linhellooud & 2785 & 278.5 & & 2785 \\
\hline Modelchisqune & 1961 & 2047 & & 219.6 \\
\hline $\mathrm{R}^{2}$ & 0.74 & 0.77 & & 0.83 \\
\hline - Boldface odtas ratios & cant & & & \\
\hline
\end{tabular}

In the third step the variables that were considered as social resources and the interaction between age and social and health consequences were entered in the equation. The results 
indicated that the model improved slightly. Unemployed and disabled drinkers were mone likely to seek help than employed drinkers, the odds to apply fot treatment is about seven times as large for unemployed or disabled men as they are for enployed men. The association of being retired or in training with help-seeking was not significant. The high OR was based only on a few men who were retired or in training (n-11) and does not allow any conclusion. Small effects were observed for social class and level of education, but without reaching statistical significance. No effects were found for martal status and network characteristics. The interactions of age with symptoms and intoxication were not significant and left out of the model for reasons of sparsity and for clarity of interpretation. The findings suggested that the effects of social and health consequences were moderated by age. Further inspection indicated that at an older age social and health consequences were more likely to lead to help seeking. The "model chi square" indicated a high goodness-of-fit of the model and the R2 indicated a strong association between the independent variables and help-seeking.

\subsection{Discussion}

The results showed that some overlap was present in the severity of alcohol-related problems between problem drinkers in the general population and problem drinkers in treatment. Nevertheless, the two groups showed a large difference in severity of alcohol-related problems.

In the bivariate analyses it was observed that problem drinkers who did not seek help for their drinking problems were younger, more often employed, more often married, higher educated and with a higher occupational status. Furthermore, they had a larger social network and more drinking partners. However, in a multivariate analysis only symptoms of problem drinking, social and health consequences of drinking, age and employment status were associated with help-seeking. More drinking problems, older age, and unemployment were predictors of seeking help and the effect of social and health consequences was stronger at older age.

It can be concluded that, firstly, alcohol related problems were the man determinants of help-seeking. In accordance with the hypotheses, alcohol-related losses (indicated by problems with the social environment and health) were associated with help-seeking more strongly than symptoms of problem drinking and the frequency of intoxication. Secondly, as hypothesized, problem drinkers of older age and unemployed or disabled problem drinkers were more likely to seek help for alcohol-related problems. Thirdly, the hypotheses about the effects of occupational status, education, marital status and network charencteristics could not be confirmed. Unmarried problem drinkers in the lower social strata and those with a "dry" social network did not seem to apply for treatment more often. Finally, size and frequency of contact of the social network were not associated with help-seeking.

Like most other studies on help-seeking behavior need characteristics were found to be the major determinants of seeking help for drinking problems (c.g. Tucker, 1995; Weisner, 1993; Bannenberg et al, 1992; Brennan \& Moos, 1991; fitzgerald \& Mulford, 1981). The 
hypothesis that alcohol-related problems indicating losses could explain help-seeking better than symptoms of problem drinking and frequency of intoxication was confirmed. Nevertheless, symptoms of problem drinking also added to the explanation of help-seeking but not as strongly as social and health consequences. In contrast to our findings, Kaskutas et al. (1997), Weisner (1993) and Tucker \& Gladsjo (1993) found no effects of symptoms of problem drinking on help-seeking after controlling for social consequences. This suggests that it might be useful to test the loss hypothesis by means of a more comprehensive measurement of alcohol-related consequences and losses.

To a large extent our results on employment and age are in line with the results of studies such as Weisner (1993), Bannenberg et al. (1992) and Knibbe \& Meyers (1988). In our study no effect of socioeconomic status was found and this resembles the results of Weisner (1993), Fitzgerald \& Mulford (1981). The hypothesis that higher socioeconomic status facilitates the avoidance of help-seeking cannot be confirmed. Similarly, in contrast to Brennan \& Moos (1991), Bannenberg et al. (1992) and Knibbe \& Meyers (1988) but in accordance with Kaskutas et al. (1997) and Weisner (1993), no effects were found for marital status. The assumption that marriage serves as a resource to continue drinking and avoid helpseeking is probably too simple and needs further specification. Towards relevant others, the marital role might suggest that a drinker is fulfilling his role obligations, but meanwhile, the spouse could be pressing the drinker to decrease consumption or to seek help (Room, Bondy \& Ferris, 1996; Room, 1989; Knibbe \& Abbenhuis, 1991). The difference between marital status and employment status is that it is probably easier to hide one's alcohol-related problems from one's employer and colleagues than from one's spouse. In terms of losses, being unmarried indicates the lack of a resource but being married also implies a potential loss and a possible reason to seek help. In general, the possession of a resource often implies the presence of a potential loss. One might argue that collinearity between marital status with employment status or age can probably explain that marital status was not associated with help-seeking. The intercorrelations of marital status with employment status and age were significant. However, an additional multivariate analysis without age and employment status (not presented) showed that marital status did not add to the explanation of help-seeking. Moreover, among those who did not seek help married drinkers reported less social and health consequences whereas this association was not observed among those who did seek help. Consequently, it seems that marital status influences primarily alcohol-related problems without a direct effect on help-seeking.

This is one of the first studies about help-seeking for alcohol-related problems that includes structural characteristics of the social network such as network size and drinking behavior. Several other studies have emphasized the importance for help-seeking of functional characteristics, such as encouragement from network members (George \& Tucker, 1996; Room, Bondy \& Ferris, 1996: Weisner, 1990). Room (1989) concluded that most people who entered treatment were pressured by family or friends. In general, women criticized men and older generations criticized younger generations. This could not be tested explicitly in our study, but the number of network members, the contact frequency, and their drinking practices were found not to be associated with help-seeking. Nevertheless, network members may have 
influenced the decision of the problem drinker to seek help by social disapproval or social pressure.

The confimation of the hypotheses on employment and age does not, of course, prove our theoretical notions about resources facilitating the continuation of a person's drinking behavior and the avoidance of help-seeking. One could even argue that older age and the lack of employment might be indicators of severity of alcohol-related problems themselves. However, an additional analysis showed that within both categories of problem drinkers no association was observed of severity of drinking problems with employment and age. In other words, this suggests that employment and age have an effect on help-seeking independent of the severity of alcohol-related problems. The theoretical notion of resources or social capital offers an explanation for these effects.

Bannenberg et al. (1992) argue that, in treatment, unemployed problem drinkers deserve special attention compared to those that are employed. However, from the perspective of entry to treatment, problem drinkers who are employed (and those at a younger age) deserve particularly special attention because they are less likely to seek help. Our study suggests that it is inaccurate to interpret the demand for treatment as the need for treatment, as Bannenberg and colleagues do. Rather, problem drinkers that have resources that enable them to avoid help-seeking will also benefit from treatment to resolve their alcohol problem. This could probably prevent these problem drinkers becoming unemployed or losing other social resources.

One of the limitations of this study is that it is restricted to male problem drinkers. It is likely and also indicated by a few studies, that gender is important for help-seeking behavior for drinking problems (e.g. Beckman \& Amaro, 1986; Weisner, 1993). Hence, applying the conclusions of this study to women should be approached with caution. Another limitation is that the number of problem drinkers applying for treatment and those problem drinkers in the general population who overlap in the severity of their alcohol-related problems is rather small. As mentioned above, although the observed differences in severity were large they were possibly somewhat enlarged by differences in the context of the interviews between both categories of problem drinkers. As a result, the effects of the resources on help-seeking conld be stronger than suggested by the analyses. Finally, only help-seeking from professional organizations was inwestigated. No data were available for help sought or obtained from members of the social network, such as the spouse, relatives or friends, or from nonprofessional organizations such as AA.

What implications does this study have for belp-seeking and the use of treatment facilities? Firstly, it is obvious that in the Netherlands the outpatient treatment services are used by severe problem drinkers. Generally, only the most severe problem drinkers seem to apply for professional help. Secondly, among the general population of men, there is a group of problem drinkers whose severity resembles the severity of problen drinkers who apply for treatment. One might question the accessibility of treatment services if a large category of problem drinkers do not apply for treatment. Usukally, a long time elapses between the onset of drinking problems and the decision to decrease alcohol consumption or to seck help (e.g. Raat, 1987). It is likely that earlier recognition of drinking problems would prevent them getting 
worse and contribute to the effects of treatment. Thirdly, from the perspective of entry to treatment, those of younger age ( $530 / 35)$ or employed merit particular attention in terms of detecting problem drinking and secondary prevention. As an effect of their resources these categorieg are less likely to recognize themselves as problem drinkers or to be identified as such by others. However, considering the severity of their alcohol-related problems, they might benefit from treatment in the same way as older, unemployed, problem drinkers.

In this study it was suggested that, besides by severity, help-seeking for alcohol-related problems can be explained by social resources. For the individual problem drinker these resources can facilitate the continuation of drinking. The utility of the drinking habits can, together wh these resources, balance the costs of drinking. Unless the costs of these drinking problems exceed the benefits of the drinking habits the drinker will be able to postpone the decision to change his drinking behavior or to seek help (Lindenberg, 1993). In contrast to moderate or social drinkers, alcohol consumption dominates the daily life of most problem drinkerss and this probably has to be seen as a stable situation producing a certain amount of benefits. In fact, the practice of problem drinkers enduring excessive drinking suggests that a change from such drinking patterns might be extremely costly and hard to establish. A theoretical model, of which some bricks were piled in this article, may indicate which resources can be expected to influence help-seeking behavior for drinking problems.

\section{References}

Aday, L.A. A Andersen, A. (1974) A framework for the stwdy of access to medicall care. Healh Sermoes Researoh, 9. pp. $208-220$.

Amaro, H. Beckman, L... \& Mays, V.M. (1987) A comparison of black and white women entering alcoholism treatment. Joumal of Snulies on Alochol, 48 , pp. $220 \mathrm{~m} 228$.

Andersen, A. Newman, J F. (1973) Societal and individual determinants of medical care utilization in the United States. The Milbank Memorial Quaterly, 51, pp. 95-124.

Bamenberg, A.F.I, Raat, H. \& Plomp, H.N. (1992) Demand for alcohol treatment by problem drinkers. Joumal of Subrance Abuse Treatment, 9, $\mathrm{pp}, 59-62$

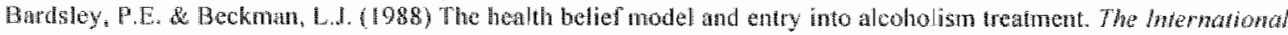
Howpral of the Adlichion, 23, pp. $19-28$

Hecker. M.M. Haefmer, D.P., Kasl, D.P., Kirscht, J.P, Mainan, L.A., Rosenstock, 1. (1977) Selected psychosocial

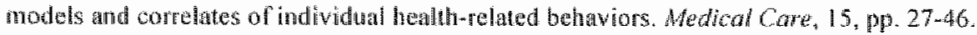

Bekman. L.d, \& Amaro. H. (1986) Personal and socinl difficulties faced by women ertering alcoholism treatment.

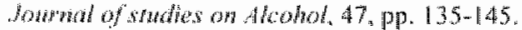

Beckman, L. \& \& Kocel, K.M. (1982) The treatment-delivery systen and alloohol abuse in women: social policy

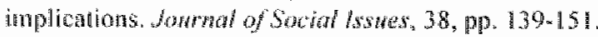

Butnan, P.L. de Moos, R.H. (1991) Functioning, life context, and help-secking anong lateonset problent drinkers:

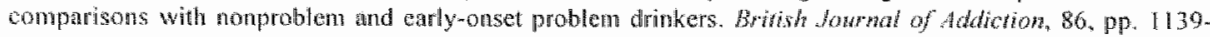
1150.

Cuncl, M., Kubbe, R.A., Zutphen, W.M. Wan, \& Drop. MJ. (1994) Problen drinkung in a general practice population: the construction of an imterval scale for the severity of problem drinking. Joumal of Sindies on Aleohot, 55, pp, 466-470.

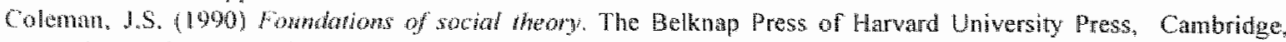
Massuchuseths, and London, Englandi.

Cumaingham., I.A.. Sobell, L.C.. Sobell, M.B., Agrawal, S. \& Toneatto. T. (1993) Barriers to treatment: why alcohol and drug abusers delay or never seek treatment Addictive Behowiow, 18, pp. 3470.353.

Fillnore, K.M. $(1987)$. Wobnons drinking across the adult life course as compared to men's. Britsh wownol of Alatidion, 82 , pp. $801-811$ 


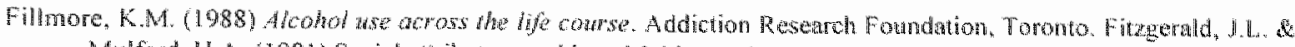

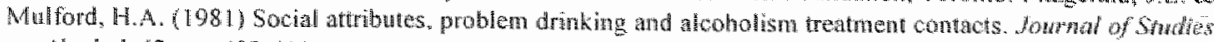
on Alcohol, 42, pp. 403-413

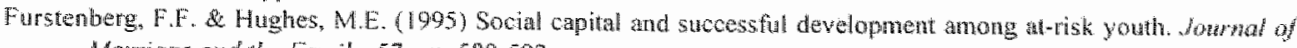
Hatringe and whe Fantly, 57 , pp. $580-592$.

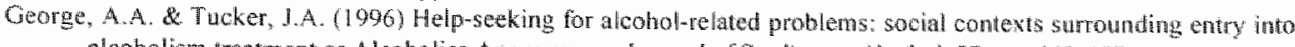

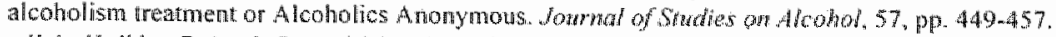

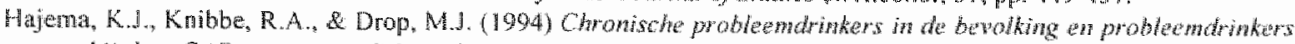
bij het CAD. een vergeljhing [Chronic problem drinkes in the general population and in treatratents a comparson]. Vakgroep Medische Sociologie, Ri.jksuniwersiteit Limburg, Masstricht.

Hajema, K.J., Knibbe, R.A., \& Drop, M.I. (1997) Changes in alcohol consumption in a general population in The Watherlands: a 9year follow-up study, Addichon, 92 , pp. 49.60 .

Hajena, K.J., Knibbe, R.A., \& Drop, M.1. (1997) Effects of dr hiking patterns and socigh conditions on incidence and chronicity of alcohol-related problems. Contempow Dryg Problens, 24, 473-511.

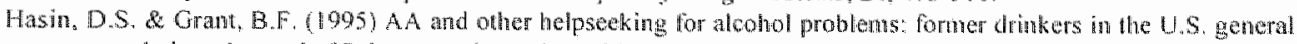
population. Foumal of Substance Abute, 7. pp. $281-292$.

Kaskutas, L.A., Weisner, C. \& Caetano, R. (1997) Predictors of help-seeking anong a longitudinal sample of the general population. Jormal of shadies on Aloohol $58, \mathrm{pp}, 155-161$.

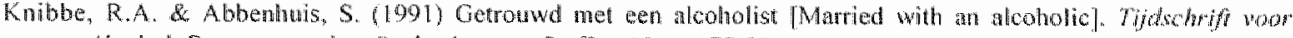
Acohol. Dragse en andere Pschychotrope Stofen, 17 , py. 77-83.

Knibbe R.A., \& Meyers J.M. (1988) Comparison of problem drinkers known to agencies with protulem arinkers in the general population. Medicine and Lan: 7, pp. $87-94$

Lindenberg, S. (1988) Contractual relations and weak solidarify: the behaional basis of restrants on gan

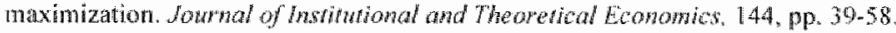

Lindenberg, S. (1993) Club hierarchie, social metering and context instruction: govenance structures in responsen to

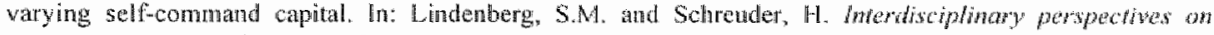
organization sudies, Pergamon Press, New York.

Makelat, K. (1991) Social and cultural preconditions of Alooholics Anonymous (A A) and factors associatiod with the strength of AA. Britis Joumal of Addichion, 86, pp. $1405-1413$.

Makela, K., Mustonen, H. (1996) The reward stucure of drinking anong yovnger and older mate atrinkers. Contemporary Drag Problems, 23, pp. 479-492.

Menard, S.W. (1995) Applied logistic regression amalysis. SAGE university papers series. Quantitative applications un the social sciences; no $07-106$, London. UK.

Pescosolido, B.A. (1992) Beyond rational choice: the social dyamics of now people seek help Aweriean forwat of Sociology, 97. pp. 1096-1138.

Raat, H. (4987) Alcoholproblemadiek ew hulpwertening [Drinking problens and belp for drinking problems]. Proefschrift, Vrije Universiteit, Amsterdam.

Room, R. (1977) Measurement and distribution of drinking paterns and problems in general populations. In: Edwands,

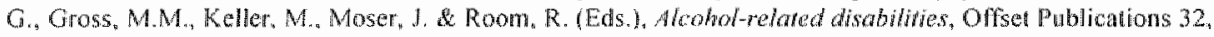
WHO, Genera.

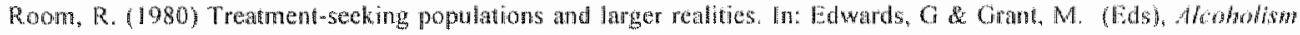

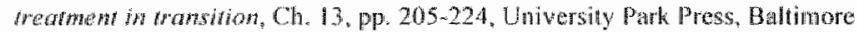

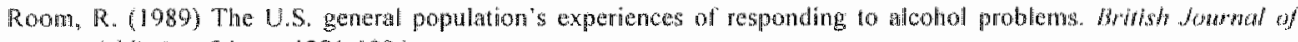
Addiction, 84, pp. $1291-1.304$.

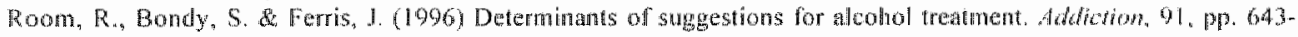
655.

Rosenstock, M. (1966) Why people use health services. Mitbowk Memoriat wat Qhathty, 44, po. 94-124.

Sobell L.C., Cunwingham, J.A., \& Sobell, M.B., (1996) Recowery hom alcohol problems with and without treatment:

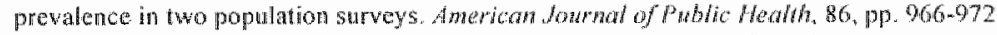

Tucker, 3.A. (1995) Predictors of help-secking and the temporal relationship of help lo recovery anong trazed and untreated recovered problen drinkers. Addiction, 90, pp. 805.809.

Thoker, A. \& Gladsjo JA. (1993) Help-secking and recovery by problem drinkers: characteristics of drinkers who

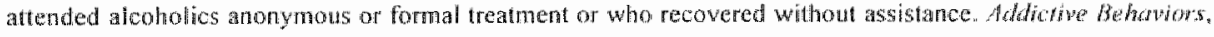
$18, p p .529-542$

Weisner, $C$. 1990) The alcohol treatment-seeking process from problems perspective responses to evonts. Brish

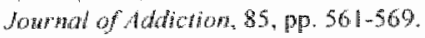

Weisner, C. (1993) Toward an alcohol treatment enty model: a comparison of problem drivere in the general

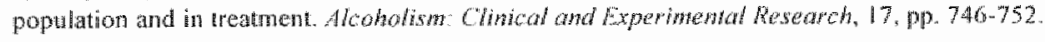




\section{Chapter 6}

\section{Conclusions and general discussion}

This dissertation is the result of a longitudinal study on drinking behavior, alcohol-related problems and help-seeking for alcohol-related problens. A panel of the general population in the province of Limburg of the Netherlands $(1980-1989, n=1327)$ is used to examine changes in drinking behavior and alcohol-related problems among 664 then and 663 women aged 1669 at first measurement. Chronic problem drinking men of the panel are compared with male outpatient clients of treatment centers in the province of Limburg (1993/94, $\mathrm{n}=129)$ to study help-seeking behavior of problem drinkers. The aim of the study is to investigate the social determination of these three phenomena. Several sociological theories are applied to explain and interpret changes in drinking behavior, the development and persistence of alcohol-related problems and help-seeking.

The three issues have been examined in four separate studies. The first study concerns the description and explanation of drinking behavior by gender and age. In chapter two both the aggregate-level changes in drinking behavior and the individual-level changes of several drinking patterns were examined. The age and gender-associated patterning of drinking behavior was examined for the incidence and chronicity of drinking (alcohol consumption or abstinence), three levels of consumption (7, 14 and 21 standard glasses weekiy) and iwo frequencies of heavy drinking (monthly and weekly 6 or more standard glasses on one occasion). In the second study it is examined whether role transitions with regarcl to marital status, employment status and parental status contribute to the explanation of changes in the level of consumption and the frequency of heavy drinking. In chapter three the effects of tols transitions were studied by comparing those who lost a role with those who kept that role and those who acquired a role with those who remained without that role.

The third study examines whether social conditions and drinking contexts (such as drinking locations and temporal aspects of drinking) add to the explanation of alcohol-related problems while level of consumption and frequency of heavy drinking are controlled for. The nature of this study is to some extent explorative. Both the incidence and chronicity of alcoholrelated problems were studied in chapter four.

In the fourth study it is examined whether alcohol-related losses and the possession or lack of social resources explain help-seeking behavior among men. Help-seeking was investigated in chapter five by comparing male problem drinkers who applied for treatment with male chronic problem drinkers in the general population. 
In this final chapter the main results of the research project will be presented and discussed. Special attention will be given to the social conditions that have been used to explain both drinking bethavior, drinking problems or help-seeking. Furthermore, some comments will be made about the social determination of the three issues of this thesis. In section 6.1.3 several methodological aspects of the study, such as the response and the validity and reliability, are discussed. Section 6.2 concerns the similarities between the results of this study and those of other studies, a discussion about the theoretical perspectives used in this thesis, and some remarkable results that deserve to be considered in more detail. In section 6.3.1. some aspects with regard to policy will be addressed. Lasty, in section 6.3 .2 a few important directions for future research will be proposed.

\subsection{Summary of the major findings}

\subsubsection{Joint results and conclusions}

The characteristics that have been used in two or more studies of the thesis are gender, age, marital status, employment and socioeconomic status. The differences between men and women were not explicitly an issue of the research project but some comments will be made. Similarly, socioeconomic status was mainly included as a control variable and will only be discussed brielly.

The main results of the four studies are summarized in table 6.1. As can be seen, a comparison of the effects of gender, age, marital status, employment status and socioeconomic status indicates that the explanatory variables of changes in alcohol consumption, changes in drinking problems and seeking help are different. The assumption that different mechanisms explain consumption, problems and help-seeking did, of course, direct the design and analyses of the three studies. However, the social characteristics as listed in table 6.1 were expected to be part of the explanation of both changes in consumption and alcohol-related problems and seeking help for these problems.

\section{Gender}

Because of the essential differences in drinking behavior, alcohol-related problems (and helpsecking) between men and women all analyses have been performed for men and women separately. The present study confimed that the results on drinking behavior and drinking problems were different according to gender. Generally, a higher proportion of men were drinkers, both quantity and frequency of drinking were higher, and a higher proportion of men had alcohol-related problems. However, the results in chapter two showed that only small differences were observed in the development of drinking behavior between men and women at the aggregate level. At the individual level the incidence and chronicity of levels of consumption and frequencies of heavy drinking were considerably higher for men. The results in chapter two and three indicated that the effects of characteristics such as age, marital status and parental status on drinking behavior, differed by gender. Firstly, age effects on incidence and chronicity of drinking patterns were stronger for women. Secondly, for men the effect of 
gaining the spouse role on consumption was moderated by age. Thirdly, in men also the effects of gaining the parental role on heavy drinking differed by age and no effect was found for consumption.

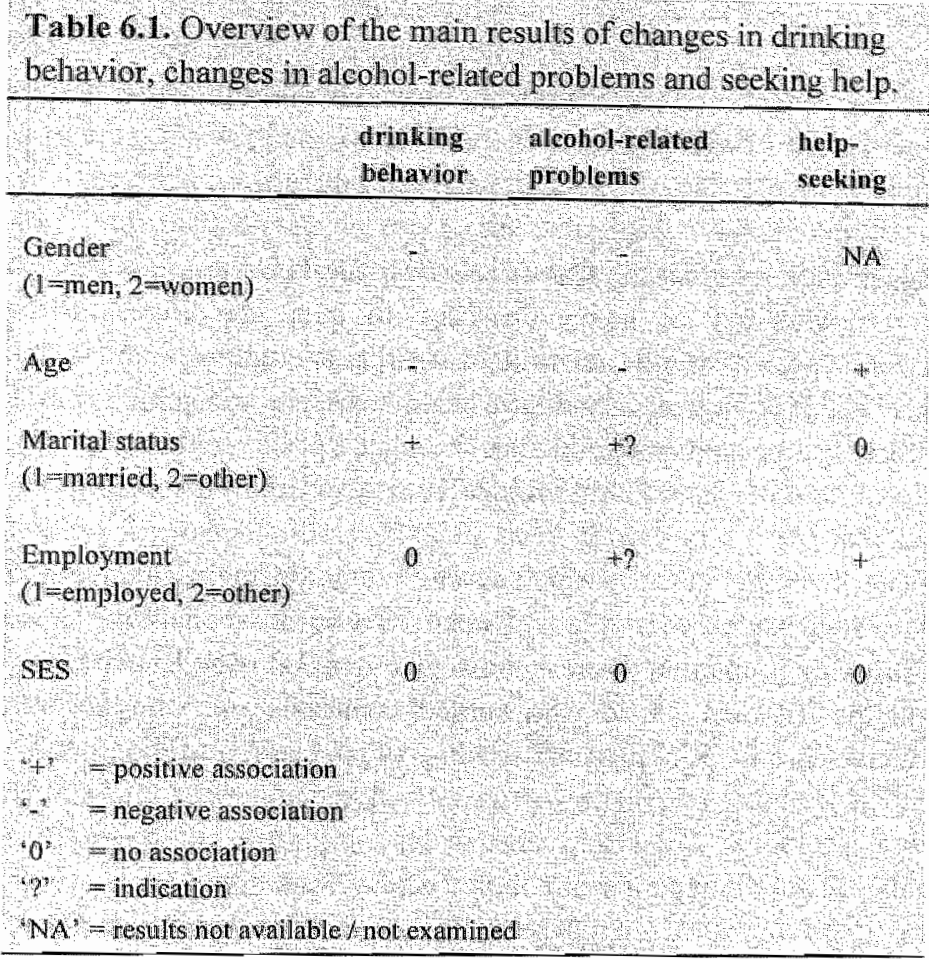

Drinking problems occurred more often in men than in women. In the study of drinking problems it was observed that both the proportions of those with chronic drinking problents and those who developed drinking problems were much higher among men. In general population studies, such as this study, only a limited number of women with chronic or severe drinking problems are detected. This is the main reason why most studies on help-seeking behavior only consider men and cannot differentiate by gender. It is obvious that the conclusions with regard to help-seeking in men are not necessarily valid for women.

\section{$A g e$}

As shown in table 6.1, age is the only factor that explained changes in drinking bethavior, changes in alcohol-related problems, as well as seeking help for drinking problems. With regard to consumption and heavy drinking the association was negative. In brief, in particular the results on incidence, those on changes in general, and to a lesser extent the results on chronicity, indicated that men and women at older age were more likely to decrease consumption or frequency of heavy drinking whereas at younger age they were more likely to 
increase consumption or heavy drinking.

Older men were less likely to show incidence or chronicity of drinking problems. Chronicity of alcohol-related problems was observed among young and middle aged women and not among older women. An erratic pattern for incidence of alcohol-related problems with age was observed among women. Finally, the effect of age was also studied with regard to help-seeking behavior among men. It was observed that older men were more likely to seek help than younger men. Moreover, it appeared that the effect of social and health consequences on help-seeking behavior was stronger at older age.

\section{Marital status}

Generally, both men and women who acquired the spouse role decreased consumption, but no effects were observed for the frequency of heavy drinking. In men, the effect of the acquirement of the spouse role differed by age. Instead of a decrease, among men in the youngest age caltegory (aged 16-19 at first measurement) an increase in consumption was observed. Women who lost their spouse role increased their frequency of heavy drinking. The loss of the spouse role had no effects on heavy drinking for both sexes and on consumption anong men.

Only weak indications were found for effects of marital status on the incidence and chronicity of alcohol-related problems. It seemed that women who started cohabiting were more likely to have chronic drinking problems, whereas those who married were less likely to have chronic drinking problems. In men, those who started cohabiting or who became divored were more likely to have chronic drinking problems.

\section{Employment status}

Only a slight indication was observed of a negative association of the loss of employment with drinking behavior, which was opposite to expected. The study of incidence and chronicity of alcohol-related problems suggested that men who became employed were more likely to show remission of problems whereas men who lost employment were less likely to show remission of drinking problems. Finally, unemployed and disabled men were nore likely to seek help for their drinking problems at an outpatient treatment center than employed men.

\section{Socioeconomic status}

With one exception, socioeconomic status was not associated with consumption, nor with drinking problems, nor with help-seeking. Among women, it was observed that those with a higher level of education increased consumption compared to those with a lower level of education.

\subsubsection{The social determination of drinking behavior, problems and seeking help}

The results of the studies on drinking behavior suggested that changes in drinking behavior can to a moderate extent be explained by gender, age and social roles. Firstly, as shown in chapter two, changes in drinking patterns differed according to age and gender. The continuation of drinking patterns was weakly associated with age and the adoption of drinking 
patterns was moderately associated with age. The differences between men and women in the adoption and continuation of drinking patterns were large. Secondly, in chapter three if was illustrated that changes in social roles did to some extent determine the development of alcohol consumption and frequency of heavy drinking. In brief, the acquirement of roles was expected to restrict drinking behavior and the loss of roles was expected to advance an increase in consumption or heavy drinking. However, the hypotheses were confirmed mainly for gaining roles and not for losing roles. Furthermore, only effects of changes in marital roles and parental roles were as expected, no effects were found for employment roles.

In chapter four the research findings suggested that both drinking contexts and social conditions added considerably to the explanation the development and persistence of alcoholrelated problems. This could be assessed for men in multivariate analyses and for women in bivariate analyses.

Finally, in chapter five it was shown that drinking problems indicating alcohol-nelated losses, were associated with help-seeking more strongly than symptoms of problem drinking and intoxication. The possession of paid employment and younger age may function as a resource and facilitate the avoidance of seeking help and the continuation one's drinking habits. In general, the results in these thesis confirmed that social conditions add to the explanation of drinking behavior, alcohol-related problems and help-seeking. However, it remains difficult to draw conclusions about the strength of the determination of the three phenomena.

\subsubsection{Methodological aspects of the study}

This study distinguishes itself from other alcohol studies of the general population in the Netherlands by a longitudinal design. In general, a longitudinal design allows conclusions about associations between variables that can be considered as a stronger indication of cause and effect than correlations in retrospective designs, surveys, trend studies or correlation studies. The same variables are used for the measurements in 1980 and 1989 . Therefore, it is not only possible to examine general changes in drinking behavior or problem drinking, but for each person the changes in drinking behavior and drinking problems can be assessed. Consequently, with panel data one obtains more extensive data about social reality. In particular, this panel study facilitates the investigation of the effects of changes in social characteristics on drinking behavior and alcohol-related problems. This is an important advantage of panel studies in comparison to surveys or trend studies.

\section{Non-response}

In general, the response in this study can be considered as quite high when compared to other general population studies in the Netherlands (e.g. Swinkels, 1991; Bongers ot al, 1997). The response at first and second measurement were $76 \%$ en $67 \%$ respectively. Nevertheless, this signifies that at second measurement only $50 \%$ of the original sample was represented. The non-response analyses in 1980 and 1989 indicate that, generally, the sample can be considered to be representative for the general population in the province of Limburg.

The main problems of the non-response in the general population study concern the 
lower response of those who divorced, started cohabiting or became widowed and of those with primary cducation only, of unskilled manual workers and small proprietors. In the clinical study, outpatient clients of the $\mathrm{CAD}$ (the nationwide Dutch treatment centers) who were hospialized, jailed, in acute crisis or who had died recently, could not be included in the sample. Therefore, probably the most severe cases of the outpatient treatment center were under-represented. Finally, it was suggested by a non-response analysis based on interviews by lelephone, that men who stopped drinking and who decreased their frequency of heawy drinking were under-represented in the panel. The non-response analysis, however, indicated that the response was not related to drinking behawior or alcohol-related problems at first measurement.

\section{Validity and reliability}

One of the most important aspects with regard to both walidity and reliability in this thesis concerns the measurement of alcohol-related problems. A problem drinking index was used to indicate the presence and magnitude of alcohol-related problems. As mentioned before, the index is a short version of the well-known problem index scale of Cahalan (Cahalan, 1970). Although a short version, it still measures a whole list of alcohol melated consequences that can be considered as problems. It includes indicators of problems in both social and personal life, such as problems with the spouse or family, work, the law, health, accidents, symptoms of problem crinking and intoxication.

The reduction of the original Cahalan-scale implies that - although the most important items were included - less persons will be classified as having allcoholrelated problems. However, it should be noted that a drinker scores on the problem index quite easily. For instance, if a person reports to be drunk once a month he or she is classified as having an alcohol-related problem. Similarly, if one reports to have experienced two symptoms during the past six months, such as drinking more as one has planned to do or skipping meals during a drinking episode, one point on the problem drinking index is scored. The scalle indicates whether one has alcohol-related problems or not, and gives an indication of the severity of the alcohol-related problems (1-8). It is an additive scale and not an interval scale, therefore, the use of the scale as a dependent variable is restricted and has not been applied in this thesis. Alhough one might argue that a drinker with two poins on the scale will be likely to have less severe problems as one with three points, this is not necessarily true for additive scales. Furilermore, the diferences in severity between the values of the scale do not have to be alike. One of the consequences is that the problem index scale cannot be used as a dependent varable in a regression analysis.

As shown in chapter fîve, most problem drinkers in a clinical population score four or more points on the index. Hence, persons in the general population who score one or two points on the index should not be labeled as having drinking problems that require professional help. It can also be argued, however, that those with less severe problems can be rreated better than those very severe problem drinkers (or alcoholics) who applied for treatment. From this perspective, problem drinkers should not wait with applying for treatment until their problems have become serious. 
Another point to be discussed with regard to the validity of the problem drinking index, is how large the differences in severity are between problem drinkers in the general population and in treament. The problem drinking index gives an indication of this difference. However, there are several arguments to assume on the one hand, that the difference is larger to some extent than as measured by the index. On the other hand, that the difference might be smaller than as indicated by the index. This measurement problem cannot be solved here, but several additional remarks can be made. Firstly, the figure in chapter five with the distribution of the scores on the problem drinking index demonstrated an obvious ceiling effect for the problem drinkers who applied for treatment. As can be seen in chapter five, the modus of the index was the highest score on the index. Therefore, it seems that with more items to indicate alcoholrelated problems the problem drinkers with a high score would have obtained an even higher score. Nevertheless, one may doubt whether this would have influenced the difference between the most severe problem drinkers in the general population and the least severe outpatient clients. Part of this problem has been addressed in the study of help-seeking behavior by the construction of scales without a reduction of the total number of problems that were reported.

Secondly, there is a significant difference in interview context. In particular, the score on the problem drinking index in the general population could be too low because of underreporting. Those who applied for treatment were selected because they sought help and will probably be less likely to pretend that they have no problems or only minon problems. Accordingly, the difference between problem drinkers in the general population and the outpatient clients could be smaller. Even if - because of the ceiling effect - the problems of some outpatient clients are more severe as indicated by the index, there may be more overlap between both categories than as indicated by the problem drinking index.

\section{Problems of collinearity and linearity}

The independent variables that are used in this study, such as marital status, employment and parenthood, are linked with each other and linked with age. Therefore, in the final analyses of the three topics of this dissertation the social characteristics were included simultaneously with age. To prevent false conclusions about one of these characteristics, the andlyses in chapter three were also performed without the variable that probably causes collinearity (e.g. chp. 3, p. 53). In addition, the bivariate analyses and statistical tests give some indication of possible problems with collinearity. However, it always remains a problem to be aware of. Because of the attention rendered to this issue the results and conclusions in this thesis are likely not to be biased by collinearity.

In the studies of the effects of social roles on drinking bethavior, the incidence and chromicity of alcohol-related problems and help-seeking behavior of problem drinkers, the effect of age is assumed to be dinear. Although this is a quite common appraach in many alcohol studies, there are numerous studies suggesting that the effects of age are not linear (e.g. Filmore, 1987a,b: Neve et al., 1991), including the study in this thesis presented in chapter two. However, it is assumed that the inclusion of role transitions - that are associated with age and make up the life course - allows an interpretation of the effect of age in terms of linearity; or at least in terms of younger drinkers compared to older drinkers. 


\subsection{Discussilon}

In this section several points of discussion will be put forward. Both empirical correspondence with other studies and some theoretical aspects of the outcomes will be discussed. Some important points that are already discussed in the preceding chapters need some additional discussion. Moreover, a few new points will be elaborated, such as the difference in the agerelated pattern between incidence and chronicity, some alternative explanations for the limited influence of changes in social roles on drinking behavior, the causality of the associations, the usefulness of the results on drinking problems at the collective level for prediction at the individual level, and, finally, a discussion and comparison of the effects of gender, age, marital status, employment status and socioeconomic status on drinking behavior, alcohol-related problems and help-seeking.

\subsubsection{Drinking behawior}

\section{The influence of gender and age}

In chapter two the main conclusion was that effects of age on drinking behavior were stronger among women, and stronger for incidence than for chronicity of drinking patterns. In general, there is a large difference between men and women with regard to alcohol consumption in daily life. Although it can be considered an ex-post facto explanation and ad hoc interpretation afterwards: this might be an important aspect for the explanation of the differences in the agerelated patterning of drinking behavior between men and women. The age effect among women may be stronger because alcohol consumption is a less important aspect of the lifestyles of women. Therefore, it is probably easier for women to drop a drinking habit and thus larger differences may evolve between age groups.

The conclusions about age and drinking behavior match to a moderate extent the results on incidence and chronicity of Fillmore $(1987 \mathrm{a}, \mathrm{b})$. In particular, the patterns with regard to incidence of drinking/abstaining and heavy drinking, were found to differ between the US and the Netherlands. In contrast to Fillmore, a strong association between age and incidence was observed in the Dutch research project. Fillmore, however, measured the incidence of several frequencies of drinking and not quantities. The difference between Fillmore"s studies and the present study have to be seen both as different findings (for levels of consumption versus frequency of drinking weekly or daily) and as contrasting findings (for drinking/abstaining and frequency of heavy drinking).

Many studies in the alcohol research field focus specifically on one of both sexes or differentrate their study by gender. It is observed that in most societies essential differences exist between men and women with regard to drinking behavior, the occurrence of problems and seeking help. Nevertheless, it is disturbing that only a few alcohol studies are concerned with a theoretical apptoach of gender differences. In fact, also in this study gender differences are expected anyway and therefore the analyses of men and women were performed separately. Positive exceptions to this empirical approach are, for instance, Johnson (1982) and Gadourek (1963). According to the latter, drinking helps to establish the male role and, therefore, men 
are expected to drink more.

It should be noted, however, that since the 1970 s a lot of theorizing and research has been done specifically on drinking behavior of women (e.g. Beckman, 1975; Wilsnack 2 Cheloha, 1987; Gomberg, 1991; Lammers, 1995; Galantar, 1995). A related issue is whether differences between women and men change over the years and which mechanisms can explain these developments. For instance, Never et al (1996) studied whether the emancipation of women leads to a decrease of gender differences in drinking behavior. In general, they found only little support for the "convergence hypothesis'.

One of the questions that may rise out of the results of this thesis is why the negative association of age is stronger with incidence than with chronicity. Generally, it is probably easier to continue a drinking habit than to start a drinking habit. $A$ hint for an explanation of this phenomenon can be found by Becker (1992). According to Becker, both habitual and addictive drinking behavior are determined by the positive association between past and present consumption. The onset of drinking cannot be explained by past consumption. However, the expected social approval of relevant others, for instance, may stimulate an abstainer to start consuming alcoholic beverages. Once alcohol consumption has started, the positive consequences of drinking may evoke subsequent consumption and the development of a drinking habit. The longer it takes to become a drinker, the less likely it will happen in the future. Stopping with drinking may imply the decrease of certain negative consequences of drinking but also the positive consequences will be lost. Therefore, once certain drinking pattems are adopted they are likely to exist for a long time. Probabjy, the loss of roles that are associated with the entrance of typical drinking situations outdoors, the lower bodily tolerance of alcohol and health-related reasons, may be an explanation of the decrease in chronicity among the elderly. All in all, this suggests that there are several reasons why, in general, drinkers are more likely to continue a certain drinking patten than to take up a new drinking pattern and that the association of age with incidence is stronger than with chronicity.

\section{The influence of role transitions}

One of the important results to be discussed concerns the difference in effect on drinking behavior of respectively marital status, parental and employment status. In this thesis the effects of gaining and losing roles on drinking behavior were examined. As mentioned above, only the acquirement of the spouse and parental role inlluenced drinking behavior. Neither gaining the employment role, nor losing the employtment role was associated with changes in drinking behavior.

The results of the effects of role transitions on drinking behavior are to a large extent in accordance with the results of the meta-analysis of Temple et al (1991). They found that compared to remaining unmarried beconing married predicted a decrease in consumption for men and women. ${ }^{3}$ Among women, the meta-analysis showed an increase in consumption for those who lost the spouse role. A similar effect in this thesis was observed with regard to

Temple et al. compared the acquirement of the spousc role only wh having the spouse rote at both measurements. However, the results indicated that both men and women who ganed the spouse roll decreased quantity of Hpical consumption compared to those remaining withou the spouse role. 
heavy drinking, but not for consumption. In the meta-analysis no effects were observed for shifis in employment roles, with the exception of an increase in consumption for older men who became employed. The latter result with respect to employment was not confirmed in this thesis. Howewer, it was confrmed that the other transitions of employment roles were not associated with changes in drinking behavior.

The few results in the alcohol research literature with regard to acquiring the parental role were not very convincing (Power \& Estaugh, 1990; Darrow et al, 1992). However, another indication of a possible effect of playing the parental role was found in the study of Gruenewald et al. (1995). In their study the number of children in the household was negatively associated with total consumption, frequency of drinking and with the number of drinks per occasion. The present study indicated that the gain of the parental role led to a decrease of consumption and heavy drinking in women. Among men, a decrease in the frequency of heavy drinking was observed in the younger age categories, only a weak indication in the expected direction was found for consumption. In the literature no studies were found that examined the effects of the loss of the parental role. As shown in chapter three, no influence of this role transition was observed on drinking behavior.

The hypotheses with regard to the effects of role transitions on drinking behavior were contirmed to a limited extent. Therefore, it was concluded in chapter three that the effects of these role transitions on drinking behavior are largely heterogeneous. The rejection of most hypotheses implied that the role theory as used in this thesis cannot explain drinking behavior. It was expected that role expectations determine behavior of those who play the roles. The rejection of the hypotheses suggests that role expectations cannot be considered as strong determinants of drinking behavior. There are several options to handle this theoretical problem. Firstly, as a defense of role theory one might argue that role theory might be valid but only the hypothesized role expectations are different and should be formulated accordingly. Moreover, one might argue that other roles should be taken into account. Therefore, it is probably useful to try to improve role theory and to test this further developed theory.

Secondly, an ad hoc explanation would be to assert that the effects of role transitions cannot be determined while there are so many other factors that influence one's drinking behavior. At least two assumptions may lie behind this line of reasoning. On the one hand, it is presumed that social structure has an effect on drinking behavior but which aspects of social structure is unknown, or barely knowm. Notwithstanding the rejection of most hypotheses, this thesis confirms that roles such as gender, age and marital status and parental status do explain drinking behavior. In contrast to expected, however, employment roles and the loss of marital and parental roles could hardly explain changes in drinking behavior. On the other hand, one might suppose that social structure has just a very small effect on drinking behavior and that drinking behavior is mostly determined by other factors, such as personal characteristics or indiviclual appetites. Gender, age and the gaining of the spouse and parental role did influence changes in drinking behavior but the effects were not very strong. In other words, social structure determines drinking behavior to a certain extent, the effect of role transitions was 
only not as straightforward as expected.

Thirdly, it is proposed in chapter three to use the insights of role theory about social roles and drinking behavior in a more general rational choice framework. Because of several critical problems with role theory (see chapter one and three), it is not proposed to improve role theory but to use the theoretical notions of this theory in a more general theory. Collective aspects of drinking behavior have to be seen as the aggregate outcome of individuals weighing the expected positive and negatiye consequences of drinking. Another point - not mentioned before - is that it will be difficult to formulate all aspects of social structure that may influence drinking behavior in terms of roles, such as income or the influence of relevant others in the social network. Nevertheless, the analyses of roles in alcohol research may indicate which particular aspects of roles are important. This study, for instance, suggested that gaining roles and not losing roles can be considered as role transitions that influence drinking behavior. The effect of gaining these roles may imply that it is less rewarding to enter typical drinking situations and that consumption in drinking situations itself is less rewarding. In other words, roles like the spouse role and parental role function as restrictions on drinking behavior. The loss of these roles leads to a relieve from these restrictions, but does not generate an increase in consumption. If there is no stimulus directed at the individual to increase consumption in the usual drinking situations or to enter other drinking situations, than drinking patterns are not likely to change.

If such a framework is elaborated into a comprehensive theory it might prove to be useful in the study of drinking behavior as social behavior. It is not considered as a specific goal of the research project of this dissertation to built this theory. However, the results of this study and the explanations that are offered for these results give an indication of a possible fruitful direction of such a theory.

As mentioned above, transitions with regard to paid employment were not associated with changes in consumption or frequency of heavy drinking. The outcome does not imply that employment in general does not influence drinking behavior. Other studies suggested that not whether one has paid employment but the different occupations of those who are employed influence drinking behavior. Some occupational groups can be characterized by particular drinking habits or drinking cultures, such as in the building industry, at the port. the military, between business people, public servants or administrators (Sonnenstuhl \& Trice, 1991). Persons working in these areas might enter siduations in which drinking is considered as appropriate, during working hours or after working hours and to establish rewarding social relations.

A final point to discuss with regard to drinking behavior concerns the causality of the associations. In this longitudinal study it was examined whether changes in roles influenced drinking behavior. However, cause and effect can be the other way round: possibly, changes in drinking behavior influence the entrance to roles. For instance, those who lose a role or remain without a role may be characterized by heavy drinking at first measurement. However, only some of the differences between those categories were significant. It was found that men and women with a low level of consumption and a low frequency of heavy drinking lost 
employment more often. Therefore, consumption and frequency of heavy drinking did not seem to influence selection with regard to employment in a negative way. Additionally, those with a lower frequency of heavy drinking were more likely to lose their parental role, women with a low level of consumption and low frequency of heavy drinking were more likely to become parent. With regard to marital status, the study at the aggregate level of Magura \& Shapiro (1988) supported the perspective that role transitions influence drinking and not that drinking influences role transitions. Whether divorce or the loss of the marital role in general, influences drinking behavior remains doubtfil. In the present study such an association was not found and in the meta-analysis of Temple et al (1991) this was confimed for young women only. It is clear, however, that the 'selection hypothesis' cannot be ruled out completely. The results in chapter four suggested that those who lost their spouse role had a higher frequency of heavy drinking than those who kept their spouse role (ns).

\subsubsection{Alcohol-related problems}

\section{Drinting contexts and alcohol-related problems}

In chapter four it was concluded that, besides volume of consumption and frequency of heavy drinking, drinking contexts and social conditions added to the explanation of the incidence and chronicity of drinking problems. There are several reasons why drinking contexts might be related to the occurrence and persistence of alcohol-related problems. However, extensive research on this topic started only recently (see Rehm et al, 1996 and the special editions of Addiction and Contemporary Drug Problems about this issue) and the effects of drinking patterns on alcohol-related problems are subject to discussion both theoretically and empirically.

In the exploration of the influence of drinking contexts on alcohol-related problems several associations between drinking contexts and drinking problems were suggested in this thesis. For men, these relationships were independent of consumption, frequency of heavy drinking and several social characteristics. For women, due to the relative small number of cases, only a bivariate analysis was applied. Women who increased the frequency of drinking in the aftemoon and in the evening were more likely to have chronic alcohol-related problems. Furthermore, besides consumption, the frequencies of drinking at home, on licensed premises (such as in bar, restaurants, discotheques, clubs, or sports clubs), in the afternoon, at dinner and in the evening were positively associated with the development of alcohol-related problems. It is not likely that all these drinking contexts will remain significant in at muhtivariate design. Generally, a higher frequency of drinking causes a higher level of consumption and frequency of heavy drinking and both these aspects of drinking behavior are likely to be the major determinants of alcohol-related problems.

For men, the incidence and chronicity of alcohol-related problems were examined with a multivariate logistic regression analysis. Men with a high frequency of drinking at other's homes were less likely to show chronicity of alcohol-related problems. Those with a high frequency of drinking in the afternoon were more likely to have chronic drinking problems. Together with the effects of consumption and heavy drinking, the probability to dewelop drinking problems was higher for men with a high frequency of drinking in the afternoon. 
Among men with a high frequency of drinking at dinner and in the evening, the probability to develop problems was lower.

Several studies confirmed that drinking patterns other than volume of consumption added to the explanation of drinking problems (Gruenewald, Mitchell \& Treno, 1996; Dawson, 1996; Walsh \& Rehm, 1996; Single \& Wortly, 1993). Every drinking occasion contains a risk of experiencing alcohol-related problems. But given a certain quantity of consumption, drinking daily was found to lead to less alcohol-related harm than drinking only a few tines a week. It seems that a high frequency of drinking only a few glasses produces less social harm. (such as contacts with the police, or with respect to perceived health, work, home life or finances) than a lower frequency of drinking more than one or two glasses (Walsh \& Rehm, 1996). It was shown that, besides volume and frequencies of consumption, in particular variations in drinking were important (Gruenewald, 1996). Drinkers of older age categories do often have a higher frequency of drinking but lower quantities on each occasion (Fillmore et al, 1991)

This thesis is one of the first studies in which the influence of the frequency of drinking at different moments of the day were examined. Dawson (1996) found that early and late-night drinking is associated with social consequences of drinking. Both studies suggested that temporal drinking patterns differed in the probability to cause drinking problems and, therefore, constituted an additional part of the explanation the incidence and persistence of alcohol-related problems.

In general, the effects of drinking contexts were interpreted in two ways. Firstly, drinking contexts imply differences in the probability to create problems. Secondly, drinking contexts can be considered as attributes of lifestyles which influence the vulnerability for drinking problems of those who possess and exhibit these styles of life. According to Knibbe, Drop \& Muytjens (1987), in particular status roles such as gender, age, ethnicity, social class and religion define values about how to live. These roles are expected to facilitate the integration of a wide diversity of behavior within a more or less unified lifestyle. It seems that on the one hand certain drinking contexts may indicate a situation in which drinking is not considered as appropriate. These drinking contexts are incompatible with the lifestyle of a drinker and generate problems. On the other hand, the drimking contexts as such may be part of a lifestyle with a higher risk for alcohol-related problems.

Drinking in the afternoon may not cause problems and drinking at dinner does not protect from getting problems. These drinking pattems are probably indicators of other aspects of drinking behavior. Drinking in the afternoon is not common in the general population and could be a indicator of a lifestyle characterized by drinking in contexts in which most others do not drink. Therefore, they are more likely to be criticized on their drinking behavior. Another plausible interpretation is that drinking in the afternoon is an indicator of drinking. behavior that is not being measured by weekly consumption or frequency of heavy drinking. In addition, drinking in the afternoon may be an indicator of the start of an occasional excessive drinking day. The more daily life is ruled by drinking the more likely one will develop drinking problems or continue to have drinking problems.

Drinking at dinner may be an indicator of a lifestyle characterized by controlled drinking 
(such as only at specific occasions) or by drinking in situations that are thought to be appropriate. Therefore, those who frequently drink at meals may be less likely to develop problems. Drinking at dinner can be considered as an indicator of less-hazardous drinking behavior. It should be noted that an altemative explanation for the effect of drinking at dinner is that the physical consequences of alcohol consumption during meals is smaller.

A comparable interpretation with regard to lifestyle is probably valid for the negative association of drinking at other"s homes and the chronicity of alcohol-related problems. These situations are a quality of social drinking that are likely to be accompanied by a lower chance on drinking problems. In fact, it is obvious that the drinking location might influence the probability to generate drinking problems. For instance, after drinking on licensed premises one might take the risk to drive home while intoxicated. On the other hand, in some drinking cultures drinking on licensed premises may be an indicator of a deviant drinking style, for instance, of occasional heavy drinking. Stockwell, Lang \& Rydon (1993) suggested that the risk associated with drinking on licensed premises is probably caused by the type of drinkers who choose to drink on licensed premises and not by drinking in bars, taverns, etc., itself. In this thesis, only amall indication was observed for an effect of drinking on licensed premises on alcohol-related problems. It seems that for the Nethertands drinking in bars cannot be considered to be part of a deviant form of drinking behavior. Besides, compared to the other provinces in the Netherlands, the density of licensed premises in Limburg is high. Hence, drinking on licensed premises is even less likely to be a deviant form of behavior in the province of Limburg than in the rest of the country.

\section{Social characteristics and alcohol-related problems}

The effects of age on alcohol-related problems in this theses can be compared with the results of a similar study about the chronicity and incidence of problems (Fillmore (1987a,b). For both sexes, the patterns for chronicity of problems were about the same: chronicity is highest at middle age and lowest at older age (see also Fillmore \& Midanik, 1984). These age differences in this thesis, however, were rather small and not significant. It seems that for the Netherlands, the conclusion that chronicily is higher at middle age (that is, spontaneous remission is thigher at younger age) cannot be confirmed.

Both in the present study and in Fillmore's (1987a,b), a strong association between incidence and age was observed. The results in this thesis indicated that the assumption that chronicity is lower at younger age than at middle age (Fillmore, 1987a) is not necessarily valid. In addition, differences in drinking problems between age categories can to a large extent be explained by differences in incidence between age groups.

Several sudies suggested that married drinkers are less likely to have alcohol-related problems (e.g. Brennan \& Moos, 1991; Wilsnack \& Cheloha, 1987; Knibbe et al, 1987; Johnson, 1982). Others (Utilton, 1987) stressed that the influence of marital status and other demographic characters is only very small and unimportant. In chapter four it was shown that, compared to those married at both measurements, men who started cohabiting or who divorced. were more likely to keep drinking problems. Similarly, employment status was reported to be associated with alcohol-related problems. Generally, men with paid employment were having 
less alcohol-related problems (Crawtord et al, 1987; Lahelma, Kangas \& Manderbacka, 1995). Women, however, were more likely to have drinking problems when they were employed (Lahelma, et al, 1995). The results of this dissertation suggested that among men the transition to employment increased the probability to show remission of problems.

This study and other studies showed that social characteristics, such as gender, age, are associated with alcohol-related problems. However, an association is only a description and not an explanation of the occurrence and persistence of alcohol-related problems of alcohol consumers. The reward structure of drinking was considered an important link between social structure and the incidence and chronicity of alcohol-related problems among drinkers. In an interesting and important study it is proposed by Majkelä \& Mustonen (1996) to take notice of the positive consequences of alcohol consumption (see also Hauge \& Irgens-Jensen, 1990). To obtain a proper estimate of the reward structure of drinking one should think of both negative and positive consequences of drinking behavior. The reward structure of drinking was found to differ according to age. However, it can be assumed that the reward structure of drinking not only differs according to drinking career or age, but also according to (other) social characteristics. The social characteristics of an individual, such as social roles, influence the appropriateness and restrictions of alcohol consumption and, therefore, influence the reward structure of an individual drinking pattern. Mäkelä \& Mustonen explicitly measured the reward structure but state that the utility or disutility of each consequence cannot be determined. Besides, the 18 items indicating negative consequences and the eight items indicating positive consequences are only an arbitrary selection of the possible benefits and costs of alcohol consumption (Mäkelä \& Mustonen, 1996:481). One of the major points of their study is that they showed that a reward structure cannot only be assumed to exist but can also be measured.

In this thesis it is assumed that individual drinkers have a certain reward structure that is determined by the positive and negative consequences of drinking. With this plausible assumption systematic differences in drinking behavior and problems at the collective level can be explained. It is not assumed that, for instance, at an older age one always experiences less positive consequences of drinking than at younger age. It is taken into account that categorical or collective differences are the result of individual action. Individuals make choices with regard to alcohol consumption based on the expected outcome of positive and negative consequences and try to make the best of it, or in other words, they aim to maximize utility. The effect of age is to a large extent defined culturally, at another place or at another time, the influence of age on the reward structure may be different.

It should be noted that the variables that proof to be important at the aggregate level are not very good predictors of behavior at the individual level. The concept reward structure is used to gain more depth in explanations of collective phenomena and not to explain individual behavior. The explanation of individual consumption or problems would require much more detailed information. Consequently, the prediction of individual consumption or drinking problems by some social characteristics would be an unreliable and uncertain step. This point of view differs from the point of view of White (1991), as presented in an overview of 
sociological theories on the etiology of alcoholism. According to white, '... the development of a theory that explains a group's use of alcohol or rate of alcoholism can be useful in predicting the probabilty of individual drinking problems" (White, 1991:205). In other words, White stresses the usefulness of a theory that was developed to explain collective behavior to predict individual bethavior. However, such theories explain a pattern in the total population but considerable differences will be found between individual drinkers. Therefore, such a theory is incomplete and it should be emphasized that a prediction at the individual level is too uncertain to allow any individual judgements. It seems, at least, that the usefulness of these probabilities at the individual level is limited.

\subsubsection{Help-seeking}

The investigation of help-seeking behavior in this thesis was focused primarily on the helpsecker applying for treatment at a local center of the national organization for outpatient treatment. The Consultation Bureaus for Alcohol and Drug Problems (CAD's) is the organization in the Dutch health care system that is to provide treatment for alloohol and other substance abusers. The so-called "treatment delivery system" or, in other words, the supplysidle of treatment was not an issue in this project and taken for granted.

The supply-side of treatment is straightforward in the Netherlands. In general, other parts of the health-care system refer persons with alcohol, drug or other addictive problems, to the CAD's. Private treatment centers and self-help groups, such as $\mathrm{AA}$, serve only a small part of the problem drinkers and alcoholics in the Netherlands. The CAD's are financed by the national and local government and changes in government policies are likely to influence their fields of activity and probably the availability of treatment for drinking problems. It remains difficult to obtain a complete impression of possible effects of the changes in the supply-side of alcohol treatment. However, it is clear that substance abuse other than alcohol consumption has received relatively more attention during the past years.

\section{Help-seeking explained by losses and resources}

As was demonstrated in chapter five, alcohol-related problems that can be considered as an indication of (potential) losses, are associated with help-seeking more strongly than symptoms of problem drinking and the frequency of intoxication. These results resembled those results of the general population study of Kaskutas (1997) who found an effect of social consequences but not of dependence-related symptoms on seeking help. Similarly, studies such as Weisner (1993) and Brennan \& Moos (1991) found no effect or a smaller effect of dependence symptoms and physical symptoms on help-seeking behavior.

Furthermore, men at a younger age and employed men were less likely to seek help. It seems, however, that the results of age on help-seeking differ between cultures. In Weisner (1993) the effect of age was confirmed for men, not for women. Kaskutas (1997) found that at younger age problem drinkers were more likely to seek help, whereas Hasin \& Grant (1995) found no effect of age on help-seeking. Studies in the Nethertands (Knibbe \& Meyers, 1988; Bannenberg, Raat \& Plomp, 1992; Bongers, Garretsen \& Van Oers, 1997) were in line with the results of this study. If the review of the literature is about complete, a striking observation 
is that quantitative, general population studies on help-seeking for alcohol-retated problems are conducted mainly in the US, Canada, and the Netherlands. Due to the strict laws and public opinion on drinking of young adults and adolescents in the US and Canada, young problem drinkers in these countries will probably be more likely to seek help.

Several studies, including the present study, suggested that those without paid employment were more likely to seek help (Bamenberg et al, 1992; Weisner, 1993; Bongers et al. 1997). In terms of Weisner, employment has to be considered as an enabling factor with regard to help-seeking and age as an individual predisposing factor. In this thesis, however, it was hypothesized that both employment and younger age could be considered as resources that facilitated the avoidance of help-seeking and the continuation of drinking. These resources are not just a property of the individual actor but a result of the structure of the relation of the actor with relevant others. Consequently, such resources can be considered as a form of social capital. With regard to employment, those who (still) have a job can maintain more easily than unemployed men that they do not have a drinking problem or only a minor problem. The fact that they have a job suggests that they are fulfilling the obligations with regard to employment. Therefore, employment can be regarded as a social-structural resource to carry on with the drinking pattern that causes problems.

At high levels of comsumption men at a younger age experience more positive and less negative consequences of drinking than men at an older age (Mäkels \& Mustonen, 1996). This pattern between age, consumption and consequences was found to be present in four Scandinavian countries. Age influenced the consequences of drinking behavior and younger age categories had an advantage compared to older age categories. Younger age categories were found to be less likely to seek help. The results support the assumption that age operates as a form of social capital with regard to continuing drinking behavior. Socioeconomic status, being married and a 'wet' social network did not operate as resources that facilitated the avoidance of seeking hellp. As mentioned in chapter five, the results regarding age and employment does not prove the theory that those with more social capital can avoid to seek help and continue their drinking behavior. It is an attempt, however, to apply this theory on help-seeking behavior and the empirical restlls do not require the rejection of this explanation.

One might object against the notion of social capital that unemploymen and older age of drinkers are probably indicators of the severity of problem drinking. Unemployment could be caused by drinking behavior and older age implies a higher probability of a longer drinking. career. Accordingly, the effect of paid employment and younger age may be induced by the less severe condition of these problem drinkers. However, both employment and age added to the explanation of help-seeking after the inclusion of measures of alcohol-related problems that included, for instance, health problems and problems with employment such as the loss or almost the loss of a job caused by drinking. The measurement of alcohol-related problems contained a selection of the problems that occur most often. Therefore, it cannot be ruled out entirely that in particular older age should be seen as an indicator of severity and not as a lack of resources. 


\section{A new perspective on thelp-seeking and changing drinking behavior}

An important aspect of help-seeking for alcohol-related problems is that the problems arise from behavior that is accompanied by positive consequences. In that sense, help-seeking for an addictive and troublesome habit seems to differ from help-seeking for an illness. The positive consequences of drinking are likely to be an important factor in the possibility to keep postponing the decision to decrease consumption or to seek help. The theory of framing offers some interesting perspectives on addiction and the deferment of changing one"s drinking behavior (Lindenberg, 1993).

The theory of framing is embedded in a rational choice framework. It is assumed that people can hawe several potential goals while they are making decisions. One of these goals is the most salient goal and structures (frames) the situation and this goal provides the criteria for the ordering and choice between alternatives. The goal that produces the greatest utility will be the goal that is most likely to stucture the sitwation. The differences between the goals can be translated into choice probabilities with which the alternatives are chosen.

In this framing theory problem drinking can be considered as a problem of selfcommand. Problem drinkers are myopic or nearsighted with regard to negative consequences of alcohol consumption. In Hajema, Knibbe \& Drop (1994) it was put forward that it is possible to postpone the decision to seek treatment until further delay will lead to imminent loss. Probably, one has the intention to seek help but this intention was also present at the moment that it was decided not to seek help. The most important goal may be the avolidance of drinking problems or the moderation of drinking behavior. If one comes into a typical drinking situation a frame switch may occur: the direct positive consequences cause that the salient goal is displaced by a minor goal, such as joining friends with drinking and having a good time. Consequently, the decision to temper drinking is postponed. According to Lindenberg (1993), the skill to handle problems like procrastination - postponing something while realizing that it should be done - and addiction, is self-command capital. Due to the time difference in positive and negative consequences, the postponing of the decision to change in drinking behavior or to seek help can be understood as rational behavior.

\subsubsection{Generalizing across consumption, problems and seeking help}

Although each of the three subjects in this thesis has a specific research question and explanation it probably yields an additional insight to discuss the similarities and differences of the effects of social structure on consumption, problems and seeking help. Similar as in section 6.1 .1 , these characteristics are gender, age, marital status, employment status and socioeconomic status.

The results in chapters two, three and four suggest that gender can be considered to be one of the major explanations of changes in consumption and alcohol-related problems. Generally, the patterns of consumption and alcohol-related problems that were studied are on the one hand more chronic and on the other hand more likely to develop among men. It was not investigated, however, whether the effect of gender on alcohol-related problems is caused by drinking behavior or that also a direct effect of gender on alcohol-related problems can be found. Whilst women in general drink less, it seems plausible that at a similar high level of 
consumption women will develop more drinking problems than men. For instance, women will be more likely to experience health problems. Men, however, will probably be more likely to take risks after drinking and, therefore, this part of the male population may be nore likely to develop problems than women.

The associations of age with drinking and alcohol-related problems were negative. Increases in consumption and drinking problems were observed at younger age and deereases in consumption and drinking problems were observed at older age. In contrast, the association of help-seeking with age was positive. These findings seem to suggest that many drinkers are likely to decrease consumption at older age and to recover from their drinking problems. Those who continue to drink and who keep alcohol-related problems will be the drinkers who finally seek help.

Marriage led to a decrease in consumption, so it seems that gaining a spouse puts restrictions on drinking behavior. Weak and no effects were found between marital status and, respectively, drinking problems among men and women and help-seeking among men. An explanation of the minor influence of marital status on drinking problems and seeking help is that the consequences of marital status are diverse. Possibly, those without a spouse may be more likely to be criticized on their drinking than those with a spouse. At the same time, the spouse himself/herself (but in particularly women) is an important critic so those (men) with a spouse might get problems because of drinking and to seek help (e.g. Room, 1989; Knibbe \& Abbenhuis, 1991).

The effect of employment status on help-seeking behavior was clear, for incidence and chronicity of alcohol-related problems only a weak effect was observed and hardly any effect was observed on changes in drinking behavior. In other words, in particular the effects of employment on help-seeking were homogeneous, the effects on drinking behavior and to a lesser extent also on alcohol-related problems were heterogeneous. Changes in employment roles cannot explain changes in drinking behavior or drinking problems.

Socioeconomic status may be associated with the development and distribution of new drinking habits (Hupkens, Knibbe \& Drop, 1993; Knibbe, Drop \& Hupkens, 1996). In this thesis, however, socioeconomic status was not associated with changes in volume of consumption or frequency of heavy drinking, neither with changes in alcohol-related problems and seeking help.

\subsection{Concluding remarks}

In the final section of this dissertation a few comments will be given on possible implications of the results with regard to policy and directions of important future research. One can al ways speculate about alcohol policy, however, in this section the suggestions of policy implications will be restricted solely to the results of the four studies of this thesis. Can the results be translated into implications for policy anyway? The main aspects of this study that are indicative for policy will be discussed for drinking behavior, alcohol-related problems and help-seeking respectively. 
Evertually, the most important aspects of alcohol research that could not be fully addressed in this thesis are considered to be the issues regarding the social network of drinkers, the influence of drinking contexts and the theoretical emptiness of most alcohol sudies.

\subsubsection{Policy appects}

The selection of social characteristics in this thesis concems attributes of individuals that can hardly be moderated or controlled by pollicy, such as social roles and age. For this reason, the results in this thesis facilitate particularly the indication of risk groups for high levels of consumption, heary drinking, the incidence and chronicity of alcoho-related problems and (the avoidance of) seeking help. The categories who were found to be at higher risk deserve special attention in terms of primary or secondary prevention.

Some drinking contexts are probably easier to influence by policy. If drinking contexts appear to be particular risky situations with regard to alcohol-related problems one can try to alter or avoid drinking in these contexts. In contrast to other studies, however, only limited support was found for higher risks on alcohol-related problems because of drinking on licensed premises. In addition, the higher risk associated with drinking in the aftemoon in this thesis does not signily any particular clue for policy making.

Generally, men at middle age can be considered as a group at high risk for the chronicity of high levels of consumption and high frequencies of heavy drinking. The probability that both younger and older age groups are likely to show remission on these drinking patterns is higher. The incidence of these two drinking pattems is about the same for young men and midcle aged men, only after the age 50 the incidence decreases.

The patterns of incidence among women suggest that young women have the highest probability to develop a high level of consumption, both women in their teens and at middle age can be considered as a risk group for evolving a pattern of weekly heavy drinking.

Effect of role transitions on the development of consumption and heavy drinking were found to a limited extent only. Both the gaining of the spouse role and the parental role often lead to a decrease in consumption or heavy drinking. These transitions provoke a moderation of drinking behavior. However, the drinking practices of those who remained without the spouse role show that they do not necessarily constitute a risk group.

Anong women, becoming married indicates a smaller probability to have chronic drinking problems, the opposite appears to be the case for cohabiting. Women with a family history of heavy drinking and women at middle age can be considered to be at higher risk to develop drinking problems. Men with a family history of drinking, who become unemployed, divorced or start cohabiting can be considered as categories at higher risk for chronic drinking problems. On the other hand, it was suggested that men who become employed are more likely to show remission, the gaining of employment has probably to be considered as a change accompanied by a lower risk for alcohol-related problems.

Both men at a younger age and men with paid employment are less likely to apply for treatment. Consequently, these men thave the same severity of drinking problems and might benetit from treatment in a similar way as older and unemployed men. If they do not change 
drinking behavior by themselves (and they have already a drinking problem for at least nine years) treatment possibly prevents them for getting worse and increases their overall wel]being. Therefore, both younger age and paid employment mark a specific category for secondary prevention. Whilst employed men are a risk group one of the important locations for secondary prevention may be the workplace itself.

The large difference between the general population and the clinical population indicates that almost exclusiwely drinkers who experience severe alcohol-related problems are likely to seek help. One can think of several explanations of this observation that might be useful for policy. Firstly, problem drinkers with less severe problems expect that help-seeking involves more negative consequences than positive consequences. On the other hand, a better explanation might be that the drinking behavior of "less severe" problem drinkers is determined by the rewards of drinking and not by possible or actual negative consequences. The avoidance of negative consequences is only a goal on the background in the determination of drinking behavior. Except if negative consequences cause a substantial loss the avoidance of negative consequences becomes an important goal that influences help-seeking behavior. If problem drinkers know and recognize possible negative physical and social consequences of high levels of alcohol consumption they might restrict their drinking practices.

A policy may aim to intluence the perception of social and physical consequences, or on the other hand, one might enlarge the negative consequences of drinking by more strict drinking laws. However, the cure - more strict drinking laws, such as total prohibition or prohibition for certain age categories - is often worse than the disease. Finally, the familiarity with treatment organizations is low (see for the Netherlands, Bongers et al., 1997). A policy should be developed that promotes treatment for alcohol, drugs and other addietive behaviors to be an integrated part of the health care system. Such a policy should bring about that those with addictive problems seek treatment before reaching a critical phase. The first step of such a policy might be to make more people familiar with treatment facilities.

\subsubsection{Directions for future research}

It is obvious that the effects of drinking contexts needs to be examined in more detail. This study and other studies showed there are many aspects of drinking behavior, besides volume of consumption, that determine the occurrence of alcohol-related problems. The explotation of drinking contexts in these studies designate drinking contexts that are of importance, such as the variation in the amounts consumed per occasion, indicators of occasional excessive drinking or risky settings. On the other hand, the effects of drinking contexts should be examined on different alcohol-related problems, such as health consequences and various social consequences. Until now, most of the studies that examine drinking contexts include only one or two of the contexts mentioned. Hence, the question remains offen whether some contexts cause problems or whether these problems are caused by other - unmeasured - aspects of drinking behavior.

Another direction of important research is indicated by studies that examine the personal or social network of drinkers. A theory about the reciprocal influence of networkmembers on each other's drinking behavior has been developed by Skog (e.g., 1986). It seems plausible 
that persons who are often together in typical drinking situations or whose meeting is accompanied by drinking, will influence each others drinking behavior (e.g. Van de Goor, Knibbe \& Drop, 1990; Bisson, Demers \& Kishchuk, 1994, Demers, Bisson \& Kishchuk. 1994).

Most alcohol research is published within journals that focus on alcohol and other issues of addiction. Only a limited part of the alcohol studies are publisled in more general joumals of epidemiology, psychology, sociology or public health. This is probably one of the reasons. that many alcohol studies are characterized by empiricism. Except for more explorative research, most of these studies would gain in strength and value when started with an explicit theoretical notion or deductive argument. In general, the rejection of certain hypotheses is likely to be more important for the development of science and for the conclusions with regard to a certain research problem than the presentation of just another empirical finding.

\section{References}

Bannenberg, A,f, Rad, H, Plomp, H.N. (1992) Denand for alcohol treatment by problem drinkers. Jow wal of

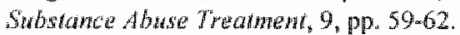

Becker, G.S. (1992) Habits, addictions and traditions. Ky/los, 45, pp. 327-346.

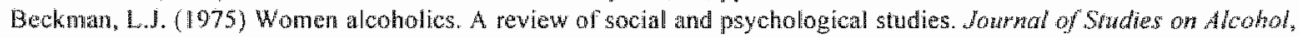
36, pp. $797-824$.

Bisson, 2. Demers, A \& Kishohuk, N. (1994) An aralysis of drinking networks structure and its influence on drinking

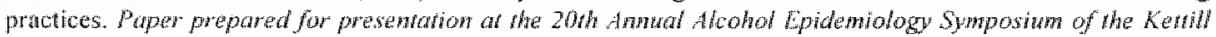

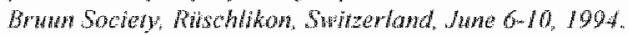

Bongers, I.M.B., Garretsen, H.F.L. \& Oers, H.A.M. van (1997) Help-seeking behaviour of problem drinkers. Aoumal of Subsionee Mhisuse, 1, pp. $216-221$.

Brennan, P.L. \& Moos, R.H. (1991) Functioning, life context, and help-seeking among late-onset problem drinkers: comparisons with nonproblen and earlywonset problem drinkers. British Jow wat of Addiction, 85, pip. 1139. 1150 .

Cahallan, D. (1970), Probienr drankers, Jossey -Bass Publishers, Sar Francisco, USA.

Crawford. A., Plart, M.A., Kreitman, N. \& Latcham, R.W. (1987) Unemployment and drinking belavior: some data from a general population survey of alcohol use. Brish Journal of Addiction, 82, pp. $1007-1016$.

Danow, S.L. Ruscall, M. Cooper, M.L.o, Midar "P. and Frone, M.R. (1992) Sociodemographic corretates of alcohol

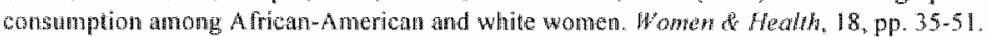

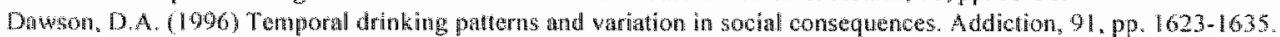

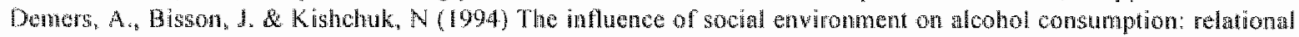

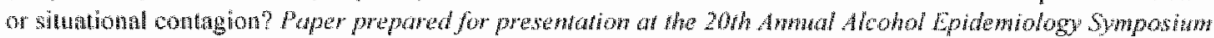

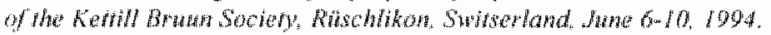

Filmore, K.M. (1987a) Prewalence, incidence and chronicity of drinking patterns and problems among men as a

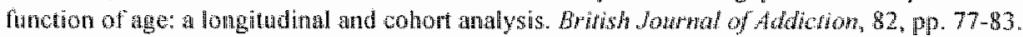

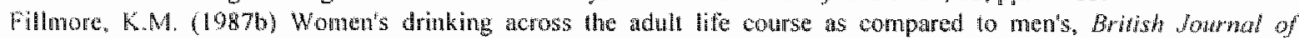
Addiction, $82, \mathrm{pp}, 801-811$.

Fillmore, K.M., Hartka, E., Johnstone, B.M., Lehno, E.V., Motoyoshi, M. and Tample, M.T. (1,991) A meta-analysis of life course variation in drinking. The Colloborative Alcohol related Longitudinal Project. Brits hownat of Addichons, $86, \mathrm{pp}, 1221-1268$

Filmore, KM. \& Mudanik, L. (1984), Chronicity of Drinking Problems anong Men: A lougitudinal Study. Journal of Sindier on Alootiol, $45,228-236$.

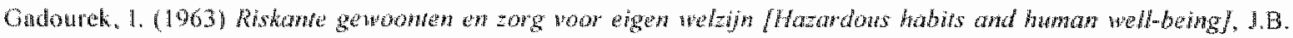
Wolters, Groningen:

Galiantar. A. (1995) Recent Dowelopmertits in Alcoholism, Vol. 12, Alcoholism and women. Plentum Press, New York and London.

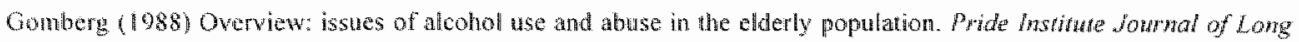




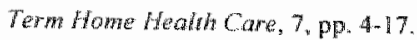

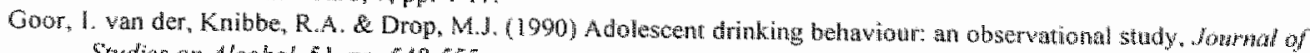
Srudies on Acchol, 51 , pp. $348-555$.

Gruenewald, P.J., Treno, A.J., Neplew, T.M. R Ponick, W.R. (1995) Routhe activities and aloohol use: constinints on

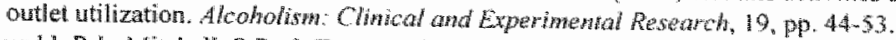

Gruenewald, P.J., Mitchell, P.R. \& Treno, A.) (1996) Drinking and drining: drinking patterns and drink hing problems. Adiction, $91, \mathrm{pp} .1637-1649$.

Hajema, Knibbe \& Drop (1994) Other factors than severity lated to help-sedking of problen drimkers paper

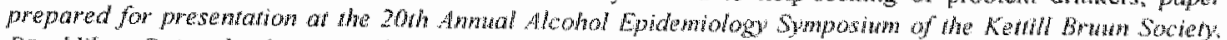

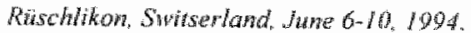

Hasin. D.S. \& Grant, B. D. (1995) A.A and other helpseeking fot aloohol problans: fomer drinkers in the US. general population. Southal of Subsiance Abuse. $7,281-292$.

Hauge, R. \& lrgens-Jensem, O. (1990) The experiencing of positive consequences of drinking in four Scandiunalat countries. British Joumal of Addiction, $35, \mathrm{pp} .645-653$.

Hilton. M.E. (1987) Demographic characteristics and the frequency of heawy drinking as predictors of selfereported drinking problems. British Jownal of Addation, 83, plo $913-925$.

Hupkers, Cl.th, Knibbe, R. R. \& Drop, MI. (1993) Allcohol consumption in countries in the European Community: uniformity and diversity of drinking patterns. Addiction, $88, \mathrm{pp}, 1391-1404$

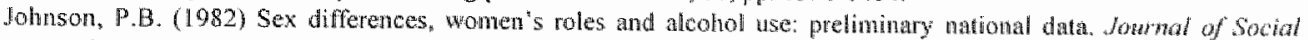
Isstues, 38, pp. 93-116

Kaskutas, L.A. Weisner. C. \& Caekano, R. (1997) Predictors of belp-seeking among a longitudinal sample of the

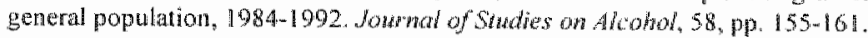

Knbbe, R.A., Drop. M.J. \& Hupkens, C.L.H. (1996) Modernization and geographical difusion as axplanations for regional differences in the consumption of wine and beer in the Enropean Communty. Showsone Usw d Misuse, 31, Dp. 1639-1655.

Knibbe, RA, Drop, MI, Muytjens, A (1987) Correlates of stages in the progression from everyday drinking to problen. drinking Socid Sicience of Medicine, $24, \mathrm{pp} .463-473$.

Knibbe, R.A., \& Meyers, J.M. (1988) Comparison of problem drinkers known to agencies with problem drinkers in the general population. Medicine amol Lan, 7, 87-94.

Lahelma, E., Kangas, R., and Manderback a, K. (1995) Drinking and unenployment: contrasting patterns among men and women. Drug and Alcohol Dependence, 37, pp. $71-82$

Lanmers, S.MM. (1995) Foncrionalny of alcohol in alcohol dependent nomen. Thesis. Katholieke Universitait Nimegen, SSN Nijmegen.

Lindenberg, S. M. (1993) Club hierarchie, social metering and context instrtaction, governance Structures in response to

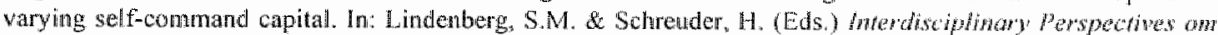
Orgamization Studies, Prergamon Press, New York.

Magura, M, \& Shapiro, E. (1988) Alcohol constuption and divorce: which causes which? Jarrod of Dinorce, 12, pp. $127-136$.

Mäkela, K., \& Mutonen, H. (1996) The reward structure of drinking anong younger and older male drinkers. Contentponary Drug Problems, $23, \mathrm{pp} .4704492$.

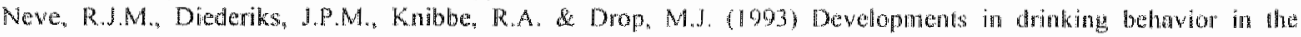
Netherlands from 1958 to 1989 , a cohot analysis. Addictom, 88, pp. 611-621.

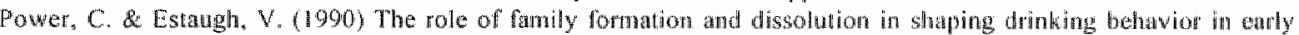
adulthood. Brifist Jownal of Addichom, 85 , pp. 521.530 .

Single, E. \& Wortley, S. (1993) Drinking in warous sethings as it relates to demographio varables and level of

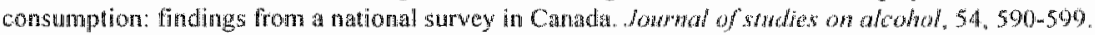

Skog, O.J. (1986) The long waves of alcolno consumption: a social netwotk perspective on cullural change. Sochal Nenworks, 8, pp. $1-32$.

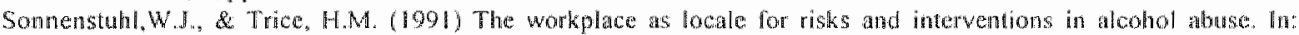

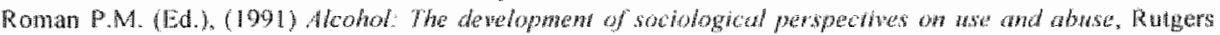
Center for Alcohol Studies, New Brthswick, New Jersey, USA

Stockwell, T., Lang, E., \& Rydan, R. (1993) High risk drinking seftings, the assoctation of serving and promational practices with harmful drinking. Addictron, $88,1519-1526$.

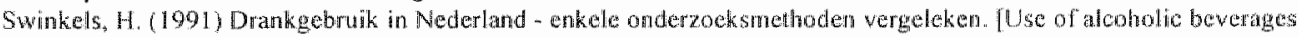

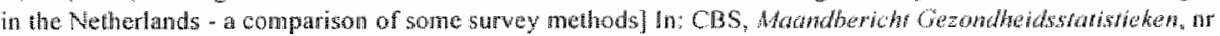
$12,5-12$.

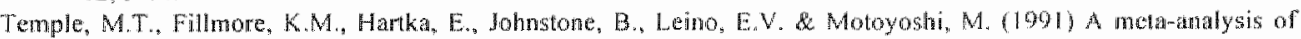
change fu marital and employment status as predictors of alcohol consumption on a typiat occasion. British 


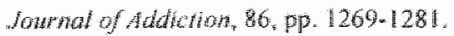

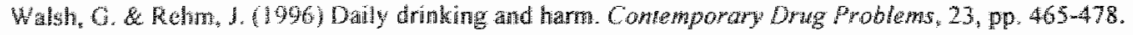

Weisner, C. (1993) Toward an Alcohol preatment Entry Model: Comparison of Problem Drinkers in the General

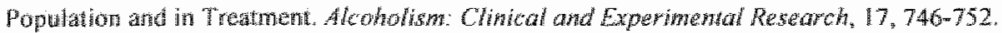

White, H.R. (1991) Sociological theories of the etiology of alcoholim. In: Gomberg, E.L., White, H.R. \& Camenter. 1.A. (Eds.) Alcohot, scieve do society revisied, The University of Michigan and Rutgers University Center of Alcohol Studies, Ann Arbor, New Brinswick and Wew Jersey.

Wilsnack. R.W. \& Cheloha, R. (1987) Women's roles and problem drinking across the lifespan. Social Problens, 34, p) $231-248$ 
Dit proefschrift is het resultaat van een longitudinale studie naar drinkgedrag, alcoholgerelateerde problemen en lyulpzoeken voor probleemdrinken. Het is het eerste langlopende onderzoek naar alcoholgebruik, met wee meetmomenten, onder de algemene bevolking in Nederland. Voor de studies naer veranderingen in drinkgedrag en alcohol-gerelateerde problemen is een panel in de provincie Limburg gebrukt in de leefujdscategorie van 16-69 jaar ten tijde van de eerste meting (1980 1989, $n=1327)$. Voor de studie naar hulpzoekgedrag zijn mannen in de algemene bevolking met chronische alcohol problemen vergeleken met mamnelijke cliẻnten van het Consultatie Bureau voor Alcohol en andere Drugs (CAD) met alcohol problemen (199394, $\mathrm{n}=129)$. Het doel van het onderzoek is to onderzoeken in hoeverre deze drie issues sociaal zijn bepaald. Verscheidene sociologische theorieen zijn toegepast ter verklaring en interpretatie van veranderingen in drinkgedrag, het ontwikkelen en voortduren van alcohol-gerelateende problemen en hulpzoeken.

De drie issues zijn onderzocht in vier studies. In de eerste studie staan de beschrijving en interpretatie van veranderingen in drinkgedrag naar leeftijd en geslacht centraal. In hoofdstuk twee zjin zowel de veranderingen in drinkgedrag op het aggregat niveau als die op individueel niveau onderzocht. De effecten van leeftijd en geslacht zijn onderzoclat voor de incidentie en chroniciteit van drinken (drinken versus geheelonthouding), drie consumptienveau's (wekelijks 7,14 en 21 standaard glazen met 10 gr. ethanol) en twee frequenties van zwaar drinken (maandelijks en wekelijks 6 of meer standaard glazen per gelegenheid).

In de tweede studie is onderzocht of veranderingen in rollen met betrekking tot burgerlijke staat, werk en thuiswonende kinderen bijdragen aan de verklaring van veranderingen in consumptieniveau en frequentie van zwaar drinken. In hoofdstuk drie zijn de effecten van roltransities onderzocht door een vergeligking van hen die een rol verforen met hen die een rol hielden on van hen die een rol kregen met hen die zonder de wol bleven. Eem belangrijke leidraad voor de opzet van het onderzock was de roltheorie. Volgents do roltheorie zoals die met name in hoofdstuk 1 en. 3 is uiteergezet, zullen personen dic, bijworbeeld, de partnerrol, werkrol of ouderrol hebben, geneigd zijn minder te drinken. Do rolverwachtingen van deze rollen beperken de mate en intensiteit van het drinken. Personen zonder deze rollen heb een minder gestructureerd dagelijks leven en zullen daarom meer drinken, onder andere omdat drinken wondt gebruikt on de dag te structureren. De hypotheses vanuit deze theorie zijn dat personen die een rol verliezen een toename in consumptie en zwar drinken laten zien en dat personen die een rol krijgen een daling in consumptie en frequentic van zwaar drinken zullen aangeven.

De derde studie behandel de vraag of drankproblemen mede kunnen worden verklard door sociale condities en drinkcontexten (zoals drinklokaties en tijdsaspecten van drinken) terwijl wordt gecontroleerd op consumptie en zwar drinken. Do aard wan deze studie is dex 
exploratief. Het onderzoek nar de effecten van drinkcontexten en aspecten van drinkgedrag anders dan consumptie of zwar drinken is van recente datum. Over het algemeen ondersteunen deze studies dat drinkpatronen (drinkedrag anders dan gemiddelde consumptie per dag, consumptie per week of frequentie van zwar drinken) van invloed zijn op de anwezigheid van drankproblemen. In het onderzoek naar de effecten van sociale kondities wordt verwacht dat de negatieve (en positieve) consequenties yan alcoholconsumptie verschillen naar gelang de sociale condities. De sociale condities die zijn onderzocht zijn leeftijd, geslacht, ouderschap, sociale statuls, burgerlijke staat, werk en drinkgedrag van de ouders toen de drinker nog thuis woonde. Zowel de incidentie als chroniciteit van drankproblemen zijn onderzocht in hoofdstuk vier.

In de vierde studie is onderzocht of problemen die kunnen worden gekenschetst als alcohol-gerelateerde verliezen en het al dan miet bezitten van sociale hulpbronnen kunnen bijdragen aan de verklaring van hulpzoekgedrag. Het wordt verondersteld dat drankproblemen die een (mogelijk) verlies impliceren beter kumnen verklaren waarom hulp wordt gezocht dan zogenaamde symptomen van drankgebruik en de trequentie van dronkenschap of kater. Met natne het verlies van werk, gezondheid en sociale waardering door drinkgewoonten, zijn beschouwd als indicatoren van alcohol-gerelatearde verliezen. Bepaalde kenmerken wan drinkers kunnen worden beschouwd als hulpbronnen die van invloed zijn op de kosten en baten van hulpzoeken. Deze kenmerken kunnen worden beschouwd als 'sociaal kapitaal': de hulpbronnen vergemakkelijken het voortzetten van het riskante drinkgedrag en het vermijden van hulp. Als potentiële hulpbronnen zijn beschouwd: betaald werk, leeftijd, gehuwd zijn, sociaal-economische status en een ('nat')sociaal netwerk watrin veel wordt gedronken. Hulpzoeken is onderzocht in hoofdstuk vijf door niddel wan een vergelijking van mannelijke probleemdrinkers die voor hun drankproblemen professionele hulp hebben gezocht met mannelijke probleemdrinkers in de algemene bevolking die geen professionele hulp hebben gezocht. Door het geringe aantal wrouwelijke chronische probleemdrinkers in het panel was het niet mogelijk hulpzoekgedrag van vrouwen te onderzoeken.

\section{De inwloed wan feefijd, geslacht en sociale rollen op drinkgedrag}

De resultaten op het aggregaat nivo laten zien dat bij zowel mannen als vrouwen het percentage drinkers is afgenomen. De chroniciteit van drinken is hoger bij jongeren dan bij ouderen en het positieve verband tussen geheelonthouding en leeftijd is sterker bij vrouwen. Voor vrouwen wordt een negatief verband gevonden tussen incidentie van drinken en leeftijd. Aangezien de meeste mannen ten tijde van de eerste meting drinkers waren kon de incidentie mour leeftijd niet worden wastgesteld.

Wat betreft chroniciteit vat consumptie werd alleen voor de mannen een verband gevonden voor het 21 glazen of meer drinken met leeftid. De chroniciteit was het laggst op oudere leefijd. In tegenstelling tot chroniciteit wordt voor incidentie van consumptie een duidelijk leeftijdsgebonden patroon gevonden. De algemene trend is dat incidentie het hoogst is onder jongeren en afmeent op oudere leefijd. De resultaten laten zien dat kleine veranderingen op het aggregaat niveau samengaan met grote verschuivingen op het individuele niveau. Bovendien, zowel de incidentie als chroniciteit is hoger bij mannen dan bij wrouwen, 
het werband met leeftijd is bij vrouwen sterker en doet zich sterker gelden woor incidentie dan woor chroniciteit.

Bij mannen worden veranderingen in drinkgedrag voor een klein deel verklluard door veranderingen in sociale rollen. Een aanzienlijk deel van de verwachtingen moest worden verworpen. Met uitzondering van de allerjongste leeftijdscategorie verminderen mannen die de partnerrol krijgen hun consumptie. De andere veranderingen in rollen waren niet van invloed op drinkgedrag. Voor zwaar drinken laten de resultaten zien jonge mannen die de ouderrol kregen hun frequentie van zwaar drinken verminderden, voor oudere mannen lijkt dit effeot niet op te gaan. De andere roltransities waren niet van invloed op de ontwikkeling van zwatr drinken.

Ook bij vrouwen verkJaren roltransities slechts een beperkt deel van de veranderingen in drinkgedrag. Zoals verwacht ging het krijgen van de partnerrol gepaard met een daling in consumptie. Zwakke verbanden werden gevonden voor zowel het krijgen van de oudertol als van de werkrol. Het verlies van rollen leidde niet tot enige verandering in consumptie. Voor zwaar drimken waren de effecten van het krijgen van de ouderrol en het varliezen van de partnerrol zoals verwacht. De andere roltransities waren niet van invloed op zwant drinken.

\section{Drankproblemen en de invloed van sociale condities en arinkcontexten}

Vanwege het relatief geringe aantal vrouwen die werden gekenmerkt door incidentie of chroniciteit van problemen is alleen een bivariate analyse verricht. De data suggereren invloed van diverse drinkcontexten op chroniciteit van problemen. Echter, slechts de toename van drinken in de namiddag en in de avond zijn mogelijk van invloed op het houden van drankproblemen. Van de sociale condities vergroot huwen de kans op remissie van drankproblemen terwijl samenwonen juist de kans op het houden van problemen lijkt te vergroten. De incidentie van drankproblemen lijkt te worden gestimuleerd door zowel het vaker thuis drinken, het drinken in cafe's, restaurants, e.d, het drinken in de namiddag, bij het avondeten en in de avond. Desahniettemin lijkt het niet waarschijnlijk dat al deze aspecten daadwerkelijk van invloed zijn op de ontwikkeling van drankproblemen. De bivariate analyse geef daar geen uitshutsel over. Vrouwen op middelbare leefijd of met een vader die wel eens zwaar dronk waren meer geneigd om problemen te ontwikkelen. Sociaal-economische status, werk en het hebben van thuiswonende kinderen waren niet van invloed op de incidentio of chroniciteit van alcohol-gerelateerde problemen.

Voor de mannen laat de multivariate analyse zien dat drinken in de namiddag de kans op chronische drankproblemen vergroot terwijl drinken bij anderen thuis deze kans verklent. Mannen met ouders gekenmerkt door een relatief hoge frequentie van dronkenschap rapporteerden vaker chronische drankproblemen. Bovendien, het krijgen van betaald werk gaat samen met een kleinere kans op chronische problemen terwijl het arbeidsongeschikt of werkloos worden gepaard gaat met een grotere kans op chronische problemen. Tenslotte is een zwak positief verband gevonden van echtscheiding en samenwonen met chroniciteit van problemen.

Voor mannen is de kans om problemen te ontwikkelen groter voor hen die in de namiddag vaak dronken. Anderzijds is de kans om problemen te ontwikkelen kleiner woor hen 
met een hoge frequentie van drinken bij het avondeten en "s avonds. Mannen op jongere leafijd zijn mear geneigd problemen te onwikkelen en. als laatste, een zwak positief verband met het krigen van problemen is gevonden woor mannen met ouders die relatief vaak dronken waran

\section{Determinantes wan hulpzoeken voor probleemdrinken}

De resultaten suggereren dat alcohol-gerelateerde verliezen een sterkere invloed hebben op hulpzoekgedrag dan andere indicatoren wan drankproblemen. De effecten van sociale consequenties en gezondheid waren sterker dan de effecten van symptomen wan probleemdrinken. De frequentie van dronkenschap of kater was geheel niet van invloed op hulpzoeken. Probleemdrinkers op oudere leefijd en werkloze- en arbeidsongeschikte probleemdrinkers hadden een grotere kans op hulpzoeken. Bovendien worden de effecten van sociale en gezondheidsconsequenties beinvloed door leeftijd. De data suggererem dat de effecten van deze consequenties sterker zijn op oudere dan op jongere leeftijd. Ongehuwde probleemdrinkers, in de lage sociale strata of met een "droog" sociaal netwerk hadden geen grotere kans op hulpzocken.

\section{Conclusies en discussie}

Het onderzoek naar veranderingen in drinkgedrag geeft aan dat deze tamelijk sterk afhankelijk zijn van geslacht en leeftijd. De effecten van veranderingen in sociale rollen op drinkgedrag zijn niet eenduidig. Het meest consistent zijn de effecten van het krijgen van de partner-en ouderrol op drinkgedrag. Beide roltransities lijken ten dele een daling in consumptie of zwaar drinken te kunnen verklaren. Het verlies van rollen leidt nauwelijks tot enige verandering in drinkgedrag. Het moet daarom worden geconcludeerd dat de meeste hypothesen die waren afgeleid uit de roltheoric moeten worden verworpen. De roltheorie zoals geformuleerd in dit proefschrift leidt niet tot een goede verklaring van veranderingen in drinkgedrag. Men kan trachten deze theorie verder wit te werken en te specificeren. Echter, het is wellicht zinvoller om enige noties ait de theorie die wel van belang lijken te zijn op te nemen in een meer algemeen verklaringsmodel...

De resultaten van het onderzoek naar incidentie en chroniciteit van alcohol-gerelateerde problemen suggereren dat arinkcontexten en sociale condities beide van invloed zijn. Met andere woorden, de context van drinken en sociale condities beïnvloeden de ontwikkeling en thet voortbestaan van drankproblemen onathankelijk van het consumptieniveau of de frequentie wan zwaar drinken. De invloed van drinkcontext is verklaard op twee manieren. Ten eerste, de context bopaalt mede de kans op het ontstaan van problemen en die kans verschilt bijvoorbeeld natar gelang men thuis drinkt of in het café. Ten weede, de context waarin men drinkt is een onderdeel van de levensstijl die men heeft en uitdraagt in het dagelijks leven. Enerzijds kan het zo zijn dat een bepalde context van drinken in strijd is met de levensstijl en daarom problemen oplevert. Anderzijds kan de context zelf onderdeel zijn van een levensstijl met een grotere kans op problemen.

Werk, burgerlijke stat, leeftijd en drinkgedrag van de ouders zijn wan invloed op de incidentic of op de chroniciteit van problemen. Een verklaring is dat werklozen of 
arbeidsongeschikten mogelijk worden geconfronteerd met meer kritiek op hun drinkgedrag. De werkloosheid kan bijwoorbeeld geweten worden aan hun drinkgedrag. Aan de andere kant, het krijgen wan betald werk betekent dat men aan zijn/haar "sociale verplichtingen" voldoet en minder kritiek krigt dan voorheen. Een andere verklaring voor het effect van sociale condities is dat het hierbij gaat om groepen die verschillen in de mate waarin zij risico's nemen met hun drinkgedrag.

Het onderzoek naar hulpzoekgedrag laat zien dat problemen de primaire oorzaak zijn van hulpzoeken maar problemen die een indicatie zijn van sociale of gezondheidsconsequenties zijn het belangrijkst. Onathankelijk van de ernst van de drankproblemen zijn werkenden en jongeren minder geneigd om hulp te zoeken. Hypothesen en theorieen kunnen alleen worden verworpen en de invloed van werk en leeftijd bewijzen dus niet dat deze twee kenmerken sociaal kapitaal vormen waarmee men hulpzoeken kan vermijden of drinkgedrag kan voortzetten. De resultaten geven wel aan dat di mogelijk een belangrijke verklaring kan zijn voor hulpzoekgedrag. Een belangrijke constatering is dat met name werkenden en jongeren geen hulp zoeken terwijl ze wel ernstige drankproblemen hebben. Deze categorieèn verdienen daarom extra aandacht in termen van het opsporen van probleemdrinkers en secundaire preventie.

Met name twee vragen resteren na dit onderzoek clie ook (nog) niet door andere onderzoekers worden beantwoord. De eerste vraag betreft het belang van drinkcontext voor het krijgen en voortduren van alcoholproblemen. De studie in het proefschrift laat samen met andere studies zien dat drinkcontext belangrijk is. Desalniettemin, het verkregen inzicht is over het algemeen niet volledig omdat vaak slechts een beperkt deel van het drinkpatroon dat mogelijk van invloed is op drankproblemen wordt onderzocht. Dit is een onderwerp dat in de toekomst extra aandacht vergt en waarbij ook een nadere theoretische ontwikkeling van belang is.

Een andere belangrijk richting voor exploratie betreft de invloed van bet persoonlijke netwerk op drinkgedrag, problemen en hulpzoeken. In dit proefschrift bleken diverse aspecten van het persoonlijke netwerk niet van invloed op hulpzoekgedrag. Over het algemeen kan gesteld worden dat op dit gebied het praktisch onderzoek achterblijft bij de theoretische ontwikkeling. Het verdient dan ook zeker aanbeveling on de nogelijke invloed van thet persoonlijk netwerk nauwkeurig te onderzoeken. 


\section{REFERENCES}

Aday, L. A. Andersen, A. (1974), A famework for the study of access to medical care. Healih Services Research, 9. pp. $208-220$.

Akers, R.L, Krohn, M.D., Larzaraduce, L. \& Radosevich, M. (1979) Social learning and dewiant behavior: a specific

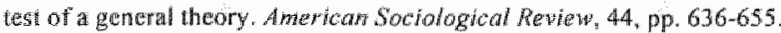

Akers, R.L. (1991) Axdiction, the troublesome concept. The Jow what of Orag fissues, 21, pp. 777-791.

Amaro, H., Beckman, L.J. \& Mays, V.M. (1987) A comparison of black and white women entering alcoholism

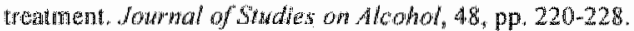

Andersen; R.M. \& Newman, J.F. (1973) Societal and individual determinants of medical care unilization in the United Stites, The Mithonk Memorid Qwarterly, 51, pp. 95-124.

Anderset, R.M. (1995) Revisiting the behawioral model and access to medical care: does it mater? Jourmal of fleath and Social Behowor, $36, \mathrm{pp} .1-10$.

Bameruberg, A.F.I, Raat, H. Plomp, H. W. (1992) Demand for aloohol treatment by problem drinkers. Jounal of Swbstance Abrise Theatment, 9. pp. 59-62.

Bardsley, P.E. Beckman, L.J. (1988) The health belief model and entry into alcoholism treatment. The International

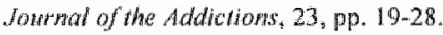

Becker, G. $\$$. (1992) Habits, addictions and traditions, Kyklos, 45, pp. 327-346.

Becker, G.S., Grosmun, M. Murphy, K.M. (1991) Rational addiction and the effect of price onconsumption. American Ecomonic Review Papers and Procedings, 81, pp. 237.24

Becker, G.S. \& Murphy, K.M. (1988) A theory of rational addiction. Journal of Political Economy, 96, pp. 675-700.

Becker, M.H., Haefuer, D.P., Kasl, D.P., Kirsch, J.P., Maiman, L.A., \& Rosenstock, 1. (1977) Selected psychosocial. models and correlates of individual health-related behaviors, Medical Care, 15, pp. 27-46.

Beckman, L.J. (1975) Women alcolholics. A review of social and psychological studies. Jouphat of Snudien on Alcohol, 36. pp. $797-824$.

Beckman, L.d. \& Amaro, M. (1986) Persomal and social difficulties faced by women entering alcoholism treatument. Jounal of stwdies on Alcohol, 47, pp. 135-1.45.

Beckman, L.J. K Kocel, K.M. (1982) The treament-delivery system and alcohol abuse un women: social policy

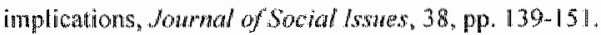

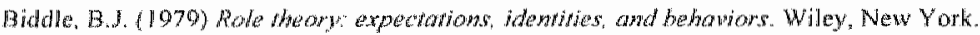

Bisson, I. Demers, A. K Kistohuk, N. (1994) An analysis of drinting networks structure and its imfluence on drinking

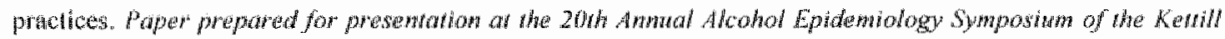

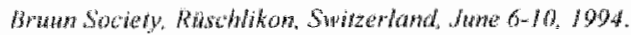

Bondy, s. (1996) Owemiew of studios on drinking patterns and consequences. Addiction, $91,0 p .1663-1674$.

Bongers, 1.M.B. Gartisen, H.F.L. Oers. H.A.M. van (1997) Help-seeking behaviour of problen drinkers. Nownat of Subranee Misuse, 1.pp. 216.221 .

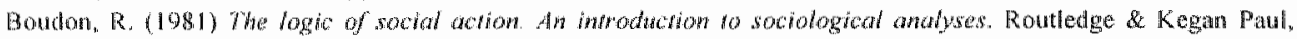
London, Grean Buitain.

Bontenult, C. k Demers, A. (1995) Solitary drinking: a risk factor for alcohol-melated problems? Paper presented at

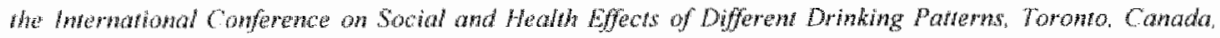
movember $13-1 \%$. 1995 .

Bromnan, P.L. \& Moos, R.H. (1991) Fundioning, life context, and helposeeking among late-onset problem drinkers: comparisons with nonproblem and early-onset problem drimkers. Bpoish Jomonal of Addickon, 86, pp. 4139 1150 .

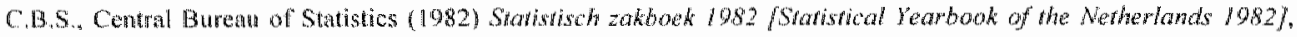
Sdu/publishers, The Hagne, The Netherlands.

C.B.S. Central Bureau of Statistics (1991) Sratistical Yearbook of the Nethertands 1991, Solu/publishers, The Hague, The Wetherlands. 


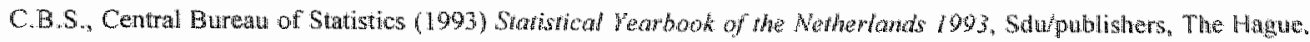
The Netheriands.

C.B.S. Central Bureau of Statistics (1994) Trend figures Netherlands healh interigen survey: aspects of unthenthy

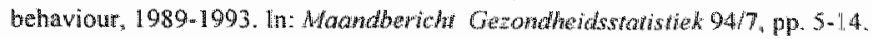

C.B.S., Central Burean of Statistios (1996) Statistod Yearbook of the Hetherdands 1996. Sdupublishers, The Hague, The Netherlands.

Canalan, D. (1970) Problem drinkers; a mallonal sumeys Jossey-Bass Publishers, San Francisco.

Cahallan. D. (1986) Studying drinking problems rather than alcoholism. In: Galantar et al. (Eds.) wecent dovelopmerts in alcoholism, Fol 5 , chapter 15, pp. 363-372, Plerum press, New Yorli, US.

Casswell, S., Zhang, I.F.\& Wyllie, A. (1993) The inportance of amount and location of drinking for the experimce of alcohol-related problems. Addiction, 88 , pp. 527-1534.

Coleman, J.S. (1990) Foundations of Social thoory, The Belkmap Press of Harvard University Press. Cumbridge, Massachusets, and London, England.

Cooney, N.L., Meyer, R.E. Kaplan, R.F. \& Baker, L.H. (1986, A validation sudy of four scales measuring severity ot alcohol dependence. British Journorl of Addiction, $81,0 p .223-229$

Cornet, M. Knibbe, R.A.. Zutphen, W. M. van, \& Drop, M.J. (1994) Probiem drinking in a general practice population:

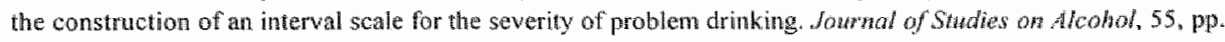
$466-470$.

Crawford, A., Plant, M.A., Kretman, N. \& Latcham, R.W. (1987) Unemploymeni and drinking behavior: some data from a general population survey of alcohol use. Brish wowmol of athdiciom, 82, pp. 1007-1016.

Cunningham, J.A., Sobell, L.C., Sobell, M.B., Agrawal, S. te Toneatto, T. (1993) Bartiers to treatmont: why alcohol and drug abusers delay or never seek treatment. Addicine Behwors, 18, pp. 347-353.

Darrow, S.L., Russell, M. Cooper, M.L., Mudar, P. and Frone, M.R. (1992) Sociodenographic correlates of alcohol consumption among A fricar-American and white women. Women d Healh, 18, pp. 35-51.

Dawies. J.B. (1992) The nyth of addiction, an application of the psychological theory of attribution to illicit drug wise. Harwood Academic Publishers, Chur, Switzerland.

Dawson, D.A. (1996) Temporal drinking patterns and variation in social consequences. Addiction, 91. pp. $1623-1635$.

Demers, A., Bisson, J. \& Kishchuk, N (1994) The influence of socival ervironment on atcohol consumption: relational

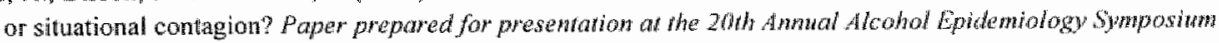
of the Ketill Brawn Society. Rüschlikom. Swizerland, Jwe 6-10. 1994.

Esser, H. (1994) Explanatory sociology. Soziologie, nr.3, pp. 177-190.

Filimore, K.M. (1987a) Prewalence, incidence and chonicity of drinking pattems and problems among men as a funchion of age: a longitudinal and cohort analysis. Brinsh Jowral of Addiction, 82 , pp. 77-83.

Fillmore, K.M. (1987b) Women's Drinking acnoss the Adult Life Course as Compared to Men's, Brinish Jounal of Addiction, 82, pp. $801-811$.

Fillmore, K.M. (1988) Alcahol ase across the life cow Ade. Adiction Reseanch Foundation, Toronto.

Filhore, K.M. Harta, E., Johrstone, B.M., Leino, V.M., Motoyosib. M. \& Temple, M.T. (1991) A meta analysis of life course wartation in drinking. British fotwnal of dediction, 86, pp. $1221-1268$.

Fillonore, K.M. \& Midanik, L. (1984), Chronicity of drinking problens annomg men. a longitudinal study. townes of

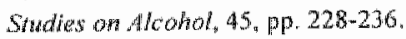

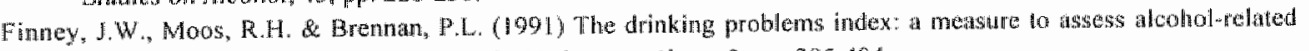
problems among older adults. Journal of 5 whsfamce Abuse, $3, \mathrm{pp} .395-404$.

Firgerald, JL. \& Mulford, H.A. (1981) Soctal attributes, probtem drinking and alcoholism treatment contacts. Jow mal of Siadies on Alcohol, $42, \mathrm{pp} .403-413$.

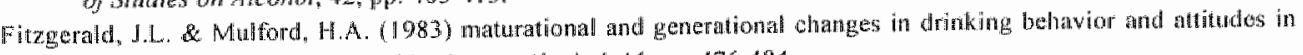
lowa, 1961-1979. Journat of Studies on Alcohol, 44, pp. 476-484.

Fitzgerald, J.L. \& Mulford, H.A. (1984) Factors related to problem-drinking rates. Jinwal of Siwdies wh Alcohol, 45. pp. $424 \times 432$.

Frurstenberg, F.F. \& Hughes, M.E. (1995) Social capital and sticcessful development among at-risk youth, Jow Marriage and the Family, 57, pp. $\$ 80-592$.

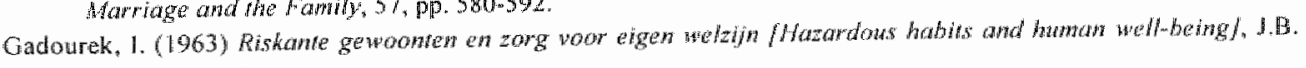
Wolters, Groningen.

Galantar, M. (1995) Recent Developments in Alcoholism, Vol. 12, Mcoholsm and womkn. Fienum Press, New York 
的期 London.

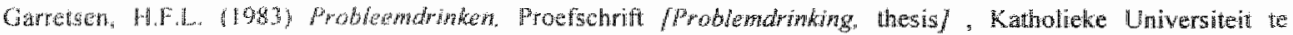
Ninnegen, Swets Le Zeitinger, Liswe.

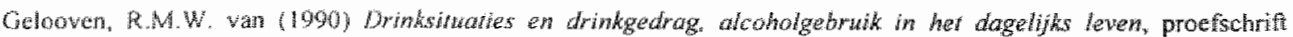

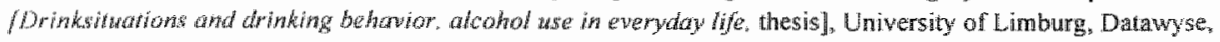
Masistricht.

George, A.A. Rucker, J.A. (1996) Help-seeking for alcohol-relatted problems: social contexts surrounding entry into alcoholisn treatment or Alcoholics A nonymous, Joumal of Sudies on Alcohol, $\$ 7$, pp. 449-457.

Gerhard, U. (1971) Rollewanalyse als Kwitse he Sozhologie. Luchterhand, Newwied, Berlin.

Gemm, M.D. (1981) Age, birth cohors, and drinking: an illustration of the hazards of inferring effects from cohort data, Sownd of Gerontohogy, 36, pp, 362 369 ,

Glynn, R.I., Botichard, G.R., LoCastro, J.S. Lalir, N.M. (1985) Aging and generational effects on drinking behaviors in men: results from the normative aging study, American Joumal of Public Heall, 75, pp. 14131419.

Gomberg (1988) Overview: issues of alcohol use and abuse in the elderly population. Pride Institute atournat of Long

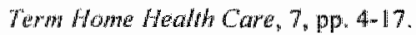

Goor. L.A.M., van de (1990) Situational aspects of actolescent drinking behavior. Thesis, University of Limburg, Datawy ge, Mastricht.

Goor, L.A.M. van der; Knibte, R.A. D Drop, M.J. (1990) Adolesent drinking belhaviour: an observational study. Jounal of Sindies on Alcohol, 51, ph. $548-555$.

Gorman, D.M. Dufy, S.W., Raine, S. Raylor, C.L. (1989) Level of agreement between questionnaire measures of allohol dependence alcoholism and problem drinking in a sample presenting at a specialist alcohol treatment service. Drug ana Allohol Dependence, 24, pp, 227-232.

Gruencwald, P.J., Treno, A.J., Nephew, T.M. \& Pon Hcki, W.R. (1995) Routine activities and alcohol use: constraints on outlet utilization. Alcaholism: Chimical and Experimenal Research, 19, pp. 44-53.

Gruenewalld, P.J., Mitchell, P.R. \& Treno, A.J. (1996) Drinking and driving: drinking patterns and drinkiug problems. Addiction, 91 , pp. $1637-1649$.

Hajema, K.J. Knibbe, R.A. \& Drop. M.J. (1994) Chrowische probleemdrinkers in de Bewolking en probleemdrinkers bij hat CAD: en wergeliking /Chronic problem drinkers in the general population and in weatment a comparison]. Vakgroep Medische Sociologic, Rijksuniversiteit Limburg, Maastricht.

Hajema, K.J., Kabbe, R.A., \& Drop* M.J. (1994) Other factors then severity related to help-seeking of problem drinkers. Poper prepared for presentation at the $20 \mathrm{~h}$ Annal Alcohol Epidemiology Symposinm of the Ketwl

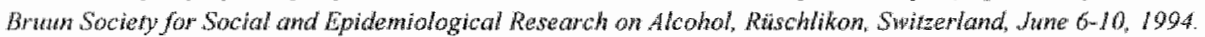

Hajema, K.J. Knibbe, R.A., \& Drop, M.J. (1997) Changes in alcohol consumption in a general popultation in The Netherlands: a 9-year follow-up study. Adtiction, 92 , pp. 49-60

Hajena, K.J. Knibbe, R.A., \& Drop, M.J. (1997) Effects of drimking patterns and social conditions on incidence and chrondeity of alcohol-related problems. Contemporary Drag Problems, 24, 473-511.

Hanta, I.Z, Finden, V.B. Hartord, T.C. (1993) Marriage does if protect young women from alcoholism? Journal of

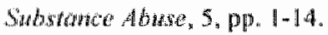

Harlord. "T.C. (1994) Public drinking contexts and alcohol dependence: is there a link? Paper prepared for

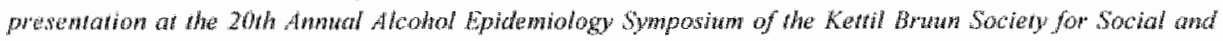

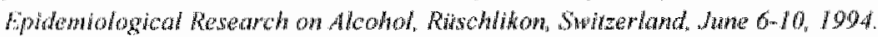

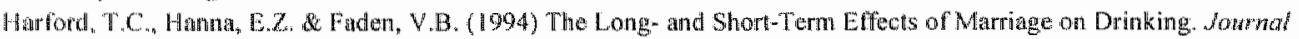

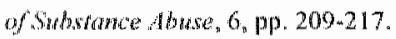

Hasim, D.S. Otant, B.F. (1995) AA and other thelpseeking for atcohol problems: former drinkers in the U.S. general population. Joumat of Substance Abuse, 7, pp. $281-292$.

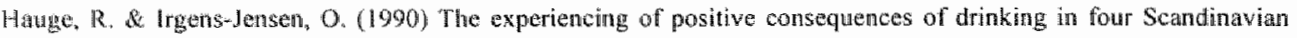
couniries. British Joumal of Addiction, 85 , pp. $645-653$.

Hilton, M.E. (1987) Demographic characteristics and the frequency of heavy drinkung as predictors of self-reported drinking problems. Britsh Jourmal of Addicticun. $82,913-925$.

Hosmer, D.W. \& Lemeshow, S. (1989) Appited logiste regression, John Wiley \& Sons, New York, USA.

Hupkens, C.L.H., Knibbe, R.A. \& Drop. M.J. (1993) Alcohol consumption in countries in the European Community: unifornity and diversity of drinking patterns, Addiction, $8 \mathrm{~B}, \mathrm{pp} .1391-1404$. 


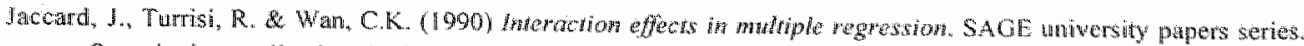
Quantitatiwe applications in the social sciences; no. 72. London. UK.

lanlert, U., Hanmerström, A. (1992) Alcohol consumption anong unemployed youths: results from a prospective study. British Jourral of Addiction, $87, \mathrm{pp} .703-714$

Johnson, P.B. (1982) Sex differences, women's roles and alcohol use: preliminary national data. Nowprat of Sochal Issues, $38, \mathrm{pp} .93-116$.

Jordan, C.M. \& Dei, T.P.S. (1989) Help-seeking behaviour in probiem drinkers: a review, British Joumat of tadiction, 84, pp. $979-988$

Kaskutas, L.A., Weisner, C. Caetano, R. (1997) Predictors of help-seeking among fongitudinal sanuple of the general population. Jound of srudies om Alowol, $5 \$$. pp. $155-161$.

Knibbe, R.A. (1984) Van gangbaar tor problematies drankgebruik ffrom social drinking to problemario drinking). Proefschrift, RU-Limaburg, Maastricht.

Knibbe, R.A. \& Abbenhuis, $S$ (1991) Getrouwd met cen alcoholist [Married with an alcoholicl. Tujdschriff wor Alcohol, Drugs en andere Pschychotrope Stoffen, 17, pp. 77-83.

Knibbe, R.A., Drop, M.J. \& Hupkens, C.L.H. (1996) Modernization and geographical diffusion as explanations for regional differences in the consumption of wine and beer in the European Community. Substance Uke di Misuse, 31, pp. I639-1655.

Knibbe, R.A., Drop M.J. \& Muytjens A (1987) Correlates of stages in the progression from everyday driaking to problem drinking. Soctial Sicience and Medicine, 24, 463-473.

Knibbe R.A. \& Meyers J.M. (1988) Comparison of problem drinkers known to agencies with problem drinkers in the general population. Medicine and Low, 7, pp. 87-94.

Knibbe, R.A. \& Swinkels, H. (1992) Alcoholgebruik in Nederland; een analyse wan gegevens tuit do CBSgezondheidsenquête 1989 [Alcohol consumption in the Netherlands; an analyses of data from the CBS Healih Interview Surwey 1989], Tijdschriff poor Alcohol, Draggs en andere Pschychotrope Sfoffen, 18, pp. 124-138.

Knupfer, G. (1984) The Risks of Drunkenness (or, Ebrietas Resurrecta), A comparisen of frequent intoxication indices of population sub-groups as to problem risks. British, Journat of Addiction, $79, \mathrm{pp} .185-196$.

Lahelma, E., Kangas, R., \& Manderbacka, K. (1995) Drinking and unemployment: contrasting patterns among men and women. Drug and Alcohol Dependence, 37, pp. 71-82.

Lammers. S.M.M. (1995) Fumiciomality of alcohol in gicohol dependent women. Thesis, Katholieke Universiteit Nijmeger, SSN Nijmegen.

Lemmens, P.H.H.M. (1991) Measurement and distribution of alcohol consumption. Thesis, University of Limburg, Datawyse, Maastricht.

Lemmens, P.H.H.M., Tan, E.S. \& Knibbe R.A. (198:8) Bias due to non-response in a Dutch survey on alcohol consumption. British Journal of Addiction, 83, pp. 1069-1077.

Lemmens, P.H.H.M., Tan, E.S. \& Knibbe, R.A. (1992) Measuring quantity and frequency of drinking in a general population surveys a comparison of five indicess. Journat of Stodies on Alcohol $\$ 3,476-486$.

Lemmens, P.H.H.M. (1996), When is a social problem alcohol-related? Addiction, 91, pp 1445-1:47.

Lewis-Beck. M.S. (1993) Regression amalysis. Intemational handbooks of quantiative applications in the sociat sciences; Vol.2, SAGE Publications, Toppan Publishing, London, UK.

Linderberg. S.M. (1983) Rational, repititive choice: the discrimination model versus the Camille-Berger modal. Soctat Psychology Qurarterly, 44, pp. 312-330.

Lindenberg. S.M. (1988) Contractual relations and weak solidarity: the beltavioral basis of restrants on gain maximization. fournal of mstitutional and theoretical Economics, 144, pp. $39-58$.

Linderberg, S.M. (1990) Homo socid-deconomicus: the emergence of a general model of man in the social sciences. Journat of Institurional and Theoretical Economics, 146, pp. 727-748.

Lindenberg, S.M. (1993) Club hierarchie, social metering and context instruction: governance structures if response to varying self-command capital. in: Lindenberg, S.M. and Schreuder, H. Interdisciplinaty perwpectives on arganizafiont studies, Pergamon Press, New York.

Linton, R. (1936) The study of wnas. Appleton-Century-Crofts, New York.

Magura, M., Shapiro, E. (1988) Alcohol consumption and divorce: which causes which? Jow not of Diverte. 12, pp. $127-136$.

Makkelä, K. (1991) Social and cultural preconditions of Alcoholics Anonymous (Ah) and faclors associated with the strength of AA. British Journal of Addiction, 86, pp. 1405-1413. 


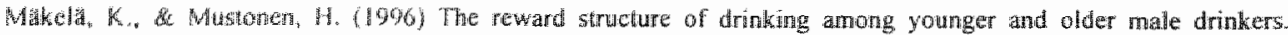

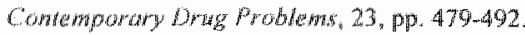

Magelat K.

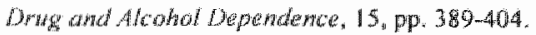

Maylield, D. McLeod, G, and Hall, P. (1974) The CACE quewtionnaire: Validation of a new alcoholism screening instrument. American wowrnat of Pychiatry, 131, pp. 1121-1123.

Menard, 9. (1995) Applied logistic regression andlyis. SAGE unversity papers series. Quantitative applications in the social sciences; no. 07-106. London, UK.

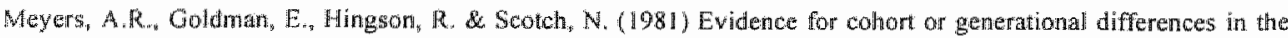
drinking behawor of older adults. Intermational Journal of Aging and Human Development, 14, pp. 31 a 4.4 .

Miller-Tutzater, C, Leonard, K.E., Windle, M. (1991) Marriage and allcohol use: a longtudinal study of "maturing out ${ }^{\text {no }}$. Jownal of studies on Alcohol, $52, \mathrm{pp} .434-440$.

Moos, RH. (1994), Whyy do some people recover from alcohol dependence, whereas others continue to drink and becomes worse over lime? Addiction, 89, pp. 3 [ $\times 34$.

Neve, R.M.M. (1998) The lffecowse, gender and alcohol use. Thesis, Maastricht University, Matastricht.

Neve, R.M., Diederits, I.P.M., Knibbe, R.A. \& Drop, M.A. (1993) Developments im drinking bettavior in the Netherlands firom 1958 to 1989 , a cohort analysis. Addichon, 88, pp. 611.621 .

\#.G.D., Productschap voor Gedestileerde Dranken (1993) World drinking trends (Henley-on-Thames, NTC Publieations Lid.

Peele, S. (1985) The meaning of addichon: compulsine experience and irs haterpration. Lexington Books, Lexington, Mass.

Fescosolido, B.A. (1992) Beyond rational choice: the social dynamics of how people seek help. Amerncan Jownol of Sociology, 97, pp. 1096-1 138 .

PGD, Productschap voor Gedestileerde Dranken (1993) Wordd Drimking Trends, Henley-on-Thames, NTC Publications Lid.

PGD, Productschap voor Gedestileerde Dranken (1996) World Drinking Trends. Henleywonmames, WTC Publications $\mathrm{LId}$.

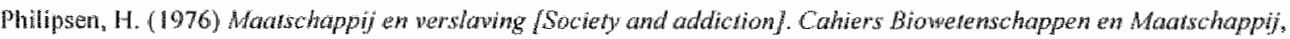
$3, p p .25-31$.

Power, C. \& Estaugl, V. (1990) Employment and drinking in early adulthood: a longitudinal perspective. British Joumal of Addicrion, 85 , pp. 487-4944.

Rat, H. (1987) Alcoholproblematiek en Aulpwerlening [Drinking problems and help for drinking probleww]. Proefschrift, Vrije Universiteit, Amsterdam.

Rehm, J., Ashley, M.l., Room, R., Single, E., Bondy, S., Ferrence, R., \& Giesbrecht, N. (1996) On the emerging paradigm of drinking patterns and their social and health consequences. Addiction, 91, pp. 1615-1621.

Roon, R, (1977) Mefusument and distribution of drinking patterns and problems in generall poptalions. In: Edwards, O., Gross, M.M., Keller, M., Moser, J. 2 Room, R. (Eds.), Aloohol-refated disabilites, Offet Publications 32, WHO, Gonevia

Room, R. (1980) Treatmert-secking populations and farger realities. Im: Edwards, G \& Grant, M. (Eds), Alooholism trectment in transilion, Ch. 13, pp. 205-224, Lniversity Park. Press, Bathimore.

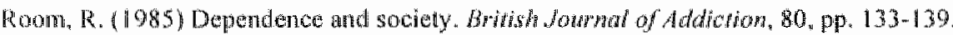

Roum, R. (1989) Thuc U.S. general population's experiences of responding to alloohol problens. British Joumat of Addichicm, 84, pp. $1291 \cdot 1304$.

Koom, R. (1996) Allcohol consumption and social harm - conceptual issues and historioal perspectives. Contenporary Drug problems. 23, pp. $373-388$.

Room, R., Bondy, S.J. \& Ferris, J. (1995), The risk of harm to oneselt from drinking, Canada 1989. Addicrioy 90, pp. $499-513$.

Room, R, Bondy, S.J, E Ferris, J. (1996), Deteminants of whgestions for alcohol treatrment. Addicrion, 91, pp. 643655 .

Rosenstock, M. (1966) Why people use health services. Mibant Memorial Fund Quarerty, 44. pp. 94-124t.

Schutte, K.K., Brennan, P.L., Moos, R.H. (1994) Remission of late-life drinking problems: a 4-year follow-tip.

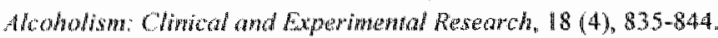

Selzer. M.L. (1971) The MAST: the quest for a new diagnostic instrment. American fow mat of Psychary, $127, \mathrm{pp}$. 
$1653-1658$

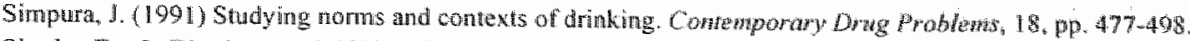

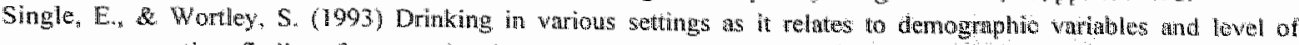

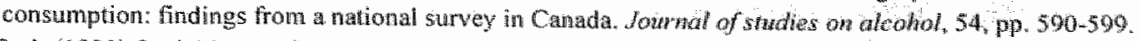

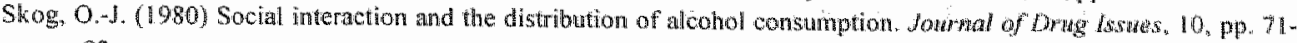
92.

Skog, 0.-J. (1985) The collectivity of drinking cultures: A theory of the distribution of alcohol comsunption. brith Journal of Addiction, 80, pp. 33.99 .

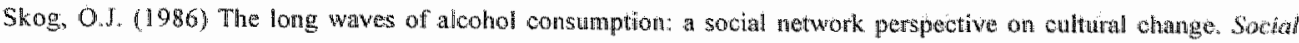
Nentorks, 8, pp. I 32 .

Skog, O.J. (1997) Rationalizy, trrationality, and addiction: Notes on Becker and Murphys theory of addiction. In.

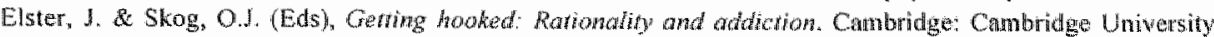
Press.

Sobell L.C., Cunwingham, J.A., \& Sobell, M.B., (1996) Recovery from alcohol problems with and without treatment:

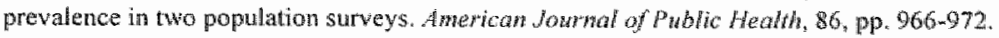

Sonnenstuhi, W.J., \& Trice, H.M. (1991) The workplace as locale for risks and interventions in alcahol abuse. In:

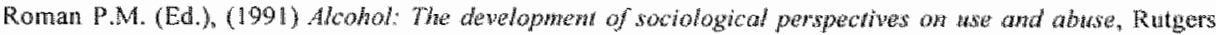
Center for Alcohol Studies, New Brunswick, New Jersey, USA.

Spruit, I.P., Kok, A.F.W. \& Knibbe, R.A. (1995) Minder alcoholzorg: een kwestie van andacht? (Less alcoholcane: a natter of attention?] Tijdschrif woor Alcokol. Drtugs en andere Psychorrope Stoffen, 21, pp. 148-156.

Stigler, G.J. and Becker, G.S. (1977) 'De Gustibus Non est Disputandum". American Economic Revan, 67, pp.76.90.

Stockwell, T., Daly, A. Philips, M., Master, L., Midford, R., Gahegan, M. d Philip, A. (1906) Tohal versus hazaldous per capita alcohol consumprion as predictors of achte and chronic alcohol-related ham. Contemporary bryg Problems, 23, pp. 441.464.

Stockwelt, T, Lang, E, \& Rydon. R. (1993) High risk drinking settings: the association of seming and promotional practices with hamful drinking. Addiction, 88, pp. 1519.1526.

Swinkels, H. (1991) Drankgebruik in Nederland - enkele onderzoeksmetinoden vergeleken. [Use of alcoholic beverages

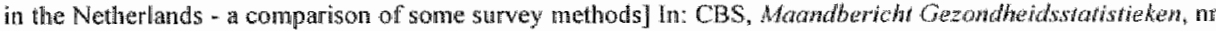
$12,5-12$.

Temple, M.T. \& Leino, E.V. (1989) Long-term Oucomes of Drinking: a 20-year longitudinal study of men. Britirh Wonthal of Addiction, 84, pp. 889-899.

Temple, M.T., Filmore, K.M., Hartka, E., Johnstone, B., Leino, E.V. \& Motoyoshi, M. (1991) A meta-analysis of change in marital and employment status as predictors of alcohol constrantion on a typical occasion. Brirtin Jourpal of Addicuion, 86, pp. 1269-1281.

Tucker, J.A. Gladsjo J.A. (1993) Help-seeking and recovery by problem drinkers, characteristics of drinkers who attended alcoholics anonymous ar formal treatment or who recovered without assistance. Alddiche Behontors $18, \mathrm{pp} .529 .542$

Turner, R. I. (1990) Role change in: Antwal Review of Solology 1990, 16, pp. 87-110.

Twcker, J.A. (1995) Predictors of help seeking and the femporal relationship of help to recovery anong trited and untrealed recovered problent dritkers, Addichon. 90 , pp. $805-809$.

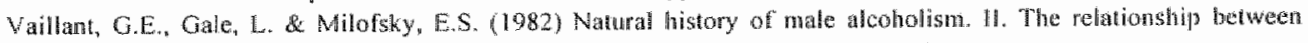
different diagnostic dimensions. Journal of sindies on Alcohol 43 , pp $216-232$.

Walsh, G. \& Rehm, J. (1996) Daily drimking and harm. Comemporary Drag Protalems. 23. pp. 46.5-478.

Wrisner, C, (1990) The alicohol treatment-seeking process from a problems pelspective: responses lo events. Brith Jorinal of Adtiction, 85, po. $561-569$

Weismer, C. (1993) Toward an alcohol treatment entry model a comparison of problem drinkwrs th the general

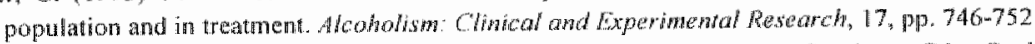

White, H.R. (1982) Sociological theories of the etiology of alcolnofism. In: Gomberg. E.L, Raskin White. H. W Carpenter, J.A. (Eds.) Acohot, Science of Socioty Revinhed, The Uniwersity of Michigan and Rutgers Center of Alcohol Studies, Am Arbor New Erunswick, 205-232.

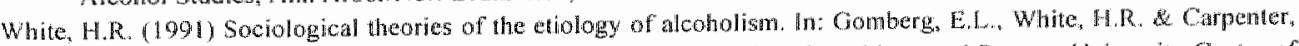

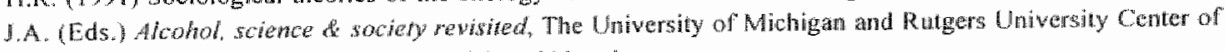
Alconol Studies, Ann Arbor Wew Brunswick and New Jersey. 


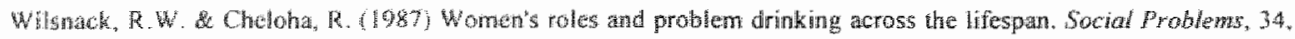
mi 234.248

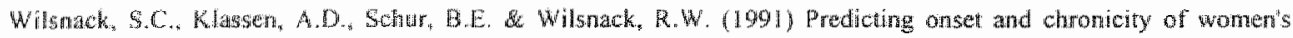

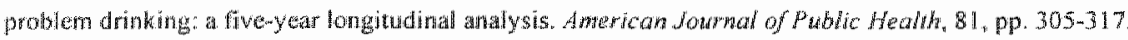

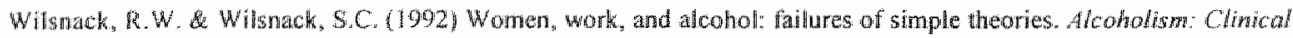
awd Experimental hesedareh, 16, pp. 172-179.

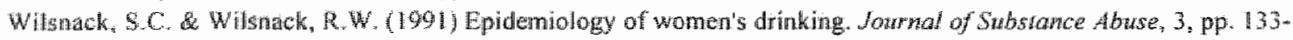
157.

Wilsmack, R.W.; Kristjanson, A.F, Vogettanz, N.D. \& Wilinack, S.C. (1997) Body water and women's drinking

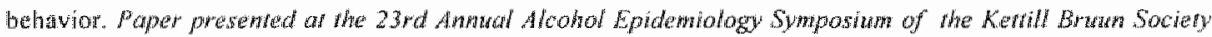

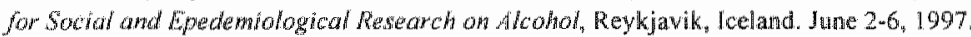

Wippler, R. (19961983). De plaats yan roltheoretische ideeem in de sociologie [Role theory and sociology]. Ir: Wippler, $R$, Soctollogie tussen empirie ery theorie, cen ketze wit het werk, 1970-1996. Thesis Publishers, Amisterdam. Originally in: Visser, A.Ph, Viert, E, wan de. Heine, E.J.H. ter, Wimulbst A.A.M. (Eds) Rollen, Persoonlibe en socialle invloeden op gedrag, Boom, Meppel.

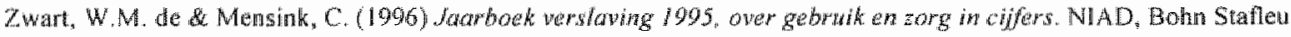
Van Loghem, Houten/Diegen: 
Dit proefschrift was niet tot stand gekomen zonder de hulp van velen.

\section{Bedankt:}

Rudie Neve (paranimf);

Rutger Engels (paraminaf en kamergenoot);

Ate Frans de Bruin (kamergenoot);

Maria Scholten, Mieke Derickx en Jolanda Royackers (dataverzameling en assistentie);

Frans Theunissen voor het laten werken van mijn computer"

Wim Meulders en collega's voor de samenwerking met het CAD-Limburg;

Cliènten van het $\mathrm{CAD}$ en alle andere respondenten;

Vrienden en callega's.

\section{Speciale dank aan:}

Co-promotor Ronald Knibbe die voor mij altijd aanspreekbaar was;

Promotor Riet Drop voor de grote lijnen en kleine details;

Agnes en Nina, voor het mij er aan helpen herinneren

dat er nog iets anders is in het leven dan een proefschrift. 


\section{CURRICULUM VITAE}

I was born in Assen, the Netherlands, on the 1st of May in 1963. After graduating from the VWO at the Dr. Nassau College in Assen in 1982, I have studied sociology at The University of Groningen. In 1988 I acquired a degree in sociology. In 1990 I obtained an additional degree in methodology of the sociall sciences and in policy studies at the same university.

I worked as a research assistant at the Department of Sociology at the University of Groningen in 1991. In 1992 I started as a Ph.D. student at the Department of Medical Sociology at the Maastricht University which resulted in this thesis. Since 1993 I live together with Agnes Nieuweweme, our daughter Nina joined us in 1997. 